\title{
Farbdiskrimination und Stroop-Effekt bei Kindern mit chronischer Tic-Störung (CTS) und/oder Aufmerksamkeits-Defizit/Hyperaktivitäts- Störung (ADHS)
}

\author{
Dissertation \\ zur Erlangung des Doktorgrades \\ der Mathematisch-Naturwissenschaftlichen Fakultät \\ der Georg-August-Universität zu Göttingen
}

vorgelegt von

Dipl. Psych. Anke Fillmer-Otte

aus Göttingen

Göttingen 2009 
D 7

Dekan: Prof. Dr. Gatz

Referent: Prof. Dr. M. Hasselhorn

Korreferent: Prof. Dr. C. Mähler

Tag der mündlichen Prüfung: 28.04.09 
Teilergebnisse der vorliegenden Arbeit wurden publiziert in:

Roessner, V., Banaschewski, T., Fillmer-Otte, A., Becker, A., Albrecht, B., Uebel, H., Sergeant, J., Tannock, R. \& Rothenberger, A. (2007). Color perception deficits in co-existing attentiondeficit/hyperactivity disorder and chronic tic disorders. Journal of Neural Transmission, 115, 235-239. 


\section{Vorwort}

Die Verfassung dieser Dissertation wäre ohne die großartige soziale Unterstützung, die ich während dieser Zeit erfahren durfte, kaum möglich gewesen. Deshalb möchte ich an dieser Stelle allen Menschen danken, die zum Gelingen dieser Arbeit beigetragen haben. Dabei gilt mein besonderer Dank den Mitarbeitern der Abteilung für Kinder- und Jugendpsychiatrie/ Psychotherapie der Universitätsmedizin Göttingen, insbesondere Prof. Rothenberger, Prof. Banaschewski, PD Rössner, Dr. Uebel und Dr. Becker, ohne deren Hilfe die Durchführung der vorliegenden Arbeit nicht denkbar gewesen wäre.

Dank auch an Prof. Hasselhorn, der mir Freiraum für die Erstellung der Arbeit und großes Vertrauen in das Gelingen entgegenbrachte.

Ganz besonders bedanken möchte ich mich bei Herrn Dipl. Psych. Björn Albrecht, der mir mit Rat, Engagement, Diskussionsbereitschaft und der nötigen Portion Optimismus bei der Datenauswertung bei Seite stand und mich immer wieder anspornte.

Für unentbehrliche Unterstützung in vielen Belangen möchte ich mich bei Dr. Alexander Heise, meinen Eltern Arno und Gerlinde Fillmer-Otte, meinem Bruder Ingo Fillmer-Otte sowie meinen Großeltern bedanken. Sie haben immer Verständnis gezeigt und mich jederzeit ermutigt.

Nicht zuletzt geht mein Dank an die Patienten, die an der Studie teilgenommen haben sowie deren Eltern. 


\section{Literaturverzeichnis}

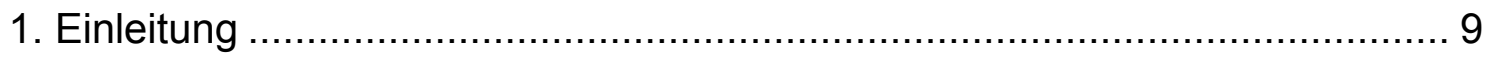

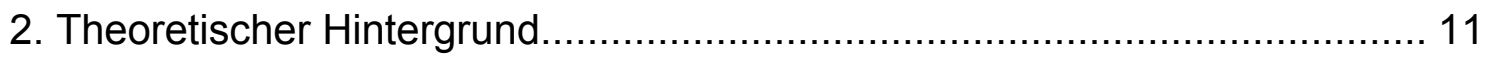

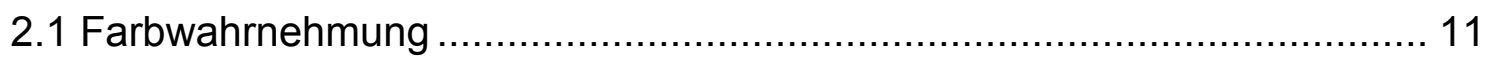

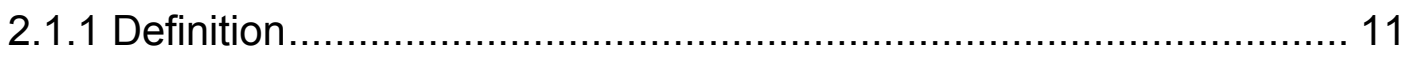

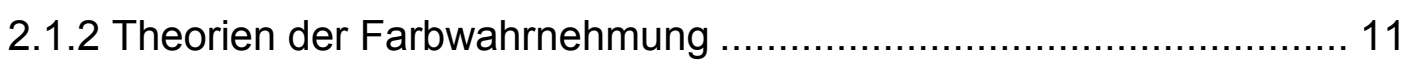

2.1.3 Informationsverarbeitung im visuellen System .............................. 13

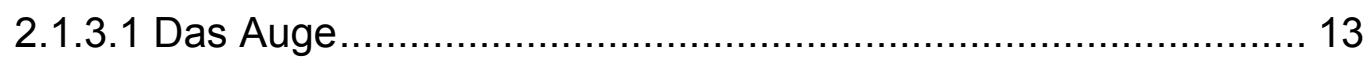

2.1.3.2 Aufbau der Retina.............................................................. 13

2.1.3.3 Informationsverarbeitung in der Retina.................................... 16

2.1.3.4 Verarbeitung im visuellen Kortex ........................................... 18

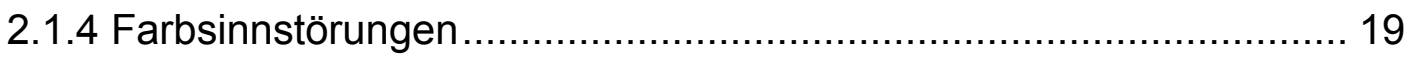

2.1.5 Dopamin und Farbwahrnehmung .................................................. 20

2.1.6 Veränderung der Farbdiskrimination bei Störungen des dopaminergen

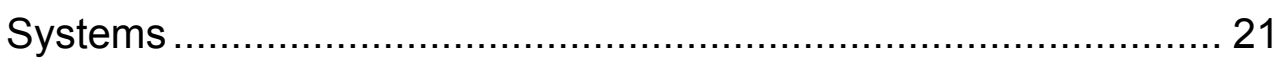

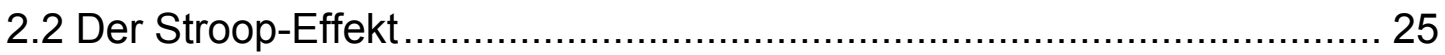

2.2.1 Der Stroop-Effekt bei ADHS ..................................................... 27

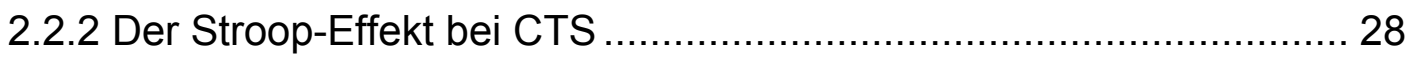

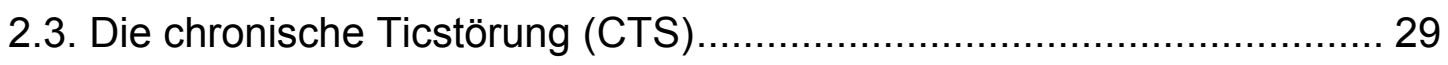

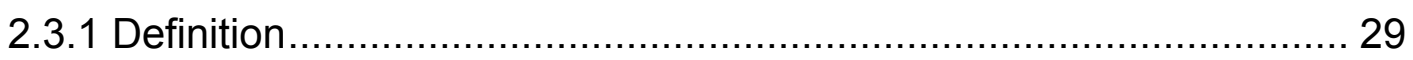

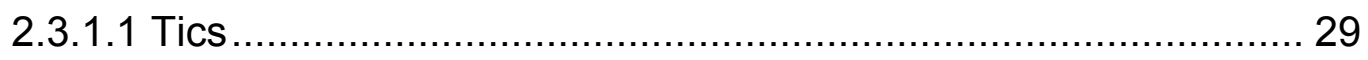

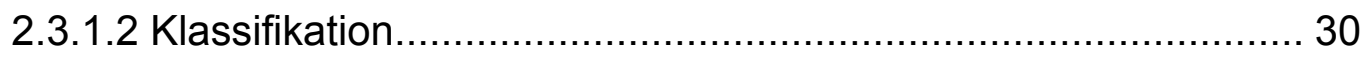

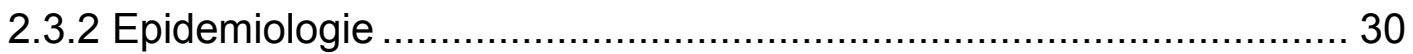

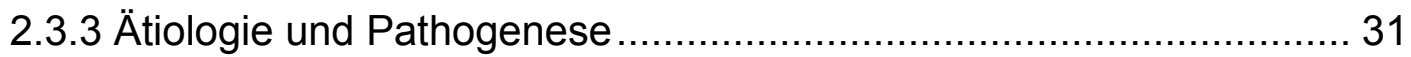

2.3.3.1 Biologische Faktoren .......................................................... 32

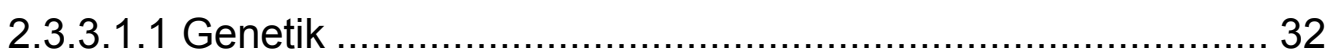

2.3.3.1.2 exogene Risikofaktoren ................................................ 32

2.3.3.2 Neurophysiologische Korrelate............................................ 33

2.3.3.2.1 Strukturelle und funktionelle Bildgebung ............................ 33

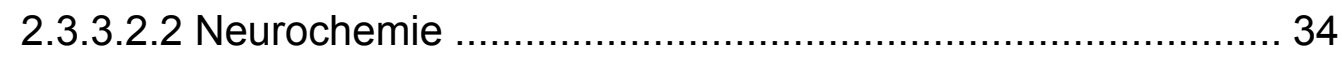

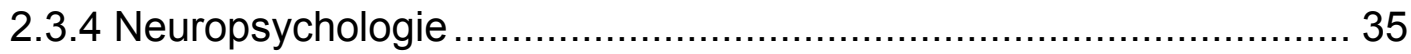

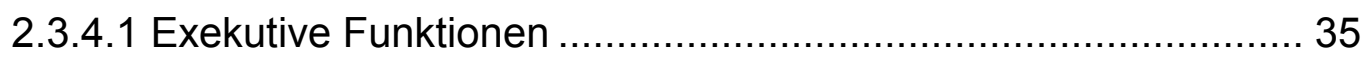

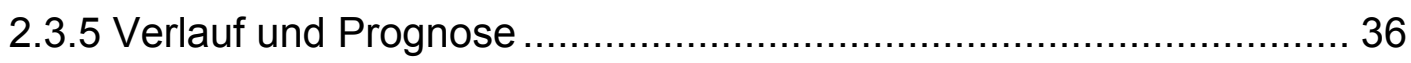




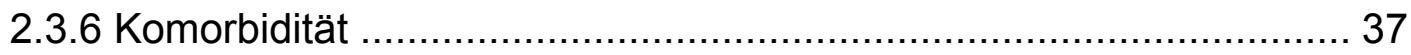

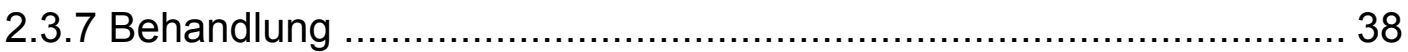

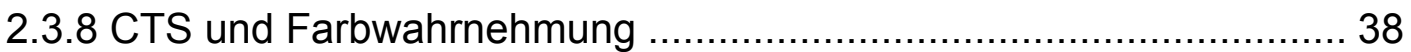

2.4 Die Aufmerksamkeits-Defizit/Hyperaktivitäts-Störung (ADHS) ............. 40

2.4.1 Definition und Klassifikation ........................................................ 40

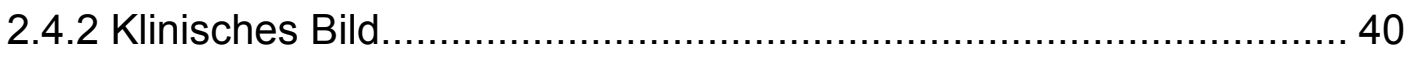

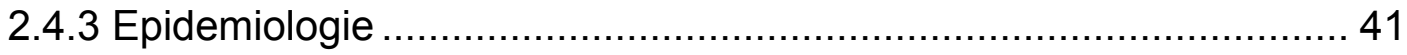

2.4.4 Ätiologie und Pathogenese ...................................................... 42

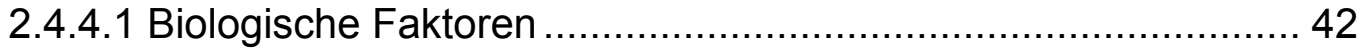

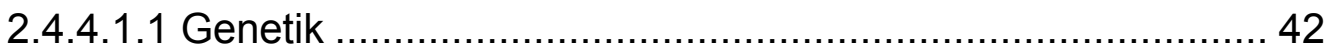

2.4.4.1.2 exogene Risikofaktoren .................................................. 43

2.4.5 Neurophysiologische Korrelate ................................................ 44

2.4.5.1 Strukturelle und funktionelle Bildgebung …............................ 44

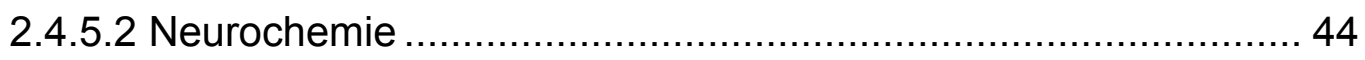

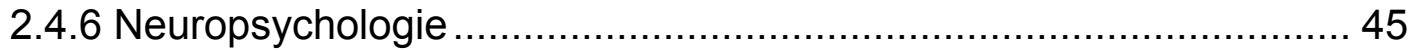

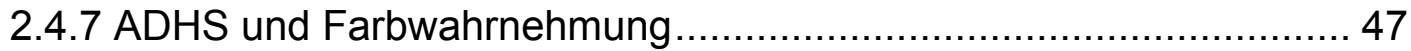

2.5 CTS und ADHS, additives oder interaktives Modell?............................. 48

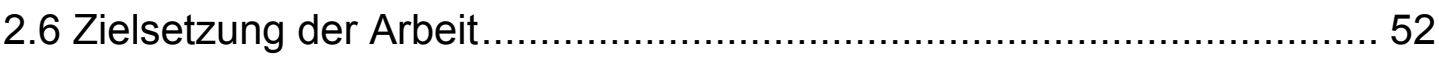

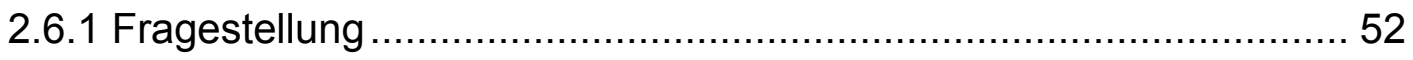

2.6.2 Ableitung inhaltlicher Hypothesen................................................. 53

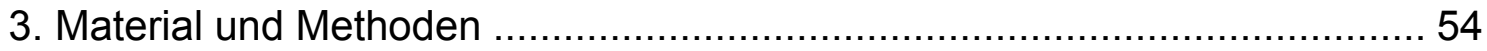

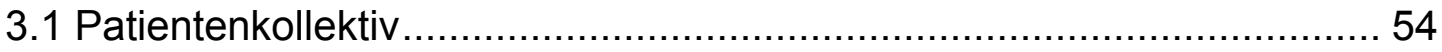

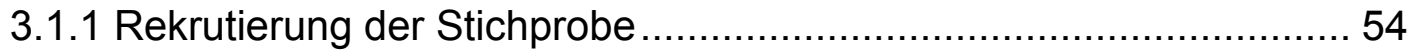

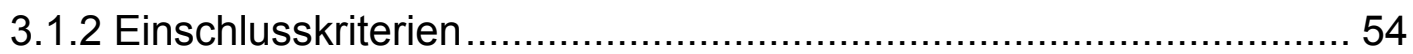

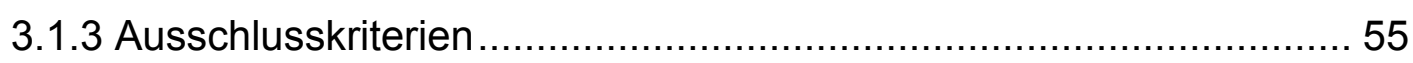

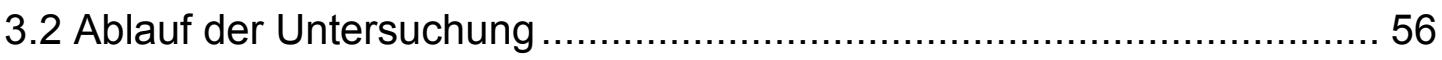

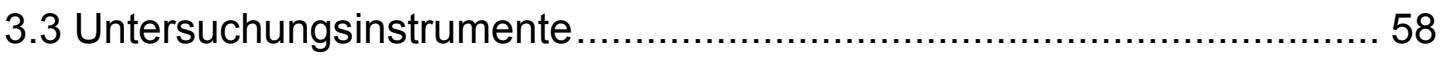

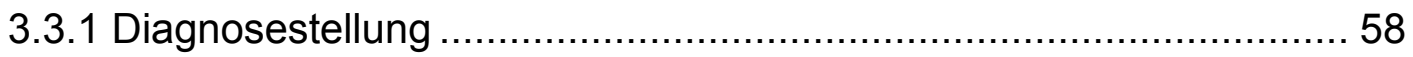

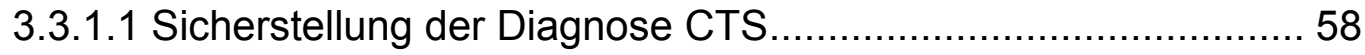

3.3.1.2 Sicherstellung der Diagnose ADHS ...................................... 60

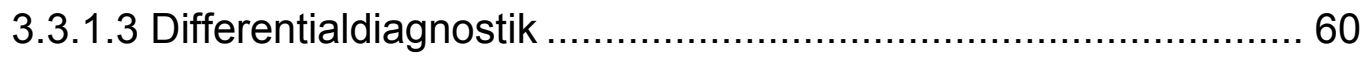

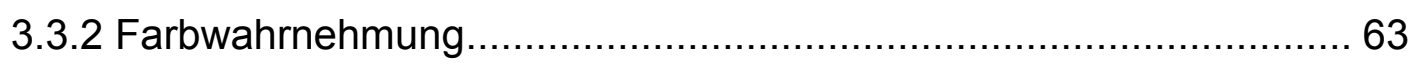

3.3.2.1 Ishihara-Tafeln zur Prüfung des Farbsinns............................... 63

3.3.2.2 Farnsworth-Munsell 100-hue-Test (FMT) ............................... 63 


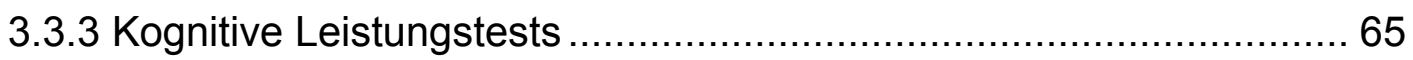

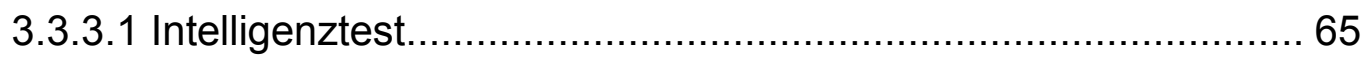

3.3.3.2 Das Frankfurter Aufmerksamkeits-Inventar (FAIR)................... 65

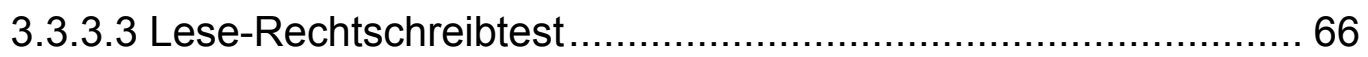

3.3.3.4 Leistungsprüfsystem (LPS); Untertest Wortflüssigkeitstest ....... 66

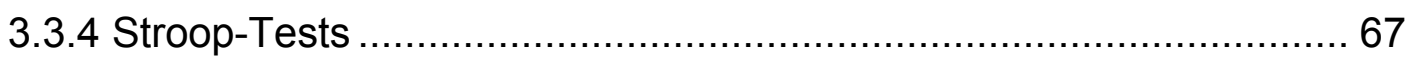

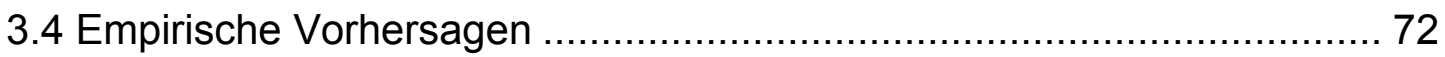

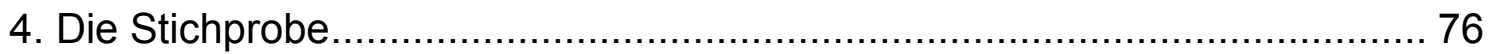

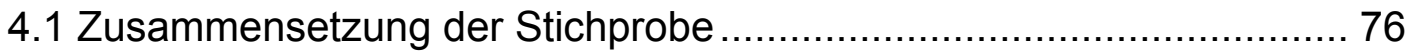

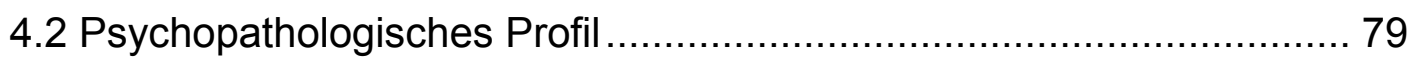

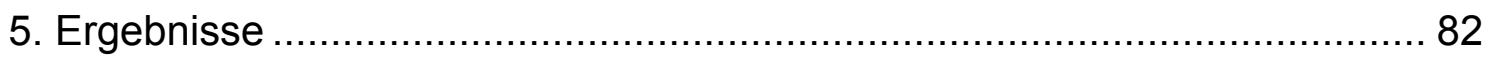

5.1 Farbdiskriminationsleistung im Farnsworth-Munsell 100-hue-Test......... 82

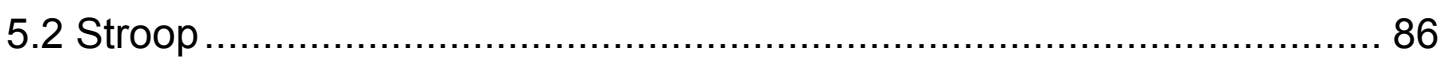

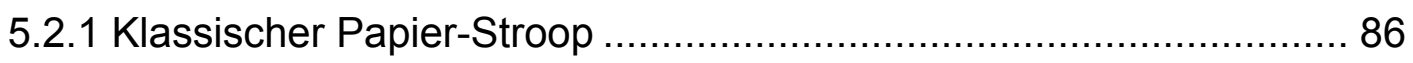

5.2.2. Zusammenhang zwischen Leistungen im Farnsworth-Munsell 100hue-Test und dem klassischen Papier-Stroop .............................. 89

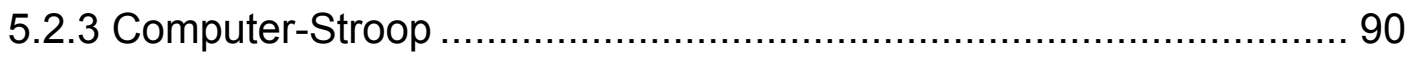

5.2.3.1 Speed-Accuracy Trade-off................................................... 90

5.2.3.2 Computer-Farb-Stroop und Zahlen-Stroop ............................. 91

5.2.3.2.1 Reaktionszeiten korrekt bearbeiteter Items........................ 91

5.2.3.2.2 Anzahl korrekt bearbeiteter Items ..................................... 94

5.2.3.2.3 Intra-individuelle Variabilität der Reaktionszeiten korrekt

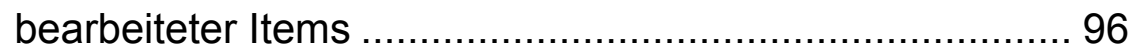

5.2.4 Zusammenhang zwischen Leistungen im Farnsworth-Munsell 100hue-Test und Computer-Stroop .................................................. 97

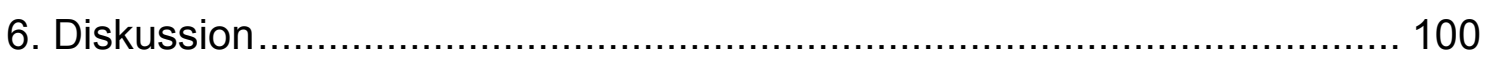

6.1 Beantwortung der Hypothesen zur Farbdiskriminationsleistung ........... 102

6.1.1 Farbdiskriminationsleistung allgemein ....................................... 102

6.1.2 Differenzen der Farbachsen .................................................... 105

6.1.3 Diskussion der Befunde bzgl. dopaminerger Transmissionstörungen bei CTS und ADHS und der Farbdiskrimination.......................... 107

6.2 Beantwortung der Hypothesen zum Stroop-Test............................... 113

6.2.1 Der klassische Papier-Stroop ................................................... 113

6.2.2 Der Computer-Stroop .............................................................. 114 
6.2.3 Beantwortung der Hypothesen zum Zusammenhang zwischen der Farbdiskriminationsfähigkeit und den Ergebnissen im Stroop ...... 117

6.3 Beantwortung der Hypothese zu Modellvorstellung bei ADHS+CTS.... 118

6.4 Beantwortung der Fragen ............................................................ 121

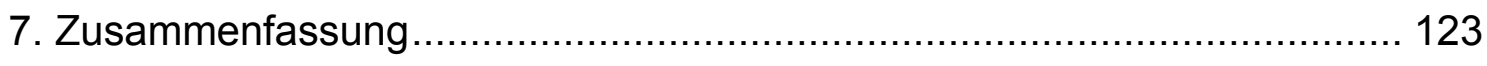

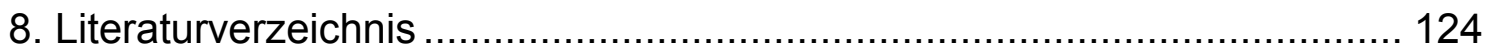

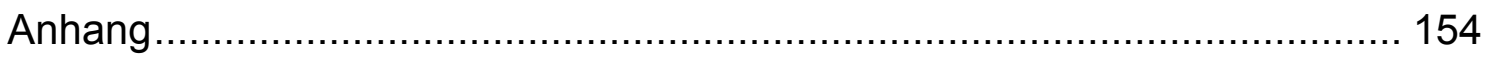

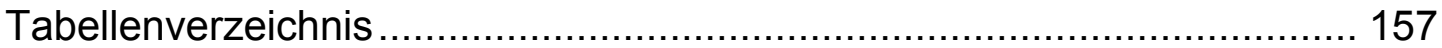

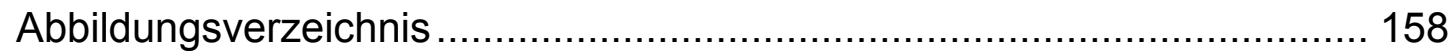

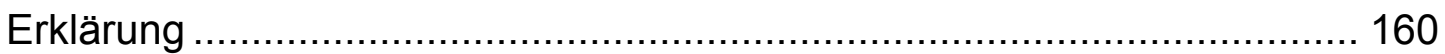

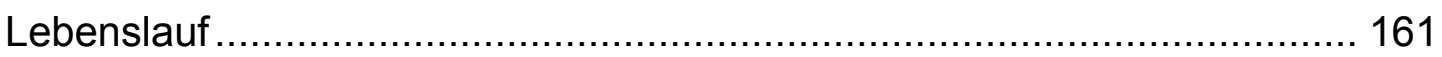




\section{Einleitung}

Die chronische Tic-Störung (CTS) sowie die AufmerksamkeitsDefizit/Hyperaktivitäts-Störung (ADHS) sind kulturübergreifend weit verbreitete kinder- und jugendpsychiatrische Störungsbilder mit einem überzufällig häufigen komorbiden Auftreten. Beiden Erkrankungen zugrunde liegend wird eine Störung zentralnervöser Inhibition insbesonderer motorischer Aktivität angenommen. Bei ADHS manifestiert sich diese in den Kernsymptomen Aufmerksamkeitsstörung, Hyperaktivität und Impulsivität, bei CTS in unwillkürlichen Lautproduktionen und/oder Bewegungen. Trotz deutlich differenter Symptomatik scheint nach aktuellem Forschungsstand beiden eine pathophysiologische Störung des dopaminerg modulierten sensomotorischen kortiko-striato-thalamokortikalen Regelkreises zugrunde zu liegen.

Darüber hinausgehend scheint ADHS mit einer Beeinträchtigung in der Verarbeitung von farbigem Stimulusmaterial, insbesondere in der Blau-GelbWahrnehmung, einherzugehen. Veränderungen in der dopaminergen Transmission durch Kokainentzug, Alterungsprozesse, Morbus Huntington und Morbus Parkinson gehen ebenfalls mit Veränderungen in der Farbdiskriminationsfähigkeit, insbesondere der Blau-Gelb-Wahrnehmung einher. Eine bisher nicht replizierte Studie zur Farbwahrnehmung bei erwachsenen CTS-Patienten kam zu entsprechenden Ergebnissen. Die Betrachtung der Farbwahrnehmung scheint demnach die Abbildung pathopysiologischer Hirnfunktionen durch ein Verhaltensexperiment zu ermöglichen und Informationen über entsprechend gestörte Prozesse zu liefern. Dabei scheinen Farbdiskriminationsdefizite dopaminerge Veränderungen im zentralen Nervensystem widerzuspiegeln, so dass spezifische chromatische Ausfälle, mutmaßlich Defizite in der neuronalen Integrität und deren Funktionen widerspiegeln könnten. Ein Vergleich von Farbdiskriminationsdefiziten bei hypodopaminergen (wie ADHS) sowie bei hyperdopaminergen Transmissionsstörungen (wie CTS) könnte Aufschluss über die neurophysiologischen Prozesse beider Störungsbilder und Prozesse der Farbverarbeitung liefern sowie helfen, Zusammenhänge sowie Modellvorstellung zum gemeinsamen Auftreten beider Störungsbilder zu beleuchten.

Die darüber hinausgehende Betrachtung des Stroop-Effekts im Farbe-WortInterferenztest erscheint in diesem Zusammenhang ebenfalls, aufgrund der un- 
terschiedlichen Leistungen von CTS- und ADHS-Patienten, relevant. Eine Interpretation der Ergebnisse unter der Betrachtung des an farbigem Stimulusmaterial angelehnten Tests führt nicht nur zu Fragen bezüglich der Abhängigkeit der Ergebnisse im Farbe-Wort-Interferenztest von der Farbdiskriminationsleistung, sondern darüber hinaus zu den kompensatorischen Mechanismen.

Um dies zu untersuchen erweiterten wir die Stichprobe der ersten Studie zur Farbwahrnehmung bei ADHS (Dissertation Ruppert, 2005; Banaschewski et. al., 2006) um Probanden mit CTS bzw. komorbiden CTS und ADHS. 


\section{Theoretischer Hintergrund}

\subsection{Farbwahrnehmung}

\subsubsection{Definition}

Farbwahrnehmung ist definiert als eine Sinnesempfindung, die durch elektromagnetische Lichtstrahlungen hervorrufen werden kann, wenn diese auf ein dafür spezifisch emfindliches Wahrnehmungssystem treffen. Farben stellen demnach eine durch den Farbreiz hervorgerufene Empfindungsgröße dar wobei die Farbwahrnehmung die Fähigkeit zur Unterscheidung elektromagnetischen Lichts unterschiedlicher Wellenlänge entspricht (Bierbaumer \& Schmidt, 1999).

Die Anfänge der Untersuchungen zur Farbwahrnehmung sind auf Sir Isaac Newtons (1642-1727) Entdeckung zurückzuführen, dass weißes Sonnenlicht anhand eines Prismas in ein Farb-Spektrum zerlegbar ist. „For the rays to speak properly are not coloured. In them there is nothing else than a certain power and disposition to stir up a sensation of this or that colour." (Newton, 1730). Diese Empfindung bzw. Wahrnehmung von Farbe ist nicht allen Lebewesen möglich, sondern nur im Zusammenhang mit entsprechend dem Lichtreiz empfindlichen Zellen (Gegenfurtner \& Kiper, 2003). Heute ist bekannt, dass die elektromagnetische Strahlung des Lichts die physikalische Grundlage der Farbwahrnehmung bildet und durch eine Aktivierung spezifischer Rezeptoren in der Retina eine Umwandlung des extrazellulären Lichtreizes in eine intrazelluläre Antwort erfolgt (Schmidt, Lang \& Thews, 2004). Dabei können unterschiedliche spektrale Zusammensetzungen des Lichts bzw. unterschiedliche Reizbegebenheiten denselben Farbeindruck hervorrufen (Solomon \& Lennie, 2007).

\subsubsection{Theorien der Farbwahrnehmung}

Ein Farbreiz kann betrachtet werden als eine Kombination elektromagnetischer Wellen. Die spektrale Reflektanz bzw. Absorption der Objekte bestimmt dabei deren farbliche Erscheinung (subtraktive Farbmischung) (Bierbaumer \& Schmidt, 1999). Trifft auf eine Netzhautstelle Licht verschiedener Wellenlänge, 
bezeichnet man dies als additive Farbmischung. Durch diesen Prozess kann, so von Young (1802) angenommen, jede beliebige Farbe aus farbigem Licht dreier Primärfarben dargestellt werden. Analog zeigte sich, dass ein normal Farbsichtiger drei Farbtöne benötigt, um alle Farbtöne darstellen zu können (Gegenfurtner, 2003). International wurde dabei, ohne Rückschlüsse auf physiologische Erkenntnisse, die Übereinkunft getroffen, die Farben Rot (700 nm), Grün (546 nm) und Blau (435 nm) als Primärfarben festzulegen. Basierend auf den Ergebnissen von Young entwickelte Helmholtz (1950) die trichromatische Theorie des Farbensehens. Diese beruht auf der Annahme, die Retina des Menschen bestehe aus drei für spezifische Wellenlängen des Lichts empfindliche Rezeptortypen, die durch unterschiedliche Aktivierung und anschließende Verrechnung der Erregungsmuster den entsprechenden Farbeindruck hervorrufen (Bierbaumer \& Schmidt, 1999). Wie folgend beschrieben wird, findet diese Theorie Unterstützung durch die in der Retina nachgewiesenen drei Photorezeptortypen unterschiedlicher spektraler Sensitivität.

Beobachtungen über Kontrastphänomene brachten Hering zu der Annahme, die Farbwahrnehmung beruhe auf antagonistischen Erregungs- und Hemmungsprozessen (Gegenfarbentheorie). Dabei soll durch antagonistische Zuordnung vierer Primärfarben (Rot, Gelb, Grün, Blau, Zuordnung: Rot/Grün, Blau/Gelb, sowie Schwarz/Weiß) sowie Aktivierung und Inhibition dieser Farbsysteme Farbeindruck und Nachbild erzeugt werden (Birbaumer \& Schmidt, 1999).

Heute wissen wir, dass beide Theorien auf unterschiedlichen Ebenen der Reizverarbeitung zutreffend sind. Die trichromatische Theorie des Farbensehens findet ihre Entsprechung in den Verarbeitungsprozesse der Photorezeptoren auf retinaler Ebene, wohingegen Funktion und Verschaltung der Ganglienzellen mit konzentrisch organisierten On- und Off-Zentrumsneuronen auf Ebene der neuronalen Signalverarbeitung im afferenten und zentralen visuellen System die Gegenfarbentheorie stützen (Schmidt, Lang \& Thews, 2004). Von Kries (1853-1928) beschrieb diese beiden Ebenen bzw. die Zusammenfassung beider Theorien in der Zonentheorie. 


\subsubsection{Informationsverarbeitung im visuellen System}

\subsubsection{Das Auge}

Zum Verständnis der Informationsverarbeitung physikalischer Lichtreize und deren Umwandlung in einen Farbeindruck, erscheint der Aufbau des Auges relevant.

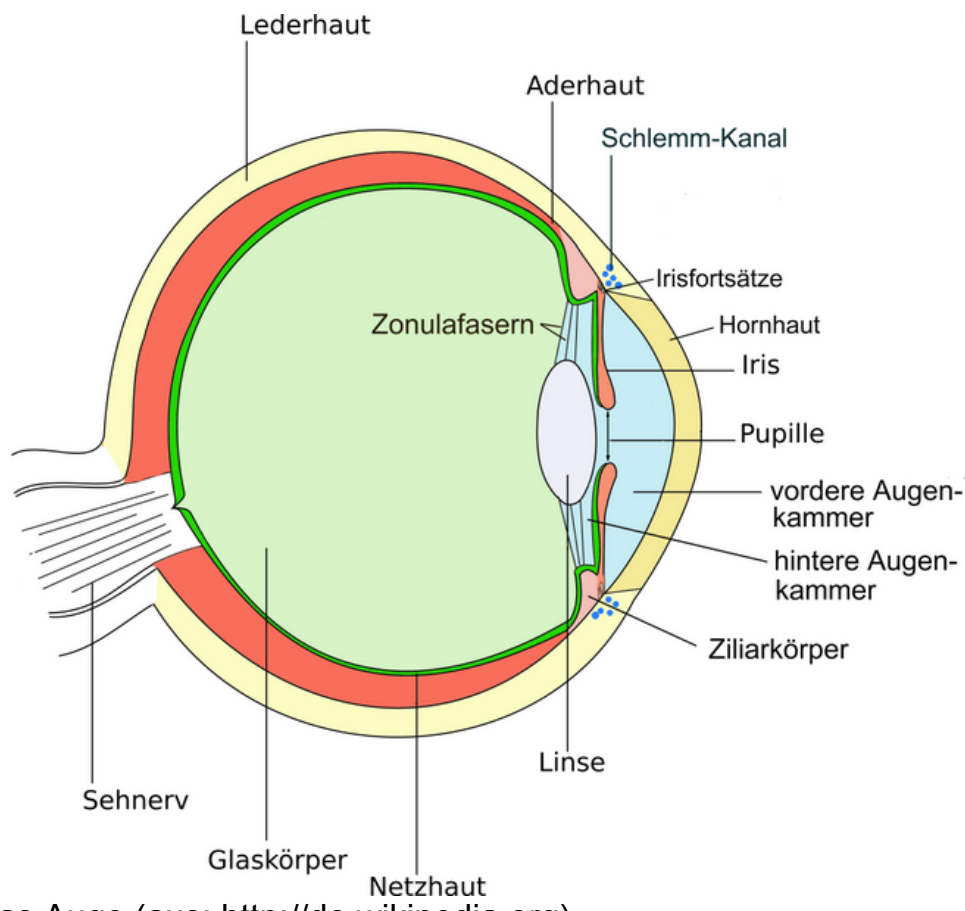

Abbildung 1: Das Auge (aus: http://de.wikipedia.org)

Das Auge erreichende Licht durchdringt Kornea, vordere Augenkammer sowie Linse und projizieren auf der Netzhaut, genauer gesagt, auf der Fovea centralis, der Stelle des schärfsten Sehens, ein umgekehrtes Abbild der Umgebung. Hinter der Linse befindet sich der mit extrazellulärer Flüssigkeit gefüllte Glaskörper. Die hintere Oberfläche des Auges bildet die Retina, wo das auftreffende Licht in Nervenimpulse umgewandelt wird (Schmidt, Lang \& Thews, 2004). Dabei reagiert das menschliche Auge auf elektromagnetische Strahlung im Wellenlängenbereich von 380-788 $\mathrm{nm}$.

\subsubsection{Aufbau der Retina}

Die Retina ist ein mehrschichtiges sensorisches Gewebe und Teil des Gehirns, welches im Laufe der Embryonalentwicklung als eine Ausstülpung des Zwischenhirnbodens entstand. Sie besteht aus unterschiedlich lichtempfindlichen 
Photorezeptoren, verschiedenen Nervenzellen zur Verarbeitung bzw. Weiterleitung der durch den Lichtreiz erzeugten Impulse sowie Strukturen, die den Prozess der Verarbeitung aufrechterhalten. Die zwei grundsätzlich zu unterscheidenden Arten von Photorezeptoren sind Stäbchen und Zapfen. Stäbchen gewährleisten skotopisches Sehen, also Sehen im Dunklen oder bei Dämmerung, Zapfen photopisches Tagessehen. Beim skotopischen Sehen können keine Farben wahrgenommen werden (Gegenfurther, 2003; Birbaumer \& Schmidt, 1999)

Die Dichte und Anzahl der Photorezeptoren in der Netzhaut unterscheidet sich stark, wobei die menschliche Retina aus insgesamt ca. 6 Millionen Zapfen sowie ca. 120 Millionen Stäbchen besteht. Foveal ist die Rezeptordichte am höchsten. In der Fovea centralis befinden sich ausschließlich Zapfen wobei die Dichte an Stäbchen paravoveal immer weiter zunimmt (Birbaumer \& Schmidt, 1999).

Für die Farbwahrnehmung sind ausschließlich die Zapfen relevant. Dabei können drei Zapfentypen (S-, M- und L- Zapfen) mit unterschiedlichen Sehfarbstoffen unterschieden werden. Die Bezeichnung der Zapfentypen wird durch die entsprechenden spektralen Absorptionsmaxima des elektromagnetischen Wellenlängenbereichs bestimmt, wobei sich die spektralen Absorptionskurven der einzelnen Photorezeptoren überlappen (siehe Abbildung 2). Die S-Zapfen (Short-Wavelength-Zapfen) weisen ihre höchste Sensitivität für Licht kurzer Wellenlängen ( 419 nm) auf, und werden daran angelehnt als Blau-Rezeptoren bezeichnet. Die M-Zapfen (Middle-Wavelength-Zapfen) reagieren maximal auf Licht mittlerer Wellenlänge $(\sim 531 \mathrm{~nm})$ und sind als Grünrezeptoren bekannt. Die L-Zapfen (Long-Wavelength-Zapfen) weisen ihr Absorptionsmaximum bei Licht langer Wellenlänge ( 559 nm) auf (Birbaumer \& Schmidt, 1999; Deeb, 2004; 2005). Mit einem Anteil von ca. $10 \%$ an der Gesamtzapfenmenge, ist der S-Zapfen-Typ der am wenigsten vorkommende (Calkin, 2001; Hofer, Carroll, Neitz, Neitz \& Williams, 2005). Darüber hinaus ist das zeitliche und räumliche Auflösungsvermögen der S-Zapfen gering und, im Gegensatz zu den L- und MZapfen, zeigen sie ein Sättigungsverhalten in der elektrophysiologischen Antwort (Huber \& Wildberger, 1991). 


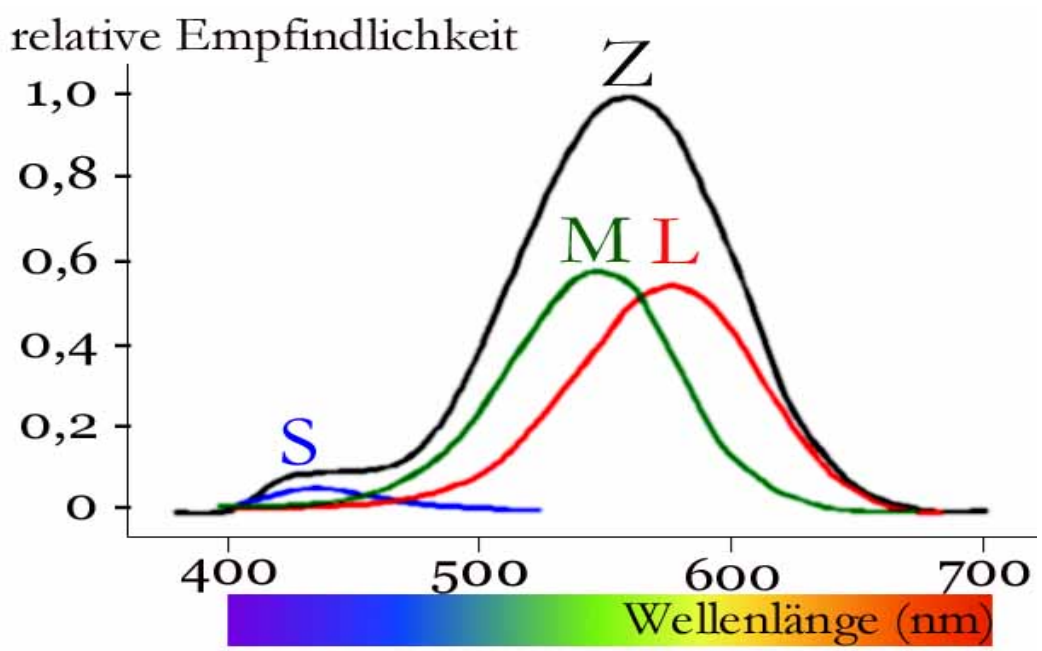

Abbildung 2: Empfindlichkeit der Zapfen beim Menschen (erstellt nach: Neumeyer C. (1985) An ultraviolet receptor as a fourth receptor type in goldfish: evidence from color mixture experiments. J. Comp. Physiol. A, 171, 639-649; Arnold K., Neumeyer C. (1987) Wavelength discrimination in the turtle Pseudemys scripta elegans. Vision Research. 27 , 1501-1511; aus: http://de.wikipedia.org) (Die Kurve für den SRezeptor ist um den Faktor 3 überhöht dargestellt. Z = Sehgrube (fovea centralis).

Ein einziger farbempfindlicher Photorezeptor kann nicht zwischen einer Veränderung in der Wellenlänge des Lichts sowie seiner Intensität unterscheiden, so dass für die Farbwahrnehmung ein Signalvergleich der Erregungsmuster verschiedener Zapfentypen nötig ist. Nur durch Kombination aller drei Zapfentypen können Menschen mit normaler Farbwahrnehmung mehrere tausend Farben unterscheiden (Krauskopf \& Gegenfurther, 1992). Dabei wird angenommen, dass die Repräsentation eines Farbtons über zwei fundamentale Dimensionen organisiert ist: das Rot-Grün-System und das Blau-Gelb-System (Salomon \& Lennie, 2007), wobei die ontogenetische Entwicklung des letzteren zeitlich 2-4 Wochen nach der des Rot/Grün-Systems beginnt (Crognale, 2002). Zusätzlich gewinnen Neurone Helligkeitsinformationen über ein drittes, antagonistisch geschaltetes Hell/Dunkel-System (Birbaumer \& Schmidt, 1999).

Die Verteilung beider Systeme im Gesichtsfeld ist unterschiedlich stark ausgeprägt (Mullan \& Kingdom, 2002), mit einer eher foveazentrierten Verteilungsdichte des Rot/Grün-System und einer gleichmäßigeren bzw. parafoveal gleichmäßiger abnehmenden Verteilungsdichte des Blau/Gelb-System. Der ge- 
ringe Prozentsatz der S-Zapfen spiegelt sich ebenfalls in der Systemverteilung wider.

Die geringe Dichte bzw. anatomische Verteilung der S-Zapfen bzw. des Blau/Gelb-Systems lässt vermuten, dass dieses System besonders vulnerabel sowohl für lokale als auch zentrale Veränderungen ist und sich systemische Veränderung zuerst in einer gestörten Wahrnehmung der Farben Blau/Gelb zeigen (Hart, 1987; Djamgoz, Hankins, Hirano \& Archer, 1997; Witkovsky, 2004).

\subsubsection{Informationsverarbeitung in der Retina}

Kommt es durch das Auftreffen von Licht im elektromagnetischen Wellenlängenbereich von 380-788 nm auf die Zapfen zu einem Zerfall des in den Zapfen eingelagerten Sehfarbstoffs (Jodopsine) werden Photonen absorbiert. Dabei korrespondieren die evozierten elektrischen Signale mit der Anzahl absorbierter Photonen. Die Information über die Wellenlänge geht dabei verloren und spiegelt sich ausschließlich in der Photonenabsorptionsmenge wider (Gegenfurtner, 2003, Salomon \& Lennie, 2007). Der durch die Lichtquantenabsorption eingeleitete Prozess durch Zerfall der Sehfarbstoffe bedingt eine Veränderung der Membranpermeabilität und bildet durch Hyperpolarisation ein lokales Membranpotential (Sensorpotential) aus (Birbaumer \& Schmidt, 1999). Komplexe Verknüpfungen retinaler Neurone (Horizontalzellen, Bipolarzellen, Amakrinzellen und Ganglienzellen) leiten die Information an zentrale Regionen weiter. Dies geschieht einerseits auf direktem Weg zwischen Photorezeptoren, Bipolarzellen und Ganglienzellen, zum Anderen auf indirektem, lateralem Weg zwischen Photorezeptoren über Interneurone (Horizontalzellen, Amakrinzellen) zu Bipolarund Ganglienzellen (Schmidt, Lang \& Thews, 2004; Salomon \& Lennie, 2007). Dabei gewährleisten die Horizontalzellen sowie Amakrinzellen die räumliche Verschaltung der Photorezeptorsignale (Solomon \& Lennie, 2007) (siehe Abbildung 3). 


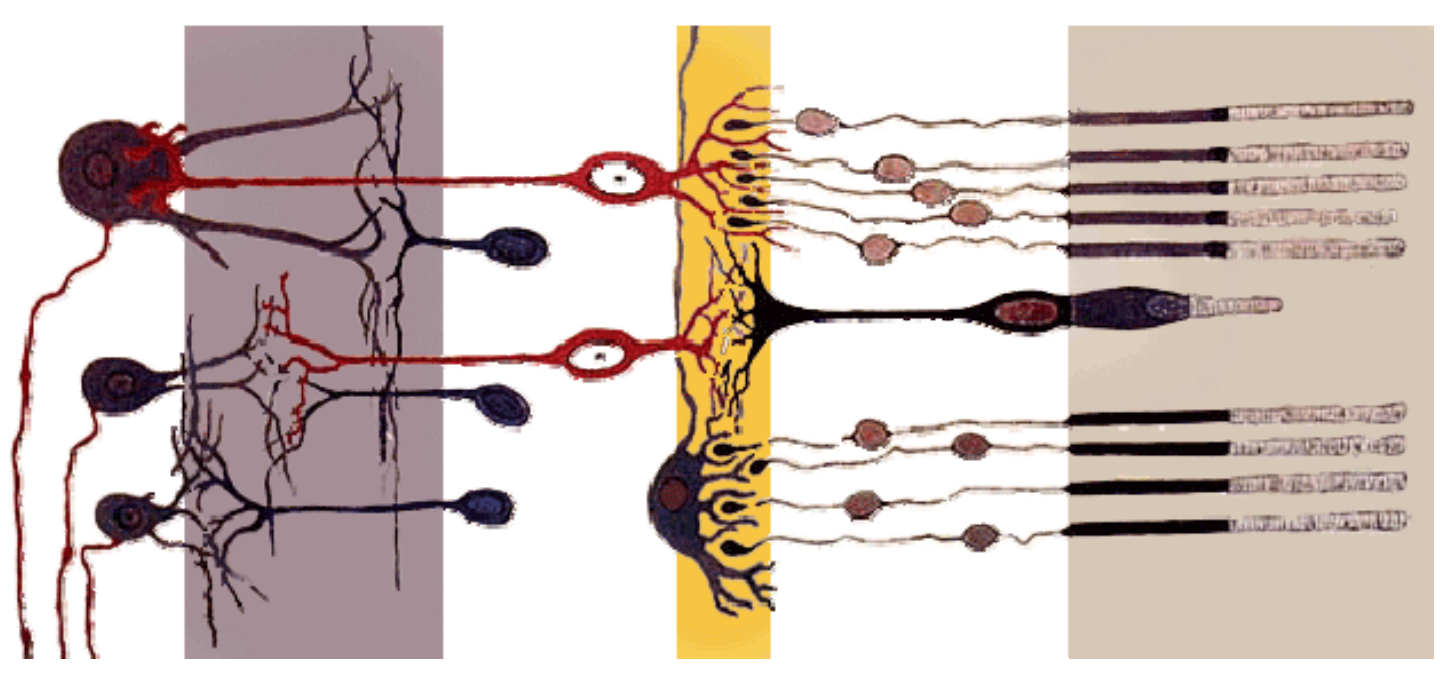

Abbildung 3: Aufbau und Informationsverarbeitung in der Retina (vInr: weiß: Ganglienzellen und ihre Axone, grau: Innere Plexiforme Schicht, weiß: Amakrine Zellen, Bipolare, Horizontalzellen, gelb: Äußere Plexiforme Schicht, weiß: Fotorezeptoren, hellbraun: Fotorezeptoren Außensegmente) (aus: http://de.wikipedia.org)

Die Axone der Ganglienzellen bilden den Sehnerv (Nervus opticus) und stellen die Ausgangsneurone der Retina dar. Sie leiten die elektrischen Informationen zu den zentralen Sehregionen weiter. Die Vereinigung bzw. Kreuzung der Sehnerven beider Augen geschieht im Chiasma nervus opticus, von wo diese die Informationen über den Tractus opticus zum wichtigsten sowie stärksten Projektionsziel der Ganglienzellen, dem Corpus geniculatum laterale (CGL) (seitlicher Kniehöcker) (Schmidt, Lang \& Thews, 2004, Solomon \& Lennie, 2007), der Schaltstelle zwischen Netzhaut und Hirnrinde, übermitteln.

Durch die Verschaltung der drei Photorezeptoren entstehen die drei oben genannten Kanäle, die funktional voneinander unabhängig sind, unterschiedliche Zellmorphologie und Physiologie aufweisen und anatomisch unabhängige retino-genikulo-kortikale Bahnen einnehmen (Mariani, 1984; Dacey, 1993; Dacey \& Lee, 1994; Calcins, Tsukamoto \& Sterling, 1998; Gegenfurther, 2003). Das Hell/Dunkel-System ist durch antagonistischen L- und M-Zapfen aufgebaut und verrechnet die Signale beider Zapfen durch Addition der Erregungsmuster. Im Rot/Grün-System werden die Informationen der L- und M-Zapfen durch Subtraktion voneinander gewonnen und so die Rot-Grün-Anteile des Stimulus erfasst. Letztlich wird im Blau/Gelb-System die Signalsumme der L- und MZapfen von jenen der S-Zapfen subtrahiert und darüber die Blau-Gelb-Anteile des Stimulus bestimmt (Gegenfurther, 2003) (siehe Abbildung 4). 


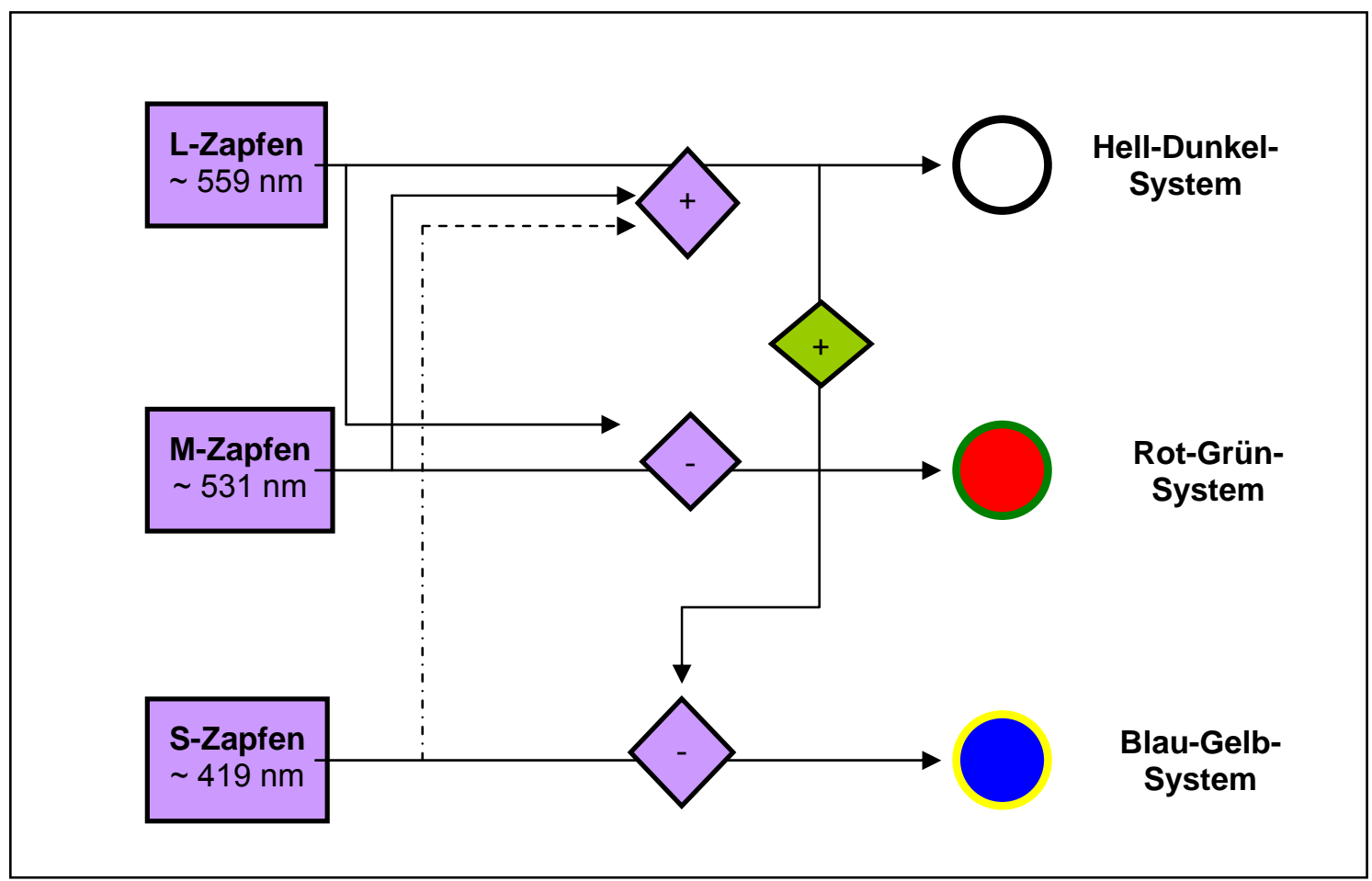

Abbildung 4: Verschaltungsmodell der Zapfen

\subsubsection{Verarbeitung im visuellen Kortex}

Der CGL projiziert mit Hilfe seiner ca. 1 Millionen Axone über die Radiatio optica zu der primären Sehrinde, der okzipitalen Großhirnrinde, genannt Area V1. Neben Informationen zur Objektfarbe enthalten die Signale Informationen über Form, Raum, Tiefe und Bewegung. Ausgehend von der Area V1 werden die neuronalen Signale in weitere Regionen (Area V2, Area V3 und Area V4) verteilt. Darüber hinaus besteht ein rückläufiger Kontakt zwischen der Area V2, V3 und V4 und der primären Sehrinde. Jeder Area sind Signale unterschiedlicher visueller Informationen betreffend zuzuordnen, wobei Farbinformationen insbesondere in Area V1, V2 und V4 verarbeitet werden (Schmidt, Lang \& Thews, 2004), alle vier Areale aber auf Farbreize reagieren (Mullen, Dumoulin, McMahon, de Zubicaray \& Hess, 2007).

Die Übertragung der visuellen Information in die subkortikalen visuellen Zentren ist retinotrop organisiert, so dass das Bild der Netzhaut über regelhafte räumliche Erregungsmuster der Neurone der zentralen Sehfelder abgebildet wird, bzw. jedem Ort auf der Netzhaut ein Ort im CGL entspricht sowie benachbarte 
Orte im CGL entsprechend benachbarte Orte auf der Netzhaut darstellen (Birbaumer \& Schmidt, 1999).

\subsubsection{Farbsinnstörungen}

Störungen in der Farbwahrnehmung sind häufig zu finden und können durch eine pathologische Veränderung der Sehfarbstoffe, der Signalverarbeitung in den Photorezeptoren sowie den nachgeschalteten Nervenzellen erklärt werden. Ferner kann die spektrale Durchlässigkeit des lichtbrechenden Teils des Auges (Linse) sowie eine Läsion der visuellen Hirnrinde Veränderungen in der Farbwahrnehmung hervorrufen (Schmidt, Lang \& Thews, 2004).

Unter den genetisch bedingten Beeinträchtigungen des Farbsinnes können grundsätzlich trichromatische und dichromatische Störungen des Farbensehens unterschieden werden. $\mathrm{Zu}$ den 3 Farbanomalien gehören die Protanomalie (Rotschwäche) sowie Deuteranomalie (Grünschwäche) und die Tritanomalie (Blauschwäche). Bei lediglich 0,01\% der Bevölkerung ist ein Ausfall des gesamten Farbsinns zu finden (Achromaten) (Birbaumer \& Schmidt, 1999).

Im Rahmen dieser Arbeit erscheint der Umstand interessant, dass ebenfalls häufig im Zusammenhang mit psychiatrisch-neurologischen Krankheiten, an deren Pathophysiologie eine Dysfunktion der dopaminergen Transmission beteiligt ist, diskrete Störungen der Farbwahrnehmung zu beobachten sind (siehe 2.5). Diese pathologischen Veränderungen des Farbsinns können, nach Krastel (1991), spezifische Ausfälle der neuronalen Funktionen und neuronalen Integrität anzeigen. Bisherige Untersuchungen konnten Veränderungen der Farbwahrnehmung, insbesondere Beeinträchtigungen auf der Blau/Gelb-Achse bei Morbus Parkinson (Haug, Kolle, Trenkwalder, Oertel, \& Paulus, 1995; Pieri et. al., 2000), Morbus Huntington (Büttner, Schulz, Kuhn \& Blumenschein, 1994), Tourette-Syndrom (Melun, Morin, Muise \& DesRosiers, 2001), ADHS (Banaschewski, Ruppert, Tannock, Albrecht, Becker, Uebel, Sergeant \& Rothenberger, 2006), Alterungsprozessen (Djamgoz et. al., 1997; Melun et. al., 2001) sowie Kokainentzug (Desai, Roy, Roy, Brown \& Smelson, 1997) nachweisen.

Als wichtiger Faktor dieser Veränderung in der Farbwahrnehmung wird die Rolle des Dopamins angenommen. 


\subsubsection{Dopamin und Farbwahrnehmung}

Dopamin ist in hoher Konzentration in der Retina nachweisbar und ein chemisch relevanter Botenstoff bei der Lichtverarbeitung (Djamgoz \& Wagner, 1992). Dopaminerge Neurone scheinen insbesondere die Organisation der rezeptiven Felder von Ganglienzellen und Bipolarzellen zu beeinflussen und die physiologische Aktivität der Photorezeptoren zu modulieren (Djamgoz et. al., 1997). Dabei wird vermutet, dass dopaminerge Neuronen zum einen exzitatorische Signale über Bipolarzellen (Neurotransmitter Glutamat), zum anderen inhibitorische Signale über Amakrinzellen (Neurotransmitter GABA und Glycerine) erhalten, wodurch die Erregbarkeit der Zelle und die Ausschüttung von Dopamin kontrolliert wird (Witkovsky, 2004). Darüber hinaus kontrollieren sie die Verschaltung von Horizontalzellen und Amakrinzellen und beeinflussen die Kontrastsensitivität sowie die räumliche und zeitliche Verarbeitung visueller Stimuli (Witkovsky, 2004).

Der Dopamin-Rezeptor D1 konnte in der Retina von Säugetieren in den Bipolarzellen, Horizontalzellen, Amakrinzellen und Ganglienzellen nachgewiesen werden (Veruki \& Wässle, 1996; Nguyen-Legros, Simon, Caille \& Bloch, 1997; Dowling, 1990; Djamgoz et. al, 1997, Witkovsky, 2004). D5-Rezeptoren befinden sich an dem Pigmentepitel der Rinderretina (Versaux-Botteri, Gibert, Nguyen-Legros \& Vernier, 1997). Bei Mäusen fanden sich D4-Rezeptoren sowohl an Zapfen als auch Stäbchen (Cohen, Todd, Harmon \& O`Malley, 1992).

Dopamin diffundiert darüber hinaus frei in der Retina („Volume Transmission“), was zu der Annahme führt, dass grundsätzlich jeder retinale Neuronentyp von Dopamin beeinflusst werden könnte. Zusätzlich wird Dopamin in Verbindung mit trophischen Funktionen der Retina wie Wachstum, Entwicklung, Zellsterben, Kurzsichtigkeit u. ä. gebracht (Witkovsky, 2004; Reis, Ventura, Kubrusly, de Mello \& de Mello, 2007).

Eine Veränderung der Dopaminkonzentration in der Retina dürfte sich aufgrund der anatomische Verteilung und der geringen Dichte der S-Zapfen, zuerst in einer Veränderung der Wahrnehmung im Blau/Gelb-System zeigen (Djamgoz, 1997). Des Weiteren scheinen die S-Zapfen, durch ihre spektrale Sensitivität für kurzwelliges Licht, anfälliger als L- und M-Zapfen für systemische Veränderungen zu sein und einen geringeren reagiblen Bereich aufzuweisen (siehe Abbil- 
dung 2) (Hood et. al., 1994; Sperling, 1991). Dieser Umstand lässt ebenfalls vermuten, dass durch systemische Veränderungen, wie sie bei neuropsychiatrische Störungen vorliegen, die Wahrnehmung von Farben, die in Verbindung mit den S-Zapfen stehen, beeinflusst wird (Djamgoz et. al., 1997; Masson, Mestre \& Blin, 1993; Witkovsky, 2003). Veränderung in der dopaminergen Transmission, wie sie bei CTS (Singer et. al., 1991) und ADHS (Banaschewski et. al., 2006; Sadile et. al., 2005) vorliegen, sollten demnach ebenfalls mit Störungen im visuellen System, insbesondere auf der Blau/Gelb-Achse einhergehen.

2.1.6 Veränderung der Farbdiskrimination bei Störungen des dopaminergen Systems

Studien über die Farbdiskrimination von Patienten mit Störungen bzw. Zuständen, deren Pathophysiologie eine Veränderung des Dopaminstoffwechsels beinhaltet, konnten die Annahme unterstützen, dass Dopamin eine entscheidende Rolle bei der Wahrnehmung von Farben spielt. Darüber hinaus bekräftigen Studiendaten die Vermutung einer erhöhten Anfälligkeit des Blau/Gelb-Systems für systemische Veränderungen in der Dopaminkonzentration.

Desai et. al (1997) zeigten, dass Patienten mit Kokainentzug im Vergleich zu einer Kontrollgruppe in einem Farbdiskriminationstest (Farnsworth-Munsell 100hue-Test und Lanthony-Desaturated-Panel D15-Test) signifikant höhere Fehlerwerte aufweisen, und dies insbesondere auf der Blau/Gelb-Achse. Des Weiteren zeigen Patienten unter Kokain-Entzug eine verminderte retinale Antwort auf blaue Lichtblitze (Roy, Roy, Williams, Weinberger \& Smelsen, 1996).

Bei Patienten mit Morbus Parkinson ist bekannt, dass dopaminerge Neurone sowohl in der Retina als auch im Hirnstamm degenerieren, und die dopaminerge Konzentration in der Retina, im Vergleich zu gesunden Kontrollgruppen, reduziert ist (Harnois \& Paolo, 1990). Dies schlägt sich nieder in einer Beeinträchtigung der Farbdiskrimination allgemein, sowie mitunter insbesondere auf der Blau/Gelb-Achse (Haug et. al, 1995; Büttner, Kuhn, Müller, Patzold, Heidbrink \& Przuntek, 1995; Pieri et. al. 2000; Sartucci \& Porciatti, 2006). Ein über die Zeit fortschreitender Krankheitsverlauf verstärkt die Farbdiskriminationsstörung (Müller, Woitalla, Peters, Kohla \& Przuntek, 2002). 
Altersbedingte Veränderungen des Dopaminstoffwechsels in der Retina gehen ebenfalls mit Störungen des Farbsehens, ebenfalls insbesondere die Blau/GelbAchse betreffend, einher (Djamgoz et. al., 1997).

Auch bei der Pathophysiologie der Schizophrenie kommt der dopaminergen Transmission eine bedeutende Rolle zu. Bei schizophrenen Patienten zeigte sich eine Beeinträchtigung der Farbdiskriminationsleistung im Vergleich zu gesunden Kontrollen, jedoch nicht, wie erwartet insbesondere im Blau/GelbBereich (Shuwairi, Cronin-Golomb, McCarley \& O’Donnell, 2002). Die Autoren erklärten dies durch die hyperdopaminerge Transmissionsstörung und postulierten, dass vermutlich nur hypodopaminerge Transmissionsstörungen mit spezifischen Farbdiskriminationsstörungen auf der Blau/Gelb-Achse einhergehen. Ein Zusammenhang zur Medikation zeigte sich nicht.

Auch beim Morbus Huntington zeigten sich chromatische Dysfunktionen in der visuellen Wahrnehmung durch erhöhte Fehlerwerte bei Tests zur Farbdiskrimination, wobei die Diskrimination im Blau/Gelb-Bereich ebenfalls besonders beeinträchtigt erschien (Büttner et. al., 1994). Paulus, Schwarz, Werner, Lange, Bayer, Hofschuster, Müller \& Zrenner (1993) konnten darüber hinaus keine erhöhten Reizschwellenunterschiede auf der Blau/Gelb-Achse im Vergleich zu Kontrollen finden. Dabei bleibt aber zu beachten, dass der Neurotransmitter GABA stärker im Zentrum der pathophysiologischen Erklärungsversuche des Störungsbildes steht als das Dopamin und damit ebenfalls hinsichtlich der Veränderungen im visuellen System zu diskutieren wäre.

Bei der Alzheimer Erkrankung gibt es widersprüchliche Befunde bezüglich Veränderungen der Farbwahrnehmung im Vergleich zu Kontrollen. Während einige Untersuchungen keine Unterschiede zu Kontrollpatienten feststellen konnten (Wijk \& Sivik, 1995) zeigten andere Studien Beeinträchtigungen im Vergleich zu Gesunden (Pache, Smeets, Gasio, Savaskan, Flammer, Wirz-Justice \& Kaiser, 2003; Wijk, Berg, Sivik \& Stehen, 1999). Kurylo, Corkin, Dolan, Risso, Parker \& Growdon (1994) fanden bei Alzheimer-Patienten in einem Farbdiskriminationstest eine höhere Fehlerrate auf der Blau/Gelb-Achse, Wijk. et. al (1999) auf der Rot/Grün-Achse. 
Auch bei Patienten mit Migräne zeigten sich Beeinträchtigungen in der Farbwahrnehmung insbesondere bei Farben, die über die S-Zapfen wahrgenommen werden (Shepherd, 2005, 2006).

Banaschewski et. al. (2006) konnten zeigen, dass Kinder mit ADHS im Farnsworth-Musell 100-hue Test eine höhere Fehlerrate aufweisen als in Alter und Geschlecht vergleichbare Kontrollkinder. Auch hier zeigte sich auf der Blau/Gelb-Achse eine stärkere Beeinträchtigung.

Erwachsene Tourette-Patienten zeigten spezifische FarbwahrnehmungsStörungen auf der Blau/Gelb-Achse (Melun et. al, 2001) nicht jedoch auf der Rot/Grün-Achse. Mit ansteigendem Alter war eine Zunahme der Fehler auf der Blau/Gelb-Achse bei den Kontrollpatienten zu beobachten, nicht aber auf der Rot/Grün-Achse.

Hinweise auf Farbdiskriminationsprobleme auf der Blau/Gelb-Achse bei Expositionen gegenüber Toxinen wie Quecksilber oder Lösungsmittel (Till, Westall, Rovet \& Koran, 2001; Iregren, Andersson \& Nylon, 2002; Sharanjeet-Kaur, Mursyid, Kamaruddin \& Ariffin, 2004) unterstreichen ebenfalls die Anfälligkeit des Blau/Gelb-Systems.

Eine Störung der Prozesse der Farbwahrnehmung kann auf zwei Ebenen der Reizverarbeitung vermutet werden. Zum Einen kann eine "frühe“ Verarbeitungsstörung auf Ebene der Retina angenommen werden (betreffend Photorezeptoren, Bipolarzellen, Horizontalzellen, Amakrinzellen und/oder Ganglienzellen) oder zum Anderen eine zentrale bzw. höhere kognitive Funktionen betreffende Störung, wobei erstgenannte Hypothese eher durch eine spezifische Beeinträchtigung der Farbwahrnehmung auf der Blau/Gelb-Achse unterstützt würde (Hart, 1987; Djamgoz et. al., 1997; Banaschewski et. al., 2006). Geht man von einer Störung der Prozess bereits auf retinaler Ebene aus, muss die Annahme vorausgesetzt werden, dass zentrale dopaminerge Veränderungen ebenfalls mit Veränderungen der retinalen dopaminergen Konzentration einhergehen. Da diese Theorie bisher keine Falsifikation erfahren hat, wird ihr Zutreffen vorerst als gegeben betrachtet. Hinweise darauf lassen sich aus verschiedenen Studien ableiten: Die Degeneration dopaminerger Neurone im ZNS bei Patienten mit Morbus Parkinson erstreckt sich ebenfalls auf die dopaminerge Neuronendegeneration in der Retina und zeigt sich in einer Beeinträchtigung 
der Farbdiskriminationsleistung (Pieri et. al., 2000; Sartucci \& Porciatti, 2006). Eine Verbesserung der Symptomatik bei Parkinson durch eine L-DopaBehandlung geht in einer Vielzahl der Fälle ebenfalls gehäuft mit einer Verbesserung der Leistungen in einem Farbtest einher (Djamgoz et. al., 1997). Unmedizierte Parkinson-Patienten zeigten post-mortem niedrigere retinale Dopaminkonzentrationen als gleichaltrige Kontrollprobanden (Harnois \& Paolo, 1990). Des Weiteren führt die Einnahme von Methylphenidat, ein Stimulanz, das durch Blockade des Dopamintransporters an der Präsynapse eine Erhöhung der Dopaminkonzentration im synatischen Spalt bedingt, zu einer Verbesserung der Farbbenennung und Wortbenennung, zeigt aber keinen Einfluss auf die Interferenzkontrolle im Stroop-Test (Bedard, Ickowicz \& Tannock, 2002) und letztendlich korreliert die Zapfen-Amplitude für die Farbe Blau im Elektroretinogramm positiv mit der zerebrospinalen Konzentration von Homovanillinsäure ((HVS), homovanillic acid), ein Dopamin-Metabolit (Roy, Roy, Berman \& Gonzales, 2003).

Untersuchungen über die Farbdiskriminationsleistung von Kindern mit CTS sowie Kindern, die sowohl von ADHS und CTS betroffen sind, sind bisher nicht publiziert worden. Dies erscheint besonders interessant, da bei CTS von einer hyperdopaminergen Störung (Minzer, Lee, Hong \& Singer, 2004; Yoon, Gause, Leckman \& Singer, 2007) ausgegangen und bei ADHS eine hypodopaminerge Regulationsstörung angenommen wird (Sadile \& Viggiano, 2005). In der Literatur wird sowohl bei hyper- als auch hypodopaminerger Transmission eine identische Beeinträchtigungen der chromatischen visuellen Funktionen beschrieben (Banaschewski et. al., 2006; Melun et. al., 2001) mit Ausnahme der Studie zu medizierten schizophrenen Patienten (Shuwairi et. al., 2002). Dies legt die Vermutung nahe, dass das Blau/Gelb-System grundsätzlich anfällig ist für Veränderungen der dopaminergen Tansmission, unabhängig von deren Richtung. Des Weiteren interessant erscheint in diesem Zusammenhang, was dies für das komorbide Auftreten beider Störungen bedeuten würde, und wie es sich mit dem Einfluss der Farbwahrnehmung auf Leistungen in kognitiven Tests, welche die Unterscheidung von Farben voraussetzt, gestaltet (Stroop-Tests) (Laeng, Lag \& Brennen, 2005; Tannock, Banaschewski \& Gold, 2006). 


\subsection{Der Stroop-Effekt}

Der Stroop-Test in klassischer Form von J. R. Stroop konzipiert (deutsche Version: Farbe-Wort-Interferenztest), ist ein an farbigem Stimulusmaterial angelehnter Test zur Erhebung der Interferenzneigung. Er bildet die Fähigkeit zur Ausblendung dominierender aber irrelevanter Reize (Interferenzkontrolle) in optisch-verbalen Bereichen ab (Bäumler, 1985).

Nach Stroop (1935, aus MacLeod, 1991) drücke sich der Stroop-Effekt dahingehend aus, dass es signifikant länger brauche, die Druckfarbe eines inkongruenten Farbwortes als die Farbe eines Farbbalkens zu benennen. Darüber hinaus gehe dies ebenfalls mit mehr Fehlern einher (zur Beschreibung des Tests siehe 3.3.4).

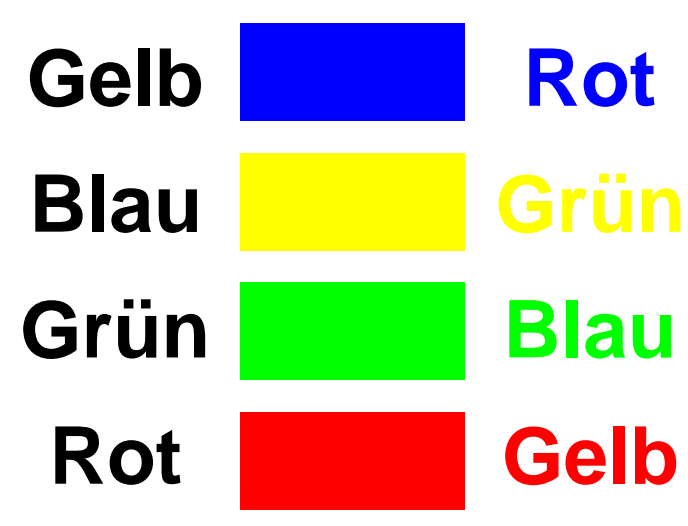

Abbildung 5: Stimulusmaterial des Farbe-Wort-Interferenztests

Zur Erklärung dieses Effekts wurden verschiedene Theorien formuliert, wobei Überlegungen zur relativen Verarbeitungsgeschwindigkeit (,Relative-Speed-ofProcessing“-Theorie) sowie Automatizität der Verarbeitung entsprechend des aktuellen Forschungsstandes überholt erscheinen (MacLeod, 1991). Erstere ging von einer parallelen Informationsverarbeitung beider Stimuluseigenschaften aus, wobei diese in Konkurrenz um die begrenzte Kapazität des Antwortkanals stehen würden. Durch die ungleich schnellere Verarbeitung der Wort- gegenüber der Farbeigenschaft des Stimulus, erreicht erstere zuerst den Antwortkanal wobei die später eintreffende mit erster konkurriert. Die Zeit, die dafür benötigt wird, so wurde angenommen, drücke sich im Interferenzeffekt aus 
(MacLeod, 1991). Die Automatizitäts-Theorie beschrieb, dass Lesen eine stärker trainierte Handlung darstelle, als die Benennung einer Farbe. Die benötigten Verarbeitungsressourcen für die Worterkennung seien somit geringer und würden zu einer schnelleren Antwort führen. Die zusätzliche Aufmerksamkeitsleistung, die durch die Verarbeitung der weniger automatisierten Handlung, in diesem Fall der Farbbenennung bereitgestellt werden müsse, drücke sich dabei im Interferenzwert aus (MacLeod, 1991). Das momentan favorisierte Erklärungsmodell zum Stroop-Effekt ist jedoch das Modell der parallelen Informationsverarbeitung von Cohen, Dunbar und McClelland (1990). Es postuliert eine gleichzeitige Verarbeitung von Informationen durch Aktivierung verschiedener Verarbeitungsbahnen unterschiedlicher Stärke. Die Stärke erscheint dabei abhängig vom Trainingsgrad. Die Unterbrechung trainierterer Handlungen, wie das des Lesens, erweist sich dabei als problematischer als die Unterbrechung von Handlungen, die aufgrund von geringen Trainingseffekten eine stärkere kognitive Verarbeitung erfordern (Cohen et al., 1990; MacLeod, 1991; van Mourik, Oosterlaan \& Sergeant, 2005). Durch Training wäre demnach der Stroop-Effekt zu reduzieren.

Letztendlich scheint darüber hinaus im Hinblick auf neuere Forschungsergebnisse, zusätzlich zum aktuellen Erklärungsmodell, der Einfluss von Unterschieden in der Farbwahrnehmung bei der Interpretation der Ergebnisse zum StroopTest zu beachten. Diesen Einfluss des Stimulusmaterials legen Ergebnisse bei ADHS-Patienten nahe (Banaschewski et. al., 2006; Albrecht, Rothenberger, Sergeant, Tannock, Uebel \& Banaschewski, 2007).

Der Versuch, den Interferenzeffekt durch Abwandlung des Ursprungsdesigns zu erheben, und somit Variationen im Stimulusmaterial zu erhalten, führte zu einer Fülle von Stroop-Tests. Dabei ist wichtig zu beachten, dass von einer Stroop-Aufgabe grundsätzlich gesprochen werden kann, wenn folgende Eigenschaften erfüllt sind: Das dargebotene Reizmaterial enthält mindestens zwei unterschiedliche Attribute (z. B. Bedeutung eines Wortes und dessen Druckfarbe), wobei die Aufgabe in der Reizklassifikation unter ausschließlicher Beachtung eines für die Aufgabe relevanten Attributs bei Ausblendung aller weiteren Reizeigenschaften besteht. So wurden auditorische Stroop-Tests, WortBild-Stroops, Antwortmodalitäts-Stroop-Tests (siehe Review: MacLeod, 1991), 
der „Frucht-Stroop“, „Tier-Stroop“ (Wright, Waterman, Prescott \& MurdochEaton, 2003) sowie der „Zahlen-Stroop“ (Flowers, Warner \& Polansky, 1979) entwickelt. Letzterer zeigte sich ebenfalls als hervorragend geeignet, um Interferenz zu erzeugen.

\subsubsection{Der Stroop-Effekt bei ADHS}

Verschiedene Autoren postulieren eine signifikant stärkere Beeinträchtigung in der Interferenzkontrolle bei ADHS-Patienten, als bei gesunden Kontrollprobanden (Carter, Krener, Chaderjian, Northcutt \& Wolfe, 1995; Pennington \& Ozonoff, 1996; Spalletta, Pasini, Pau, Guido, Menghini \& Caltagirone, 2001; Scheres, Oosterlaan, Geurt, Morein-Zamir, Meiran, Schut, Vlasveld \& Sergeant, 2004; Lansbergen, Kenemans \& van Engeland, 2007), wobei die Ergebnisse sich jedoch als uneinheitlich erwiesen haben (Willcutt, Pennington, Boada, Ogline, Tunick, Chabildas \& Olson, 2001). Robustere Befunde lassen sich bei der Betrachtung einzelner Stimuluseigenschaften finden. Unterschiede zwischen Kontrollprobanden und ADHS-Patienten zeigen sich im Sinne von langsameren Benennungsgeschwindigkeiten bei Farbwörtern und Farben (Nigg, Blaskey, Huang-Pollock \& Rappley, 2002; von Mourik, Oosterlaan \& Sergeant, 2005; Banaschewski et. al., 2006), die durch Gabe von Methylphenidat verbessert werden konnte (Bedard et. al., 2002).

Banaschewski et. al. (2006) fanden bei Kindern mit ADHS eine signifikant langsamerer Benennung von Farben und inkongruenten Farbwörter. Unterschiede in der Benennungsgeschwindigkeit schwarzer Farbwörter sowie der Interferenzkontrolle im Vergleich zu Kontrollprobanden ergaben sich hingegen nicht (Rucklidge \& Tannock, 2002; Banaschewski, Hollis, Oosterlaan, Roeyers, Rubia, Willcutt \& Taylor, 2005).

Albrecht und Mitarbeiter (2007) fanden eine stärkere Interferenzneigung bei Probanden mit ADHS ausschließlich in einem Computer-Farb-Stroop jedoch nicht in einem von farbigem Stimulusmaterial unabhängigen Zahlen-Stroop. Sie postulierten, dass nicht von einer generell stärkeren Interferenzneigung bei ADHS Probanden auszugehen ist, sondern der Stimuluscharakter des StroopTests einen wichtigen Effekt auf die Ergebnisse zu haben scheint. Die erhöhte 
Interferenzneigung bei ADHS könnte demnach auf Beeinträchtigungen in der Verarbeitung von Farben bei ADHS zurückzuführen sei (Semrud-Clikeman, Guy, Griffin \& Hynd, 2000; Laeng, Lag \& Brennen, 2005). Wurden in der Inkongruenzbedingung inkongruente antagonistische Farben dargeboten (z. B. Wort "Gelb“ in blauer Druckfarbe geschrieben), ging dies mit einer Reduzierung der Interferenzneigung einher (Laeng et. al., 2005).

\subsubsection{Der Stroop-Effekt bei CTS}

Patienten mit CTS zeigen keine erhöhte Interferenzneigung oder Unterschiede in Parametern des Stroop-Tests als bzw. zu vergleichbaren Kontrollen (Ozonoff, Strayer, McMahon \& Filloux, 1998; Ozonoff \& Jensen, 1999; Channon, Pratt \& Robertson, 2003, Roessner, Banaschewski \& Rothenberger, 2006; Roessner et. al., 2007b).

Auch bei Probanden mit komorbidem CTS und ADHS lassen sich keine Unterschiede in allen Stroop-Parametern im Vergleich zur Kontrollgruppe feststellen (Brand et. al., 2002, Channon et. al., 2003; Lavoie et. al 2007; Marsh et. al. 2007, Roessner et. al, 2007a), eine erhöhte frontostriatale Aktivität, die bei jener Gruppe zu beobachten ist, scheint dabei die Leistungen im Stroop aufrechtzuerhalten (Marsh et. al. 2007).

Sollten CTS-Probanden aber ähnliche Beeinträchtigungen wie ADHSProbanden in der Farbwahrnehmung zeigen (Melun et. al., 2001; Banaschewski et. al., 2006) und sich mitunter langsamere Reaktionszeiten in einzelnen Bedigungen des Farbe-Wort-Interferenztest durch mögliche Zusammenhänge zwischen Farbdiskriminationsfähigkeit und Stimulusmaterial erklären lassen (Albrecht et. al, 2007), stellt sich die Frage, warum Probanden mit CTS sich nicht beeinträchtigter im Farbe-Wort-Interferenztest zeigen. 


\subsection{Die chronische Ticstörung (CTS)}

\subsubsection{Definition}

Ticstörungen sind komplexe neuropsychiatrische Störungen, die definitionsgemäß vor dem 21. Lebensjahr auftreten und in den gängigen Klassifikationssystemen ICD-10 und DSM-IV als ein Syndrom beschrieben werden, welches charakterisiert ist durch sein vorherrschendes Symptom, den Tic (Dilling, Mombour \& Schmidt, 1993; Saß, Wittchen \& Zaudig 1996). Die diagnostische Einordnung wird anhand des Vorliegens isolierter bzw. kombinierter motorischer und/oder vokaler Symptome sowie des Chronifizierungsgrades getroffen.

\subsubsection{Tics}

Ein Tic ist eine nicht zweckgerichtet plötzlich einschießende, unwillkürliche, nicht rhythmische, stereotype motorische Bewegung oder Lautäußerung, die funktionell zusammenhängende Muskelgruppen betrifft. Unterschieden werden Tics sowohl hinsichtlich Qualität (motorisch versus vokal) als auch Komplexität (einfach versus komplex). Einfache Tics (motorische: z. B. Blinzeln; vokale: z. B. Grunzen) betreffen nur wenige Muskelgruppen, während komplexe Tics (motorische: z. B. Echopraxie; vokal: z. B. Echolalie) im Verlauf langsamer sind und scheinbar sinnvollen Bewegungen ähneln, dabei aber außerhalb eines sinnvollen Kontextes stehen (Banaschewski \& Rothenberger, 2003). Ihr Auftreten fluktuiert in Häufigkeit, Intensität und Komplexität über den Tag (Rothenberger, 1996; Snider, Seligman, Ketchen, Levitt, Bates, Garvey \& Swedo, 2002). Im Schlaf können sie in allen Schlafphasen auftreten, jedoch in deutlich abgeschwächter Form (Rothenberger, Kostanecka, Kinkelbur, Cohrs, Woerner \& Hajak, 2001). Nach Leckman und Cohen (1999) sind Tics isolierte und enthemmt Fragmente willkürlicher Bewegungen sowie Lautproduktionen.

Ca. $80 \%$ der betroffenen Erwachsenen beschreiben ein dem Tic vorangehendes sensomotorisches Vorgefühl fokaler oder auch diffuser Natur, das den Betroffenen mitunter ermöglicht, den sich ankündigenden Tic kurzzeitig zu unterdrücken (Rothenberger, 1996; Moll \& Rothenberger, 1999). Konzentrative bzw. 
entspannende Tätigkeiten vermindern in der Regel die Auftretenshäufigkeit und bzw. oder Intensität, wobei emotionale Anspannung bzw. Aktivierung sowie Müdigkeit zu einer Verstärkung dieser führen können. Die Einnahme von Stimulanzien kann ebenfalls zu einer Zunahme der Tics führen.

Im Laufe der Erkrankung ist eine oft kraniokaudale Ticausbreitung beginnend in der Gesichtsmuskulatur zu beobachten (Riederer, Stamenkovic, Schindler \& Kasper, 2002).

\subsubsection{Klassifikation}

Der ICD-10 unterscheidet innerhalb der Gruppe der Ticstörungen die vorübergehende Ticstörung (F 95.0), die chronisch motorische bzw. chronisch vokale Ticstörung (F 95.1), das Tourette-Syndrom (TS) (F 95.2) sowie die nicht näher bezeichnete Ticstörung ( $F$ 95.9) bzw. sonstige Ticstörungen ( $F$ 95.8). In der folgenden Untersuchung wird ausschließlich Bezug auf die chronisch motorische bzw. vokale Ticstörung sowie das Tourette-Syndrom genommen.

Die Diagnose eines TS setzt das Auftreten mindestens eines vokalen Tics sowie multipler motorische Tics voraus, die sich über einen Zeitraum von mindestens einem Jahr, ohne ticfreie Phasen von mehr als drei aufeinanderfolgenden Monaten zeigen.

Die chronisch motorische bzw. vokale Ticstörung entspricht zeitlich den Kriterien des TS, anamnestisch sowie aktuell treten jedoch entsprechend ausschließlich motorische bzw. ausschließlich vokale Tics auf (Dilling, et. al., 1993).

\subsubsection{Epidemiologie}

Ticstörungen sind die häufigsten im Kindesalter diagnostizierten Bewegungsstörungen. Die Prävalenzraten variieren erheblich in Abhängigkeit von diagnostischen Kriterien, Erhebungsmethoden und dem Untersuchungszeitraum. Nach aktuellen Schätzungen weisen ca. 3 bis 4 Prozent der Kinder im Grundschulalter eine chronisch motorische bzw. vokale Ticstörung auf (Apter et. al., 1993; 
Mason et. al. 1998; Kadesjö et. al., 2000; Khalifa et. al., 2003; 2005). Im DSMIV werden für das TS Prävalenzraten von 0.004-0.005 angegeben. Aktuelle Studien gehen jedoch von einem häufigeren Vorkommen bei bis zu 0.05 bis 3 Prozent der Bevölkerung aus.

Ticstörungen treten bevorzugt beim männlichen Geschlecht auf (Verhältnis ca. 3-4,5:1). Die Inzidenz ist unabhängig von ethnischer Zugehörigkeit, kulturellem Hintergrund und sozialem Status (Burd, Kerbeshian, Wikenheiser \& Fisher, 1986). Die Tendenz zur Spontanremission im Entwicklungsverlauf wird deutlich an einem Vergleich des Störungsvorkommens zwischen Kindern und Erwachsenen mit einer ca. 10-fach höheren Betroffenheit bei erstgenannten (Krebeshian \& Burt, 1992).

$\mathrm{Da}$ angenommen wird, dass TS, motorische CTS und vokale CTS lediglich verschiedene phänotypische Ausprägungen derselben Störung sind, wird im Folgenden eine Zusammenfassung der Störungsgruppen zur chronischen Ticstörung (CTS) vorgenommen.

\subsection{3 Ätiologie und Pathogenese}

Die Ätiologie der CTS ist bisher nach aktuellem Wissensstand bestmöglich durch ein multimodales Erklärungsmodell zu beschreiben. Wechselwirkungen zwischen genetischen, neurobiologischen, psychologischen sowie umweltbedingten Faktoren werden als denkbar angenommen, wobei deren Verknüpfungen trotz vielfältiger Bemühungen bisher weitestgehend unklar bleiben (Cohen \& Leckman, 1994; Banaschewski \& Rothenberger, 1998).

Aktuell wird ein neurophysiologisches Pathogenesemodell favorisiert, welches ein Funktions- bzw. Inhibitionsdefizit im dopaminerg modulierten sensomotorischen kortiko-striato-thalamo-kortikalen Regelkreis postuliert (Rothenberger, 1990; Ziemann, Paulus \& Rothenberger, 1997; Banaschewski \& Rothenberger, 1998). Veränderungen in diesem Bereich, insbesondere Basalganglien, Motorkortex sowie limbisches System betreffend (Singer, 1997; Adams, Troiano \& Calne, 2004) scheinen durch eine erhöhte dopaminerge Aktivität im Striatum die automatische Bewegungskontrolle sowie die subkortikale Eigenhemmung zu beeinflussen bzw. zu stören. 


\subsubsection{Biologische Faktoren}

\subsection{Genetik}

Familien-, Zwillings- und Adoptionsstudien verweisen auf die Bedeutung genetischer Faktoren sowie Expressionsbeeinflussungen durch epigenetische Faktoren bei der Genese der CTS. Monozygote Zwillinge zeigen eine Konkordanzrate von $50-90 \%$ für das TS sowie $77-100 \%$ für Ticstörungen. Konkordanzraten bei dizygoten Zwillingen liegen für das TS bei $8 \%$, für Ticstörungen bei $23 \%$ (Hyde, Aaronson, Randolph, Rickler \& Weinberger, 1992; Price, Kidd, Cohen \& Leckman, 1985). Angenommen wird eine autosomal dominante Vererbung (Pauls, Pakstis, Kurlan, Kidd, Leckman, Cohen, Kidd, Como \& Sparkes, 1990; Eapen, Pauls \& Robertson, 1993) mit einer herabgesetzten Penetranz, insbesondere beim weiblichen Geschlecht. Genomanalysen verweisen auf eine Kopplung der Chromosomen 4q sowie $8 \mathrm{q}$ beim TS (The Tourette Syndrome Association International Consortium for Genetics, 1999), was einen Hauptgenlokus mit multifaktoriell beeinflussendem Hintergrund an dem phänotypischen Erscheinungsbild des TS nahe legen würde. Neuere Studien konnten die These einer hauptgenlokalisierten Vulnerabilitätsvererbung jedoch nicht bestätigen (Seuchter, Hebebrand, Klug, Knapp, Lehmkuhl, Poustka, Schmidt, Remschmidt \& Baur, 2000) und fokussierten erneut Modellvorstellungen zur polygenen Vererbung (Comings, Comings, Devor \& Cloninger, 1984; The Tourette Syndrome Association International Consortium for Genetics, 1999).

\subsubsection{2 exogene Risikofaktoren}

Segregationsanalysen monozygoter Zwillinge unterstützen, neben der These der genetischen Vulnerabilitätsvererbung, die Annahme, dass epigenetische sowie umgebungsbedingte Faktoren einen bedeutsamen Einfluss, auf die Genese sowie insbesondere auf Schwere und Art der Symptome haben (Cohen \& Leckman, 1994; Leckman, Petersen, Anderson, Arnsten, Pauls \& Cohen, 1997). Ein niedriges Geburtsgewicht (Heyde et. al., 1992) sowie unspezifische Schwangerschafts- (z. B. psychosozialer Stress der Mutter, übermäßiger Kaffeegenuss, Nikotin- oder Alkoholkonsum, psychosoziale Traumata während der Schwangerschaft) und Geburtskomplikationen (Leckman, 2002) scheinen ne- 
ben einer Streptokokkeninfektion (PANDAS) (Swedo, Leonard, Garvey, Mittelma, Allen, Perlmutter, Lougee, Dow, Zamkoff \& Dubbert, 1998; Rizzo, Gulisano, Pavone, Fogliari \& Robertson, 2006) sowie Kopfverletzungen beim Kind relevant. Der Gebrauch von Stimulanzien wie Methylphenidat oder Kokain kann, ebenso wie die Gabe anaboler Steroidhormone, zu einer Exazerbation von Tics führen. Als weitere triggernde Faktoren bei Ausbruch der Symptome kommen schwerer psychosozialer Stress sowie dauerhafte emotionale Nervosität in Frage (Leckman, 2002).

\subsubsection{Neurophysiologische Korrelate}

Eindeutige Befunde auf molekularer und zellulärer Ebene, die die Pathogenese der CTS erklären könnten liegen bisher nicht vor. Stützende Befunde für die vermutete Beteiligung des kortiko-striato-thalamo-kortikalen Strukturen (Leckman et. al., 1997) liefern neurophysiologische Studien, die neben struktureller sowie neurochemischer Veränderungen in diesen Bereichen eine Verminderung der intrakortikalen Inhibitionsmechanismen beim CTS mittels transkranieller Magnetstimulation (TMS) belegen konnten (Ziemann, Paulus \& Rothenberger, 1997).

\subsection{Strukturelle und funktionelle Bildgebung}

Anatomisch zeigte sich eine im Vergleich zu Kontrollprobanden verminderte Volumenasymmetrie des Putamens sowie des Globus pallidus (Peterson, Riddle, Cohen, Katz, Smith, Hardin \& Leckman, 1997; Singer, 1997) außerdem linkshemisphärisch eine Volumenminderung im Bereich des Nucleus caudatus (Peterson, Thomas, Kane, Scahill, Zhang, Bronen, King, Leckman \& Staib, 2003).

Mit Hilfe von Positronenemissionstomograpie (PET), Singlephotonenemissionstomographie (SPECT) sowie funktioneller Bildgebung (fMRI) zur Bestimmung der zerebralen Stoffwechselaktivität konnte eine verminderte Durchblutung sowie Metabolisierung im Bereich der Basalganglien sowie im Mittelhirn und im orbifrontalen Kortex gezeigt werden (Braun, Stoetter, Randolph, Hasiao, 
Vladar, Gernert, Carson, Herscovitch \& Chase, 1994). In wieweit diese Unterschiede zwischen Patienten mit CTS und Kontrollprobanden Ausdruck von Kompensationsmechanismen im Rahmen der bestehenden CTS sind, oder eine Beteilung dieser Hirnregionen bei der Entwicklung des Störungsbildes vorliegt, ist bisher ungeklärt (Vloet, Neufang, Herpertz-Dahlmann \& Konrad, 2006). Eine in den sensomotorischen und supplementärmotorischen Regionen gefundene erhöhte Stoffwechselaktivität stellt möglicherweise einen Artefakt dar, der durch eine unspezifische Aktivierung, hervorgerufen durch Tics unter der Untersuchung, bedingt sein könnte (Braun et. al, 1994; Eidelberg, Moeller, Antonini, Kazumata, Dhawan, Budman \& Feigin, 1997). Motorische Tics scheinen insbesondere den sensomotorischen Kortexarealen zugeordnet, vokale Tics kortikalen und subkortikalen Sprachregionen (Stern, Silbersweig, Chee, Holmes, Robertson, Trimble, Frith, Frackowiak \& Dolan, 2000).

Insgesamt zeigten sich die morphologischen Daten über Abweichungen in den Volumina und Symmetrien in der Morphologie als wenig einheitlich und vor allem nicht konstant, was auf mögliche Alters- und Geschlechtsunterschiede in der Gruppenauswahl sowie mögliche Unterschiede hinsichtlich der Berücksichtung von Medikation und Komorbidität zurückzuführen sein könnte.

\subsection{Neurochemie}

Auf Ebene der Neurotransmittersysteme wird dem Dopamin eine bedeutende Rolle an der Pathophysiologie der CTS zugeschrieben, wobei eine Überaktivität dopaminerger Neurone im Bereich der Basalganglien die automatische Bewegungskontrolle sowie subkortikale Eigenhemmung zu beeinflussen scheint (Rothenberger, 1996; Rothenberger et. al., 2002).

Neurochemisch könnte dieser Überaktivität eine DopaminrezeptorÜberempfindlichkeit und/oder eine erhöhte Dopamintransporterdichte im Striatum zu Grunde liegen (Singer, Hahn \& Moran, 1991; Müller-Vahl, Berding, Kolbe, Meyer, Hundeshagen, Dengler, Knapp \& Emrich, 2000; Singer \& Minzer, 2003). Die durch dopaminerge Überstimulation striataler Neurone bedingte mangelhafte motorische Eigenhemmung bzw. erhöhten thalamo-kortikalen Stimulation im Motorkortex könnte, in Folge einer neuronalen Spontanentladung, 
zur Auslösung motorischer Bewegungsprogramme, die als Tics in Erscheinung treten, führen (Moll \& Rothenberger, 1999). Durch Aktivierung kortikaler Kontrollinstanzen (frontaler Kortex) kann diese mangelnde Eigenhemmung kompensiert und eine kurzfristige Unterdrückung der Tics erreicht werden (Banaschewski \& Rothenberger, 1998).

Evidenzen für die Annahme einer dopaminergen Dysregulation lassen sich insbesondere durch D2-Rezeptor blockierende Neuroleptika finden, die durch postsynaptische Besetzung der Dopaminrezeptoren eine Reduktion der Ticsymptomatik bewirken (Shapiro, Shapiro, Fulop, Hubbard, Mandeli, Nordlie \& Phillips, 1989). Darüber hinaus sind bei Einnahme von Stimulanzien Hinweise zu finden, dass es zu einer Exazerbation der Tics kommen kann (Erenberg, Cruse, \& Rothner, 1985), was jedoch dosisabhängig erscheint und nicht durchgängig zu beobachten ist (Castellanos, Giedd, Elia, Marsh, Ritchie, Hamburger \& Rapoport, 1997).

Weitere Untersuchung zur Neurotransmission bei CTS weisen auf eine Beteilung serotonerger, noradrenerger und cholinerger Systeme, des Neurotransmitters GABA und des Opiodsystem hin (zur Übersicht siehe Singer \& Walkup, 1991; Hoekstra, Anderson, Limburg, Kallenberg \& Minderaa, 2004, Singer \& Minzer, 2003), wobei vermutet wird, dass das noradrenerge System indirekt an der Modulierung dopaminerger Neurone beteiligt ist (Singer, 1997).

\subsubsection{Neuropsychologie}

\subsubsection{Exekutive Funktionen}

Eine Betrachtung der kognitiven Funktionen von Patienten mit CTS zeigte, dass sich jene ohne komorbide Störungen hinsichtlich ihrer allgemeinen Intelligenzleistung nicht von der Durchschnittspopulation unterscheiden (Como, 2005). Höhere kognitive Funktion, die inhaltliche Planung, Impulskontrolle, Organisation, Daueraufmerksamkeit und kognitive Flexibilität erfordern sowie Arbeitsgedächtnisprozesse betreffen, stehen im Zusammenhang mit dem frontalen Kortex und dessen Verbindungen zu den Basalganglien (fronto-striataler Regelkreis). Diese Funktionen werden als exekutiven Funktionen beschrieben, und stellen ein kognitives Konstrukt dar, welches zielgerichtetes Handeln sowie 
Selbstregulationsprozesse beschreibt. Beeinträchtigungen des frontalen Kortex führen zu Defiziten in der Kontrolle bzw. Inhibition motorischer Aktionen sowie kognitiver Prozesse. Da CTS mit einer Dysregulation im Bereich der Basalganglien einhergeht, wären Defizite bei Patienten mit CTS in den exekutiven Funktionen zu vermuten (Como, 2005). Diese konnten bisher jedoch nicht grundsätzlich nachgewiesen werden (Pennington \& Ozonoff, 1996; Channon, Pratt \& Robertson, 2003). Stop-Signal-Paradigmen zur Untersuchung intrakortikaler Inhibitionsmechanismen konnten keine Beeinträchtigung bei Patienten mit CTS gegenüber Kontrollprobanden finden (Chiang-Shan Ray Li, Hsueh-Ling Chang, Yuan-Pei Hsu, Huei-Shyong Wang \& Nai-Chi Ko, 2006). Die Daueraufmerksamkeitsleistung (Continuous performance task) scheint zwar bei TourettePatienten signifikant beeinträchtigter als die einer Vergleichsgruppe, jedoch im Vergleich zu Patienten mit komorbidem ADHS bzw. Patienten mit isoliertem ADHS weniger beeinträchtigt (Harris, Schuerholz, Singer, Reader, Brown, Cox, Mohr, Chase \& Denckla, 1995). Vielmehr zeigte sich, dass Auffälligkeiten in den exekutiven Funktionen in der Regel mit ADHS-Merkmalen assoziiert waren (Rothenberger, Wörner, Dumais-Huber, Moll, Röhrkohl \& Yordanova, 1994; Como, 2005; Channon, Pratt \& Robertson, 2003). So kann insgesamt vermutet werden, dass die kognitiven Funktionen bei CTS nicht verändert sind.

\subsubsection{Verlauf und Prognose}

Ticstörungen weisen einen Manifestationsgipfel um das 7. Lebensjahr auf (Freeman et al., 2000; Cardona, Romano, Bollea \& Chiarotti, 2004). Erstsymptome sind dabei meist im Gesichtbereich zu finden. Motorische Tics manifestieren sich häufig ca. 2 Jahre vor dem Auftreten erster vokaler Ticphänomene (Rothenberger, 1991), wobei die physiologischen Hintergründe dieser Beobachtung bisher unklar bleiben. Die interindividuelle Störungsentwicklung ist, genau wie das Erscheinungsbild der Störung, heterogen. Bei 3-18\% der TS-Patienten zeigen sich Spontanremissionen (Rothenberger, 1991). Präpubertär ist allgemein mit einer Zunahme der Symptome zu rechnen wobei im frühen Erwachsenenalter mit einer Verringerung der Symptomatik hinsichtlich Intensität, Frequenz und Anzahl sowie einer Verbesserung der Selbstkontrollstrategien gerechnet werden kann (Cohen \& Leckman, 1994). Etwa 10-30\% der im Kindesalter vorstellig 
gewordenen CTS-Patienten zeigen sich auch im Erwachsenenalter chronisch beeinträchtigt (Banaschewski \& Rothenberger, 2003).

Als prognostische Risikofaktoren sind neben prä- und perinatalen Belastungen der Mutter auch komorbide psychiatrische Erkrankungen sowie der Grad der emotionalen Beeinträchtigung zu nennen (Banaschewski \& Rothenberger, 2003). Den Störungsverlauf günstig beeinflussend scheint das Ausmaß der interpersonellen Beziehungsfähigkeit, die soziale Eingebundenheit, eine gut ausgebildete Affektregulation und Impulskontrolle sowie gute allgemeine kognitive Fähigkeiten (Cohen \& Leckman, 1994).

\subsubsection{Komorbidität}

Isoliert auftretende Ticsymptome zeigen sich in der Minderheit der Fälle. Bei ca. 90\% der Patienten tritt komorbid zur CTS mindestens eine weitere Störung auf (Freeman et. al., 2000), wobei hyperkinetische Störung, Zwangsstörungen, Depressionen, Angststörungen und Lern- bzw. Teilleistungsstörungen als die häufigsten Komorbiditäten zu nennen sind (Kurlan, Como, Miller, Palumbo, Deeley, Andresen, Eapen \& McDermott, 2002).

50-75\% der Patienten mit TS erfüllen gleichzeitig die Kriterien einer ADHS. Das Manifestationsalter der ADHS liegt in der Regel 2-3 Jahre vor Auftreten der ersten Ticsymptome und geht häufig mit der Entwicklung zusätzlicher Verhaltensprobleme einher. Dabei wird die Wahrscheinlichkeit eines komorbiden Auftretens von CTS und ADHS durch die Schwere der Ticsymptomatik moduliert (Comings \& Comings, 1993). 30-90\% der CTS-Patienten zeigen komorbid auftretende Zwangsstörungen, welche sich in der Regel nach Manifestation der Ticstörung entwickeln (Rothenberger, 1996; Moll \& Rothenberger, 1999; Teive, Germiniani, Coletta \& Werneck, 2001). Die Punktprävalenz einer depressiven Episode liegt nach Comings und Comings (1987) bei 23\%. Schlafstörungen treten bei ca. 10-45 \% auf (Comings \& Comings, 1987; Rothenberger, 1996; Rothenberger, Kostanecka, Kinkelbur, Cohrs, Woerner \& Hajak, 2001). Probleme im Rechnen, Lesen und Schreiben zeigen, trotz normaler Intelligenz, ca. $20 \%$ der Betroffenen, wobei Assoziationen zu einer komorbiden ADHS vermutet werden können (Scholz \& Rothenberger, 2001). 


\subsubsection{Behandlung}

Die Behandlung der CTS erfolgt symptomatisch und orientiert an einer Verbesserung des psychosozialen Funktionsniveaus. Unterschieden werden pharmakotherapeutische und psychotherapeutische Maßnahmen („übende Verfahren“, Entspannungsverfahren), wobei multidisziplinär orientierte Behandlungsstrategien bevorzugt zur Anwendung kommen, da so förderlichere und beständigere Effekte erzielt werden können (Rothenberger \& Banaschewski, 2001).

Als Medikament erster Wahl zur Behandlung motorischer und vokaler Tics sind Dopamin-2-Rezeptor-blockierende Medikamente (z. B. Tiaprid, Risperidon, Pimozid, Sulpirid) zu nennen (Rothenberger, 1991; 1993; 1994; Rothenberger \& Banaschewski, 2001), wobei je nach komorbider Begleitsymptomatik ein kombiniertes medikamentöses Vorgehen angezeigt ist (Rothenberger, 1996). Eine Reduktion der Ticsymptomatik um ca. 70\%, bei einer Ansprechbarkeit auf die Behandlung bei ca. 70\% der Patienten, konnte durch placebokontrollierte Doppelblindstudien gezeigt werden (Robertson \& Stern, 2000). Bei sogenannten Non-Respondern können als alternativ-medikamentöse Behandlungen noradrenerg wirksame Medikamente wie Clonidin, Antidepressiva wie Clomipramin oder GABA-modulierende Medikamente wie Clonazepam sowie weitere Dopamin-Antagonisten wie Haloperidol eingesetzt werden (Bandelow, Heise, Banaschewski \& Rothenberger, 2006). Medikamente der 2. und 3. Wahl gehen häufiger mit unerwünschten Nebenwirkungen einher.

An psychotherapeutischen Maßnahmen haben sich, neben einer Aufklärung der Patienten und der Familie, verhaltenstherapeutische Techniken wie Entspannungsverfahren sowie das Training der willkürlichen motorischen Gegenantwort (Reaktionsumkehr) von Azrin und Nunn (1973) als effektiv erwiesen (Azrin \& Peterson, 1990; Döpfner, 1996).

\subsubsection{CTS und Farbwahrnehmung}

Die dargestellten Befunde zur Farbdiskrimination sowie deren Zusammenhänge zu Störungsbildern mit dopaminergen Transmissionsstörungen lassen vermuten, dass ebenfalls bei Kindern mit CTS die Diskriminationsfähigkeit für Farben, insbesondere im Blau/Gelb-Bereich, vermindert sein könnte. Die Ergebnisse 
von Melun et. al. (2001) an erwachsenen CTS-Patienten unterstützen diese Annahme. Meluns CTS-Gruppe zeigte einen höheren Fehlerwert auf der Blau/Gelb-Achse, nicht aber auf der Rot/Grün-Achse. Weitere Studien zur Farbwahrnehmung bei CTS liegen bisher nicht vor.

Untersuchungen des Gesichtsfelds verweisen zusätzlich auf Defizite in diesem Bereich bei Probanden mit CTS und erhärten den vermuteten Zusammenhang zwischen CTS und Farbdiskriminationsfähigkeit. So konnten Enoch, Lakshminarayana, Itzhaki, Khamar, Landau, Lowe, Surendran \& Comerford (1991) zeigen, dass $96 \%$ der untersuchten TS-Patienten sowie 93\% ihrer Väter und über 80\% ihrer Mütter parazentrale Gesichtsfeldveränderungen aufweisen, wobei zu bemerken bleibt, dass Angaben über mögliche Komorbiditäten zum TS nicht vorlagen. Vermutet werden darf jedoch, dass diese Veränderungen ebenfalls abweichende visuelle Informationsverarbeitungsprozesse auf sensorischem und perzeptuellen Level implizieren. 


\subsection{Die Aufmerksamkeits-Defizit/Hyperaktivitäts-Störung (ADHS)}

\subsubsection{Definition und Klassifikation}

Die Aufmerksamkeits-Defizit/Hyperaktivitäts-Störung (ADHS) ist nach DSM-IV (Saß, Wittchen \& Zaudig 1996) und ICD-10 (Dilling, Mombour \& Schmidt, 1993) definiert durch ein anhaltendes Muster von Unaufmerksamkeit, Hyperaktivität und Beeinträchtigungen der Impulskontrolle, deren Ausmaß Alter, Entwicklungsstand und Intelligenz des Kindes nicht angemessen sind (Döpfner, Frölich \& Lehmkuhl, 2000). Die Symptomatik tritt über einen Zeitraum von mindestens 6 Monaten situationsübergreifend in mindestens 2 verschiedenen Lebensbereichen auf, wobei das Ausmaß der Symptomausprägung zu einer Beeinträchtigung der entwicklungsgemäßen kognitiven und sozialen Fähigkeiten und Funktionen des Kindes führt (Saß et. al., 1996). Der Beginn der Störung liegt definitionsgemäß vor Vollendung des 7. Lebensjahrs.

Zur Diagnosestellung einer ADHS nach ICD-10 fordert die WHO das gleichzeitige Vorliegen aller drei Kernsymptome. Im DSM-IV werden je nach vorherrschender Symptomkombination drei Subtypen unterschieden (vorwiegend unaufmerksamer Typ, vorwiegend hyperaktiv-impulsiver Typ, kombinierter Typ) (Brühl, Döpfner \& Lehmkuhl, 2000; Döpfner et. al., 2000). Werden zusätzlich die Kriterien für eine Störung des Sozialverhaltens erfüllt, sind nach DSM-IV zwei getrennte Diagnosen zu vergeben, nach ICD-10 wird die Diagnose einer "hyperkinetische Störung des Sozialverhaltens" gestellt.

\subsubsection{Klinisches Bild}

Zu den Kernsymptomen der ADHS zählen Aufmerksamkeitsstörung, Hyperaktivität und Impulsivität. Erstere zeigt sich beispielsweise durch Probleme bei der Aufmerksamkeitsaufrechterhaltung im Spiel oder den Hausaufgaben, so dass schnell und häufig von einer Aktivität zur nächsten gewechselt wird und Spieloder Aufgabenbeendigungen von den Kindern oft schwer fallen. Bei der Organisation von Aufgaben zeigen sich Probleme und Arbeiten werden häufig nicht beendet. Eine leichte Ablenkbarkeit durch Außenreize ist typisch und Aufgaben, 
die fremdbestimmt sind oder eine längere kognitive Anstrengung erfordern, werden häufig vermieden (Döpfner, 2000).

Hyperaktives Verhalten ist gekennzeichnet durch ein Muster exzessiver motorischer Aktivität, das bedeutsam stärker ausgeprägt ist, als bei Kindern mit entsprechendem Alter und Intelligenz in gleicher Situation zu erwarten wäre. In neuen Situationen und Umgebungen ist dieses Symptom oft schwächer ausgeprägt und entspricht im Jugend- und Erwachsenenalter häufig lediglich einem unangenehmen Unruhegefühl (Döpfner, Frölich \& Lehmkuhl, 2000).

Des Weiteren zeigen Kinder mit ADHS Schwierigkeiten, die Befriedigung ihrer Bedürfnisse aufzuschieben sowie Reaktionen zurückzuhalten und Impulse zu kontrollieren. Diese umfassende Ungeduld, die sich in verschiedenen Bereichen manifestieren kann, wird als Impulsivität bezeichnet (Saß et. al., 1996). Unter kognitiver Impulsivität wird insbesondere die Tendenz verstanden, Handlungsimpulsen zu folgen, ohne diese vollständig zu durchdenken (Döpfner, 2000).

Das phänomenologische Störungsbild der ADHS kann sich, auch in Abhängigkeit vom jeweiligen Alter der Patienten, sehr heterogen gestalten. Zusätzlich zur Kernsymptomatik bestehen vielfach komorbide Störungen sowie assoziierte Beeinträchtigungen.

\subsubsection{Epidemiologie}

Aus gesundheits- und sozialpolitischer Sicht ist die ADHS eine der bedeutendsten und häufigsten Störungen des Kindes- und Jugendalters. Abhängig von den zugrundeliegenden diagnostischen Kriterien, Erhebungsmethoden sowie dem Alter der Patienten zeigen sich Prävalenzraten zwischen 3-5\% nach DSM-IV (Saß et. al., 1996) bzw. 1-2\% nach ICD-10 (Taylor et. al., 1998). Die Punktprävalenz für Kinder im Grundschulalter wird mit 1,5 \% angegeben (Swanson, Seargent, Taylor, Sonuga-Barke, Jensen \& Cantwell, 1998). Im Kindesalter zeigt sich vermehrt der vorwiegend hyperaktiv-impulsive Subtypus, im Jugendalter dominiert häufig das Symptom der Unaufmerksamkeit.

Gegenüber Mädchen sind Jungen deutlich häufiger betroffen (Verhältnis zwischen 3-9:1) (vgl. Döpfner, 2000). Das Geschlechtsverhältnis Jungen zu Mäd- 
chen wird nach Baumgaertel, Wolraich und Dietrich (1995) beim unaufmerksamen Typus mit 2:1, beim hyperaktiv-impulsiven Typus mit 5:1 angegeben.

\subsection{4 Ätiologie und Pathogenese}

Ausführliche Forschung zur Psychophysiologie, Genetik, Biochemie, Neuroanatomie und Neuropsychologyogie der ADHS durch bildgebende Verfahren, Familien-, Adoptions- und Zwillingsuntersuchungen, Tiermodellen sowie weiteren Methoden, konnte die Ätiologie und Pathogenese der ADHS bis heute nicht vollständig erklären. Am wahrscheinlichsten gelten heterogener Entstehungsmechanismen (siehe unten), denen unterschiedliche neurobiologische und neuropsychologische Korrelate entsprechen (Seidman, Biederman, Faraone, Milberger, Norman, Seiverd, Benedict, Guite, Mick \& Kiely, 1995) und welche sich in unterschiedlichen Teilen des Spektrums der ADHS klinisch manifestieren können.

\subsubsection{Biologische Faktoren}

\subsection{Genetik}

Studienergebnisse weisen darauf hin, dass ADHS als eine Extremausprägung einer primär genetisch beeinflussten Verhaltensdimension betrachtet werden kann (Faraone \& Biederman, 1998). Familienstudien belegen, dass Eltern oder Geschwister von Kindern mit ADHS eine bis zu fünffach höhere Wahrscheinlichkeit aufweisen, selbst ein ADHS zu entwickeln, als Probanden ohne familiäre Belastung (Biederman, Faraone, Keenan, Benjamin, Krifcher, Moore, SprichBuckminster, Ugaglia, Jellinek, Steingard, Spencer, Norman, Kolodny, Kruas, Perrin, Keller \& Tsuang, 1992; Faraone, Biederman, Chen, Milberger, Warburton \& Tsuang, 1995; Faraone \& Biederman, 1994a; Faraone \& Biederman, 1994b).

Molekulargenetische Untersuchungen weisen darauf hin, dass ein Zusammenspiel zahlreicher Gene an der Entstehung der ADHS beteiligt ist (polygene Vererbung), die in ihrer Kombination komplexe Neurotransmitterfunktionen regulieren. Dabei stehen insbesondere das dopaminerge System und deren geneti- 
scher Hintergrund im Fokus der Aufmerksamkeit (Faraone, Doyle, Mick \& Biederman, 2001). Gut untersucht sind bisher das Dopamin-Transporter-Gen (DAT1) (Cook, Stein, Krasowski, Cox, Olkon, Kieffer \& Leventhal, 1995; Roman, Schmitz, Polanczky, Eizirik, Rohde \& Hutz, 2001), das Dopamin-BetaHydroxylase-Gen (taq 1 Polymorphismus) (Smith, Daly, Fischer, Yiannoutsos, Bauer, Barkley \& Navia, 2003), die Dopamin-Rezeptor-Gene DRD4, DRD5 und DRD1 (Comings, Comings, Muhleman, Dietz, Shahbahrami, Tast, Knell, Kocsis, Baumgarten, Kovacs, Levy, Smith, Borison, Evans, Klein, MacMurray, Tosk, Sverd, Gysin, \& Flanagan, 1991; Gill, Daly, Heron, Hawi \& Fitzgerald, 1997; Faraone, Beiderman, Weiffenbach, Keith, Chu, Weaver, Spencer, Wilens, Frazier, Cleves, \& Sakai, 1999; Swanson, Flodman, Kennedy, Spence, Moyzis, Schuck, Murias, Moriarity, Barr, Smith \& Posner, 2000) sowie das Serotonin-Rezeptor-Gen 5-HAT (Quist, Barr, Schachar, Roberts, Malone, Tannock, Basile, Beitchman \& Kennedy, 2003). Diese bisher identifizierten Genloci unterstützen die These einer polygenen Risikogenvererbung für eine ADHS- Prädisposition. Eine Fehlfunktion bzw. -regulation im dopaminergen Stoffwechsel wird durch die vorliegenden Befunde gestützt (Faraone \& Biederman, 1998).

\subsubsection{2 exogene Risikofaktoren}

Genetisch determinierte Störungen im Neurotransmitterstoffwechsel können, unter Wirksamwerden negativer externaler Risikofaktoren, wie Infektionen oder Exposition gegenüber Toxinen, Geburtskomplikationen, niedriges Geburtsgewicht oder mütterliches Rauchen, Alkohol- oder Benzodiazepinkonsum während der Schwangerschaft (Milberger, Biederman, Faraone, Guite, \& Tsuang, M., 1997; Banaschewski, Roessner, Uebel \& Rothenberger, 2004) eine Störung der Selbstregulation bedingen und in den Kernsymptomen der ADHS münden. Inadäquate Interaktionen mit Bezugspersonen können zu einer Verfestigung der ADHS-Symptome führen und weitere psychosoziale, emotionale und kognitive Beeinträchtigungen begünstigen (Döpfner et. al., 2000). 


\subsubsection{Neurophysiologische Korrelate}

\subsubsection{Strukturelle und funktionelle Bildgebung}

Untersuchungen mit bildgebenden Verfahren konnten neben morphologischen und strukturellen Besonderheiten auch funktionelle Veränderungen im Gehirn bei Patienten mit ADHS aufzeigen. Diese zeigen sich insbesondere in Arealen, die reich an dopaminerger Innervation sind, wie beispielsweise Bereiche des präfrontalen Kortexes (Castellanos, Giedd, Marsh, Hamburger, Vaituzis, Dickstein, Sarfatti, Vauss, Snell, Lange, Kaysen, Krain, Ritchie, Rajapakse \& Rapoport, 1996), der Basalganglien (Nucleus caudatus, Globus pallidus, Striatum) (Castellanos et. al., 1996), des Cerebellum, des Corpus callosum (Giedd, Castellanos, Casey, Kozuch, King, Hamburger \& Rapoport, 1994) sowie der grauen und weißen Substanz (Castellanos, Lee, Sharp, Jeffries, Greenstein, Clasen, Blumenthal, James, Ebens, Walter, Zijdenbos, Evans, Giedd \& Rapoport, 2002). Eine Volumenminderung der zerebralen Hemisphären um ca. 5\% sowie eine Verminderung der Hemisphären-Asymmetrie konnten Castellanos und Mitarbeiter (1996) zeigen. Funktionell konnten bildgebende Verfahren bei der Bearbeitung des Stroop-Tests Auffälligkeiten im Striatum sowie im anterioren-cingulären Kortex bei Patienten mit ADHS feststellen (Bush, Frazier, Rauch, Seidman, Whalen, Jenike, Rosen \& Biederman, 1999). Darüber hinaus zeigten sich Veränderungen im cerebralen Blutfluss.

\subsubsection{Neurochemie}

Neurochemische Befunde deuten auf eine Dysregulation katecholaminerger Transmittersysteme hin, wobei dopaminerge und noradrenerge Transmitter die bedeutendste Rolle zu spielen scheinen.

Kinder und Erwachsene mit einem ADHS weisen gegenüber Kontrollgruppen eine um $70 \%$ erhöhte Bindungskapazität der präsynaptischen Dopamintransporter auf (Dougherty, Bonab, Spencer, Rauch, Madras \& Fischman, 1999). Durch den dadurch bedingten beschleunigten Rücktransport des Dopamins im synaptischen Spalt erreicht weniger Dopamin die Postsynapse (Bana- 
schewski, Rössner, Uebel \& Rothenberger, 2004). Methylphenidat setzt direkt an diesem Mechanismus an und führt zu einer Reduktion der Bindungskapazität, so dass die Wiederaufnahme in die Präsynapse gehemmt wird und Dopamin länger wirken kann (Krause, Dresel, Krause, Kung \& Tatsch, 2000).

Tiermodelle, wie die „spontaneous hypertensive rat“ (DeJong, Lindhorst \& Versteeg, 1995; Russell, de Villers, Sagvolden, Lamm \& Taljaard, 1995) und Befunde zu den DAT- und D3-Knock-out Mäuse, bei denen durch eine selektive Ausschaltung des Dopamintransporters bzw. -Rezeptors ADHS-ähnliche Verhaltensweisen zu beobachten sind, stützen die Hypothese einer dopaminergen Beteiligung an der Genese der ADHS (Accili, Fishburn, Drago, Steiner, Lachowicz, Park, Gauda, Lee, Cool, Sibley, Gerfen, Westphal \& Fuchs, 1996).

Weitere Studien geben Hinweise auf eine Modulation der dopaminergen kortikale Transmission durch das noradrenerge System (Banaschewski et. al., 2004).

\subsubsection{Neuropsychologie}

Neuropsychologisch zeigen Patienten mit ADHS schlechtere Leistungen in Aufgaben, die Anforderungen an motorische Kontrollprozesse, Aufmerksamkeitsfunktionen wie Aufmerksamkeitsorientierung, Daueraufmerksamkeit oder geteilte Aufmerksamkeit, die sensomotorische Integrationsfähigkeit sowie höhere kognitive Prozesse (exekutive Funktionen) stellen. Ebenfalls zeigen sie sich hinsichtlich ihrer allgemeinen Lern- und Leistungsmöglichkeiten durchschnittlich schlechter als Kontrollen (Banaschewski et. al., 2006). Die Befunde sind jedoch widersprüchlich und ein einheitliches neuropsychologisches ADHS-Profil zeigte sich bisher nicht. Ebenso gibt es kein einheitliches Aufmerksamkeitsprofil bei ADHS (Koschack, Kunert, Derichs, Weniger \& Irle, 2003). Die robustesten Befunde betreffen langsamere und variablere Reaktionszeiten sowie höhere Fehlerraten in neuropsychologischen Tests, die rasches und sorgfältiges Reagieren erfordern (z. B. Pennington \& Ozonoff, 1996; Kuntsi, Oosterlaan \& Stevenson, 2001; Sergeant, Geurts \& Oosterlaan, 2002).

Leistungseinbußen sind insbesondere in Situationen mit geringem Stimulationsgehalt zu finden (Gerjets, Graw, Heise, Westermann \& Rothenberger, 2002) 
wobei unklar ist, ob dies durch unzureichende kortikale Aktivierung bedingt ist, eine Abweichung motivationaler Präferenzen aufzeigt oder auf beides zurückzuführen ist.

Anzunehmen ist, dass, wie von Barkley (1997) in seinem Modell postuliert, das Kernmerkmal der ADHS in einer defizitäre Fähigkeit zur Verhaltensinhibition besteht, welche die hyperkinetischen Symptome sowie Störungen verschiedener exekutiver Funktionen bedingt (siehe Abbildung 6). Dabei sind reaktionsbezogene Verhaltensbeeinträchtigungen, insbesondere motorische Antworten betreffend, sowie Planung, Auswahl, Ausführung und Hemmung entsprechender Alternativen nachgewiesen (Barkley, 1998; Sergeant, Geurts \& Oosterlaan, 2002). Zielgerichtetes sowie flexibles Verhalten, Affektsteuerung, problemlösendes Denken, Motivation und Antriebsregulierung (exekutive Funktionen) sind eng gekoppelt an Funktionen des präfrontalen Kortex und assoziierten Regionen und weichen bei ADHS oftmals von Kontrollprobanden ab. Ein charakteristisches Profil selektiver Beeinträchtigung in diesen Bereichen lies sich jedoch ebenfalls nicht zeigen (Sergeant, Geurts \& Oosterlaan, 2002; Sergeant, Geurts, Huijbregts, Scheres \& Oosterlaan, 2003).

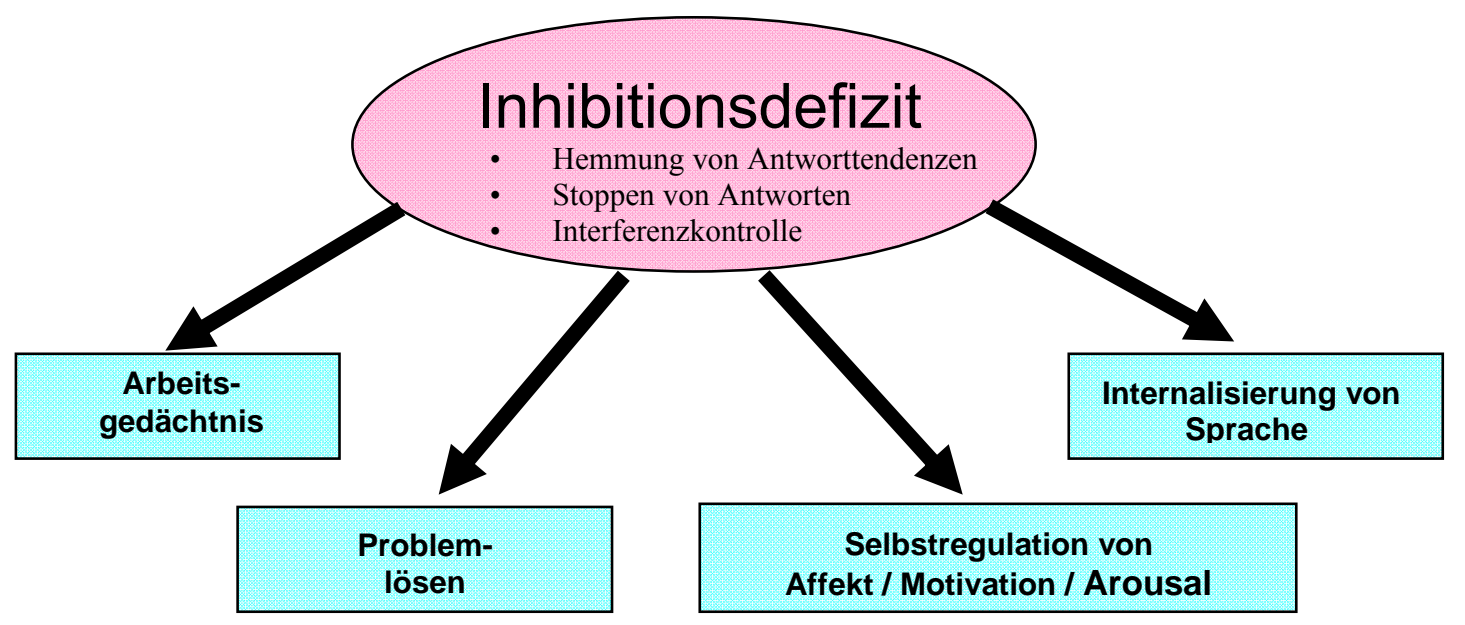

Abbildung 6: Modell der Verhaltensinhibition nach Barkley (1997a,b)

Diese Veränderungen höherer Kontrollmechanismen und reaktionsbezogene Beeinträchtigungen vermögen demnach nicht ausreichend zur Erklärung der Symptomatik beizutragen und scheinen durch zusätzliche motivationale Aspekte moduliert zu werden (Grejtes et. al., 2002), so dass nach Kuntsi et. al. (2001) 
sowie Sergeant et. al. (2002) die Befunde zum ADHS am ehesten mit einer inadäquat ausgebildeten Fähigkeit zur optimalen Anpassung des Aktivierungsniveaus bzw. einer Abneigung gegenüber Belohungsaufschub zu erklären seien könnten.

Ergebnisse zum Stroop-Effekt fielen in zahlreichen Studien uneinheitlich aus (siehe 2.2.1).

\subsubsection{ADHS und Farbwahrnehmung}

Banaschewski et. al. (2006) gingen der Frage nach, warum Patienten mit ADHS langsamere Reaktionszeiten in Tests aufweisen, in denen eine schnelle Verarbeitung farbiger Stimuli gefordert wurde, sich diese Probleme jedoch nicht bei der Verarbeitung von Buchstaben, Zahlen oder auch Wörtern zeigten (Tannock, Martinussen \& Frijters, 2000; Van Mourik, Oosterlaan \& Sergeant, 2005). Sie konnten bei Kindern mit ADHS im Farnsworth-Munsell 100-hue-Test signifikant höhere Fehlerquote, insbesondere auf der Blau-Gelb-Achse, als bei vergleichbaren Kontrollprobanden finden. In den Fehlerwerten der Rot-Grün-Achse fanden sich keine Unterschiede zwischen beiden Gruppen, was als Hinweis auf eine spezifische retinale Beeinträchtigung der Farbwahrnehmung bei ADHSPatienten gewertet wurde. Darüber hinaus zeigte sich, dass Kinder mit ADHS im Stroop-Test in den Bedingungen „Farbe benennen“ und „Inkongruenz“ langsamer waren als Kontrollprobanden, jedoch keine Unterschiede zwischen beiden Gruppen hinsichtlich der Benennungsgeschwindigkeit von Wörtern feststellbar waren. Eine weitere Studie ergab, dass Kinder mit ADHS eine verzögerte Reaktion auf blaue Stimuli aufweisen (Brodeur \& Andrade, 2002).

Untersuchungen zur Wirkung von Methylphenidat stellten eine Verbesserung in der Benennungsgeschwindigkeit für Farben unter Medikamenteneinnahme heraus (Tannock, Martinussen \& Frijters, 2000; Bedard et. al., 2002), wobei der Interferenzeffekt im Stroop-Test davon unbeeinflusst zu bleiben scheint (Bedard et. al., 2002). 


\subsection{CTS und ADHS, additives oder interaktives Modell?}

Epidemiologische Studien zeigen, dass CTS und ADHS nicht nur zu den häufigsten kinder- und jugendpsychiatrischen Störung gehören, sondern beide ein ungleich höheres als zu erwartendes komorbides Auftreten zeigen. Während in ca. $50 \%$ der Fälle bei Patienten mit Ticstörungen gleichzeitig die Kriterien einer ADHS erfüllt werden (Kurlan, Como, Miller, Palumbo, Deeley, Andresen, Eapen \& McDermott, 2002; Khalifa \& von Knorring, 2006; Freeman, 2007) bestehen bei Kindern mit ADHS in ca. $20 \%$ komorbide Ticsymptome (Kadesjö \& Gillberg, 2001; Robertson, 2006; Steinhausen, Novik, Baldursson, Curatolo, Lorenzo, Rodrigues Pereira, Ralston \& Rothenberger, 2006).

Dabei ist fraglich, ob das gemeinsame Auftreten beider Störungen einer Kombination zweier unabhängiger Störungsbilder entspricht (additives Modell) oder die Störungskombination eine separate nosologische Einheit bildet (interaktives Modell) (Moll, Heinrich, Trott, Wirth, Bock \& Rothenberger, 2001; Banaschewski, Neale, Rothenberger \& Roessner, 2007; Kirov, Kinkelbur, Banaschewski \& Rothenberger, 2007; Rothenberger, Roessner, Banaschewski \& Leckman, 2007). Ebenfalls denkbar erscheint das gleichzeitige Zutreffen beider Modelle auf unterschiedlichen Ebenen. Elektrophysiologische Studien bezüglich grundlegender Funktionen wie Hemmung motorischer Antworten, Schlafparameter oder das psychopathologische Profil betreffend, unterstützen eher das additive Modell (Moll, Heinrich, Trott, Wirth, Bock \& Rothenberger, 2001; Kirov, Banaschewski, Uebel, Kinkelbur \& Rothenberger, 2007a; Kirov, Kinkelbur, Banaschewski \& Rothenberger, 2007b; Roessner, Becker, Banaschewski \& Rothenberger, 2007c), während Studien zu komplexeren Verhaltensweisen, insbesondere höhere kognitive Prozesse betreffend, eher das interaktive Modell stützen (Yordanova, Dumais-Huber \& Rothenberger, 1996; Yordanova, Dumais-Huber, Rothenberger \& Woerner, 1997; Yordanova, Heinrich, Kolev \& Rothenberger, 2006). Die Annahmen einer nosologischen Einheit von Ticstörungen und ADHS erfährt ebenfalls Unterstützung durch verhaltensgenetische Untersuchungen, in denen das Risiko einer komorbiden Erkrankung sich nicht direkt durch das Einzelrisiko für eine ADHS bzw. eine Ticstörung erklären lässt (Stewart, Illmann, Geller, Leckman, King \& Pauls, 2006) 
Untersuchungen der exekutiven Funktionen demonstrieren (Harris, Schuerholz, Singer, Reader, Brown, Cox, Mohr, Chase \& Denckla, 1995), dass Kinder mit isoliertem CTS weniger Beeinträchtigungen zeigen, als Kinder mit CTS und ADHS oder isoliertem ADHS. Wenn Beeinträchtigungen der exekutiven Funktionen bei CTS sichtbar wurden, standen sie hauptsächlich in Verbindung mit einem komorbiden Auftreten von ADHS und/oder Zwangsstörungen (Ozonoff, Strayer, McMahon \& Filloux, 1998; Pennington \& Ozonoff, 1996; Brand, Geenen, Oudenhoven, Lindenborn, van der Ree, Cohen-Kettenis \& Buitelaar, 2002). Kinder mit Ticstörungen weisen eine kürzere corticale silent period als Vergleichsprobanden, Kinder mit ADHS eine reduzierte intrakortikale Inhibition und Kinder mit beiden Störungen beide Auffälligkeiten auf (Moll et. al. (2001)

Eine gemeinsame genetische Disposition beider Störungen wird bisher hinsichtlich der Fälle diskutiert, in welchen die ADHS-Symptomatik nach Manifestation der Ticsymptome auftritt (Pauls, Leckman \& Cohen, 1993; Yordanova, DumaisHuber \& Rothenberger, 1996). Das komorbide Auftreten beider Störungen bedingt dabei ein erhöhtes Risiko für weitere psychopathologische Auffälligkeiten wie Schlafprobleme, Lernschwierigkeiten, Angststörungen, affektive Störungen, emotionale Beeinträchtigungen, externalisierende Verhaltensweisen oder schulische Entwicklungsstörungen (Leckman \& Cohen, 1999; Freeman et. al., 2000; Roessner, Becker, Banaschewski, Freeman \& Rothenberger, 2007).

Pathophysiologisch wird sowohl bei CTS als auch bei ADHS eine Störung des dopaminerg modulierten sensomotorischen kortiko-striato-thalamo-kortikalen Regelkreises vermutet (Vloet, Neufang, Herpertz-Dahlmann \& Konrad, 2006) wobei zentralnervöse Inhibitionsdefizite, insbesondere das motorische Verhalten betreffend, eine wesentliche Rolle zu spielen scheinen. Wird bei ADHS eher eine Störung des direkten exzitatorischen Pfades zwischen frontalem Kortex und Thalamus angenommen, geht man bei CTS eher von einer Störung indirekter inhibitorischer Verbindungen aus (siehe Abbildung 7). 


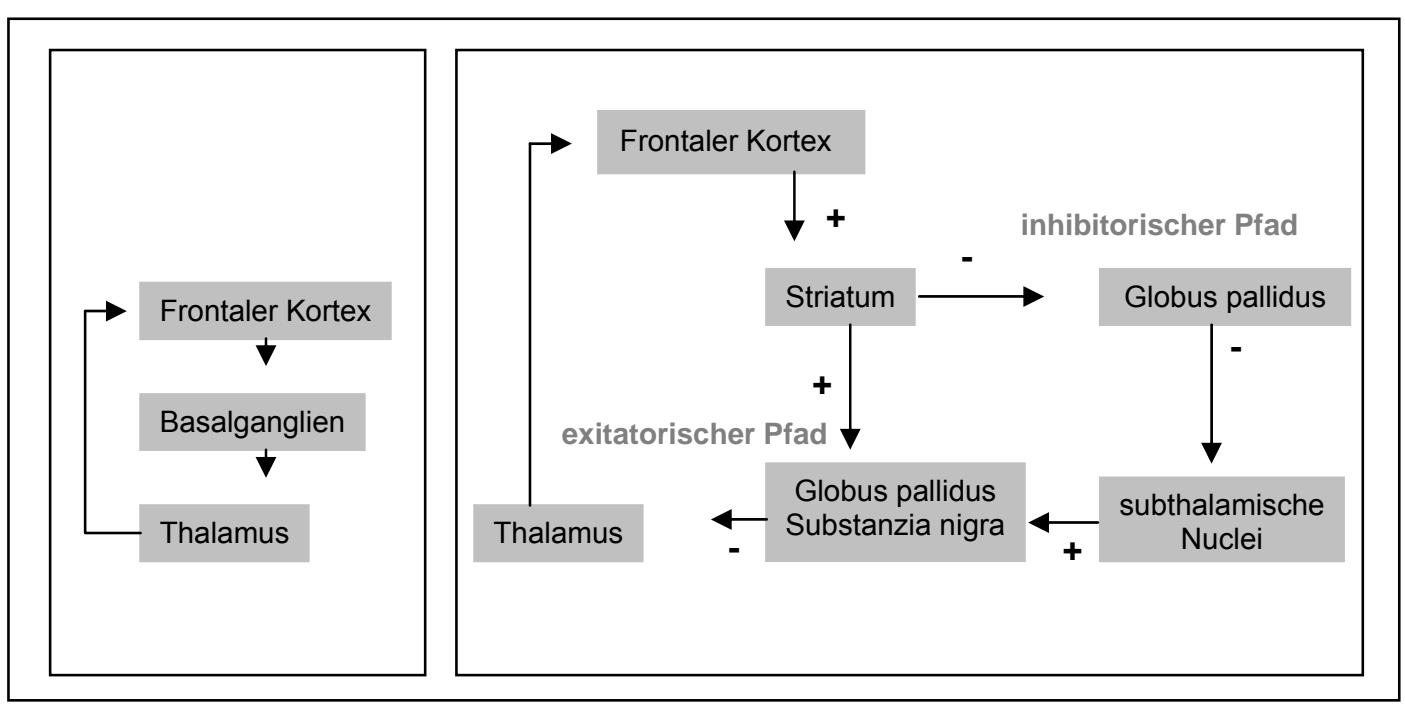

Abbildung 7: Schematische Darstellung des kortiko-striato-thalamo-kortikalen Kreislaufs (links: vereinfachte Darstellung; rechts: differenzierte Darstellung der Verschaltung zwischen Kortex, Basalganglien und Thamalus) (nach Casey, Durston \& Fossella, 2001; aus Vloet, et. al., 2006)

Strukturelle und funktionelle bildgebende Verfahren konnten sowohl bei CTS als auch bei ADHS im Vergleich zu gesunden Kontrollen Veränderungen in den Basalganglien, Corpus Callosum sowie kortiko-striatalen Systemen finden. Ein reduziertes Volumen des Nukleus caudatus wurde sowohl bei den isolierten Störungen als auch in der komorbiden Gruppe festgestellt (Castellanos et. al., 1996; 2002; Banaschewski et. al., 2007). Das präfrontale Volumen bei Kindern mit ADHS erscheint verkleinert (Castellanos et. al., 2002) im Gegensatz zu einer vergrößerten dorsopräfrontalen Region bei Kindern mit CTS (Peterson, Staib, Scahill, Zhang, Anderson, Leckman, Cohen, Gore, Albert \& Webster, 2001).

Das komorbides Auftreten von ADHS und CTS beeinflusst maßgeblich das psychosoziale Funktionsniveau der Patienten. CTS-Patienten mit einem komorbiden ADHS sind deutlich stärker beeinträchtigt als Patienten mit isoliertem ADHS (Spencer, Biederman, Harding, O`Donnell, Wilens, Faraone, Coffey \& Geller, 1998). Das gemeinsame Auftreten beider Störungen geht mit deutlicheren sozialen Problemen einher, als eine Kombination von CTS mit drei weiteren Störungen (TIC Consortium mit $\mathrm{n}=5800$ Fällen, 2004; in Rothenberger, Roessner, Banaschewski \& Leckman, 2007). Eine Parallelisierung bezüglich Geschlecht, Alter und IQ beider isolierter sowie der komorbiden Gruppe zeigte 
additive Effekte der Beeinträchtigung, wobei der Faktor ADHS in der komorbiden Gruppe den deutlicheren Einfluss auf das psychopathologischen Profil zu haben scheint (Roessner, Becker, Banaschewski, Freeman \& Rothenberger, 2007a). 


\subsection{Zielsetzung der Arbeit}

\subsubsection{Fragestellung}

Eine Vielzahl von Untersuchungen hat gezeigt, dass Störungsbilder, an deren Pathophysiologie eine Dysregulation bzw. Veränderung der dopaminergen Transmission beteiligt ist mit spezifischen Veränderungen der Farbwahrnehmung einhergehen. Die zentralen dopaminergen Transmissionsänderungen werden dabei in einen hypothetischen Zusammenhang mit etwaigen retinalen Veränderungen der Dopaminkonzentration gebracht, was mit einer Beeinträchtigung der Farbdiskrimination allgemein sowie insbesondere auf der Blau/GelbAchse einherzugehen scheint.

In der vorliegenden Arbeit wurden Kinder mit CTS und/oder ADHS sowie gesunde Kontrollprobanden auf ihre Farbdiskriminationsfähigkeit, insbesondere im Hinblick auf Diskriminationsfähigkeit auf der Blau/Gelb-Achse, in einem 2×2Design sowie auf Gruppenebene untersucht. Andere mögliche Komorbiditäten wurden dabei ausgeschlossen.

Isolierte Befunde zu Kindern mit ADHS sowie Erwachsenen mit CTS und Farbwahrnehmung liegen bereits vor, wobei ungeklärt ist, ob die Befunde für Kinder mit CTS replizierbar sind bzw. wie es sich bei komorbidem Auftreten beider Störungsbilder verhält. Ebenfalls ist derzeit ungeklärt, was Ergebnisse zur Farbwahrnehmung bei hyper- sowie hypodopaminergen Transmissionsstörungen sowie deren Kombination an Informationen zur Pathophysiologie beider Störungsbilder liefern und ob diese mit bisherigen Ergebnissen zur dopaminergen Transmission vereinbar sind. Darüber hinaus soll der Frage nach der Angemessenheit additver bzw. interaktiver Modellvorstellungen nachgegangen werden.

Um mögliche Einflüsse durch andere Variablen auszuschließen wurden Aufmerksamkeitsleistung, Intelligenz, Alter, Wortflüssigkeit, LeseRechtschreibleistung und Stimulanzienbehandlung kontrolliert.

Die Betrachtung des Stroop-Effekts im Farbe-Wort-Interferenztest sowie deren Ergebnisse und Zusammenhänge zur Farbdiskriminationsleistung stellte ebenfalls das Ziel dieser Arbeit dar. Darüber sollen die Ergebnisse beider Störungsgruppen im Hinblick auf Leistungen im Stroop-Test, der Farbdiskrimination und 
dopaminergen Störungen diskutiert werden. Hierzu wurden, zusätzlich zur klassischen Variante des Stroop-Tests (klassischer Papier-Stroop), eine computerisierte Form (Computer-Farb-Stroop) sowie eine farbunabhängigen Variante (Zahlen-Stroop) durchgeführt.

\subsubsection{Ableitung inhaltlicher Hypothesen}

Vor dem Hintergrund der bisherigen theoretischen Erläuterungen den aktuellen Forschungsstand entsprechend, lassen sich folgende inhaltlichen Hypothesen ableiten, deren Präszisierung unter 3.4 in empirischen Vorhersagen erfolgen wird.

\section{Hypothesen zur Farbdiskriminationsleistung}

Es wird erwartet, dass Kinder mit CTS sowie Kinder mit ADHS Beeinträchtigungen in der Farbdiskriminationsleistung, besonders in der Blau-GelbWahrnehmung, zeigen.

Ferner wird erwartet, dass die Farbdiskriminationssleistung bei Kindern mit komorbider Diagnose stärker beeinträchtigt ist, als bei Kindern mit isolierter Diagnose ADHS bzw. CTS.

\section{Hypothesen zum Stroop-Test}

Es wird erwartet, dass Kinder mit CTS keine Schwierigkeiten bei der Farbbenennung und dem Lesen von Farbwörtern im Stroop-Test zeigen. Bei Kindern mit ADHS werden Schwierigkeiten bei der Bewältigung dieser Aufgaben erwartet. Ferner wird ein Interferenzeffekt in allen Grupen mit besonderer Ausprägung bei Kindern mit ADHS erwartet.

Darüber hinaus wird erwartet, dass Kinder mit CTS und Kinder mit ADHS größere Schwierigkeiten bei der Bearbeitung eines Farb-Stroops zeigen, als bei der Bearbeitung eines von farbigem Stimulusmaterial unabhängigen StroopTests. 


\section{Material und Methoden}

\subsection{Patientenkollektiv}

\subsubsection{Rekrutierung der Stichprobe}

Die Rekrutierung des Patientenkollektivs erfolgte über die Ambulanz der Kinderund Jugendpsychiatrie der Universitätsmedizin Göttingen. Patienten mit der Diagnose "chronische Ticstörung (CTS)" (F95.1 und F95.2 nach ICD-10) bzw. „Aufmerksamkeits-Defizit/Hyperaktivitäts-Störung plus chronische Ticstörung (CTS+ADHS)" wurden im Rahmen der vorliegenden Studie untersucht. Die Testung der Probanden mit isolierter Diagnose „AufmerksamkeitsDefizit/Hyperaktivitätsstörung (ADHS)“ erfolgte bereits unter identischen Bedingungen im Rahmen der Studie „Beeinträchtigung der Farbdiskrimination bei Kindern mit Aufmerksamkeits-Defizit/Hyperaktivitätsstörung“ (Ruppert, 2005, Banaschewski et. al., 2006). Als Kontrollgruppe diente eine, ebenfalls im Rahmen der ersten Studie untersuchte Probandengruppe, deren Rekrutierung über ortsansässige Grundschulen und Orientierungsstufen der Stadt Göttingen erfolgte. Sämtliche Kontrollprobanden erfüllten weder zum Untersuchungszeitpunkt noch in der Vergangenheit die diagnostischen Kriterien einer psychiatrischen Störung, mit Ausnahme einer Legasthenie. Insgesamt wurden 73 Kinder im Alter zwischen 8.0 und 12.6 Jahren untersucht.

Die Studie wurde durch die Ethikkommission geprüft und bewilligt.

\subsubsection{Einschlusskriterien}

In die Studie wurden konsekutiv alle Patienten aufgenommen, die bereit waren, an der Studie teilzunehmen, keine Ausschlusskriterien erfüllten sowie den entsprechenden Diagnosekriterien genügten.

Die Diagnosestellung bzw. Diagnoseüberprüfung einer CTS (ICD-10; F95.2/F95.1) bzw. einer ADHS (ICD-10; F90.0) erfolgte anhand klinischer Anamnese, medizinischer Befunde, Diagnosechecklisten (DISYPS-KJ) sowie Eltern-/ Lehrer- und Selbstbeurteilungsbögen (siehe 3.3.1). 
Zum Ausschluss komorbider psychiatrischer Störungen kamen weitere klinische Fragebögen zum Einsatz (Achenbachfragebögen, Strengths and Difficulties Questionnaire (SDQ), Leyton-Fragebogen, Birleson-DepressionSelbstbeurteilungsskala, Angstfragebogen für Schüler (AFS)).

\subsubsection{Ausschlusskriterien}

Kinder, die neben der Diagnosen CTS und/oder ADHS, Kriterien für eine weitere psychische Störung der Achse 1 oder Achse 2 erfüllten (mit Ausnahme von Legasthenie) wurden aus der Studie ausgeschlossen. Schwere neurologische Auffälligkeiten oder Erkrankungen, allgemeine kognitive Leistungsmöglichkeiten im unterdurchschnittlichen Bereich (Intelligenzquotient $(I Q)<85$ ), eine bilinguale oder nicht-deutschsprachige Spracherziehung sowie eine diagnostizierte Schwerhörigkeit führten des Weiteren zum Studienausschluss. Lag eine leichte Verminderung der Sehschärfe vor, musste diese durch eine entsprechende Brille korrigiert sein. Darüber hinaus hatte bei allen Kindern die Fähigkeit zum sicheren Lesen von Wörtern und einfachen Sätzen vorzuliegen. Eine Behandlung mit Stimulanzien wurde 48 Stunden vor Beginn der Untersuchung abgesetzt um den Einfluss möglicher medikamentöser Effekte auf die Ergebnisse zu kontrollieren. Medikationen zur Behandlung der Tic-Symptomatik wurden fortgesetzt. 


\subsection{Ablauf der Untersuchung}

Die Untersuchung der Probanden erfolgte in Einzelversuchen in einem schallgedämmten Raum der Abteilung für Kinder- und Jugendpsychiatrie der Universität Göttingen. Die Anordnung der Versuchsmaterialien, die Sitzposition sowie die Lichtverhältnisse (325 Lux, gemessen mit LT Lutron LX-101 Lux-Meter) wurde über sämtliche Probanden konstant gehalten. Die Testdauer betrug, inklusive Pausen, ca. 2 Stunden. Die Reihenfolge der einzelnen Testdarbietungen wurde entsprechend der Abbildung 8 durchgeführt.

Sowohl Probanden als auch Eltern wurden ausführlich über Zweck, Art, Ablauf und Dauer der Studie aufgeklärt. Im Anschluss an die Untersuchung bestand die Möglichkeit zur Vereinbarung eines Beratungstermins, um Informationen über die Leistungen des Kindes zu erhalten. Die Teilnahme an der Untersuchung erfolgte freiwillig, ein Abbruch ohne Angaben von Gründen war jederzeit möglich. Zu Untersuchungsbeginn lagen für Elternteil bzw. Erziehungsberechtigte sowie das zu untersuchende Kind getrennte schriftliche Einverständniserklärungen vor, welche den Probanden in Kopie ausgehändigt wurden.

Nach Abschluss der Untersuchung wurden den Probanden die Fahrkosten sowie eine Aufwandsentschädigung über 15 Euro erstattet. 


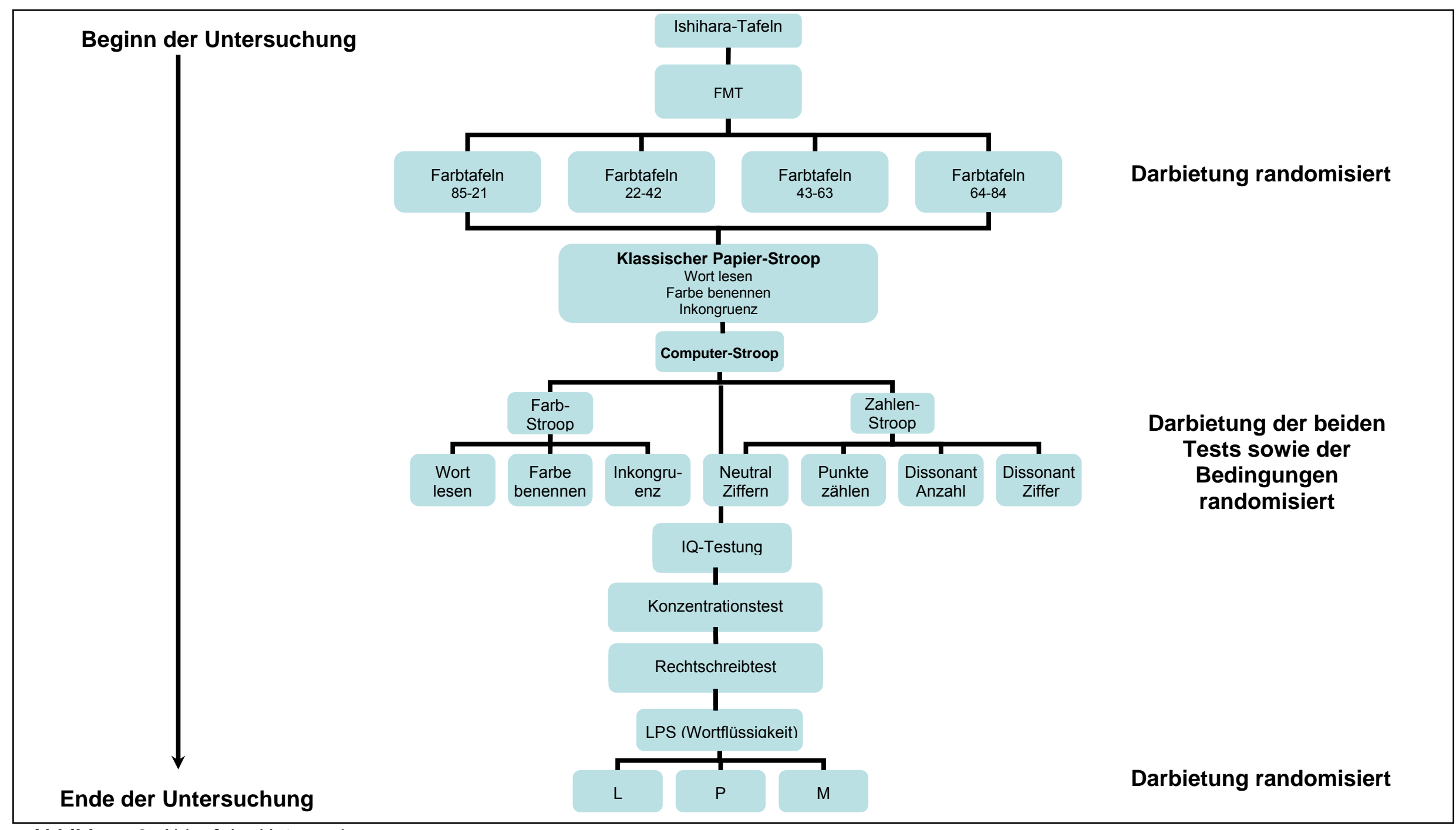

Abbildung 8: Ablauf der Untersuchung 


\subsection{Untersuchungsinstrumente}

\subsubsection{Diagnosestellung}

\subsubsection{Sicherstellung der Diagnose CTS}

\section{Diagnostiksystem zur Erfassung psychischer Störungen bei Kindern und Jugendlichen (DISYPS-KJ)}

Die klinische Beurteilung der Symptomatik sowie Diagnosestellung erfolgte über das Diagnostiksystem zur Erfassung psychischer Störungen bei Kindern und Jugendlichen (DISYPS-KJ). Orientierend an den Diagnosekriterien des ICD-10 sowie DSM-IV ermöglicht das DISYPS-KJ eine kombinierte Einschätzung der Symptomatik auf drei Beurteilungsebenen (Döpfner \& Lehmkuhl, 2003). Die klinisch-symptomatische Einschätzung der Ticstörung erfolgte dabei über die Diagnose-Checkliste (DCL-TIC) welche 106 Items umfasst.

Zusätzlich zur klinischen Beurteilung der Tic-Symptomatik wurden Informationen hinsichtlich des Ausprägungsgrads der Störung erhoben. Dies erfolgte über Elternurteile sowie Einschätzungen weiterer Bezugspersonen. Die folgenden Verfahren kamen dabei zur Anwendung:

\section{Fragebogen zum Tourette-Syndrom (TGD-Fragebogen)}

Zur umfassenden Beurteilung der Häufigkeit sowie Versorgungssituation von TS-Patienten wurde der TGD-Fragebogen von der Tourette-Gesellschaft Deutschland e. V. eingesetzt. Die hier verwendete zweite Version wurde von der Klinik und Poliklinik für Kinder- und Jugendpsychiatrie und Psychotherapie des Universitäts-Klinikum Göttingen im Oktober 2001 herausgegeben und stellt eine Überarbeitung des ersten TGD-Fragebogens dar. Dieser ermöglicht eine strukturierte kurzanamnestische Erfassung störungsrelevanter Informationen über Selbst- bzw. Fremdurteile. Auf 14 Seiten werden über 49 Items klinisch relevante Daten zum individuellen Krankheitsverlauf erfragt. Die Items stellen eine Kombination aus geschlossenen und offene Fragen dar und gliedern sich inhaltlich in drei Themengebiete: „allgemeine Angaben“, „Angaben zum Touret- 
te-Syndrom bzw. zur Tic-Störung“ und „Angaben zur Behandlung“. Die Auswertung erfolgt rein deskriptiv.

Bewertungsskala für motorische Tics, vokale Tics, Zwangsgedanken und Zwangshandlungen

Die Bewertungsskala für motorische Tics, vokale Tics, Zwangsgedanken und Zwangshandlungen wurde von Gaffney et al. (1994) entwickelte und von Rothenberger (1996) modifiziert. In Fragebogenform erhebt er quantitative Angaben des Ausprägungsgrad motorischer und vokaler Tics, Zwangsgedanken sowie Zwangshandlungen. Die Beurteilung der 20 Items erfolgt auf einer vierfach gestuften Skala $(0=$ nie, $1=$ manchmal, $2=$ oft, $3=$ immer $)$. Zur Auswertung können isolierte Summenscores einzelner Skalenwerte (motorische Tics, vokale Tics, Zwangsgedanken, Zwangshandlungen) sowie ein Gesamtsummenscore für Tics bzw. Zwänge sowie assoziierte Auffälligkeiten gebildet werden. Ein Vergleich dieser mit kritischen Referenzwerten ermöglicht eine qualitative Einstufung und Bewertung der Merkmalsausprägung. Psychometrische Untersuchungen liegen bislang nicht vor.

Yale-Tourette-Syndrome-Symptome-Liste (YTSS) (Cohen et. al., 1985; bearbeitet von Steinhausen)

Die YTSS ermöglicht eine sowohl quantitative als auch qualitative Einschätzung der aktuellen Ticsymptomatik über Fremd- bzw. Selbsturteile. Auf einer 6-fach ( 0 = überhaupt nicht, $1=$ ein wenig, $2=$ oft, $3=$ sehr oft, $4=$ extrem oft, $5=$ fast immer) gestuften qualitativen Bewertungsskala wird das Vorliegen einzelner ticspezifischer Auffälligkeiten über den Zeitraum einer Woche beurteilt. Die zu beurteilenden Bereiche gliedern sich dabei in die Kategorien „einfache motorische Symptome", „komplexe motorische Symptome“, „einfache Phonationssymptome“" „komplexe Phonationssymptome“ sowie „Verhalten“.

Tourette-Syndrome-Schweregrad-Skala (TSSS) (Shapiro et al., 1988)

Die TSSS dient der globalen Schweregradeinschätzung der Ticsymptomatik und erfordert die Beurteilung der Funktionsfähigkeit bzw. Beeinträchtigung des 
Betroffenen. Die Einschätzung kann sowohl über Selbst- als auch Fremdbeurteilungen erfolgen. Die Summenwerte der fünf erfragten Items („Tics werden von anderen wahrgenommen“, "Tics rufen Bemerkungen oder Neugier hervor", „der Patient wird als verrückt oder bizarr angesehen“, „Tics interferieren mit Alltagsfunktionen“, „Leistungsfähigkeit“) bilden die Basis für die globale Schweregradeinschätzung der Symptomatik durch Normgruppenvergleiche.

\subsubsection{Sicherstellung der Diagnose ADHS}

Die Diagnosestellung ADHS erfolgte ebenfalls über das DISYPS-KJ, wobei die klinische Symptombeurteilung anhand der DCL-HKS vorgenommen wurde. Die DCL-HKS umfasst die drei Bereiche „Aufmerksamkeitsstörung“, „Hyperaktivität“ und "Impulsivität" und lehnt sich an die diagnostischen Kriterien des ICD-10 und DSM-IV an. Eltern- und Lehrerurteile über den Grad der Symptomausprägung in den entsprechenden Lebensbereichen wurden anhand des FBB-HKS erhoben (Brühl, Doepfner \& Lehmkuhl, 2000), welcher entsprechend der DCL-HKS die Symptomkriterien im Fremdurteil über 20 Items erfasst. Ein Selbsturteil über die Symptomausprägung wurde bei Kindern ab elf Jahren über den SBB-HKS eingeholt.

Als weiteres diagnostisches Instrument wurde die Kurzversion der ConnersRating-Scale, die an den ADHS-Diagnosekriterien des DSM-IV orientiert ist, eingesetzt.

\subsubsection{Differentialdiagnostik}

Zum Ausschluss weiterer, bisher nicht diagnostizierter psychiatrischer Störungen, kamen die folgenden Instrumente zur Anwendung:

Achenbach-Fragebögen (Child Behavior Checklist (CBCL/4-18), Teachers Report Form (TRF) \& Youth Self Report (YSR/11-18))

Die CBCL/4-18 besteht aus zwei Teilen und erhebt über Elternurteile Kompetenzen und Verhaltensprobleme sowie emotionale Auffälligkeiten von Kinder 
und Jugendliche im Alter zwischen 4 und 18 Jahren. Die Auswertung erfolgt über drei Kompetenzskalen (Aktivität, soziale Kompetenz und Schule), sowie acht Syndromskalen (sozialer Rückzug, körperliche Beschwerden, Angst/Depressivität, soziale Probleme, Schizoid/Zwanghaft, Aufmerksamkeitsstörung, delinquentes Verhalten, aggressives Verhalten) (Achenbach, 1991a). Die Syndromskalen sind aggregierbar zu den Gesamtskalen „internalisierende Störungen", „externalisierende Störungen" sowie einem Gesamtproblemwert (Achenbach, 1991a). Hinsichtlich der Syndromskalen gilt ein T-Wert von $\geq 71$ als auffällig. Bei den Gesamtskalen wird ab einem T-Wert von $\geq 64$ von einem auffälligen Wert gesprochen.

Der TRF erfasst, identisch der CBCL/4-18, Probleme und Kompetenzen des Kindes, bezieht schulische Leistungen sowie Hintergrundinformationen mit ein und ist äquivalent zur Elternversion (Achenbach, 1991b).

Der YSR/11-18 ist ein Selbstbeurteilungsfragebogen und entspricht im Aufbau der CBCL/4-18. Die Items sind, bis auf 16, mit denen der Elternversion identisch. Die Normierung erfolgte über den Altersbereich der elf bis 18-jährigen und wurde den Probanden dieser Studie ab einem Alter von elf Jahren vorgelegt. Die Auswertungsskalen des YSR/11-18 entsprechen denen des CBCL/4-18 (Achenbach, 1991c).

Über alle Bögen können Vergleiche der einzelnen Syndromskalen bestimmt werden.

\section{Strengths and Difficulties Questionnaire (SDQ)}

Der SDQ ist ein hoch valider Kurzfragebogen, der, ähnlich der Achenbachfragebögen, Kompetenzen und Probleme bei Kindern und Jugendlichen über Selbst- und Fremdurteile erhebt (Klasen, Woerner, Wolke, Meyer, Overmeyer, Kaschnitz, Rothenberger \& Goodman, 2000; Becker, Hagenberg, Roessner, Woerner \& Rothenberger, 2004; Becker, Woerner, Hasselhorn, Banaschewski \& Rothenberger, 2004; Rothenberger \& Wörner, 2004). Die Eltern- und Lehrerversion wird für Kinder zwischen vier bis 16 Jahren, der Selbstbeurteilungsbogen im Alter ab elf Jahren eingesetzt.

Bei der Konzipierung der 25 Items wurde insbesondere Wert auf eine ausgewogene Formulierung positiver und negativer Verhaltensaspekte gelegt und zur 
Orientierung Diagnosekriterien des ICD-10 bzw. DSM-IV herangezogen. Die Einschätzung der Items erfolgt auf einer dreifach gestuften Skala $(0=$ nicht zutreffend, 1 = teilweise zutreffend, 2 = eindeutig zutreffend). Für die Auswertung werden fünf Summenscores gebildet, die inhaltlich auf "emotionale Probleme“, „Verhaltensauffälligkeiten“, „Hyperaktivität“, „Probleme im Umgang mit Gleichaltrigen“ und „prosoziales Verhalten“ Bezug nehmen. Darüber hinaus wird ein Gesamtproblemwert über Summebildung der vier erstgenannten Skalen erzeugt. Ein Vergleich aller Summenwerte mit altersentsprechenden Normwerten ermöglicht die Beurteilung des Symptomausprägungsgrads (Woerner, Becker, Friedrich, Klasen, Goodman \& Rothenberger, 2002; Achenbach, Becker, Döpfner, Heiervang, Roessner, Steinhausen \& Rothenberger, 2008).

Leyton-Fragebogen (Kurzfassung) (nach Berg et. al, 1988, bearbeitet von M. Döpfner, 1992)

Der Leyton-Fragebogen dient der Erfassung von Zwangssymptomen und erhebt in zwei Schritten zuerst das Vorliegen eines Symptoms und im Anschluss den Grad der Beeinträchtigung, der aus dem entsprechenden Symptom resultiert. Insgesamt sind 20 Items zu beurteilen. Die Werte ermöglichen eine gute ökonomische Trennung zwischen auffälligen und unauffälligen Probanden im Bezug auf Zwangssymptome (Bamber, Tamplin, Park, Kyte \& Goodyer, 2002).

\section{Birleson-Depression-Selbstberuteilungsskala (von Birleson, 1981)}

Dieser Selbstbeurteilungsfragebogen ist ein Screening-Instrument zur Einschätzung depressiver Symptome bei Kindern und Jugendlichen. Über die Beurteilung von 18 Items auf einer dreifach gestuften Skala (,meistens“, „gelegentlich“, „niemals“) hinsichtlich des Zutreffens bezogen auf das aktuelle Befinden, werden depressive Tendenzen bzw. Symptome erfragt (Birleson, 1981).

\section{Angstfragebogen für Schüler (AFS)}

Der AFS ist ein mehrfaktorieller Fragebogen und einsetzbar für Schulkinder im Alter zwischen neun bis 16/17 Jahre. Er erhebt neben der Tendenz zu angepasstem bzw. sozial erwünschtem Verhalten, ängstigende und unlustbereitende Erfahrungen von Schüler unter den drei Aspekten „Prüfungsangst“, 
"manifeste Angst" und "Schulunlust" (Wieczerkowski, Nickel, Janowski, Fittkau \& Rauer, 1981). Für alle Skalen stehen Normwerte zur Verfügung.

\subsubsection{Farbwahrnehmung}

\subsubsection{Ishihara-Tafeln zur Prüfung des Farbsinns}

Dieser Farbsinntest wird zur Überprüfung der häufigsten angeborenen Farbsinnstörungen Protanopie (Rotblindheit), Protanomalie (Rotschwäche), Deuteranopie (Grünblindheit) sowie Deuteranomalie (Grünschwäche) eingesetzt. Die Darbietung der 24 Tafeln erfolgt senkrecht zur Blickrichtung in ca. $75 \mathrm{~cm}$ Entfernung. Jede Tafel ist mit einer bunten Punktekombination auf einem farbigen Hintergrund bedruckt, durch welche entweder Zahlen oder Linien dargestellt werden. Diese müssen von dem Probanden, bei Vorliegen einer Zahl, benannt, bei Vorliegen einer Linie mit dem Finger nachgezeichnet werden. Eine Benennung der gesehenen Zahl sollte innerhalb eines Zeitfensters von drei Sekunden erfolgen. Zur Erkennung einer Farbsinnstörung ohne entsprechende Diagnosestellung genügt die Vorlage der Tafeln eins bis 15. Diese ermöglichen eine sichere Trennung zwischen Personen mit normalem und gestörtem Farbsinn. Daher wurde bei der vorliegenden Studie auf die Darbietung der Tafel 16-24 verzichtet (Ishihara, 24 Plates Edition). Wurde bei Probanden eine Farbsinnstörung festgestellt, erfolgte ein Ausschluss dieser aus der Studie. Dies betraf einen Probanden (Rot-Grün-Schwäche).

\subsubsection{Farnsworth-Munsell 100-hue-Test (FMT)}

Die Beurteilung der Farbdiskriminationsfähigkeit der Probanden erfolgte mit dem Farnsworth-Munsell 100-hue-Test (Farnsworth, Revised; 1957). Dieser „Powertest" besteht aus insgesamt 85 in schwarze Plastikrahmen eingefasste Farbplättchen (Durchmesser: $12 \mathrm{~mm}$, Höhe: $5 \mathrm{~mm}$ ) gleicher Lichtdichte und Sättigung. Die Unterscheidung der einzelnen Farbproben ist für den Betrachter ausschließlich anhand des Farbtons möglich, wobei diese an das menschliche Auge hohe Anforderungen stellt, aufgrund der schwer differenzierbaren Abstufungen der Farbplättchen (Farnsworth, 1943). Die Farbdiskriminationsleistung 
stellt die Fähigkeit des Probanden dar, einzelne Farbnuancen richtig zu unterscheiden und in eine gestufte Ordnung zu bringen.

Die Anordnung der Farbplättchen ist in vier Boxen mit jeweils festen Anfangsund Endpunkten eingeteilt. Die dazwischen liegenden Plättchen sind frei beweglich. Die Rückseite der Plättchen ist in fortlaufender Weise nummeriert. Eine Anordnung der 85 Farbproben in aufsteigender Reihenfolge ergibt ein vollständiger Farbkreis und ermöglicht so eine einfache Überprüfung der Farbdiskriminationsfähigkeit.

Die Darbietung der vier Farbboxen erfolgt getrennt voneinander. Dabei werden die einzelnen Farbproben der jeweiligen Box entnommen und dem Probanden in zufälliger Reihenfolge präsentiert. Die Aufgabe besteht, orientierend am jeweiligen Anfangs- und Endpunkt der Serie, in der korrekten fortlaufenden Einordnung der verbleibenden Farbproben. Dabei unterliegen die Probanden keiner zeitlichen Begrenzung, eine Korrektur der Sequenz war darüber hinaus jederzeit möglich.

Die Auswertung des Farnsworth-Munsell 100-hue-Test erfolgt über die auf der Rückseite der Plättchen vermerkten Nummerierungen. Die vom Probanden gelegte Reihenfolge wird notiert und ein Fehlerwert für jede einzelne Farbprobe ermittelt. Durch Addition der Differenzen des vorangehenden und nachfolgenden Plättchen und der anschließenden Subtraktion des Wertes „2“ von der erhaltenen Summe, erhält jede Farbprobe bei richtiger Platzierung den Fehlerwert 0 (Kinnear \& Sahraie, 2002). Durch Aufsummierung der Fehlerwerte jedes einzelnen Farbplättchens kann ein Gesamtfehlerwert für jeden Probanden bestimmt werden. Darüber hinaus kann ein Fehlerwert für die Achsen Rot/Grün sowie Blau/Gelb bestimmt werden und eine Beurteilung selektiver Farbdiskriminationsstörungen erfolgen (Smith et. al, 1985). Außerdem ist die Ermittlung der Differenz zwischen dem Fehlerwert der Blau/Gelb-Achse und der Rot/GrünAchse möglich (Differenz der Farbachsen).

Die Reihenfolge der Präsentation der vier Farbreihen wurde über alle Probanden randomisiert. Die Testung erfolgte binokular. 


\subsubsection{Kognitive Leistungstests}

\subsubsection{Intelligenztest}

Die Überprüfung der kognitiven Lern- und Leistungsmöglichkeiten erfolgte, je nach Alter des Kindes, anhand des Grundintelligenztests Skala 1 (CFT 1) bzw. des Grundintelligenztests Skala 2 (CFT 20). Bis zu einem Alter von einschließlich 9;5 Jahren wurde mit den Kindern der CFT 1 durchgeführt, bei Kinder, die dieses Alter überschritten hatten, wurde der CFT 20 eingesetzt. Der CFT 1 bzw. CFT 20 wurde in Anlehnung an den Culture-Fair-Intelligenz-Test Skala 1 bzw. Skala 2 von Cattell entwickelt und ermöglicht die Bestimmung der Grundintelligenz im Sinne der Cattell'schen "General Fluid Ability" (Weiß \& Osterland, 1997; Weiß, 1998).

Der CFT 1 erfasst anhand sprachfreien, figuralen Materials die Fähigkeit formallogische Denkprobleme zu erfassen, Regeln zu erkennen, Beziehungen herzustellen sowie die schnelle Identifizierung und Wahrnehmung von Merkmalen (Weiß \& Osterland, 1997). Über die Bearbeitung von fünf Untertests („Substitutionen“, „Labyrinthe“, „Klassifikationen“, „Ähnlichkeiten“ und „Matrizen“) kann ein Gesamt-IQ bestimmt werden.

Der CFT 20 setzt sich aus den aus vier Untertests „Reihen fortsetzen“, „Klassifikationen“, „Matrizen“ sowie „topologische Schlussfolgerungen“ zusammen und erhebt die Fähigkeit, Denkprobleme von unterschiedlichem Komplexitätsgrad in einer vorgegebenen Zeit zu erkennen und zu verarbeiten. Das Material ist ebenfalls rein figural (Weiß, 1998).

\subsubsection{Das Frankfurter Aufmerksamkeits-Inventar (FAIR)}

Das FAIR ist ein Papier- und Bleistift-Test und wurde in der vorliegenden Arbeit zur Kontrolle der Ergebnisse bzw. Minimierung von aufmerksamkeitsbedingten Störeinflüssen auf die fragestellungsrelevanten Tests eingesetzt. Er erfasst Aufmerksamkeits- bzw. Konzentrationsleistungen auf den Dimensionen „Leistung", "Qualität" und „Kontinuität“. Die Aufgabe des Probanden besteht bei der Bearbeitung im Treffen von Diskriminationsurteilen über visuell ähnliche Reize. Die relevanten Zielitems sind, unter Beachtung des vollständigen Markierungs- 
prinzips, fortlaufend zu kennzeichnen, aufgabenirrelevante Reize sind auszublenden (Moosbrugger \& Oehlschlägel, 1996).

Die Auswertung erfolgt über die Ermittlung von Linienfehlern, Verpassfehlern sowie Falscher-Alarm-Fehlern, über die vier verschiedene Beurteilungsmaßstäbe berechnet werden können. Dabei gibt der Leistungswert (L) Aufschluss über die Menge der konzentriert bearbeiteten Items. Der Qualitätswert $(Q)$ bildet die Relation zwischen allen Beurteilungen sowie den konzentriert bearbeiteten Items ab. Die Kontinuität der Bearbeitung wird über den Kontinuitätswert (K) angegeben und ein Maß für die instruktionsgenaue Bearbeitung stellt der Markierungswert (M) dar (Moosbrugger \& Oehlschlägel, 1996).

\subsubsection{Lese-Rechtschreibtest}

Die Bearbeitung des Rechtschreibtests diente ebenfalls der Kontrolle der Testergebnisse und Minimierung der Einflüsse durch Beeinträchtigungen in der Rechtschreibfähigkeit. Zu diesem Zweck wurde, je nach besuchter Schulklasse, der entsprechende, zur Legastheniediagnostik geeignete Rechtschreibtest durchgeführt (Diagnostischer Rechtschreibtest (DRT) bzw. Weingartener Grundwortschatz Rechtschreib-Test (WRT)). Die Aufgabenstellung jedes Rechtschreibtests verlangt nach Diktat das Einsetzen einer bestimmten Anzahl von Wörtern unterschiedlichen Schwierigkeitsgrads in einen Lückentext. Anhand eines Vergleichs des ermittelten Rohwertes mit altersspezifischen Normwerten, ist die Bestimmung eines T-Wertes und dementsprechend eine qualitative Leistungsbewertung der Rechtschreibfähigkeit des Probanden möglich. Im Anschluss kann, anhand der Diskrepanz zum Intelligenzquotienten, das Vorliegen einer Legasthenie überprüft werden.

\subsubsection{Leistungsprüfsystem (LPS); Untertest Wortflüssigkeitstest}

Zur Überprüfung von Beeinträchtigungen der Sprechmotorik kam der Untertest „Wortflüssigkeit" des Leistungsprüfsystems (LPS) nach Horn zur Anwendung. In diesem besteht die Aufgabe des Probanden in der Produktion von möglichst vielen existierenden Wörtern, innerhalb eines festgelegten Zeitraums, welche 
mit einem entsprechend vorgegebenen Anfangsbuchstaben zu beginnen haben. Diese nacheinander präsentierten Anfangsbuchstaben waren „L“, „P“ und „R“, wobei für jeden Buchstaben eine Bearbeitungszeit von 60 Sekunden zur Verfügung stand (Horn, 1983).

Die Darbietungsreihenfolge der einzelnen Anfangsbuchstaben wurde über alle Probanden randomisiert.

\subsubsection{Stroop-Tests}

Zur Überprüfung der Interferenzneigung sowie des Einflusses der Farbdiskriminationsfähigkeit auf Leistungen in einem mit farbigem Material arbeitenden Leistungstest, wurden verschiedene Versionen des Stroop-Tests durchgeführt.

\section{Farbe-Wort-Interferenztest (klassischer Papier-Stroop)}

Diese klassische Form des Stroop-Tests ist ein sensumotorischer Geschwindigkeits-Leistungstest. Er erfasst die Interferenzneigung, eine zentralen exekutiven Funktion, die die Beeinflussbarkeit der Informationsverarbeitung durch dominierende aber irrelevante Stimuli misst. Angewendet wurde er in dieser Untersuchung in deutscher Version von Prof. Bäumler (Farbe-WortInteferenztest nach Stroop) (Bäumler, 1985).

Im Einzelnen werden die kognitiven Leistungsfunktionen „Lesegeschwindigkeit“, „Benennungsgeschwindigkeit“ (Nomination), „Interferenzneigung“ und „sensumotorische Aktionsgeschwindigkeit“ (Grundgeschwindigkeit der Informationsverarbeitung) über drei Aufgabenbedingungen („Wort lesen“, „Farbe benennen“ und „Inkongruenz“) erhoben. Zusätzlich zum Grundleistungsprofil kann ein DreiFaktoren-Profil erstellt werden, das die regressionsbereinigten Leistungsfaktoren abbildet („allgemeine Aktionsgeschwindigkeit“, „Nomination“ und „Selektivität“) (Bäumler, 1985), worauf in der vorliegenden Untersuchung jedoch verzichtet wurde. Der Interferenzwert als Maß für die Interferenzneigung wurde hier als vierter Kennwert nach der von Jensen (1965) beschriebenen Methode („Reaktionszeit in der Bedingung Inkongruenz" minus „Reaktionszeit in der Bedingung Farbe benennen“) bestimmt und ist im Folgenden gemeint, wenn von Interferenzneigung gesprochen wird. 
Der klassische Papier-Stroop besteht aus einer Übungstafel und 3 Prüftafeln. Jede der drei Aufgabenbedingungen („Wort lesen“, „Farbe benennen“ und „Inkongruenz") setzt sich aus 72 Items zusammen, die die Farben Rot, Gelb, Grün und Blau betreffen. In der ersten Aufgabenbedingung „Wort lesen“ werden dem Probanden auf einer Karte Items mit den schwarz gedruckten Farbwörtern „rot“, "gelb“, "grün" und „blau“ dargeboten. Der Proband wird aufgefordert, die gesehenen Wörter möglichst schnell und fehlerfrei vorzulesen. In der folgenden Bedingung „Farbe benennen“ werden Farbbalken in denselben vier Farben vorgelegt und bei gleicher Instruktion die Benennungsgeschwindigkeit der 72 Items erhoben. Die Aufgabe in der dritten Bedingung "Inkongruenz" besteht in der Benennung der Druckfarbe der Farbwörter, wobei die beiden Reizattribute Druckfarbe und Wortbedeutung inkongruent zueinander sind (z. B. gelb) (siehe Abbildung 9).

Die Gesamtzeit zur Benennung aller Items in jeder Bedingung wird separat für alle drei Prüftafeln bestimmt.
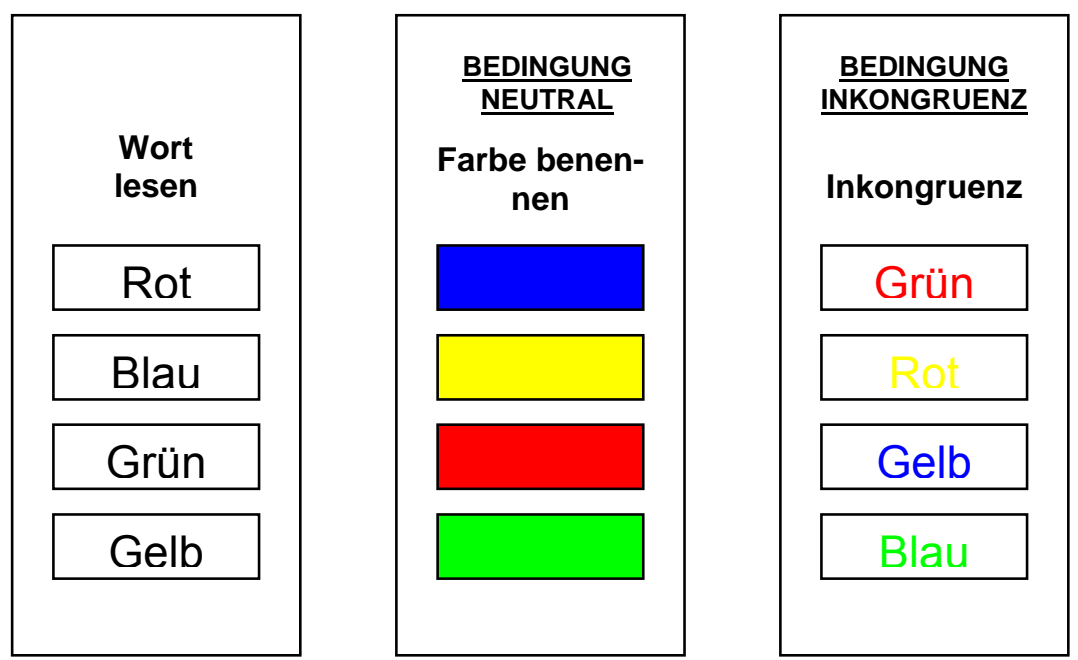

Abbildung 9: klassischer Farb-Stroop und Computer-Farb-Stroop

\section{Computer-Stroop}

Der klassische Stroop-Test erlaubt keine, über die drei Bedingungen hinausgehende, Auswertung der Ergebnisse auf Itemebene aufgrund seiner Darbietungsform über Itemkarten. Die computerisierte Form des klassischen PapierStroops, welche in Zusammenarbeit mit J. Sergeant und R. Tannock in der Ab- 
teilung für Kinder- und Jugendpsychiatrie der Universität Göttingen entwickelt wurde, ermöglicht diese aufgrund der Registrierung der Antwortgabe bezüglich jedes einzelnen Items. Die Darbietung jedes Items erfolgt dabei über einen Computermonitor, wobei über ein Multiple-Choice-Pad itembezogen eine Antwort zu jedem einzelnen Reiz zu erfolgen hat. Diese Antwort ist auswertbar hinsichtlich Reaktionszeit, Variabilität in der Antwortgabe und Anzahl korrekter Antworten. Über die verschiedenen Bedingungen, Trials sowie Antworttasten der Computer-Stroop-Tests wurden Mittelwerte der Reaktionszeiten sowie die beschriebenen Parameter bestimmt. Dabei wurden Trials mit einer Reaktionszeit von unter 150 ms aus den Analysen ausgeschlossen.

In den neutralen Bedingung des Computer-Stroops wurde ein Minimum an 51\% $(\mathrm{N}>35)$ korrekter Antworten, sowie in der inkongruenten Bedingung ein Minimum von $34 \%(N>24)$ gefordert. Dieses Kriterium wurde von jedem Probanden erfüllt.

\section{Computer-Farb-Stroop}

Der Computer-Farb-Stroop stellt eine, der klassischen Stroop-Variante entsprechende, computerisierte Version dar und erhebt entsprechen über jeweils 72 Items die drei Bedingungen „Wort lesen“, „Farbe benennen“ und „Inkongruenz". Dem Probanden werden nacheinander über einen Bildschirm (17-Zoll Monitor, Sehwinkel ca. $3^{\circ}$ horizontal und $1^{\circ}$ vertikal) Farbwörter bzw. Farbbalken auf weißem Hintergrund dargeboten. Zu Beginn einer jeden Bedingung erfolgt über den Bildschirm die Präsentation der schriftlichen Instruktion, die dem Probanden von dem Versuchsleiter laut vorzulesen ist. Im Anschluss, nach Klärung auftretender Fragen, folgt ein Übungsdurchgang. Zu Beginn jedes Trials erscheint ein Fixaktionspunkt für $250 \mathrm{~ms}$, gefolgt von einem ebenfalls $250 \mathrm{~ms}$ dargebotenem weißen Bildschirm. Die Stimuluspräsentation erscheint im Anschluss für einen Zeitraum von $750 \mathrm{~ms}$. Nach einer Latenzzeit von $1000 \mathrm{~ms}$, in welcher erneut ein weißer Bildschirm sichtbar ist, folgt die Präsentation des nächsten Trials. Die itembezogene Antwortgabe ist bis zum Ablauf der $1000 \mathrm{~ms}-$ Latenzzeit über die Multiple-Choice-Tastatur möglich. Jedem der 4 Knöpfe auf der Tastatur ist sowohl eine Farbe als auch Ziffer zugeordnet. Die Betätigung der Knöpfe sollte dabei mit Zeigefinger und Daumen der rechten sowie der lin- 
ken Hand erfolgen (Knopfanordnung trapezförmig, von links nach rechts und oben nach unten: grün, rot, blau, gelb bzw. 1, 2, 3, 4) (siehe Abbildung 10).

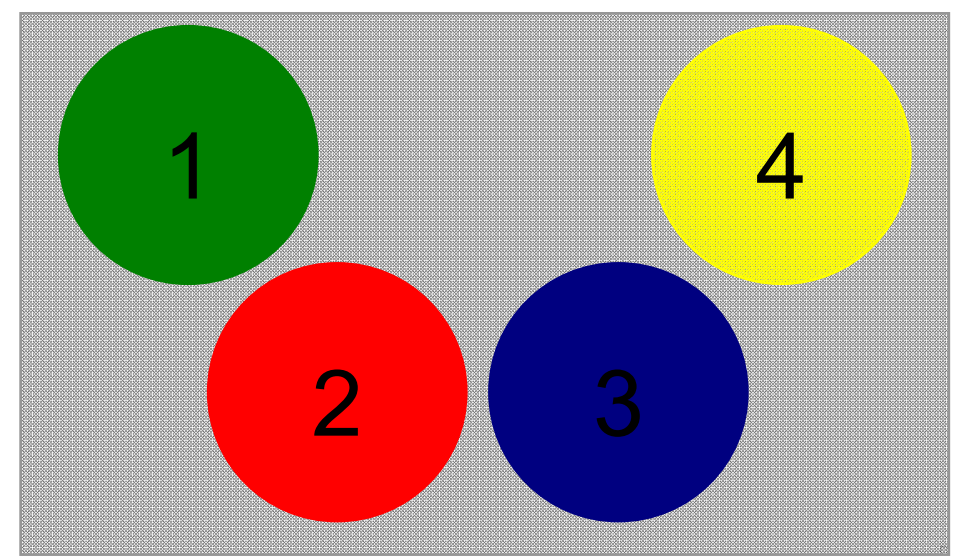

Abbildung 10: Tastatur des Computer-Stroops

Um mögliche Sequenzeffekte zu vermeiden, wurde die Darbietung der Bedingungen blockrandomisiert.

Für jeden Trial wurden Reaktionszeiten, Anzahl richtiger Antworten in Prozent sowie intra-individuelle Variabilität in der Reaktionszeit bestimmt.

\section{Zahlen-Stroop}

Kognitive Interferenzneigung kann nicht nur über Varianten des Farb-Stroops bestimmt werden, sondern, wie oben beschrieben, über jede Form der Reizdarbietung mit mindestens zwei unterschiedlichen miteinander konkurrierenden Attributen. Eine Abwandlung des Ursprungsdesigns stellt beispielsweise der Tier-Stroop dar (Wright et. al., 2003). Da die Durchführung eines farbunabhängigen Tests für die hier vorliegende Fragestellung unerlässlich ist, wird der Zahlen-Stroop als Kontrollbedingung, ebenfalls als Computer-Version, verwendet. Die durch diesen erhobene Interferenzneigung bezieht sich auf das Zählen von Punkten oder Zahlen sowie das Benennen von Ziffern.

Der Aufbau und Ablauf des Zahlen-Stroops ist dem Design des Computer-FarbStroops identisch. Auch hier werden dem Probanden kongruente sowie inkongruente Bedingungen mit jeweils 72 Durchgängen über den Computerbildschirm dargeboten. Die Präsentationszeiten der einzelnen Items entsprechen 
denen des Computer-Farb-Stroops, wobei der Zahlen-Stroop insgesamt $4 \mathrm{Be}-$ dingungen umfasst.

Zwei neutralen Bedingungen fordern das schnellstmögliche Drücken der korrekten Taste auf der Multiple-Choice-Tastatur (Tastatur siehe Computer-FarbStroop) entsprechend der Anzahl von Punkten ( $\cdots, \cdot, \cdots, \cdots$, oder $\bullet$; Instruktion: „nenne die Anzahl“) bzw. Bedeutung von Ziffern (1, 2, 3 oder 4; Instruktion: „nenne die Zahl“). In zwei Inkongruenzbedingungen werden jeweils mehrere gleiche Zahlen präsentiert, wobei, in einem der Durchgänge, die Anzahl der Zahlen zu beurteilen ist, in einem anderen Durchgang, die Ziffer unabhängig von ihrer dargebotenen Anzahl (siehe Abbildung 11). In beiden neutralen Bedingungen konkurrieren die beiden geforderten automatisierten Reaktionen bezüglich der Reizattribute nicht miteinander. Die beiden in der Abbildung als „Bedingung neutral“ sowie "Bedingung inkongruenz" gekennzeichneten Durchgänge, sind die in der Auswertung verwendeten. Die beiden nicht weiter benannten Bedingungen dienten der Kontrolle.
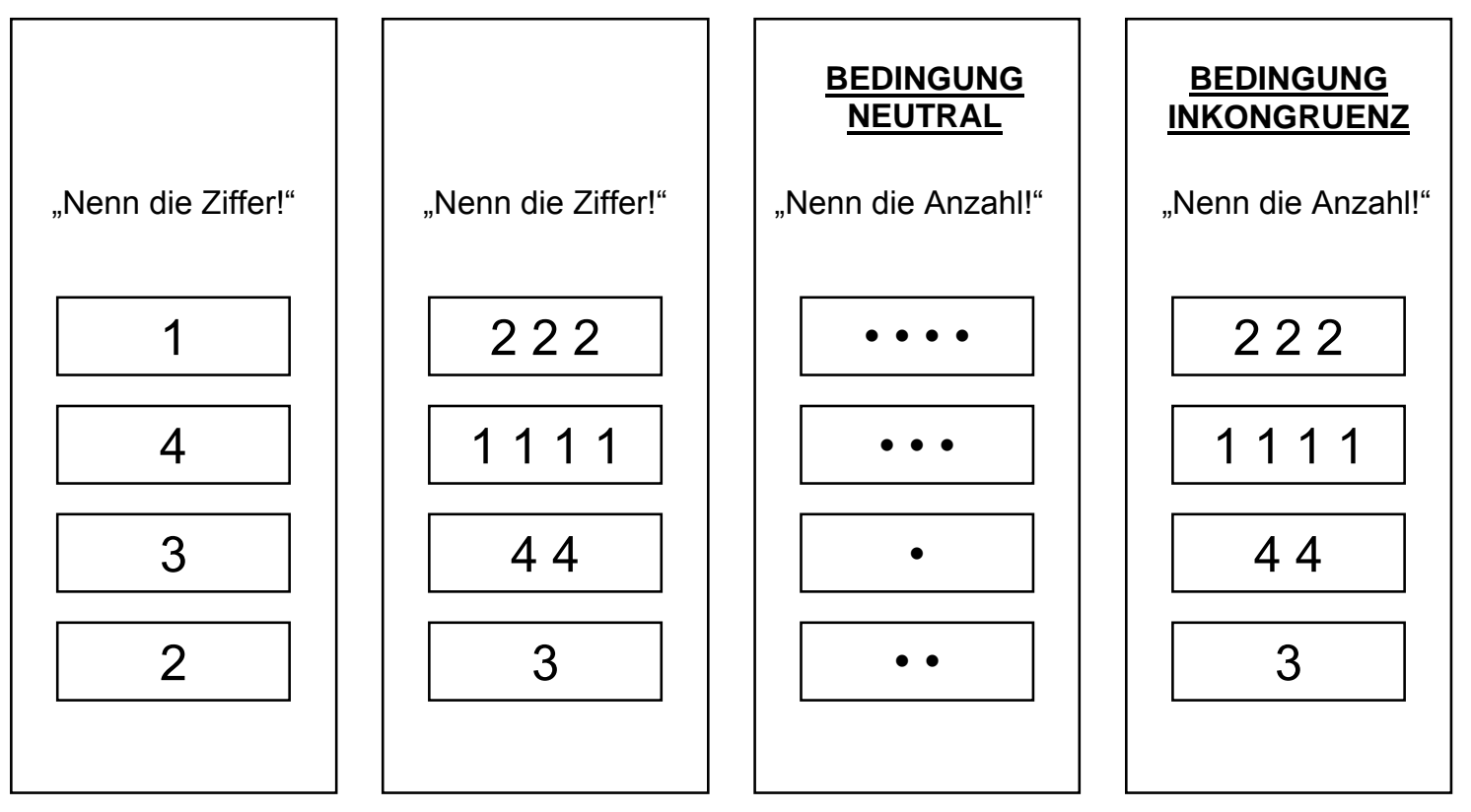

Abbildung 11: Zahlen-Stroop

Die Darbietungsreihenfolge der vier Untertest erfolgte blockrandomisiert. Die Auswertung wurde entsprechend des Computer-Farb-Stroops vorgenommen. 


\subsection{Empirische Vorhersagen}

Bezugnehmend auf die unter 2.6 formulierten inhaltlichen Hypothesen, lassen sich entsprechend den vorliegenden Untersuchungsmethoden die folgenden empirischen Vorhersagen treffen.

Die Analyse der Daten erfolgt dabei über zweifaktorielle Varianzanalysen mit den Faktoren ADHS (ja/nein) und CTS (ja/nein).

Zur Erhebung des Einflusses beider Faktoren auf die Farbdiskriminationsfähigkeit, erhoben mit dem Farnsworth-Munsell 100-hue-Test, wurden die abhängigen Variablen "Gesamtfehlerwert", „Fehlerwert Blau/Gelb-Achse“ sowie „Fehlerwert Rot/Grün-Achse“ sowie „Differenz der Farbachsen“ eingeführt. Zur Aufklärung signifikanter Interaktions- sowie Gruppen-Effekte wurden ergänzend post-hoc Tests (Konfidenzintervallanalysen) durchgeführt (Signifikanzniveau $p=.05$ ). Beim Vergleich der Farbdiskriminationsleistung zwischen den einzelnen Gruppen kann von signifikanten Gruppenunterschieden gesprochen werden, wenn der Mittelwert der einen Gruppe nicht eingeschlossen wird vom Konfidenzintervall der entsprechend zu vergleichenden Gruppe.

1. Hypothesen zur Farbdiskriminationsleistung gemessen mit dem Farnsworth-Munsell 100-Hue-Test

1.1 Es wird erwartet, dass Kinder mit CTS schlechtere Leistungen in der Farbdiskrimination im Farnsworth-Munsell 100-hue-Test zeigen als Kinder ohne CTS. Diese zeigt sich dahingehend, dass der Faktor CTS (CTS allein und CTS+ADHS) mit einem höheren Gesamtfehlerwert im FarnsworthMunsell 100-hue-Test sowie einem höheren Fehlerwert auf der Blau/GelbAchse einher geht. Für die Differenzen der Fehlerwerte der Blau/GelbAchse und Rot/Grün-Achse werden signifikante Unterschiede hinsichtlich einer stärken Beeinträchtigung auf der Blau/Gelb-Achse erwartet.

1.2 Es wird erwartet, dass Kinder mit ADHS schlechtere Leistungen in der Farbdiskrimination im Farnsworth-Munsell 100-hue-Test zeigen. Diese zeigt sich darin, dass der Faktor ADHS (ADHS allein und CTS+ADHS) mit einem höheren Gesamtfehlerwert im Farnsworth-Munsell 100-hue-Test sowie einem höheren Fehlerwert auf der Blau/Gelb-Achse einher geht. Für 
die Differenzen der Fehlerwerte der Blau/Gelb-Achse und Rot/Grün-Achse werden signifikante Unterschiede hinsichtlich einer stärken Beeinträchtigung auf der Blau/Gelb-Achse erwartet.

1.3 Es wird in der komorbiden Gruppe ein additiver Effekt hinsichtlich der Farbdiskriminationsfähigkeit erwartet. Kindern mit ADHS und CTS weisen einen höheren Gesamtfehlerwert sowie einen höheren Fehlerwert auf der Blau/Gelb-Achse auf, als Probanden mit isolierter Diganose CTS bzw. ADHS. Die isolierten Störungsgruppen unterscheiden sich nicht in ihrer Farbdiskriminationsfähigkeit.

\section{Hypothesen zum Stroop-Test}

Bei der Analyse des klassischen Farb-Stroops stellen die Bearbeitungszeiten in den Bedingungen „Wort lesen“, „Farbe benennen“ und „Inkongruenz“ sowie der Interferenzwert die abhängigen Variablen dar.

Eine Analyse der beiden computergestützten Stroop-Tests "Computer-FarbStroop" sowie "Zahlen-Stroop" erfolgt anhand von Messwiederholungsvarianzanalysen. Die abhängigen Variablen bilden die „Bedingung“ („Farb-Stroop“ vs. „Zahlen-Stroop“) sowie die „Kongruenz“ („, neutrale Stimuli“ vs. „inkongruente Stimuli“).

Zur Aufklärung signifikanter Interaktionseffekte werden ebenfalls post-hoc Tests (Konfidenzintervallanalysen) durchgeführt (Signifikanzniveau $p=.05$ ). Wird dabei der Wert Null nicht vom Konfidenzintervall eingeschlossen, liegt ein StroopEffekt in der entsprechenden Gruppe vor. Von signifikanten Gruppenunterschieden auf dem 5\%-Niveau kann gesprochen werden, wenn der Mittelwert der einen Gruppe nicht vom Konfidenzintervall der entsprechend zu vergleichenden Gruppe eingeschlossen wird.

Darüber hinaus werden Korrelationen zwischen den Farnsworth-Munsell 100hue-Parametern sowie den Stroop-Parametern „Farbe benennen“, „Inkongruenz" und Interferenzwert beider Farb-Stroop-Tests (klassischer PapierStroop und Computer-Farb-Stroop) bestimmt, um Einflüsse von Farbwahrnehmungsleistungen auf die entsprechenden Variablen des Stroop-Tests zu überprüfen. 


\subsection{Hypothesen zum klassischen Farb-Stroop}

2.1.1 Es wird erwartet, dass der Faktor CTS (CTS allein und ADHS+CTS) zu keinen längeren Bearbeitungszeiten in den Bedingungen „Farbe benennen“ und „Inkongruenz" führt.

2.1.2 Es wird erwartet, dass der Faktor ADHS (ADHS allein und ADHS+CTS) mit längeren Bearbeitungszeiten in den Bedingungen „Farbe benennen“ und "Inkongruenz" im Zusammenhang steht.

2.1.3 Es wird erwartet, dass die Kinder mit komorbider Diagnose keine längeren Bearbeitungszeiten in den Bedingungen „Farbe benennen“ und „Inkongruenz" zeigen als Kinder mit der isolierten Diagnose CTS.

2.1.4 In allen Gruppen wird ein Interferenzeffekt erwartet. Der Faktor ADHS zeigt einen bedeutsam negativen Einfluss auf die Interferenzneigung im klassischen Papier-Stroop (der Interferenzeffekt ist bei Patienten mit ADHS größer als bei anderen). Der Faktor CTS zeigt keinen bedeutsamen Einfluss auf die Interferenzneigung.

2.1.5 Es besteht ein positiver Zusammenhang zwischen den Leistungen im Farnsworth-Munsell 100-hue-Test und den Leistungen im klassischen Papier-Stroop. Ein geringerer Fehlerwert im Farbwahrnehmungstest geht demnach mit schnelleren Bearbeitungszeiten in der Bedingung „Farbe benennen" und "Inkongruenz" einher.

\subsection{Hypothesen zum Computer-Stroop}

2.2.1 Es wird erwartet, dass Kinder mit CTS (CTS allein und ADHS+CTS) keine langsameren Reaktionszeiten im Computer-Farb-Stroop in den Bedingungen „Farbe benennen“ und „Inkongruenz" zeigen. Ebenso wird angenommen, dass die Anzahl korrekt bearbeiteter Items bei Kindern mit CTS nicht geringer ist.

2.2.2 Es wird erwartet, dass Kinder mit ADHS langsamerer und variablerer Reaktionszeiten im Computer-Farb-Stroop in den Bedingungen „Farbe benennen“ und "Inkongruenz" zeigen. Ebenso wird die Anzahl korrekt bearbeiteter Items bei Kindern mit ADHS geringer sein. 
2.2.3 Es wird erwartet, dass Kinder mit ADHS eine höhere Interferenzneigung zeigen als Kinder ohne ADHS. Ebenso wird erwartet, dass Kinder mit CTS keine höhere Interferenzneigung aufweisen. Die Interferenzneigung in der komorbiden Gruppe unterscheidet sich nicht von der bei Probanden mit ADHS allein.

2.2.4 Es wird erwartet, dass Kinder mit CTS und Kinder mit ADHS größere Schwierigkeiten in der Bearbeitung des Computer-Farb-Stroops aufweisen als beim Computer-Zahlen-Stroop. Demnach zeigen sie im ZahlenStroop eine höhere Anzahl korrekt bearbeiteter Items, weniger variable Reaktionszeiten und in allen Bedingungen schnellere Reaktionszeiten als im Computer-Farb-Stroop.

2.2.5 Im Computer-Zahlen-Stroop zeigen sich Unterschiede zwischen den Gruppen nur hinsichtlich der Interferenzneigung. Kinder mit ADHS zeigen eine höhere Interferenzneigung als Kinder ohne ADHS.

2.2.6 Es wird erwartet, dass ein positiver Zusammenhang zwischen den Leistungen im Farnsworth-Munsell 100-hue-Test und den Reaktionszeiten im Computer-Farb-Stroop besteht. Ein geringerer Fehlerwert geht demnach mit einer schnelleren Reaktionszeit in den Bedingungen „Farbe benennen" und "Inkongruenz" einher. 


\section{Die Stichprobe}

\subsection{Zusammensetzung der Stichprobe}

Von den 73 in der Studie untersuchten Kinder erfüllten 69 die Einschlusskriterien und wurden in die Studie einbezogen wurden. Neun Probanden waren weiblich, 60 männlich. Ophthalmologische Erkrankung oder angeborene Farbsinnstörung führten bei einem Probanden zum Ausschluss aus der Studie.

54 Probanden wurden über die Kinder- und Jugendpsychiatrie der Universität Göttingen, 15 über ortsansässige Grundschulen und Orientierungsstufen rekrutiert. 20 der einbezogenen Kinder erfüllten die ICD-10-Diagnosekriterien für eine CTS (: $N=2$ ). Weitere 20 Kinder erfüllten zeitgleich die Kriterien einer ADHS sowie einer komorbiden CTS (ADHS+CTS) ( $(9: N=4)$ ) 29 Probanden wurden im Rahmen der Studie „Beeinträchtigungen der Farbdiskrimination bei Kindern mit Aufmerksamkeits-Defizit/Hyperaktivitäts-Störung“ (Dissertation Ruppert, 2005) rekrutiert und in die Datenauswertung eingeschlossen. Von diesen erfültten 14 die diagnostischen Kriterien einer ADHS ( $(\mathrm{P}: \mathrm{N}=1$ ) und 15 stellten die nach Alter und Geschlecht gematchte Kontrollgruppe dar ( $(+\mathrm{N}=2$ ) (siehe Abbildung 12).

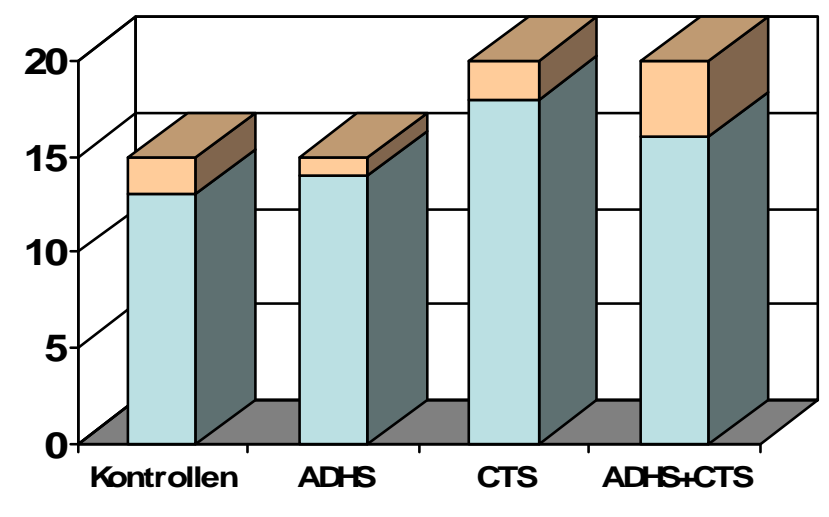

$\square$ männlich $\square$ weiblich

Abbildung 12: Stichprobenzusammensetzung 
Zum Studieneinschluss der Kontrollprobanden wurde auf der Skala „Aufmerksamkeitsprobleme" der CBCL ein T-Wert von $<55$ gefordert. Auf den Skalen "delinquentes Verhalten“ sowie „aggressives Verhalten“ war ein T-Wert von $<60$ erforderlich. Dieses Kriterium erfüllten alle rekrutierten Kontrollprobanden.

In Abhängigkeit vom Messniveau der Variablen wurden geeignete deskriptive Statistiken (Mittelwerte und Standardabweichungen) sowie Chi-Quadrat-Tests zur Überprüfung der Verteilungseigenschaften bestimmt bzw. durchgeführt. Die vier Patientengruppen (ADHS, CTS, Kontrolle sowie ADHS+CTS) wurden einem Gruppenmatch nach Alter $\left(F_{(1,65)}<1.4 ; p>.71\right)$ und Geschlecht $\left(\chi_{(3)}^{2}=1.45\right.$, $\mathrm{p}=.69$; zweiseitige Testung) unterzogen. Der Intelligenzquotient der Probanden mit ADHS (ADHS allein, ADHS+CTS) war niedriger als der von Probanden ohne ADHS (CTS allein, KON) $\left(F_{(1,65)}=7.8, p=.01\right)$. Die Leistungen im Wortflüssigkeitstest unterschieden sich nicht (alle $F_{(1,64)}<1.9, p>17$ ) (siehe Tabelle 1).

Acht Probanden (KON: $N=2, A D H S: N=3, C T S: N=2, C T S+A D H S: N=1$ ) erfüllten die Kriterien einer Lese-Rechtschreibschwäche, wobei ein Drop-Out in der Gruppe CTS+ADHS aufgrund starker Tics beim Rechtschreibtest zu keiner Beurteilung der Rechtschreibleistung führte. Ein bedeutsamer Unterschied zwischen den einzelnen Gruppen im Bezug auf das Vorliegen einer LeseRechtschreibschwäche $\left(\chi^{2}{ }_{(3)}=2.13, p=.55\right.$; zweiseitige Testung) zeigte sich dabei nicht. Auch allgemein, unabhängig vom Vorliegen einer LeseRechtschreibschwäche, zeigten sich keine signifikanten Unterschiede in der Rechtschreibleistung (alle $\mathrm{F}_{(1,64)}<2.1, \mathrm{p}>.16$ ). 
Tabelle 1: 2 x 2 ANOVA für die Faktoren CTS und ADHS, deskriptive Statistiken

\begin{tabular}{|c|c|c|c|c|c|c|c|c|c|c|c|c|}
\hline & \multicolumn{2}{|c|}{$\frac{\text { KON }}{(n=15)}$} & \multicolumn{2}{|c|}{$\frac{\text { ADHS }}{(n=14)}$} & \multicolumn{2}{|c|}{$\frac{\text { CTS }}{(n=20)}$} & \multicolumn{2}{|c|}{$\frac{\underline{\text { ADHS }+ \text { CTS }}}{(n=20)}$} & \multicolumn{4}{|c|}{$\mathbf{F}_{(1,65) ; \text { partial } \eta^{2}} \frac{\text { ANOVA }}{2}$} \\
\hline & M & $\mathrm{SD}$ & M & SD & M & $\mathrm{SD}$ & M & SD & ADHD & & CTS & $\begin{array}{l}\text { ADHD } x \\
\text { CTS }\end{array}$ \\
\hline Gesamt- IQ & 113.2 & $(13.6)$ & 103.1 & (7.9) & 107.5 & $(10.7)$ & 103.4 & $(9.0)$ & $7.8^{*}$. & .11 & 1.1 .02 & 1.4 .02 \\
\hline Alter (in Monaten) & 10.8 & $(.8)$ & 10.6 & (.9) & 10.6 & (1.3) & 10.6 & $(1.2)$ & .05. & .00 & .13 .00 & .14 .00 \\
\hline $\begin{array}{l}\text { Rechtschreibtest } \\
\text { (T-Wert) }\end{array}$ & 50.6 & $(12.3)$ & 46.1 & $(9.2)$ & 48.7 & (7.5) & 46.7 & (7.8) & 2.0 . & .03 & .09.00 & .32 .01 \\
\hline Wortflüssigkeit & 25.7 & $(7.2)$ & 27.2 & (11.4) & 22.8 & (5.5) & 24.5 & $(9.7)$ & .58 & .01 & 1.9 .03 & .00 .00 \\
\hline \multicolumn{13}{|l|}{ FAIR } \\
\hline $\begin{array}{l}\text { Markierungswert } \\
\text { (M) }\end{array}$ & .97 & $(.04)$ & .96 & $(.04)$ & .97 & $(.03)$ & .98 & $(.01)$ & .06. & .00 & 1.5 .02 & $1.5 \quad .02$ \\
\hline Leistungswert (L) & 262.1 & $(82.6)$ & 218.8 & $(80.0)$ & 239.3 & $(56.0)$ & 218.3 & $(68.3)$ & 3.5 . & .05 & . $45 \quad .01$ & .42 .01 \\
\hline Qualitätswert (Q) & .91 & $(.06)$ & .86 & $(.08)$ & .90 & $(.08)$ & .86 & $(.07)$ & $4.8^{*}$. & .07 & .02.00 & .00 \\
\hline $\begin{array}{l}\text { Kontinuitätswert } \\
\text { (K) }\end{array}$ & 239.2 & $(82.8)$ & 190.8 & $(80.9)$ & 215.9 & $(58.3)$ & 189.6 & $(63.3)$ & $4.7^{*}$. & .07 & $\begin{array}{ll}.51 & .01\end{array}$ & .41 .01 \\
\hline Falscher Alarm & 2.8 & (3.0) & 6.4 & $(6.0)$ & 4.2 & (6.4) & 6.2 & (5.7) & $4.2 *$. & .06 & .20 .00 & .36 .01 \\
\hline Verpassfehler & 6.6 & $(6.2)$ & 6.1 & (5.4) & 6.2 & (6.7) & 8.6 & (6.4) & .43. & .01 & . 43.01 & $.91 \quad .01$ \\
\hline Linienfehler & 7.3 & (8.7) & 8.9 & (9.9) & 7.3 & $(7.5)$ & 5.0 & $(3.5)$ & .03. & .00 & 1.2 .02 & 1.1 .02 \\
\hline Gesamt & 288.2 & $(84.9)$ & 252.7 & $(80.9)$ & 267.2 & (58.1) & 252.6 & $(76.2)$ & 1.9 & .03 & $\begin{array}{ll}.34 & .01\end{array}$ & . 33.01 \\
\hline
\end{tabular}

Beachte: $\mathrm{M}=$ Mittelwert, $\mathrm{SD}=$ Standardabweichung. Die Effektgrößen der 2x2 ANOVA werden als Eta-Quadrat angegeben. Cohen (1977) schlägt dabei folgende Richtlinien zur Interpretation des Eta-Quadrats $\left(\eta^{2}\right)$ vor Wert: $.01-.059=$ kleine Effektgröße; $.06-.139=$ mittlerer Effektgröße; $>.14=$ große Effektgröße. *** $\mathrm{p}<0.001 ;{ }^{* *} \mathrm{p}<0.01 ;{ }^{*} \mathrm{p}<0.05 ;$ Trend: ${ }^{+} \mathrm{p}<0.1$

Die Aufmerksamkeitsleistung der Probanden, erhoben mit dem FAIR, zeigte einen Haupteffekt für den Faktor ADHS bei Betrachtung des Qualitätswerts (Q) $\left(F_{(1,65)}=4.8, p=.03\right)$, des Kontinuitätswerts $(K)\left(F_{(1,65)}=4.7, p=.03\right)$ sowie der Falschen-Alarm-Fehler $\left(F_{(1,65)}=4.2, p=.05\right)$. Probanden mit ADHS machten mehr Falsche-Alarm-Fehler (Markierung eines neutralen Zeichens als Zielitem), arbeiteten weniger konstant sowie qualitativ schlechter als Probanden ohne ADHS (siehe Tabelle 1).

Patienten, die mit Methylphenidat behandelt wurden, waren zum Untersuchungszeitpunkt seit mindestens 48 Stunden unmediziert. Eine etwaige bestehende Ticmedikation wurde fortgesetzt (CTS: $n=2$, CTS+ADHS: $n=8$ ). Von zehn Probanden, die aufgrund der Ticsymptomatik medikamentös behandelt wurden, nahmen neun Probanden D2-Blocker ( $C T S+A D H S: N=7, C T S: N=2$ ), ein Proband einen selektiven Serotonin-Wideraufnahmehemmer (CTS+ADHS: $N=1$ ) und vier Probanden Atomoxetin (CTS+ADHS: $N=4$ ) (Mehrfachnennungen waren möglich). 
Es zeigte sich ein bedeutsamer Gruppenunterschied bezüglich des Vorliegens einer medikamentösen Behandlung aufgrund der Ticsymptomatik $\left(\chi_{(1)}^{2}=4.8\right.$, $\mathrm{p}=.03$; zweiseitige Testung), wobei Probanden mit einer komorbiden Diagnose signifikant häufiger eine medikamentöse Behandlung erhielten als Probanden mit einer isolierten CTS.

\subsection{Psychopathologisches Profil}

Zur Beurteilung des psychosozialen Funktionsniveaus der Probanden wurden die Fremdbeurteilungsbögen $\mathrm{CBCL}$ und SDQ herangezogen. Die Betrachtung der Skalenwerte der CBCL, beruhend auf 68 Elternangaben (ein Drop-Out in der Gruppe ADHS+CTS), erbrachte einen Haupteffekt ADHS auf den Skalen „sozialer Rückzug“ $\left(F_{(1,64)}=6.7, p=.01\right)$, „Angst/Depressivität“ $\left(F_{(1,64)}=11.5\right.$, $p=.001)$, „soziale Probleme“ $\left(F_{(1,64)}=21.4, p<.001\right)$, „Aufmerksamkeitsstörung“ $\left(F_{(1,64)}=42.4, p<.001\right)$, „delinquentes Verhalten“ $\left(F_{(1,64)}=26.2, p<.001\right)$ und „aggressives Verhalten" $\left(F_{(1,64)}=39.0, p<.001\right)$. Darüber hinaus zeigte sich ein Trend in Richtung eines Haupteffektes auf den Skalen „körperliche Beschwerden" $\left(F_{(1,64)}=2.9, p=.09\right)$ und "Schizoid/Zwanghaft" $\left(F_{(1,64)}=3.3, p=.07\right)$. Probanden mit ADHS (allein sowie komorbid mit CTS) zeigten sich demnach hinsichtlich dieser, auf den entsprechenden Skalen erhobenen Beschwerden, signifikant beeinträchtigter als Probanden ohne ADHS (KON, CTS allein).

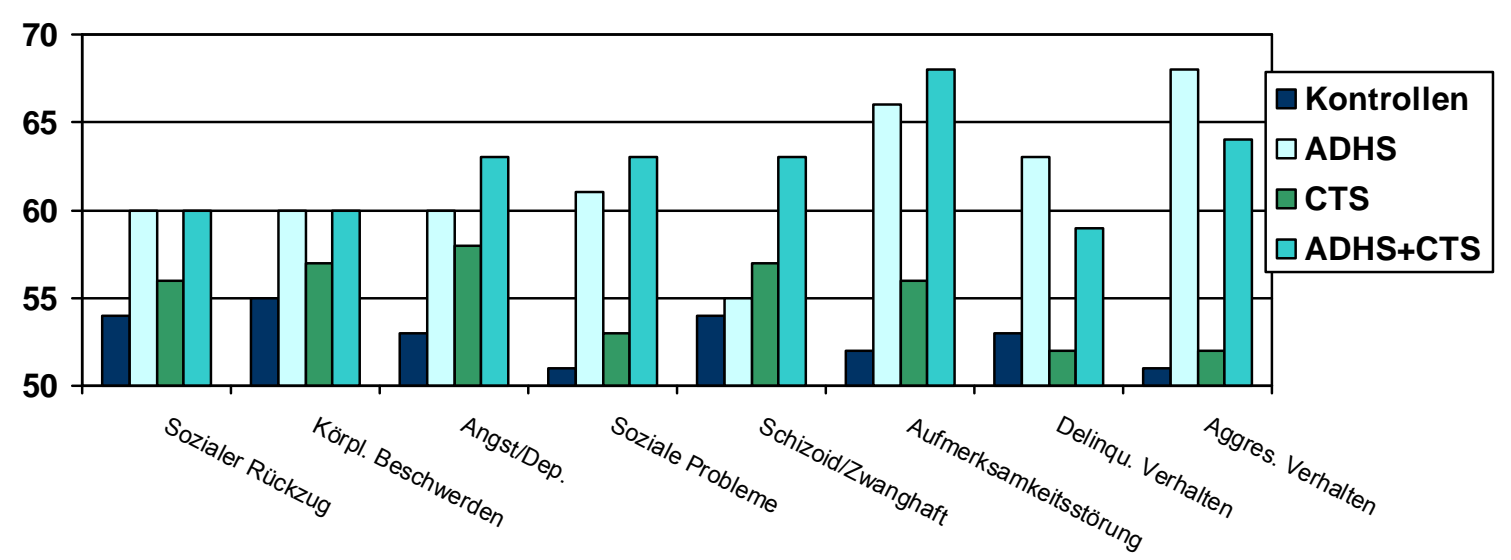

Abbildung 13: Psychopathologisches Profil CBCL (T-Werte) 
Ein Haupteffekt CTS zeigte sich auf den Skalen „Angst/Depressivität“ ( $F_{(1 \text {, }}$ $64)=4.2, p=.05)$ und „Schizoid/Zwanghaft" $\left(F_{(1,64)}=6.7, p=.01\right)$. Auf der Skala „Aufmerksamkeitsstörungen“ zeigte sich ein Trend für einen Haupteffekt CTS $\left(F_{(1,64)}=3.4, p=.07\right)$. Interaktionseffekte zeigten sich für keine der Syndromskalen (alle $\left.\mathrm{F}_{(1,64)}<1.8, \mathrm{p}>.20\right)$ (siehe Tabelle 2).

Tabelle 2: 2 x 2 ANOVA mit den Faktoren CTS und ADHS, Psychopathologie CBCL (T-Werte)

\begin{tabular}{|c|c|c|c|c|c|c|c|c|c|c|c|}
\hline & \multicolumn{2}{|c|}{$\underline{\text { KON }}$} & \multicolumn{2}{|c|}{$\frac{\text { ADHS }}{(n=14)}$} & \multicolumn{2}{|c|}{$\frac{\text { CTS }}{(n=20)}$} & \multicolumn{2}{|c|}{$\frac{\text { ADHS+CTS }}{(n=19)}$} & \multicolumn{3}{|c|}{$\frac{\text { ANOVA }}{\mathbf{F}_{(1,64)} ; \text { partial } \eta^{2}}$} \\
\hline & M & SD & M & SD & M & SD & M & SD & ADHD & CTS & $\begin{array}{c}\text { ADHD } x \\
\text { CTS }\end{array}$ \\
\hline \multicolumn{12}{|c|}{ Child behavior checklist (CBCL) } \\
\hline Sozialer Rückzug & 53.9 & $(7.0)$ & 60.1 & $(6.8)$ & 55.8 & $(9.2)$ & 60.4 & (9.7) & $6.7^{*} \quad .10$ & .28 .00 & .13 .00 \\
\hline Körperliche Beschwerden & 55.3 & $(5.5)$ & 59.7 & (8.4) & 57.4 & $(8.5)$ & 59.7 & (8.9) & $2.9^{+} \quad .04$ & .27 .00 & .29 .00 \\
\hline Angst/Depressivität & 52.5 & $(4.2)$ & 60.1 & (7.3) & 57.5 & (7.9) & 63.4 & $(11.0)$ & $11.5 * * .15$ & $4.2 * .06$ & .19 .00 \\
\hline Soziale Probleme & 50.9 & (2.6) & 61.1 & $(10.0)$ & 52.9 & $(5.2)$ & 63.1 & $(13.5)$ & $21.4 * * * .25$ & .79 .01 & .00 .00 \\
\hline Schizoid/Zwanghaft & 53.5 & (5.7) & 55.0 & $(6.8)$ & 56.5 & (7.6) & 61.9 & $(9.8)$ & $3.3^{+} \quad .05$ & $6.7 * .10$ & 1.1 .02 \\
\hline Aufmerksamkeitsstörung & 51.5 & $(3.1)$ & 65.7 & (8.4) & 56.3 & (7.9) & 68.4 & $(10.8)$ & $42.4 * * * .40$ & $3.4^{+} .05$ & .26 .00 \\
\hline Delinquentes Verhalten & 52.8 & $(4.5)$ & 62.9 & (9.3) & 52.1 & $(4.8)$ & 58.8 & (7.7) & $26.2 * * * .29$ & 2.1 .03 & .98 .02 \\
\hline Aggressives Verhalten & 50.5 & (1.6) & 68.1 & $(16.8)$ & 52.1 & (4.5) & 63.5 & (9.7) & $39.0 * * * .38$ & .40 .01 & 1.7 .03 \\
\hline
\end{tabular}

Beachte: $\mathrm{M}=$ Mittelwert, $\mathrm{SD}=$ Standardabweichung. Die Effektgrößen der 2x2 ANOVA werden als Eta-Quadrat angegeben. Cohen (1977) schlägt dabei folgende Richtlinien zur Interpretation des Eta-Quadrats $\left(\eta^{2}\right)$ vor Wert: $.01-.059=$ kleine Effektgröße; $.06-.139=$ mittlerer Effektgröße; $>.14=$ große Effektgröße. *** $\mathrm{p}<0.001 ;{ }^{* *} \mathrm{p}<0.01 ;{ }^{*} \mathrm{p}<0.05 ;$ Trend: ${ }^{+} \mathrm{p}<0.1$

Die Erhebung des psychosozialen Funktionsniveaus über Elternratings des SDQs zeigte einen Haupteffekt ADHS auf allen Skalen. Patienten mit ADHS wurden von den Beurteilern als signifikant stärker betroffen bezüglich emotionaler Probleme $\left(F_{(1,65)}=7.6, p=.01\right)$, Verhaltensprobleme $\left(F_{(1,65)}=52.7, p=.000\right)$, Hyperaktivität $\left(F_{(1,65)}=86.9, p<.001\right)$, Problemen mit Gleichaltrigen $\left(F_{(1,65)}=21.0\right.$, $\mathrm{p}<.001)$ und im Gesamtproblemwert $\left(\mathrm{F}_{(1,65)}=59.7, \mathrm{p}<.001\right)$ beschrieben. Prosoziales Verhalten zeigten Probanden mit ADHS, nach Angaben der Eltern, in geringerem Maße $\left(F_{(1,65)}=5.0, p=.03\right)$ als Probanden ohne ADHS.

Ein Haupteffekt CTS zeigte sich auf der Skala „emotionale Beeinträchtigung“ $\left(F_{(1,65)}=6.2, p=.02\right)$. Das Vorliegen einer CTS scheint einen signifikant negativen Einfluss auf das emotionale Befinden zu haben.

Interaktionen ergaben sich hinsichtlich der Skalen „Verhaltensprobleme“ ( $F_{(1 \text {, }}$ $65)=9.8, p<.001)$, „Hyperaktivität“ $\left(F_{(1,65)}=15.3, p<.001\right)$ und „Gesamtproblem- 
wert" $\left(F_{(1,65)}=7.4, p=.01\right)$. Ein Interaktionstrend zeigte sich auf der Skala „prosoziales Verhalten“ $\left(F_{(1,65)}=3.7, p=.06\right)$ (siehe Tabelle 3$)$.

Tabelle 3: 2 x 2 ANOVA mit den Faktoren CTS und ADHS, Psychopathologie SDQ-Eltern

\begin{tabular}{|c|c|c|c|c|c|c|c|c|c|c|c|c|c|c|}
\hline & \multicolumn{2}{|c|}{$\frac{\text { KON }}{(n=15)}$} & \multicolumn{2}{|c|}{$\frac{\text { ADHS }}{(n=14)}$} & \multicolumn{2}{|c|}{$\frac{\text { CTS }}{(n=20)}$} & \multicolumn{2}{|c|}{$\frac{\text { ADHS+CTS }}{(n=20)}$} & \multicolumn{6}{|c|}{$\frac{\text { ANOVA }}{\mathbf{F}_{(1,65)} ; \text { partial } \eta^{2}}$} \\
\hline & M & SD & M & SD & M & SD & M & SD & ADHD & & CTs & & ADHD $\times C$ & TS \\
\hline \multicolumn{15}{|c|}{ Strengths and Difficulties Questionnaire (SDQ-Eltern) } \\
\hline Emotionale Probleme & .9 & $(1.3)$ & 3.2 & (1.7) & 3.0 & $(2.6)$ & 4.0 & $(3.0)$ & $7.6 * *$ & .11 & $6.2^{*}$ & .09 & 1.3 & .02 \\
\hline Verhaltensprobleme & .7 & (.7) & 4.9 & $(2.1)$ & 1.7 & $(1.5)$ & 3.3 & $(1.9)$ & $52.7 * * *$ & .46 & .7 & .01 & $9.8^{* *}$ & .13 \\
\hline Hyperaktivität & 1.3 & $(1.4)$ & 8.2 & $(2.0)$ & 4.0 & $(2.1)$ & 6.7 & $(2.5)$ & $86.9 * * *$ & .58 & 1.4 & .02 & $15.3 * * *$ & .20 \\
\hline Probl. mit Gleichaltrigen & .7 & (1.1) & 3.3 & (2.6) & 1.3 & $(1.8)$ & 3.6 & (2.7) & $21.0 * * *$ & .25 & 7.1 & .01 & .1 & .00 \\
\hline Prosoziales Verhalten & 8.3 & (1.7) & 6.4 & $(2.1)$ & 7.3 & (1.9) & 7.1 & (1.7) & $5.0^{*}$ & .07 & .1 & .00 & $3.7^{+}$ & .06 \\
\hline Gesamtproblemwert & 3.6 & $(3.0)$ & 19.6 & (6.6) & 9.9 & $(5.7)$ & 17.6 & $(8.0)$ & $59.7 * * *$ & .49 & 1.9 & .03 & $7.4 * *$ & .11 \\
\hline
\end{tabular}

Beachte: $\mathrm{M}=$ Mittelwert, SD = Standardabweichung. Die Effektgrößen der 2x2 ANOVA werden als Eta-Quadrat angegeben. Cohen (1977) schlägt dabei folgende Richtlinien zur Interpretation des Eta-Quadrats $\left(\eta^{2}\right)$ vor Wert: $.01-.059=$ kleine Effektgröße; $.06-.139=$ mittlerer Effektgröße; $>.14=$ große Effektgröße. $* * *_{p}<0.001 ; * * \mathrm{p}<0.01 ; *_{\mathrm{p}}<0.05 ;$ Trend: ${ }^{+} \mathrm{p}<0.1$ 


\section{Ergebnisse}

5.1 Farbdiskriminationsleistung im Farnsworth-Munsell 100-hueTest

Die varianzanalytische Betrachtung des Einflusses der Faktoren ADHS (ja/nein) und CTS (ja/nein) auf die Farbdiskriminationsfähigkeit der abhängigen Variablen "Gesamtfehlerwert", „Fehlerwert Blau/Gelb-Achse“ sowie „Fehlerwert Rot/Grün-Achse" erbrachte einen Haupteffekt ADHS auf der Blau/Gelb-Achse $\left(F_{(1,65)}=20.9, p<.001\right)$, im Gesamtfehlerwert $\left(F_{(1,65)}=22.6, p<.001\right)$ sowie auf der Rot/Grün-Achse $\left(F_{(1,65)}=14.2, p<.001\right)$. Hypothesenkonform zeigte sich des Weiteren ein Haupteffekt CTS auf der Blau/Gelb-Achse $\left(F_{(1,65)}=28.5, p<.001\right)$ und im Gesamtfehlerscore $\left(F_{(1,65)}=36.5, p<.001\right)$. Auch hier zeigte sich darüber hinaus ein signifikanter Haupteffekt CTS auf der Rot/Grün-Achse $\left(F_{(1,65)}=28.7\right.$, p <.001) (siehe Tabelle 4). Die Effekte der Faktoren CTS sowie ADHS auf die Farbdiskriminationsleistung sind gemäß den Konventionen nach Cohen (1977) groß $\left(\eta^{2}: \geq .18\right.$ bzw. $\left.\leq .36\right)$ und klären zwischen $18-36 \%$ der Varianz in der Farbdiskriminationsleistung auf.

Interaktionseffekte zeigten sich weder bezüglich beider Farbachsen (Blau/Gelb: $F_{(1,65)}=.8, p=.36$; Rot/Grün: $\left.F_{(1,65)}=2.1, p=.16\right)$ noch hinsichtlich des Gesamtfehlerwerts $\left(F_{(1,65)}=1.7, p=.20\right)$.

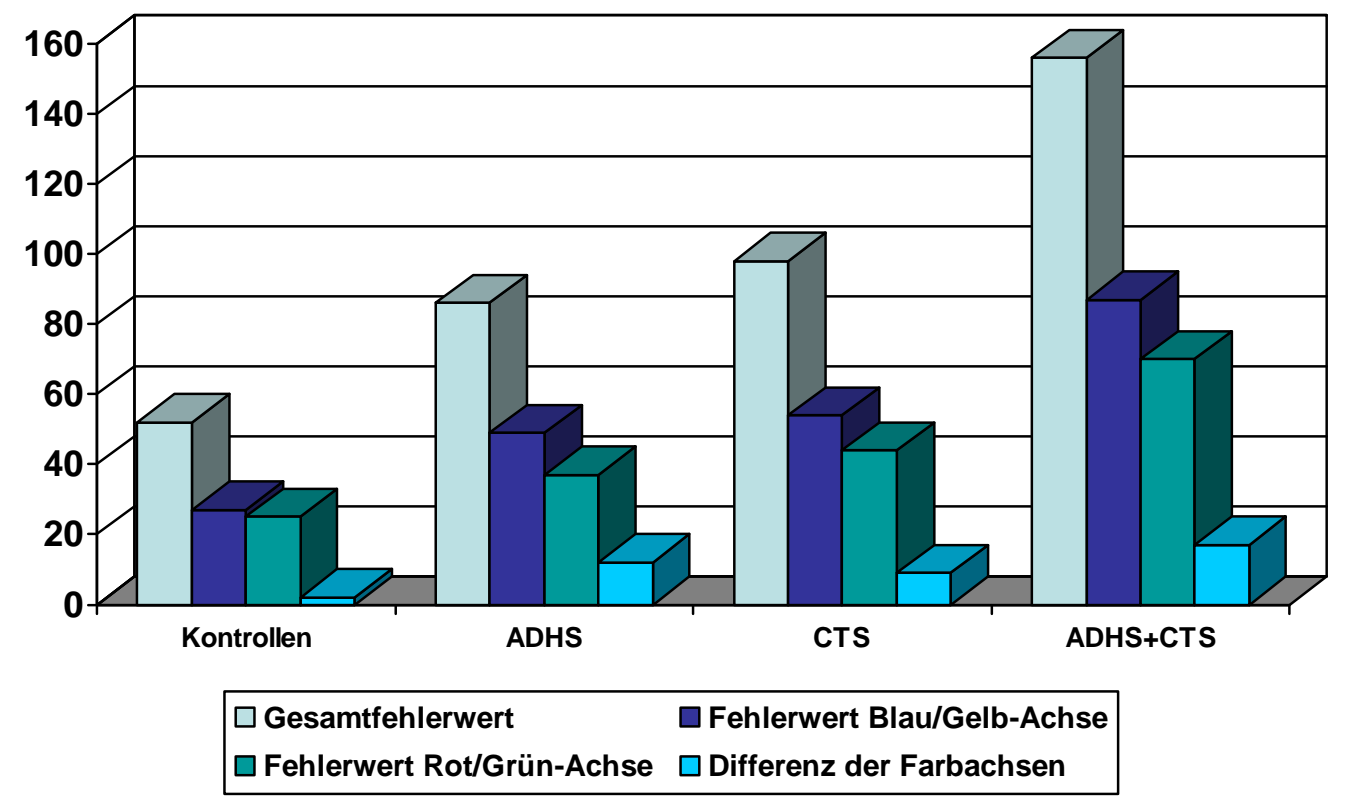

Abbildung 14: Farnsworth-Munsell 100-hue-Test, deskriptive Darstellung der Fehlerwerte 
Zur weiteren Datenanalyse wurden Differenzwerte zwischen den Fehlerwerten der Blau/Gelb-Achse sowie der Rot/Grün-Achse getrennt für alle vier Gruppen bestimmt. Die varianzanalytischen Testung erbrachte einen tendenziellen Haupteffekt für den Faktor ADHS $\left(F_{(1,65)}=3.1, p=.08\right)$. Probanden mit ADHS weisen eine tendenziell größere Fehlerdifferenz zwischen den Farbachsen Blau/Gelb und Rot/Grün auf, als Probanden ohne ADHS. Demnach begehen Probanden mit ADHS hypothesenkonform tendenziell mehr Fehler auf der Blau/Gelb-Achse als auf der Rot/Grün-Achse.

Ein Haupteffekt CTS zeigte sich hinsichtlich der Differenz der Farbachsen nicht $\left(F_{(1,65)}=1.4, p=.25\right)$. Signifikante Unterschiede hinsichtlich der Fehleranzahl auf den einzelnen Farbachsen scheinen für Probanden mit CTS nicht vorzuliegen. Ein Interaktionseffekt blieb ebenfalls aus $\left(F_{(1,65)}=.1, p=.78\right)$ (siehe Tabelle 4).

Eine Betrachtung der Konfidenzintervalle für alle vier Gruppen hinsichtlich der Fehlerdifferenzen der Farbachsen zeigte, dass Probanden der Kontrollgruppe sowie der Gruppe CTS keine signifikanten Differenzen hinsichtlich der Fehler auf beiden Achsen aufwiesen, der Differenzwert unterschied sich demnach nicht bedeutsam von Null. Probanden der Gruppen ADHS sowie ADHS+CTS zeigten bei Betrachtung des Konfidenzintervalls eine signifikante Verschiedenheit des Differenzwertes von Null und somit bedeutsame Differenzen in den Fehlerwerten mit einem höheren Fehlerwert auf der Blau/Gelb-Achse (siehe Tabelle 5).

Tabelle 4: Farbdiskriminationsleistung im Farnsworth-Munsell 100-Hue-Test

\begin{tabular}{|c|c|c|c|c|c|c|c|c|c|c|c|c|c|c|}
\hline & \multicolumn{2}{|c|}{$\frac{\mathrm{KON}}{(n=15)}$} & \multicolumn{2}{|c|}{$\frac{\text { ADHS }}{(n=14)}$} & \multicolumn{2}{|c|}{$\frac{\text { CTS }}{(n=20)}$} & \multicolumn{2}{|c|}{$\frac{\text { ADHS+CTS }}{(n=20)}$} & \multicolumn{6}{|c|}{$\frac{\text { ANOVA }}{\mathbf{F}_{(1,65)} ; \text { partial } \eta^{2}}$} \\
\hline & M & $\mathrm{SD}$ & M & SD & M & SD & M & SD & ADHD & & CTS & & $\begin{array}{r}\text { ADH } \\
\text { CT }\end{array}$ & 5 \\
\hline \multicolumn{15}{|c|}{ Farnsworth-Munsell 100-hue-Test } \\
\hline $\begin{array}{l}\text { Fehlerwert } \\
\text { Blau/Gelb-Achse }\end{array}$ & 27.1 & $(17.5)$ & 49.0 & $(21.8)$ & 53.6 & $(25.0)$ & 86.5 & (29.8) & $20.9 * * *$ & .24 & $28.5^{* * *}$ & .31 & .8 & .01 \\
\hline $\begin{array}{l}\text { Fehlerwert } \\
\text { Rot/Grün-Achse }\end{array}$ & 25.3 & $(11.8)$ & 36.6 & $(15.1)$ & 44.4 & $(19.3)$ & 69.6 & $(26.8)$ & $14.2 * * *$ & .18 & $28.7 * * *$ & .31 & 2.1 & .03 \\
\hline
\end{tabular}

Beachte: $\mathrm{M}=$ Mittelwert, $\mathrm{SD}=$ Standardabweichung. Die Effektgrößen der 2x2 ANOVA werden als Eta-Quadrat angegeben. Cohen (1977) schlägt dabei folgende Richtlinien zur Interpretation des Eta-Quadrats $\left(\eta^{2}\right)$ vor Wert: .01 - .059= kleine Effektgröße; .06 - .139= mittlerer Effektgröße; $>.14=$ große Effektgröße. $* * * \mathrm{p}<0.001 ; * * \mathrm{p}<0.01 ;{ }^{*} \mathrm{p}<0.05 ;$ Trend: ${ }^{+} \mathrm{p}<0.1$ 
Um die Farbwahrnehmungsleistung differenzierter prüfen zu können, wurden, hinausgehend über die Betrachtung des Einflusses der Faktor ADHS und CTS, Analysen auf Gruppenebene über die Auswertung der Konfidenzintervalle durchgeführt. Hierbei konnte von signifikanten Gruppenunterschieden gesprochen werden, wenn der Mittelwert der einen Gruppe nicht vom Konfidenzintervall der entsprechend zu vergleichenden Gruppe eingeschlossen wurde. Dabei zeigte sich, dass sich alle drei klinischen Gruppen (ADHS, CTS, ADHS+CTS) bedeutsam auf einem Niveau von $\alpha=0,05$ hinsichtlich des Gesamtfehlerwerts, des Fehlerwerts der Blau/Gelb-Achse, sowie des Fehlerwerts der Rot/GrünAchse von Kontrollprobanden unterscheiden. Im Mittel machten Probanden mit ADHS allein, CTS allein und Probanden mit beiden Diagnosen sowohl insgesamt sowie auf den einzelnen Achsen mehr Fehler als Kontrollprobanden (siehe Tabelle 5).

Die Gruppen ADHS und CTS unterscheiden sich in keinem der drei Fehlerwerte bedeutsam voneinander.

Die komorbide Gruppe unterscheidet sich im Mittel bedeutsam von den Gruppe ADHS sowie CTS betreffend aller Fehlerwerte (Gesamtfehlerwert, Fehler Rot/Grün-Achse, Fehler Blau/Gelb-Achse). Die Fehlerwerte der Gruppe ADHS+CTS zeigten sich dabei in allen drei Kennwerten des Farbdiskriminationstests signifikant höher als bei Probanden mit der Diagnose ADHS-allein bzw. CTS-allein $(p=.05)$ (siehe Tabelle 5).

Signifikante Fehlerwertdifferenzen beider Farbachsen zeigte sich nur für die Gruppe ADHS sowie für die Gruppe ADHS+CTS. Die Kontrollgruppe sowie die Kinder der Gruppe CTS zeigten keine signifikanten Unterschiede in den Fehlerwerten beider Farbachsen (siehe Tabelle 5 und Abbildung 15). 
Tabelle 5: Konfidenzintervallanalyse der Farbdiskriminationsleistung im FMT auf Gruppenebene

\begin{tabular}{|c|c|c|c|c|c|c|c|c|c|c|c|c|c|c|c|c|}
\hline & \multicolumn{4}{|c|}{$\frac{\mathrm{KON}}{(n=15)}$} & \multicolumn{4}{|c|}{$\frac{\text { ADHS }}{(n=14)}$} & \multicolumn{4}{|c|}{$\frac{\text { CTS }}{(n=20)}$} & \multicolumn{4}{|c|}{$\frac{\text { ADHS+CTS }}{(n=20)}$} \\
\hline & $\underline{\mathrm{GF}}$ & $\underline{\mathrm{BG}}$ & $\underline{\mathrm{RG}}$ & $\underline{\mathrm{DF}}$ & $\underline{\mathrm{GF}}$ & $\underline{\mathrm{BG}}$ & $\underline{\mathrm{RG}}$ & $\underline{\mathrm{DF}}$ & $\underline{\mathrm{GF}}$ & $\underline{\mathrm{BG}}$ & $\underline{\mathrm{RG}}$ & $\underline{\mathrm{DF}}$ & $\underline{\mathrm{GF}}$ & $\underline{\mathrm{BG}}$ & $\underline{\mathrm{RG}}$ & $\underline{\mathrm{DF}}$ \\
\hline $\mathbf{M}$ & 52.4 & 27.1 & 25.3 & 1.7 & 85.6 & 49.0 & 36.6 & 12.4 & 97.9 & 53.6 & 44.4 & 9.2 & 156.1 & 86.5 & 69.5 & 17.0 \\
\hline $\begin{array}{l}\text { 95\%-KI; } \\
\text { Untergr. }\end{array}$ & 32.1 & 14.4 & 15.1 & -9.2 & 64.6 & 35.8 & 26.0 & 1.0 & 80.4 & 42.6 & 35.5 & -.2 & 138.5 & 75.5 & 60.7 & 7.5 \\
\hline $\begin{array}{l}95 \%-K I ; \\
\text { Obergr. }\end{array}$ & 72.7 & 39.7 & 35.6 & 12.7 & 106.6 & 62.1 & 47.2 & 23.6 & 115.5 & 64.5 & 53.2 & 18.7 & 173.6 & 97.5 & 78.4 & 26.4 \\
\hline Note: & $\begin{array}{l}\mathrm{GF}= \\
\text { Differ } \\
\text { zinterv }\end{array}$ & $\begin{array}{l}\text { Jesa } \\
\text { Izwe } \\
11, \mathrm{U}\end{array}$ & $\begin{array}{l}\text { fehle } \\
\text { der I } \\
\text { erg. }\end{array}$ & $\begin{array}{l}\text { vert, } \\
\text { ler } \\
\text { Unte }\end{array}$ & der & ber & b-A & $\begin{array}{l}\mathrm{u} / \mathrm{G} \\
\text { se } \mathrm{m} \\
\mathrm{rgre}\end{array}$ & e. & $\begin{array}{l}\mathrm{RC} \\
\text { Grün }\end{array}$ & chs & $4=$ & $\begin{array}{l}\text { Rot/C } \\
\text { ittelwe }\end{array}$ & $\begin{array}{l}\text { rün- } \\
\mathrm{rt}, \mathrm{KI}\end{array}$ & $\begin{array}{l}\text { hse, } \\
\text { Kon }\end{array}$ & $\begin{array}{l}F= \\
\text { den- }\end{array}$ \\
\hline
\end{tabular}

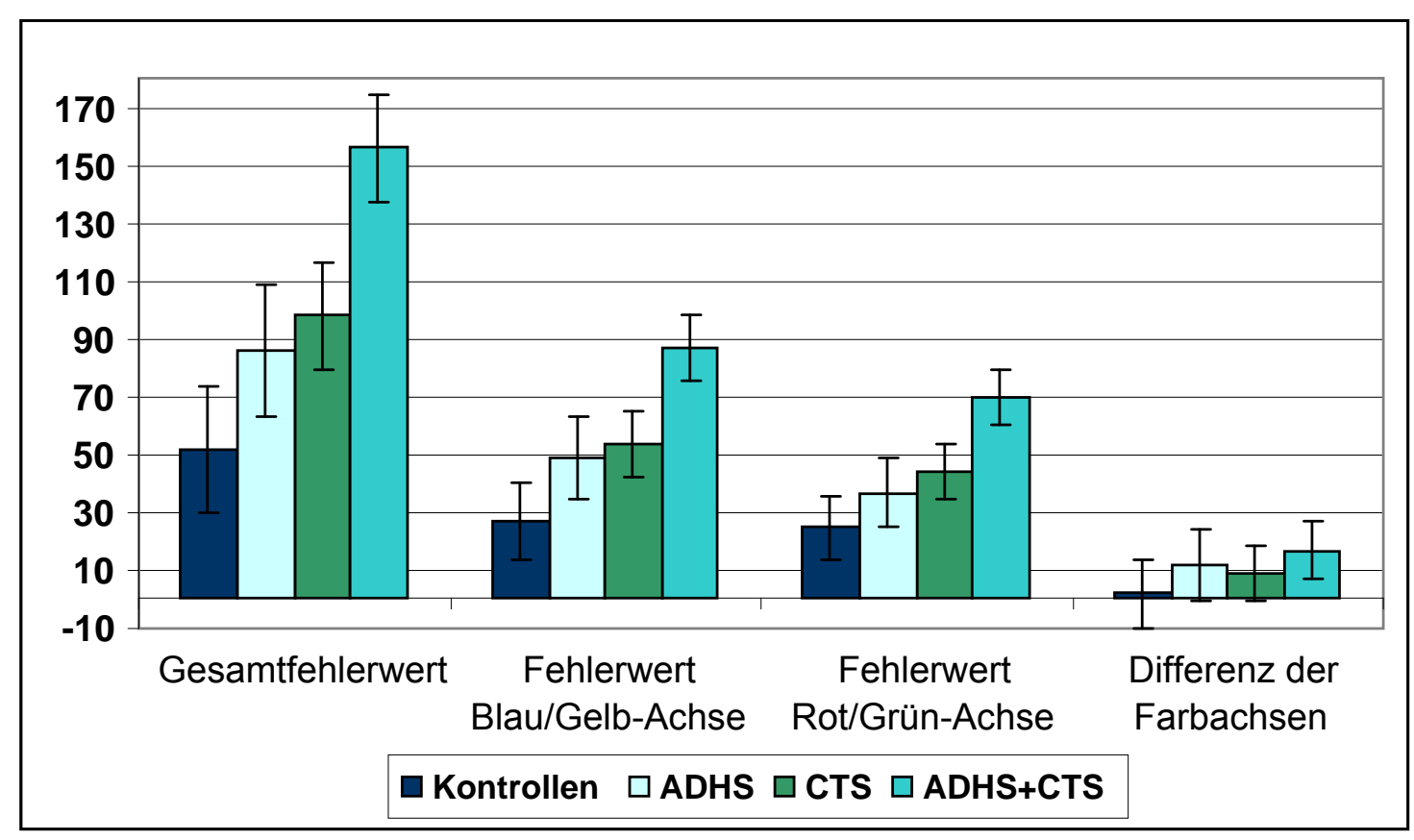

Abbildung 15: Konfidenzintervalle der Fehlerwerte im Farnsworth-Munsell 100-hue-Test 


\subsection{Stroop}

\subsubsection{Klassischer Papier-Stroop}

Im klassischen Papier-Stroop wurden die Bearbeitungszeiten für die drei Bedingungen „Wort lesen“, „Farbe benennen“ und „Inkongruenz" bestimmt. Die Ermittlung der Interferenzneigung (Beeinflussbarkeit durch dominierende aber irrelevante Stimuli) erfolgte über den Interferenzwert nach der von Jensen (1965) beschriebenen Methode (,Bearbeitungszeit in der Bedingung Inkongruenz“ minus „Bearbeitungszeit in der Bedingung Farbe benennen“).

Die varianzanalytische Auswertung erbrachte einen signifikanten Haupteffekt für den Faktor CTS in der Bedingung „Wort lesen“ $\left(F_{(1,65)}=4.6, p=.04\right)$. Probanden mit CTS wiesen eine signifikant schnellere Bearbeitungszeit beim Vorlesen von Farbwörter auf als Probanden ohne CTS. Es existierte, den Hypothesen entsprechend, kein Einfluss des Faktors CTS auf die Benennungsgeschwindigkeit in der Bedingung „Farbe benennen“ und „Inkongruenz" sowie auf den Interferenzwert (alle $F_{(1,65)}<2.3, p>$.13) (siehe Tabelle 6).

Tabelle 6: 2 x 2 ANOVA mit den Faktoren CTS und ADHS, klassischer Papier-Stroop

\begin{tabular}{|c|c|c|c|c|c|c|c|c|c|c|c|c|c|c|}
\hline & \multicolumn{2}{|c|}{$\frac{\text { KON }}{(n=15)}$} & \multicolumn{2}{|c|}{$\frac{\text { ADHS }}{(n=14)}$} & \multicolumn{2}{|c|}{$\frac{\text { CTS }}{(n=20)}$} & \multicolumn{2}{|c|}{$\frac{\text { ADHS+CTS }}{(n=20)}$} & \multicolumn{6}{|c|}{$\frac{\text { ANOVA }}{F_{(1,65) ; \text { partial } \eta^{2}}}$} \\
\hline & M & SD & M & SD & M & SD & M & SD & ADHD & & CTS & & $\begin{array}{l}\text { ADHD } x \\
\text { CTS }\end{array}$ & \\
\hline \multicolumn{15}{|l|}{ Papier-Stroop } \\
\hline $\begin{array}{l}\text { Wort lesen (Sec/72 } \\
\text { Items) }\end{array}$ & 43.4 & $(10.1)$ & 54.5 & $(25.8)$ & 40.4 & $(9.2)$ & 42.5 & $(10.1)$ & $3.5^{+}$ & .05 & $4.6^{*}$ & .07 & 1.6 & .02 \\
\hline $\begin{array}{l}\text { Farbe benennen } \\
\text { (Sec/72 Items) }\end{array}$ & 65.5 & $(12.6)$ & 79.5 & $(26.2)$ & 64.8 & (12.3) & 67.7 & $(19.4)$ & $3.6^{+}$ & .05 & 2.0 & .03 & 1.6 & .02 \\
\hline $\begin{array}{l}\text { Inkongruenz } \\
\text { (Sec/72 Items) }\end{array}$ & 119.9 & $(33.3)$ & 166.1 & $(50.0)$ & 125.0 & (32.3) & 132.9 & $(37.2)$ & $8.5^{* *}$ & .12 & 2.3 & .03 & $4.3 * .0$ & .06 \\
\hline Interferenzwert $^{\mathrm{a}}$ & 54.3 & (24.1) & 86.6 & $(47.0)$ & 60.2 & (21.7) & 65.2 & (27.4) & $6.3^{*}$ & .09 & 1.1 & .02 & $3.4^{+}$ & .05 \\
\hline
\end{tabular}

Beachte: $\mathrm{M}=$ Mittelwert, SD = Standardabweichung. Die Effektgrößen der 2x2 ANOVA werden als Eta-Quadrat angegeben. Cohen (1977) schlägt dabei folgende Richtlinien zur Interpretation des Eta-Quadrats $\left(\eta^{2}\right)$ vor Wert: $.01-.059=$ kleine Effektgröße; $.06-.139=$ mittlerer Effektgröße; $>.14=$ große Effektgröße. $* * * \mathrm{p}<0.001 ;{ }^{* *} \mathrm{p}<0.01 ;{ }^{*} \mathrm{p}<0.05 ;$ Trend: ${ }^{+} \mathrm{p}<0.1$

a der Interferenzwert wurde wie folgt bestimmt: (Inkongruenz) - (Farbe benennen)

Ein Haupteffekt ADHS resultierte hypothesenkonform in der Bedingung „Inkongruenz" $\left(F_{(1,65)}=8.5, p=.01\right)$ sowie im Interferenzwert $\left(F_{(1,65)}=6.3, p=.02\right)$. Probanden mit ADHS waren bei der Benennung der inkongruenten Druckfarbe ei- 
nes Farbwortes signifikant langsamer als Probanden ohne ADHS. Dabei klärt der Faktor ADHS 12 \% der Varianz in der Bedingung „Inkongruenz“ auf. Dieser Effekt wird durch einen Interaktionseffekt der beiden Faktoren moduliert $\left(F_{(1}\right.$, $65)=4.3, p=.04$ ) (siehe Tabelle 6). Post-hoc-Tests zur Aufklärung der Interaktion in der Bedingung „Inkongruenz“ ergaben eine auf einem Signifikanzniveau von $p<.05$ signifikant längere Bearbeitungszeit bei Probanden der Gruppe ADHS als bei Probanden der drei anderen Gruppen. Unter den Probanden der Gruppen Kontrolle, CTS und ADHS+CTS ließen sich keine signifikanten Unterschiede in den Bearbeitungszeiten feststellen (siehe Tabelle 7 und Abbildung 16).

Tabelle 7: Aufklärung der Interaktion CTS*ADHS im klassischen Papier-Stroop, Bedingung Inkongruenz; Konfidenzintervallanalyse

\begin{tabular}{|c|c|c|c|c|}
\hline & $\frac{\text { KON }}{(n=15)}$ & $\frac{\underline{A D H S}}{(n=14)}$ & $\frac{\text { CTS }}{(n=20)}$ & $\frac{\underline{A D H S}+\mathrm{CTS}}{(n=20)}$ \\
\hline & $\begin{array}{c}\text { Stroop Inkon- } \\
\begin{array}{c}\text { gruenz- } \\
\text { Bedingung }\end{array}\end{array}$ & $\begin{array}{c}\text { Stroop Inkon- } \\
\begin{array}{c}\text { gruenz- } \\
\text { Bedingung }\end{array}\end{array}$ & $\frac{\text { Stroop Inkon- }}{\begin{array}{c}\text { gruenz- } \\
\text { Bedingung }\end{array}}$ & $\frac{\text { Stroop Inkon- }}{\begin{array}{c}\text { gruenz- } \\
\text { Bedingung }\end{array}}$ \\
\hline $\mathbf{M}$ & 119.9 & 166.1 & 125.0 & 132.9 \\
\hline 95\%-KI; Untergrenze & 100.2 & 145.8 & 108.0 & 115.9 \\
\hline 95\%-KI; Obergrenze & 139.5 & 186.4 & 142.0 & 149.8 \\
\hline
\end{tabular}

Beachte: $\mathrm{M}=$ Mittelwert, $\mathrm{KI}=$ Konfidenzintervall

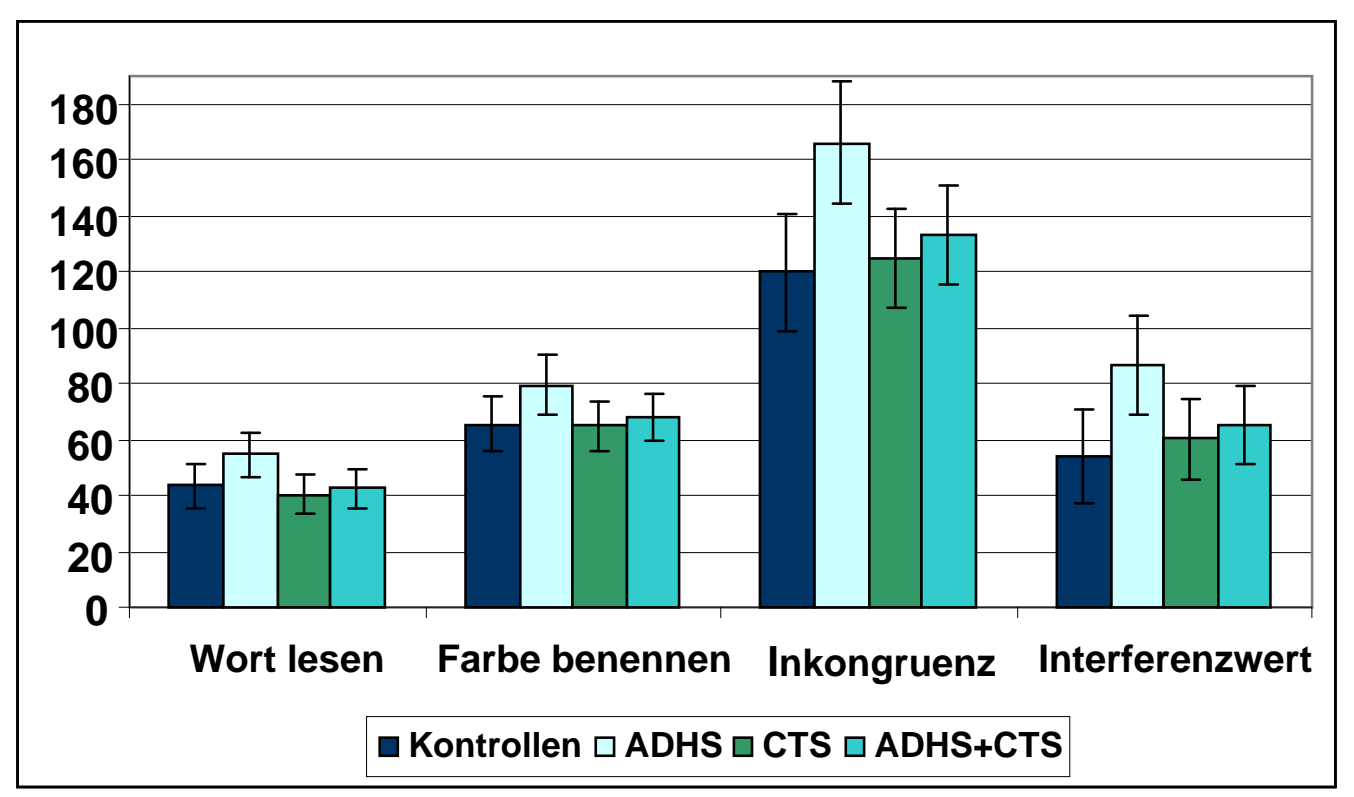

Abbildung 16: Konfidenzintervallanalyse klassischer Papier-Stroop 
Darüber hinaus zeigten Probanden mit ADHS eine höhere Beeinflussbarkeit durch dominierende, aber irrelevante Stimuli (Interferenzwert). Dabei zeigte sich ein Trend hinsichtlich einer Beeinflussung dieses Ergebnisses durch eine Interaktion der Faktoren CTS und ADHS $\left(F_{(1,65)}=3.4, p=.07\right)$. Post-hoc-Tests erbrachten ein zur Interaktion in der Bedingung „Inkongruenz“ ähnliches Bild: Probanden der Gruppe ADHS wiesen eine signifikant höhere Interferenzneigung auf als Probanden der Gruppe KON, CTS und ADHS+CTS. Die drei letztgenannten Gruppen unterschieden sich dabei nicht voneinander (siehe Tabelle 8 und Abbildung 16). Alle Probanden wiesen demnach eine Interferenzneigung auf, die darin bestand, dass die Bearbeitungszeiten in der Bedingung „Inkongruenz“ generell länger waren als in der Bedingung „Farbe benennen“. Probanden mit der ausschließlichen Diagnose ADHS zeigten jedoch eine signifikant stärkerer Interferenzneigung als Probanden der Gruppe KON, CTS und ADHS+CTS.

Tabelle 8: Aufklärung des Interaktionstrends im Interferenzwert CTS*ADHS im klassischen Papier-Stroop; Konfidenzintervallanalyse

\begin{tabular}{|c|c|c|c|c|}
\hline & $\underline{\text { KON }}$ & $\underline{\text { ADHS }}$ & $\frac{\mathrm{CTS}}{(n=20)}$ & $\frac{\text { ADHS+CTS }}{(n=20)}$ \\
\hline & $\frac{\text { Stroop Interfe- }}{\text { renzwert }}$ & $\frac{\text { Stroop Interfe- }}{\text { renzwert }}$ & $\frac{\text { Stroop Interfe- }}{\text { renzwert }}$ & $\frac{\text { Stroop Interfe- }}{\text { renzwert }}$ \\
\hline $\mathbf{M}$ & 54.3 & 86.6 & 60.2 & 65.2 \\
\hline 95\%-KI; Untergrenze & 38.7 & 70.3 & 46.6 & 51.6 \\
\hline 95\%-KI; Obergrenze & 70.0 & 102.8 & 73.7 & 78.8 \\
\hline
\end{tabular}

Beachte: $\mathrm{M}=$ Mittelwert, $\mathrm{KI}=$ Konfidenzintervall

Des Weiteren zeigte sich ein Trend in Richtung eines Haupteffektes ADHS in den Bedingungen „Wort lesen“ $\left(F_{(1,65)}=3.5, p=.07\right)$ sowie „Farbe benennen“ ( $F_{(1}$ $, 65)=3.6, p=.06)($ siehe Tabelle 6).

Zur weiteren Analyse wurden über Post-hoc-Tests Gruppenvergleiche in den Bedingungen „Wort lesen“ sowie „Farbe benennen“ berechnet. In der Bedingung „Wort lesen“ konnte ein identisches Bild zu dem oben beschriebenen festgestellt werden. Hier unterschieden sich ebenfalls ausschließlich die Patienten der Gruppe ADHS von den drei anderen Gruppen in der Geschwindigkeit, mit der Farbwörter vorgelesen wurden. Die Gruppen CTS, ADHS+CTS sowie KON 
unterschieden sich hinsichtlich ihrer Lesegeschwindigkeit von Farbwörtern nicht bedeutsamen (siehe Tabelle 9 und Abbildung 16).

Tabelle 9: Post-hoc Gruppenvergleich in der Bedingung „Wort lesen“ des klassischen PapierStroops

\begin{tabular}{|c|c|c|c|c|}
\hline & $\frac{\mathrm{KON}}{(n=15)}$ & $\frac{\text { ADHS }}{(n=14)}$ & $\begin{array}{c}\text { CTS } \\
(n=20)\end{array}$ & $\frac{\text { ADHS+CTS }}{(n=20)}$ \\
\hline & $\frac{\text { Stroop }}{\text { Wort lesen }}$ & $\frac{\text { Stroop }}{\text { Wort lesen }}$ & $\frac{\text { Stroop }}{\text { Wort lesen }}$ & $\frac{\text { Stroop }}{\text { Wort lesen }}$ \\
\hline $\mathbf{M}$ & 43.4 & 54.5 & 40.4 & 42.5 \\
\hline 95\%-KI; Obergrenze & 50.9 & 62.2 & 46.8 & 48.9 \\
\hline
\end{tabular}

Beachte: $\mathrm{M}=$ Mittelwert, $\mathrm{KI}=$ Konfidenzintervall

Entsprechendes gilt für die Bedingung „Farbe benennen“. Auch hier zeigten sich ausschließlich die Patienten der Gruppe ADHS bedeutsam langsamer als Patienten der drei anderen Gruppen. Einen signifikanten Unterschied in den Bearbeitungszeiten zwischen Probanden der Gruppen CTS, ADHS+CTS und KON zeigte sich den Hypothesen entsprechend auch in dieser Bedingung nicht (siehe Tabelle 10 und Abbildung 11).

Tabelle 10: Post-hoc Gruppenvergleich in der Bedingung "Farbe benennen" des klassischen Papier-Stroops

\begin{tabular}{|c|c|c|c|c|}
\hline & $\underline{\text { KON }}$ & $\underline{\text { ADHS }}$ & $\frac{\text { CTS }}{(n=20)}$ & $\frac{\text { ADHS+CTS }}{(n=20)}$ \\
\hline & $\stackrel{\text { Stroop }}{\text { Farbe benennen }}$ & $\stackrel{\text { Stroop }}{\text { Farbe benennen }}$ & $\stackrel{\text { Stroop }}{\text { Farbe benennen }}$ & $\underset{\text { Farbe benennen }}{\text { Stroop }}$ \\
\hline $\mathbf{M}$ & 65.5 & 79.5 & 64.8 & 67.7 \\
\hline 95\%-KI; Untergrenze & 56.2 & 69.9 & 56.7 & 59.6 \\
\hline 95\%-KI; Obergrenze & 74.8 & 89.1 & 72.9 & 75.7 \\
\hline
\end{tabular}

Beachte: $\mathrm{M}=$ Mittelwert, $\mathrm{KI}=$ Konfidenzintervall

5.2.2. Zusammenhang zwischen Leistungen im Farnsworth-Munsell 100-hueTest und dem klassischen Papier-Stroop

Zur Ermittlung des Einflusses der Farbwahrnehmungsleistung auf Leistungen im klassischen Papier-Stroop wurden Korrelationen zwischen Parametern des Farnsworth-Munsell 100-hue-Tests (Gesamtfehlerwert, Fehlerwert Blau/Gelb- 
Achse sowie Fehlerwert Rot/Grün-Achse) und Parametern des klassischen Papier-Stroops (Bedingung „Farbe benennen“, Bedingung „Inkongruenz“, Interferenzwert) bestimmt. Zur Vermeidung von Scheinkorrelationen aufgrund von Alterseffekten wurde der Einfluss der Variable Alter herauspartialisiert. Als Signifikanzkriterim wurde $p<.05$ festgelegt.

Erwartungswidrig zeigten sich keine signifikanten Zusammenhänge zwischen den Parameter des klassischen Papier-Stroops und der Farbdiskriminationsleistung im Farnsworth-Munsell 100-hue auf Faktorebene (siehe Tabelle 11).

Tabelle 11: Partial-Korrelation zwischen der Leistung im Farnsworth-Munsell 100-hue-Test und dem klassischen Papier-Stroop, kontrolliert für Alter der Probanden

\begin{tabular}{lccc}
\hline & \multicolumn{3}{c}{ Klassischer Papier-Stroop } \\
\hline & Farbe benennen & Inkongruenz & Interferenzwert \\
\cline { 2 - 4 } & $\mathbf{r}^{\mathrm{a}}$ & $\mathbf{r}^{\mathrm{a}}$ & $\mathbf{r}^{\mathrm{a}}$ \\
\cline { 2 - 4 } Farnsworth-Munsell 100-hue-Test & .11 & .12 & .09 \\
Gesamtfehlerwert & .12 & .13 & .09 \\
Fehlerwert Blau/Gelb-Achse & .08 & .09 & .07 \\
Fehlerwert Rot/Grün-Achse & & & \\
\hline
\end{tabular}

Beachte: $r=$ Korrelationskoeffizient

a alle Korrelationskoeffizienten verfehlten das Signifikanzkriterium von $\mathrm{p}<.05$

\subsubsection{Computer-Stroop}

\subsubsection{Speed-Accuracy Trade-off}

In einem Speed-Test, wie dem klassischen Papier-Stroop, gehen die Variablen "Genauigkeit" und "Schnelligkeit" in der Regel als eine Variable in die Auswertung ein. Der Computer-Stroop-Test erlaubt jedoch eine getrennte Auswertung von Reaktionszeiten sowie der Anzahl richtiger Antworten. Aus Gründen der Interpretierbarkeit der Ergebnisse ist dabei jedoch, um beide Variablen getrennt bewerten zu können, das Vorliegen von Strategieeffekten in der Aufgabenbearbeitung auszuschließen (Speed-Accuracy Trade-off; beschreibt den Zusammenhang zwischen der Reaktionszeit und der Genauigkeit in einem SpeedTest). Bei Bearbeitung des Computer-Stroops wäre, bei Vorlage einer positiven Korrelation zwischen der mittleren Reaktionszeit bei korrekten Antworten und der Anzahl korrekt bearbeiteter Items, anzunehmen, dass die Probanden stra- 
tegisch auf eine schnellere Reaktionszeit zu Lasten der Genauigkeit in der Antwortgabe setzen. Dies würde die Interpretierbarkeit der Effekte erschweren und eine Auswertung beider Variablen unabhängig voneinander verbieten.

Um derartige Strategieeffekte aufzudecken bzw. auszuschließen, wurden über die Gesamtstichprobe sowie alle 4 Tasten hinweg Partialkorrelationen mit der Kovariate „Alter" zwischen der mittleren Reaktionszeit korrekt bearbeiteter Items und der Anzahl korrekt bearbeiteter Items sowohl für neutrale als auch für inkongruente Items im Computer-Farb-Stroop und im Zahlen-Stroop bestimmt. Es zeigten sich keine signifikanten Korrelationen (alle $p>.30$ ).

Im Folgenden wird demnach davon ausgegangen, dass zwischen den Reaktionszeiten sowie der Anzahl korrekt bearbeiteter Items kein Zusammenhang besteht und eine getrennte Auswertung beider Variablen möglich ist.

\subsubsection{Computer-Farb-Stroop und Zahlen-Stroop}

Die Analyse der beiden computergestützten Stroop-Tests "Computer-FarbStroop“ sowie "Zahlen-Stroop“ erfolgte anhand von Messwiederholungsvarianzanalysen. Die abhängigen Variablen bildeten die „Bedingung“ („Farb-Stroop“ vs. „Zahlen-Stroop“) sowie die „Kongruenz“ („,neutrale Stimuli“ vs. „inkongruente Stimuli“).

Zur Aufklärung signifikanter Interaktionseffekte wurden post-hoc Tests (Konfidenzintervallanalysen) durchgeführt (Signifikanzniveau $p=.05$ ). Wurde dabei der Wert Null nicht vom Konfidenzintervall eingeschlossen, lag ein Stroop-Effekt in der entsprechenden Gruppe vor. Von signifikanten Gruppenunterschieden auf dem 5\%-Niveau wird gesprochen, wenn der Mittelwert der einen Gruppe nicht vom Konfidenzintervall der entsprechend zu vergleichenden Gruppe eingeschlossen wurde.

\subsection{Reaktionszeiten korrekt bearbeiteter Items}

Die Auswertung der Reaktionszeiten korrekt bearbeiteter Items (siehe Abbildung 17) anhand einer Messwiederholungsvarianzanalyse über alle Bedingungen ergab einen statistisch bedeutsamen Haupteffekt für den Faktor CTS. Patienten mit CTS reagieren insgesamt signifikant langsamer (Konfidenzintervalla- 
nalysen mit $\alpha=.05)$ als Probanden ohne CTS $\left(F_{(1,65)}=7.2, p<.01\right)$. Der Faktor CTS klärt dabei $10 \%$ der Varianz in den Reaktionszeiten auf. Weder der Haupteffekt ADHS $\left(F_{(1,65)}=2.2, p>.14\right)$ noch der Interaktionseffekt zwischen CTS und ADHS $\left(F_{(1,65)}=0.7, p>.40\right)$ erwiesen sich als bedeutsam.

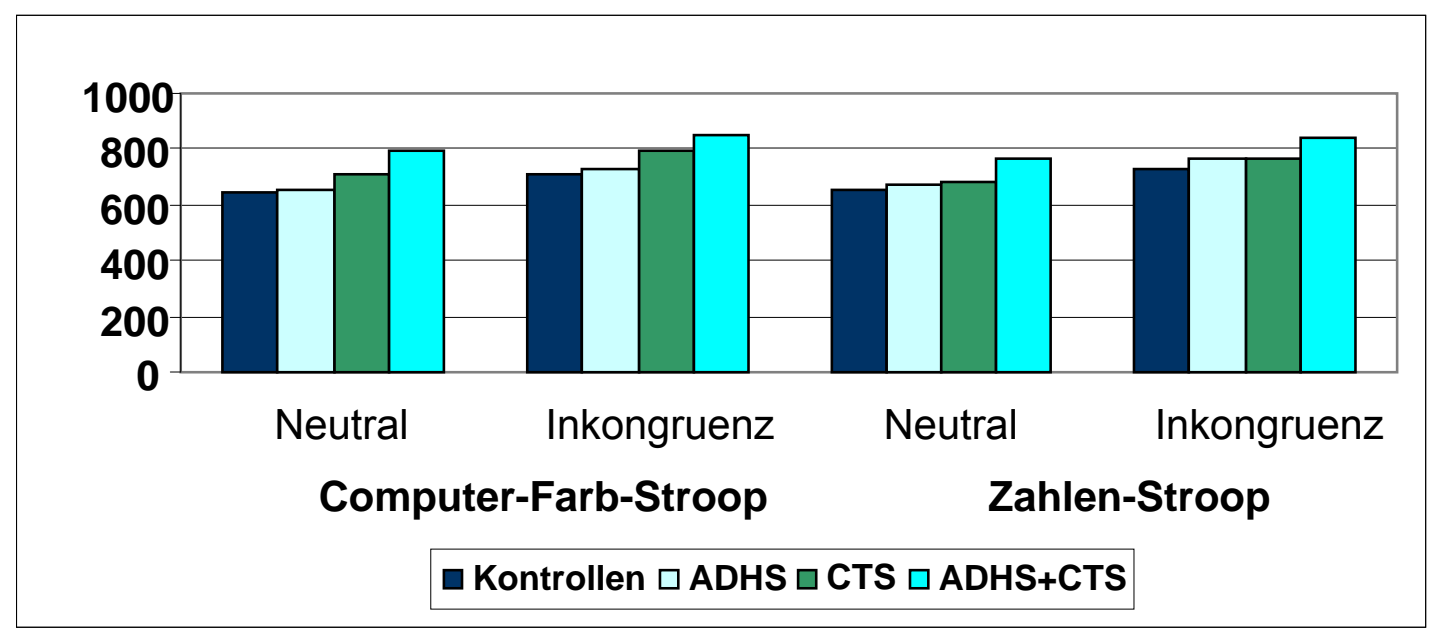

Abbildung 17: Mittlere Reaktionszeiten(ms) korrekter Antworten im Computer-Stroop

Ebenfalls zeigte sich kein bedeutsamer Haupteffekt für den Faktor „Bedingung“ $\left(F_{(1,65)}=.01, p=.93\right)$, so dass keine grundsätzlichen Unterschiede in den Reaktionszeiten im Computer-Farb-Stroop im Vergleich zu den Reaktionszeiten im Zahlen-Stroop zu finden waren. Darüber hinaus zeigte sich jedoch ein signifikanter Interaktionseffekt „Bedingung“ mal „CTS“ $\left(F_{(1,65)}=4.6, p=.04\right)$. Probanden mit CTS unterscheiden sich hinsichtlich der Reaktionszeiten im Farb-Stroop versus Zahlen-Stroop von Probanden ohne CTS. Eine Post-hoc-Analyse zeigte, dass die Differenz der Reaktionszeiten in den beiden Bedingungen (Reaktionszeit Computer-Farb-Stroop minus Reaktionszeit Zahlen-Stroop) in der Gruppe der Probanden mit CTS größer ist als in der Gruppe der Probanden ohne CTS. Die Richtung der Differenzen unterscheidet sich dabei. Probanden ohne CTS zeigen dabei hypothesenkonform eine im Mittel schnellere Reaktionszeit im Computer-Farb-Stroop als im Zahlen-Stroop, während Probanden mit CTS im Mittel eine schnellere Reaktionszeit im Zahlen-Stroop zeigen (siehe Abbildung 18). 


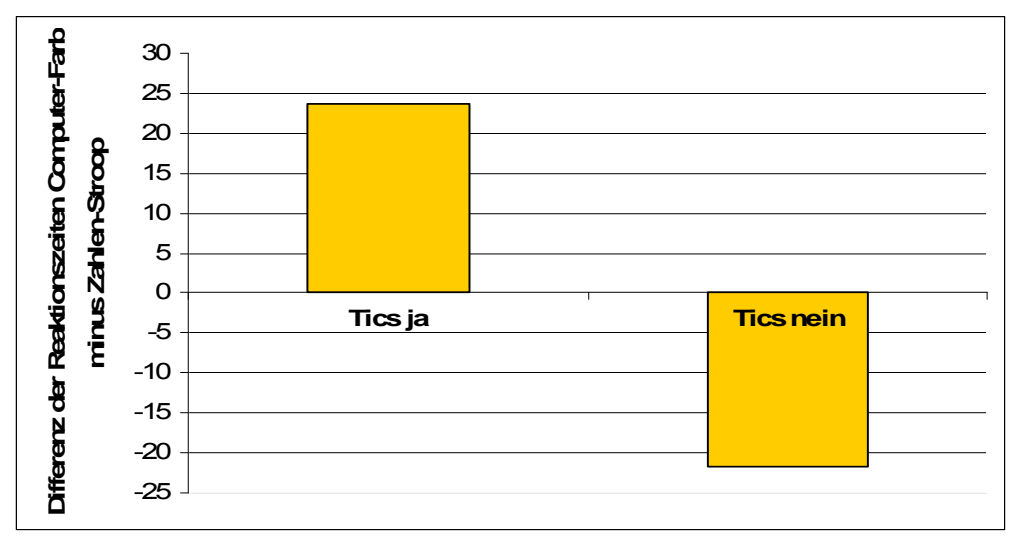

Abbildung 18: Differenz der Reaktionszeiten im Computer-Stroop in Abhängigkeit bzgl. des Vorliegens einer Tic-Störung bzw. keiner Tic-Störung

Eine Interaktion mit dem Faktor ADHS zeigte sich nicht (ADHS*Bedingung: $F_{(1}$, $\left.\left.{ }_{65}\right)=.34, p=.56\right)$. Ein übergeordneter Interaktionseffekt Bedingung ${ }^{*}{ }{ }^{2} S^{*} A D H S$ zeigte sich ebenfalls nicht $\left(F_{(1,65)}=.01, p=.94\right)$.

Bezüglich des Faktors „Kongruenz“ zeigte sich ein bedeutsamer Haupteffekt $\left(F_{(1,65)}=115.6, p=.00\right)$, der $64 \%$ der Varianz in den Reaktionszeiten aufzuklären vermag. Die Reaktionszeiten auf inkongruente Items sind über alle Gruppen sowie Bedingungen langsamer als für neutrale Items. Ein Interaktionseffekt mit den Faktoren ADHS bzw. CTS ergab sich nicht, so dass die Gruppenzugehörigkeit nicht signifikant Einfluss auf die Reaktionszeiten auf neutrale vs. inkongruente Items nahm bzw. es keine bedeutsamen Unterschiede in Abhängigkeit vom Vorliegen einer CTS bzw. einer ADHS hinsichtlich der Reaktionszeiten für korrekt bearbeitete Items bei Betrachtung neutraler vs. inkongruenter Stimuli gab (Kongruenz ${ }^{*}$ CTS: $F_{(1,65)}=.00, p=.96$; Kongruenz ${ }^{*}$ ADHS: $F_{(1,65)}=.09, p=.77$; Kongruenz ${ }^{*} C T S^{*} A D H S$ : $F_{(1,65)}=1.1, p=.30$ ) (siehe Abbildung 14 sowie Tabelle 15).

Es zeigten sich keine weiteren Interaktionseffekte (siehe Tabelle 15). 


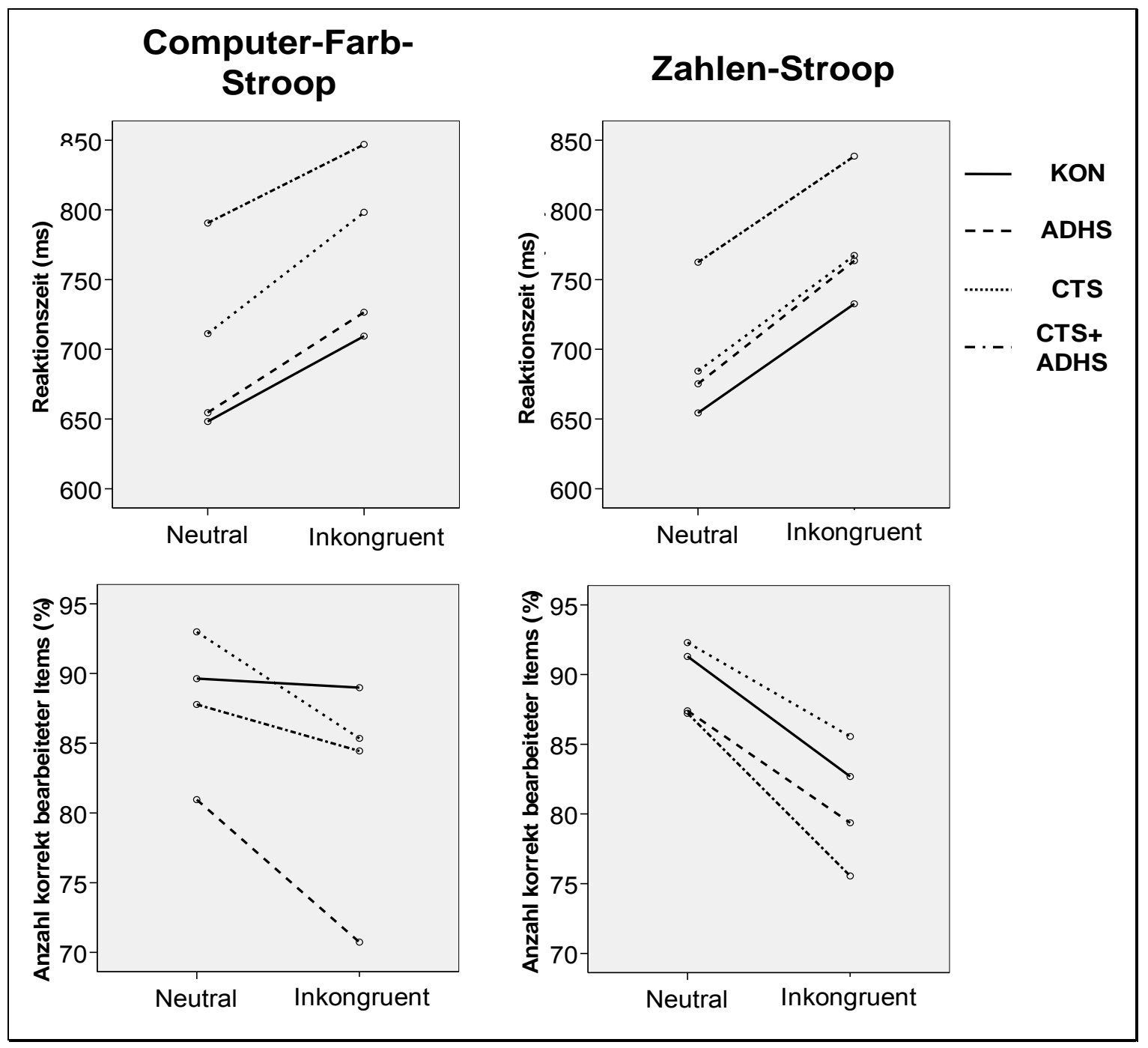

Abbildung 19: Farb-Stroop vs. Zahlen-Stroop, Reaktionszeiten und Anzahl korrekt bearbeiteter Items

\subsection{Anzahl korrekt bearbeiteter Items}

Eine Analyse der Anzahl korrekt bearbeiteter Items ergab einen signifikanten Haupteffekt für den Faktor „ADHS“ $\left(F_{(1,65)}=12.6, p<.01\right)$ sowie für den Faktor „Kongruenz" $\left(F_{(1,65)}=75.3, p<.01\right)$. Patienten mit der Diagnose ADHS machten im Mittel mehr Fehler im Computer-Stroop, unabhängig von der Bedingung und Kongruenz der Items, als Probanden ohne ADHS. Bei der Bearbeitung neutraler Stimuli wurden bedeutsam weniger Fehler gemacht als bei der Bearbeitung inkongruenter Items, unabhängig von den Faktoren „TIC“ und „ADHS“.

Interaktionseffekte zeigten sich hinsichtlich „Bedingung ${ }^{*} C T S$ “ $\left(F_{(1,65)}=7.5\right.$, $\mathrm{p}=.01)$, „Bedingung ${ }^{*} \mathrm{CTS}^{*} \mathrm{ADHS}$ “ $\left.\left(\mathrm{F}_{(1,}, 65\right)=14.8, \quad \mathrm{p}<.001\right)$ und „Bedin- 
gung ${ }^{*}$ Kongruenz ${ }^{*} \mathrm{CTS}^{*} \mathrm{ADHS}\left(\mathrm{F}_{(1,65)}=6.9, \mathrm{p}=.01\right)$ (siehe Tabelle 15 und Abbildung 20).

Zur Aufklärung der Interaktionen wurden post-hoc Konfidenzintervallanalysen durchgeführt indem die Differenz zwischen der Anzahl korrekter Antworten bei kongruenten und inkongruenten Items bestimmt wurde. Dabei ergaben sich Unterschiede im Stroop-Effekt. Bei Betrachtung der Anzahl korrekt bearbeiteter Items wiesen Probanden der Kontrollgruppe keinen Stroop-Effekt im FarbStroop auf, da die abgebildeten Differenzen zwischen „Farbe benennen“ und „Inkongruenz" den Wert Null im 5\%-Konfidenzintervall einschließen. Im ZahlenStroop zeigte sich bei den Kontrollprobanden jedoch ein solcher Stroop-Effekt (siehe Abbildung 20 sowie Tabelle 12).

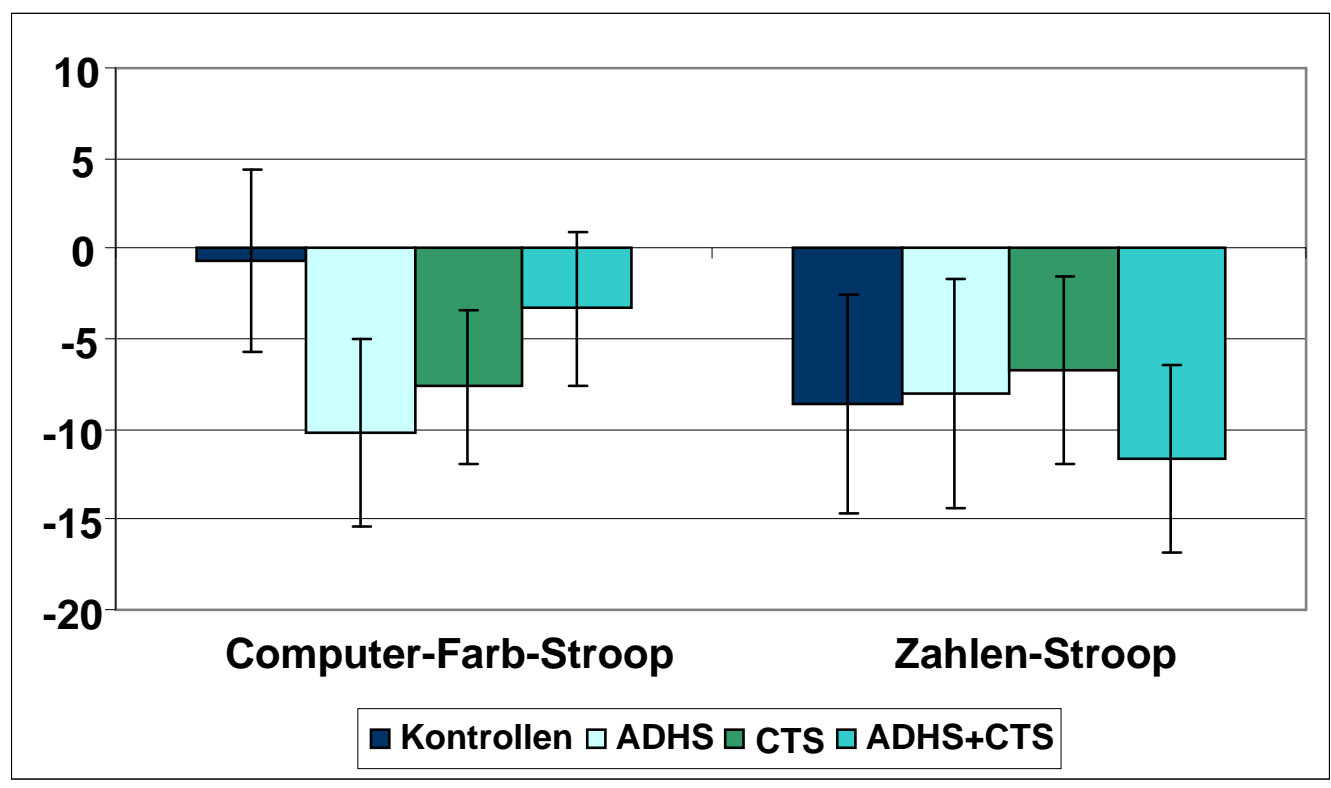

Abbildung 20: Differenzen in der Anzahl korrekter Antworten bei neutralen und inkongruenten Items über die Bedingungen Computer-Farb-Stroop und Zahlen-Stroop 
Sowohl bei Probanden der Gruppe ADHS als auch in der CTS-Gruppe ließ sich im Farb- sowie im Zahlen-Stroop ein Stroop-Effekt nachweisen.

Im Farb-Stroop konnte bei Probanden der Gruppe ADHS+CTS kein StroopEffekt nachgewiesen werden, während sich im Zahlen-Stroop ein solcher zeigte.

Ein Vergleich zwischen den Gruppen ergab, dass sich Probanden mit isoliertem ADHS bedeutsam von Probanden der Kontrollgruppe sowie Probanden mit komorbider Diagnose, jedoch nicht von Probanden mit isoliertem CTS hinsichtlich des Stroop-Effekts im Computer-Farb-Stroop unterscheiden. Im Zahlen-Stroop wurden insgesamt keine bedeutsamen Abweichungen über die Gruppen hinweg festgestellt (siehe auch Abbildung 20).

Tabelle 12: Aufklärung der Interaktion CTS*ADHS*Bedingung; Konfidenzintervallanalyse

\begin{tabular}{|c|c|c|c|c|c|c|c|c|}
\hline & \multicolumn{2}{|c|}{$\underline{\text { KON }}$} & \multicolumn{2}{|c|}{ 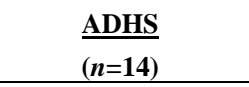 } & \multicolumn{2}{|c|}{$\underset{(n=20)}{\text { CTS }}$} & \multicolumn{2}{|c|}{$\frac{\text { ADHS }+ \text { CTS }}{(n=20)}$} \\
\hline & $\begin{array}{l}\text { Farb- } \\
\text { Stroop }\end{array}$ & $\begin{array}{l}\text { Zahlen- } \\
\text { Stroop }\end{array}$ & $\begin{array}{l}\text { Farb- } \\
\text { Stroop }\end{array}$ & $\begin{array}{l}\text { Zahlen- } \\
\text { Stroop }\end{array}$ & $\begin{array}{l}\text { Farb- } \\
\text { Stroop }\end{array}$ & $\begin{array}{l}\text { Zahlen- } \\
\text { Stroop }\end{array}$ & $\begin{array}{l}\text { Farb- } \\
\text { Stroop }\end{array}$ & $\begin{array}{l}\text { Zahlen- } \\
\text { Stroop }\end{array}$ \\
\hline $\mathbf{M}$ & -.65 & -8.61 & -10.22 & -8.04 & -7.64 & -6.74 & -3.33 & -11.67 \\
\hline 95\%-KI, Untergrenze & -5.30 & -14.31 & -15.04 & -13.94 & -11.67 & -11.67 & -7.37 & -16.61 \\
\hline 95\%-KI, Obergrenze & 4.01 & -2.91 & -5.40 & -2.13 & -3.61 & -1.80 & .70 & -6.73 \\
\hline
\end{tabular}

Beachte: $\mathrm{M}=$ Mittelwert, $\mathrm{KI}=$ Konfidenzintervall

5.2.3.2.3 Intra-individuelle Variabilität der Reaktionszeiten korrekt bearbeiteter Items

Analysen der intra-individuellen Variabilität in den Reaktionszeiten erbrachten einen Haupteffekt „ADHS“ $\left(F_{(1,65)}=8.5, p=.01\right)$, „Bedingung“ $\left(F_{(1,65)}=5.0, p=.03\right)$ und „Kongruenz" $\left(F_{(1,65)}=22.1, p<.001\right)$ wobei letzterer durch einen Interaktionseffekt „Kongruenz ${ }^{*} \mathrm{CTS}^{*}$ ADHS“ beeinflusst wurde $\left(\mathrm{F}_{(1,65)}=6.1, \mathrm{p}=.02\right)$ (siehe Tabelle 15).

Probanden mit ADHS (allein oder in Kombination mit CTS) zeigten eine signifikant stärkere Variabilität der Reaktionszeiten bei korrekt bearbeiteten Items, als Probanden ohne ADHS. Ebenso variiert die Reaktionszeit signifikant in Abhängigkeit von der Bedingung. Im Computer-Farb-Stroop zeigte sich im Vergleich zum Zahlen-Stroop eine bedeutsam erhöhte Variabilität in den Reaktionszeiten 
bei korrekter Antwortgabe, wobei sich diese als abhängig von der Kongruenz der Items erwies (neutral vs. inkongruent). Die Variabilität in den Reaktionszeiten bei neutralen bzw. inkongruenten Items wurde durch die Gruppenzugehörigkeit CTS*ADHS moduliert. In Post-hoc-Tests über eine Analyse der Konfidenzintervalle erbrachte, dass die Kontrollgruppe sowie die Patienten mit der komorbiden Diagnose ADHS+CTS keine bedeutsame Variabilität in den Reaktionszeiten zeigten. Probanden mit der Diagnose ADHS allein sowie CTS allein wiesen jedoch eine bedeutsame Variabilitäten der Reaktionszeiten bei korrekter Antwortgabe auf (siehe Tabelle 13). Ein komorbides Auftreten beider Störungen scheint demnach eher mit einer Stabilisierung der Reaktionszeiten einher zu gehen.

Tabelle 13: Aufklärung der Interaktion Kongruenz ${ }^{*} C T S^{*} A D H S$; Konfidenzintervallanalyse, Differenz der Variabilität in den Reaktionszeiten

\begin{tabular}{lcccc}
\hline & $\underline{\text { KON }}$ & $\underline{\text { ADHS }}$ & $\underline{\text { CTS }}$ & $\underline{\text { ADHS+CTS }}$ \\
\hline $\mathbf{( n = 1 5 )}$ & $(\boldsymbol{n = 1 4 )}$ & $\mathbf{( n = 2 0 )}$ & $(\boldsymbol{n = 2 0 )}$ \\
\hline $\mathbf{9 5 \% - K I , ~ U n t e r g r e n z e ~}$ & -10.73 & -55.12 & -39.99 & -19.02 \\
$\mathbf{9 5 \% - K I , ~ O b e r g r e n z e ~}$ & -38.78 & -84.15 & -64.28 & -43.31 \\
\hline
\end{tabular}

Beachte: $\mathrm{M}=$ Mittelwert, $\mathrm{KI}=$ Konfidenzintervall

5.2.4 Zusammenhang zwischen Leistungen im Farnsworth-Munsell 100-hueTest und Computer-Stroop

Hinausgehend über Analysen der Zusammenhänge der Farbdiskriminationsleistung und Ergebnissen im klassischen Papier-Stroop führten wir Korrelationsanalysen zwischen Parametern des Farnsworth-Munsell 100-hue-Tests (Gesamtfehlerwert, Fehlerwert Blau/Gelb-Achse sowie Fehlerwert Rot/GrünAchse) und Reaktionszeiten im Computer-Farb-Stroop (Bedingung „Farbe benennen“, Bedingung „Inkongruenz“, Interferenzwert) durch. Zur Vermeidung von Scheinkorrelationen aufgrund von Alterseffekten wurde auch hier der Einfluss der Variable Alter herauspartialisiert. Darüber hinaus wurde ebenfalls ein Signifikanzkriterium von $\mathrm{p}<.05$ festgelegt.

Hypothesenkonform korrelierten alle Parameter des Farnsworth-Munsell 100hue-Tests signifikant positiv mit den Reaktionszeiten in den Bedingungen „Far- 
be benennen“ und "Inkongruenz" des Computer-Farb-Stroops (siehe Tabelle 14).

Darüber hinaus konnte kein Zusammenhang zwischen den Parametern des Farnsworth-Munsell 100-hue-Tests und dem Interferenzwert festgestellt werden (alle $r<.03, p>.42$ ) (siehe Tabelle 14).

Tabelle 14: Korrelation zwischen der Leistung im Farnsworth-Munsell 100-hue-Test und dem Computer-Farb-Stroop

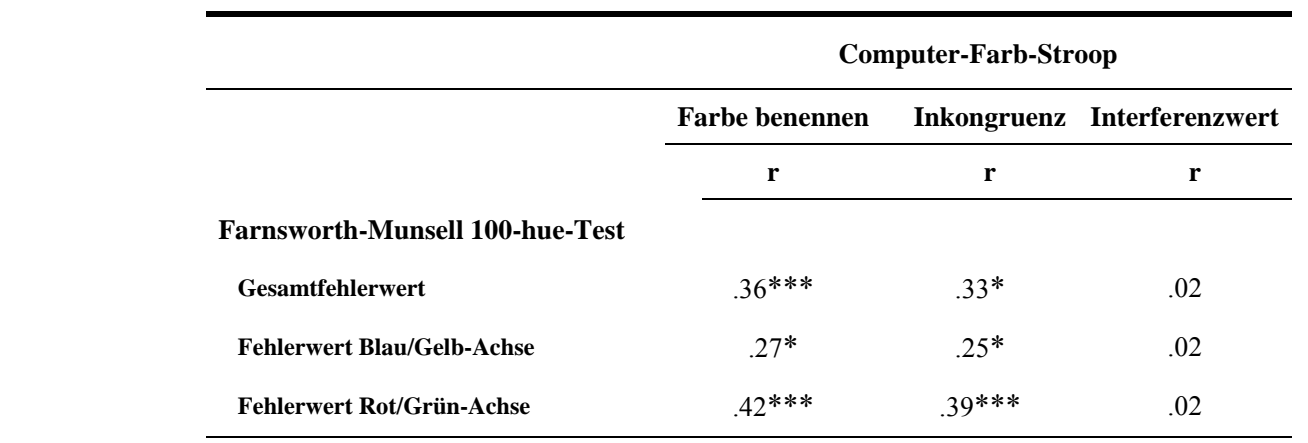

Beachte: $r=$ Korrelationskoeffizient

$* * * \mathrm{p}<0.001 ; * * \mathrm{p}<0.01 ;{ }^{*} \mathrm{p}<0.05 ;$ Trend: ${ }^{+} \mathrm{p}<0.1$

Im Rahmen der Fragestellung wäre eine Analyse der Reaktionszeiten der einzelnen Farbtasten bei der Bearbeitung des Computer-Farb-Stroops sowie deren Zusammenhang zu den Parametern im Farnsworth-Munsell 100-hue-Test interessant gewesen. Der Versuchsaufbau (siehe 3.3.4) erlaubt jedoch keine isolierte Auswertung der einzelnen Tasten (rot, gelb, grün, blau), da die tastenspezifische Bearbeitung durch verschiedene, nicht kontrollierte Faktoren, wie z. B. Links/Rechts-Effekte und fingerspezifische Effekte beeinflusst sein könnte. Durch eine randomisierte Zuordnung der einzelnen Farben zu den vier Tasten könnten solche Effekte kontrolliert werden. Da diese randomisierte Zuordnung in diesem Versuchsaufbau nicht stattgefunden hat, muss von einer Analyse des Faktors "Taste“ Abstand genommen werden. 
Tabelle 15: Computer-Stroop

\begin{tabular}{|c|c|c|c|c|c|c|c|c|c|}
\hline & \multicolumn{2}{|c|}{$\underline{\text { KON }}$} & \multicolumn{2}{|c|}{$\underline{\text { ADHD }}$} & \multicolumn{2}{|c|}{$\underline{\text { CTS }}$} & \multicolumn{2}{|c|}{$\underline{\text { ADHD + CTS }}$} & \multirow{3}{*}{$\underline{\text { ANOVA }}$} \\
\hline & Farb-Stroop & $\begin{array}{l}\text { Zahlen- } \\
\text { Stroop }\end{array}$ & Farb-Stroop & $\begin{array}{l}\text { Zahlen- } \\
\text { Stroop }\end{array}$ & Farb-Stroop & $\begin{array}{c}\text { Zahlen- } \\
\text { Stroop }\end{array}$ & Farb-Stroop & $\begin{array}{c}\text { Zahlen- } \\
\text { Stroop }\end{array}$ & \\
\hline & $\mathrm{M}(\mathrm{SD})$ & $\mathrm{M}(\mathrm{SD})$ & $\mathrm{M}(\mathrm{SD})$ & $\mathrm{M}(\mathrm{SD})$ & $\mathrm{M}(\mathrm{SD})$ & $\mathrm{M}(\mathrm{SD})$ & $\mathrm{M}(\mathrm{SD})$ & $\mathrm{M}(\mathrm{SD})$ & \\
\hline \multicolumn{10}{|l|}{ RZ korrekt bearb. Items (ms) } \\
\hline Neutral & $648.2(104.2)$ & $654.3(99.1)$ & $654.5(93.1)$ & $675.2(66.3)$ & $711.2(119.8)$ & $684.3(116.5)$ & $790.6(185.8)$ & $762.4(151.4)$ & \multirow{3}{*}{$\begin{array}{l}\text { „Gruppe }(\mathrm{CTS}) \text { ”: } \mathrm{F}_{(1,65)}=7.2, \mathrm{p}=.01 \text {, part. } \eta^{2}=.10 \\
\text { „Bedingung*CTS": } \mathrm{F}_{(1,65)}=4.6, \mathrm{p}=.04 \text {, part. } \eta^{2}=.07 \\
\text { „Kongruenz": } \mathrm{F}_{(1,65)}=115.6, \mathrm{p}<.001 \text {, part. } \eta^{2}=.64\end{array}$} \\
\hline Inkongruent & $709.4(142.9)$ & $732.6(138.5)$ & $726.6(116.5)$ & $763.5(80.4)$ & $798.3(140.0)$ & $767.3(137.1)$ & $846.9(174.3)$ & $838.5(159.6)$ & \\
\hline Differenz & $61.2(47.4)$ & $78.3(78.3)$ & $72.1(48.2)$ & $88.3(69.4)$ & $87.1(78.9)$ & $83.0(68.0)$ & $56.3(117.2)$ & $76.1(74.0)$ & \\
\hline AZ korrekt bearb. Items (\%) & & & & & & & & & \multirow{4}{*}{$\begin{array}{c}\text { „Gruppe (ADHS)”: } \mathrm{F}_{(1,65)}=12.6, \mathrm{p}<.001 \text {, part. } \eta^{2}=.16 \\
\text { „Bedingung*CTS”: } \mathrm{F}_{(1,65)}=7.5, \mathrm{p}=.01, \text { part. } \eta^{2}=.10 \\
\text { „Bedingung*CTS*ADHS”: } \mathrm{F}_{(1,65)}=14.8, \mathrm{p}<.001 \text {, part. } \\
\eta^{2}=.19 \\
\text { „Kongruenz": } \mathrm{F}_{(1,65)}=75.3, \mathrm{p}=.00 \text {, part. } \eta^{2}=.54 \\
\text { „Bedingung*Interferenz*CTS*ADHS”: } \mathrm{F}_{(1,65)}=6.9 \text {, } \\
\mathrm{p}=.01 \text {, part. } \eta^{2}=.10\end{array}$} \\
\hline Neutral & $89.6(9.7)$ & $91.3(7.8)$ & $81.0(10.7)$ & $87.4(10.0)$ & $93.0(4.4)$ & $92.3(6.6)$ & $87.8(12.2)$ & $87.2(11.6)$ & \\
\hline Inkongruent & $89.0(6.9)$ & $82.7(9.6)$ & $70.7(15.3)$ & $79.4(8.4)$ & $85.3(9.6)$ & $85.6(8.7)$ & $84.4(11.3)$ & $75.6(14.2)$ & \\
\hline Differenz & $-.6(2.3)$ & $-8.6(2.9)$ & $-10.3(2.4)$ & $-8.0(3.0)$ & $-7.7(2.0)$ & $-6.7(2.5)$ & $-3.4(2.0)$ & $-11.6(2.5)$ & \\
\hline \multicolumn{10}{|l|}{ RZ-Variabilität (ms) } \\
\hline Neutral & $160.2(54.2)$ & $159.7(52.8)$ & $185.1(42.6)$ & $173.0(36.9)$ & $176.4(50.4)$ & $153.3(29.2)$ & $217.1(82.1)$ & $187.6(58.5)$ & \multirow{3}{*}{$\begin{array}{c}\text { „Gruppe (ADHS)”: } \mathrm{F}_{(1,65)}=8.5, \mathrm{p}=.01 \text {, part. } \eta^{2}=.12 \\
\text { „Bedingung”: } \mathrm{F}_{(1,65)}=5.0, \mathrm{p}=.03 \text {, part. } \eta^{2}=.07 \\
\text { „Kongruenz”: } \mathrm{F}_{(1,65)}=22.1, \mathrm{p}<.001 \text {, part. } \eta^{2}=.25 \\
\text { „Kongruenz*CTS*ADHS”: } \mathrm{F}_{(1,65)}=6.1, \mathrm{p}=.02 \text {, part. } \\
\eta^{2}=.09\end{array}$} \\
\hline Inkongruent & $161.9(57.4)$ & $168.8(52.4)$ & $216.0(60.5)$ & $197.2(30.6)$ & $199.9(61.1)$ & $169.7(45.8)$ & $212.3(57.2)$ & $211.4(68.2)$ & \\
\hline Differenz & 1.7 (18.9) & $9.1(32.7)$ & $30.9(48.4)$ & $24.2(32.9)$ & $23.5(44.7)$ & $16.4(37.5)$ & $-4.8(52.6)$ & $23.8(61.6)$ & \\
\hline
\end{tabular}

$\mathrm{RZ}=$ Reaktionszeit, $\mathrm{AZ}=\mathrm{Anzahl}$ 


\section{Diskussion}

Das Ziel der vorliegenden Arbeit bestand in der Untersuchung der Farbdiskriminationsleistung von Kindern mit CTS, ADHS und CTS+ADHS. Überprüft werden sollte, in wieweit das Bestehen dieser Störungen mit einer Leistungsminderung in der Farbdiskriminationsfähigkeit einhergeht. Von besonderem Interesse erschien dabei die Betrachtung spezifischer Farbdiskriminationsstörungen in der Farbdimension Blau/Gelb. Die Erhebung spezifischer Farbdiskriminationsstörungen ermöglicht Rückschlüsse auf dahinterliegende Hirnfunktionen und kann helfen zu einem besseren Verständnis der psychophysiologischen Prozesse beider Störungsbilder sowie deren Komorbidität beizutragen sowie Ergänzungen zur grundlegenden Diskussion über Modellvorstellungen der dopaminergen Transmission bei CTS und CTS+ADHS liefern. Des Weiteren sollte die Komorbidität beider Störungen im Hinblick auf Hypothesen zu additiven bzw. interaktiven Störungsmodellvorstellungen vor dem Hintergrund der Farbdiskriminationsleistung diskutiert werden. Als dritten wesentlichen Aspekt dieser Studie wurde der Einfluss der Farbdiskriminationsleistung auf Leistungen in einem farbabhängigen Test zur Messung der Interferenzkontrolle (Stroop-Test) überprüft. Dazu wurde der klassische Farb-Stroop als Papierversion, eine Computerversion des klassischen Farb-Stroops und ein farbunabhängiger Test zur Messung der Interferenzkontrolle (Zahlen-Stroop), ebenfalls als Computerversion, verwendet. Die Farbdiskriminationsleistung wurde mit Hilfe des FarnsworthMunsell 100-Hue-Test erhoben. Zur Kontrolle von unerwünschten Einflüssen auf die Testergebnisse wurden ein Aufmerksamkeitstest, ein LeseRechtschreibtest, ein Wortflüssigkeitstest sowie ein Intelligenztest durchgeführt und eine etwaige Stimulanzieneinnahme (dopaminerg-modulierende Medikation) durch eine Wash-Out-Phase von 48 Stunden kontrolliert.

Die im Verlauf folgende Diskussion der formulierten Hypothesen soll zur Beantwortung folgender Fragen beitragen:

1. Sind Kinder mit CTS und/oder ADHS beeinträchtigt in ihrer Farbdiskriminationsfähigkeit? Und wenn ja, liegt eine größere Beeinträchtigung der 
Farbdiskrimination auf der Blau/Gelb-Achse vor als auf der Rot/GrünAchse?

2. Gibt es einen Zusammenhang zwischen Farbwahrnehmung und Leistungen im Farb-Stroop? Stimmen die Ergebnisse zur Interferenzneigung mit den in der Literatur beschriebenen Ergebnissen überein?

3. Unterstützen die Ergebnisse das Vorliegen eines additiven Modells oder eines interaktiven Modells?

Bei der Interpretation der vorliegenden Ergebnisse sollte zu beachten bleiben, dass die untersuchten Kinder mit CTS und/oder ADHS aus einer kinder- und jugendpsychiatrischen Inanspruchnahmepopulation rekrutiert wurden. Eine Verallgemeinerung der dargestellten Ergebnisse auf ein nicht-klinisches Kollektiv sollte somit nicht ohne Weiteres erfolgen. 


\subsection{Beantwortung der Hypothesen zur Farbdiskriminationsleistung}

\subsubsection{Farbdiskriminationsleistung allgemein}

Der angenommene Zusammenhang zwischen CTS und schwächeren Leistungen in der Farbdiskrimination, erhoben mit dem Farnsworth-Munsell 100-hueTest, konnte in dieser Untersuchung bestätigt werden.

Die Analyse der Farbdiskriminationsleistung erbrachte hypothesenkonform einen Haupteffekt für den Faktor CTS betreffend Fehlerwert Blau/Gelb-Achse, Fehlerwert Rot-Grün-Achse sowie Gesamtfehlerwert. Der Einfluss des Faktors CTS war dabei hochbedeutsam und vermochte mehr als $30 \%$ der Varianz in der Farbdiskriminationsleistung aufzuklären.

Ebenso wurde der Einfluss des Faktors ADHS auf die Farbdiskriminationsleistung bestätigt. Hypothesenkonform zeigte sich ein Haupteffekt ADHS betreffend Gesamtfehlerwert, Fehlerwert Blau/Gelb-Achse sowie Fehlerwert RotGrün-Achse. Die Effektstärken entsprechen dabei nach Cohen (1977) großen Effekten.

Diese Ergebnisse bzgl. schlechteren Diskriminationsleistungen im Blau/GelbBereich sowie insgesamt entsprechen den von Melun et. al. (2001) sowie Banaschewski und Mitarbeitern (2006) beschriebenen Befunden bezüglich der Farbdiskriminationsleistung bei Patienten mit CTS bzw. ADHS. Darüber hinaus stimmen sie mit Studienergebnissen zur Farbdiskriminationsleistung bei Probanden mit pathologischen Veränderung in der dopaminergen Transmission überein (Desai et. al., 1997; Pieri et. al., 1999; Shuwairi et. al., 2002).

Die Signifikanz beider Haupteffekte in Abwesenheit von Interaktionseffekten in jedem der Farnsworth-Munsell 100-hue Parameter stehen mit additiven Modellvorstellungen zum Störungsbild ADHS+CTS im Einklang (siehe 6.3).

Die in dieser Untersuchung festgestellte Farbdiskriminationsschwäche im Rot/Grün-Bereich bei Probanden mit CTS und/oder ADHS geht jedoch nicht konform mit vergleichbaren Untersuchungen (Melun et. al., 2001; Banaschewski et. al., 2006), in denen die Farbdiskriminationsleistung der klinischen Gruppe auf der Rot/Grün-Achse den Leistungen der Kontrollgruppe entsprach. Jedoch ergaben die Untersuchungen bei Banaschewski et. al. (2006) einen Un- 
terschiedstrend zwischen ADHS und Kontrollen, der vermuten lässt, dass Divergenz auf die geringe statistische Power zurückzuführen sein könnte und bei größerer Stichprobe signifikant zu Tage treten würde.

Darüber hinaus zeigten diverse Studie, die sich mit einer entsprechenden Fragestellungen zur Farbwahrnehmung bei Störungsbildern mit Veränderungen der dopaminergen Transmission beschäftigten, eine signifikant höhere Fehlerquote im Farbdiskriminationstest auf beiden Farb-Achsen im Vergleich zur Kontrollgruppe (Büttner et. al., 1995; Haug et. al., 1995; Pieri et. al., 2000). Was dieses Ergebnis im Einzelnen bedeuten könnte, wird unter 6.1.2 bei Betrachtung der Differenzen beider Farbachsen ausführlich diskutiert.

Die gezeigte verminderte Farbdiskriminationsleistung bei CTS und/oder ADHS im Vergleich zur altersentsprechenden Kontrollgruppe lässt sich nicht allein durch Unterschiede in der Aufmerksamkeitsleistung erklären, da Kinder mit CTS und ADHS in gleicher Weise Probleme bei der Farbwahrnehmung zeigten, sich aber nur ein Haupteffekt ADHS im Aufmerksamkeitstest bezüglich schlechterer Leistungen im Qualitätswerts, Kontinuitätswerts sowie hinsichtlich Falscher-Alarm-Fehlern zeigte. Sämtliche übrigen aufmerksamkeitsspezifschen Kennwerte unterschieden sich darüber hinaus in Abhängigkeit von der Gruppenzugehörigkeit nicht.

Auf Gruppenebene konnten hypothesenkonform bei Kindern der Gruppen CTS, ADHS und ADHS+CTS mehr Fehler auf beiden Farbachsen sowie insgesamt im Vergleich zu gesunden Gleichaltrigen festgestellt werden. Die beiden Störungsgruppen CTS und ADHS unterschieden sich, wie vorhergesagt in keinem der Parameter. Hypothesenkonform wies jedoch die komorbide Gruppe signifikant schwächere Leistungen in allen drei Kennwerten auf, als die isolierten Störungsgruppen. In der Literatur gibt es diesbezüglich keine vergleichbaren Untersuchungen.

$\mathrm{Zu}$ beachten bleibt bei der Betrachtung dieser Ergebnisse jedoch, dass eine Fortsetzung der Tic-Medikation mit Neuroleptika wie Risperidon, Sulpirid und Tiaprid bei Probanden mit CTS zu einer Verfälschung der Ergebnisse beigetragen haben könnte. Dies scheint insbesondere relevant, da sich ein bedeutsamer Unterschied in der Behandlung der Tic-Symptomatik in Abhängigkeit von der Gruppenzugehörigkeit CTS bzw. ADHS+CTS zeigte. Die bekannten Neuro- 
leptika hemmen die kortikale Übertragung des Dopamins und könnten demnach ebenfalls die Farbdiskrimination beeinflussen. Eine niedrig dosierte kurzfristiger Gabe von Risperidon (Allain, Tessier, Bentue-Ferrer, Tarral, Le Braton, Gandon \& Bouhours, 2003) oder Tiaprid (Eggers, Rothenberger \& Berghaus, 1988) bei gesunden Freiwilligen oder Kindern mit Ticstörungen scheinen jedoch, entsprechend der momentanen Forschungslage, keinen Einfluss auf die kognitive Leistungsfähigkeit zu haben, jedoch ist unbekannt, welche Auswirkungen eine Dauermedikation haben könnte. In der Studie von Hyde, Stacey, Coppopla, Handel, Rickler \& Weinberger (1995) ergaben sich Hinwiese auf eine nicht rein genetisch bedingte Größe der Basalganglien bei monozygoten Zwillingen mit CTS. Die Beeinflussung dieser durch Neuroleptikagabe scheint diskutabel.

Ähnliches ist zu beachten bei Stimulanziengabe zur Behandlung der ADHS. Es ist bekannt, dass Methylphenidat die Farbbenennung sowie Wortbenennung verbessert (Bedard et. al., 2002). Zur Minimierung dieses Einflusses wurde 48 Stunden vor Untersuchungsbeginn bei allen Probanden dieser Studie die Stimulanzien-Medikation abgesetzt. Nicht auszuschließen bleibt jedoch, dass eine dauerhafte Gabe zu überdauernden Veränderungen der Dopamintransmission geführt haben könnte, die, wie beispielsweise bei langfristigem Kokainabusus (Roy, Smelson \& Roy, 1996b), auch 48 Stunden nach letztmaliger Einnahme besteht und Einfluss auf die Farbdiskrimination nimmt. 


\subsubsection{Differenzen der Farbachsen}

Hinausgehend über die Überprüfung eines generellen Einflusses der beiden Faktoren ADHS und CTS auf Leistungen in der Farbdiskrimination wurde der Unterschied zwischen den Diskriminationsleistungen auf beiden Farbachsen innerhalb der Faktoren untersucht. Darüber hinaus fand eine post-hoc Analyse auf Gruppenebene bzgl. der Fehlerdifferenzen auf beiden Farbachsen statt.

\section{Faktor CTS}

Die Auswertung der Fehlerdifferenzen beider Farbachsen bestätigte dabei nicht die Hypothese einer unterschiedlichen Fehlerverteilung mit höheren Fehlerwerten auf der Blau-Gelb-Achse für Probanden mit CTS. Im Gegensatz zu den Ergebnissen von Melun et. al. (2001) fanden wir keine Hinweise auf eine insbesondere die Blau/Gelb-Achse betreffenden Verminderung der Farbwahrnehmungsleistung bei Kindern mit CTS. Zum Einen könnte dies erklärt werden durch fehlende Kontrollen möglicher komorbider ADHS-Symptome bei CTSProbanden in der Studie von Melun et. al. (2001).

Darüber hinaus könnte die Betrachtung der Geschlechtsverteilung beider Studien zur Erklärung der Ergebnisunterschiede beitragen. Das Geschlechterverhältnis männlich-weiblich bei Melun beträgt 2:1 (in der CTS-Gruppe), in unserer Arbeit (CTS allein, CTS+ADHS) liegt das Verhältnis bei 6.6:1. Ergebnisse zur geschlechtsspezifischen Hormonverteilung insbesondere Östrogen betreffend und der vermutete modulierende Effekte des Östrogens auf die dopaminerge Aktivität bzw. die Dopaminrezeptordichte (Andersen \& Teicher, 2000; Walker, Rooney, Wightman \& Kuhn, 2000) lässt einen Einfluss des Geschlechts auf die Ergebnisse beider Studien als erwägenswert erscheinen.

Der mögliche Alterseinfluss auf Ergebnisse zur Farbdiskrimination bleibt ebenfalls zu diskutieren, da die Probanden beider Untersuchungen beträchtlich in ihrer Altersverteilung differieren. So lag der Altersdurchschnitt in Meluns et. al.'s (2001) Studie bei 35.4 Jahre. Bei den hier untersuchten Probanden zeigte sich ein mittleres Alter von 10.7 Jahre. Der Einfluss von Alterungsprozessen auf die Wahrnehmung von Farben wird als bestätigt angesehen (Djamgoz et. al., 1997; Meluns et. al., 2001; Kinnear \& Sahraie, 2002). So geht ein fortschreitendes 
Alter mit einer Verminderung der Farbdiskriminationsleistung auf der Blau/GelbAchse sowie einer verminderten Durchlässigkeit für Licht kurzer Wellenlänge einher, und steht darüber hinaus mit einer Vergilbung der Linse im Zusammenhang (Knoblauch, Saunders, Kusuda, Hynes, Podgor, Higgins \& Monastero, 1987; Pokorny, Smith \& Lutze, 1987; Weale, 1988; Geller \& Hudnell, 1997; Melun et. al., 2001). Suzuiki, Qiang, Sakuragawa, Tamura und Okajima (2005, 2006) beschreiben, dass die Vergilbung bzw. verminderte Durchlässigkeit für kurzwelliges Licht mit einer verlängerten Reaktionszeit auf blaue sowie graue Stimuli einhergeht. Darüber hinaus verändert sich mit zunehmendem Alter die Dopaminkonzentration in der Retina (Smith, Sharma \& Steinle, 2007), was ebenfalls Einfluss auf Leistungen in Farbdiskriminationstests nimmt (Djamgoz et. al., 1997). Kinnear und Mitarbeiter (2005) beschreiben eine stärker die Blau/Gelb-Achse betreffende Leistungsverschlechterung im Sinne von größeren Fehlerwerten im Farnsworth-Munsell 100-hue-Test bei Probanden über 40 Jahre. Ferner besteht ein allgemeiner Zusammenhang zwischen dopaminerger Aktivität und Altern, so dass beispielsweise in Abhängigkeit vom Alter der Patienten die Lernleistung über Belohnung schwerer fällt (Schott, Niehaus, Wittmann, Schütze, Seidenbecher, Heinze \& Düzel, 2007). Die Vergleichbarkeit der Studienergebnisse scheint demnach nur mit Einschränkungen gegeben, so dass die Unterschiede in den Ergebnissen durch alters- und geschlechtsspezifische Einflüsse sowie komorbide Diagnosen bzw. Symptome in der CTS-Gruppe erklärbar sein könnten.

\section{Faktor ADHS}

Bei Kindern mit ADHS zeigte sich hypothesenkonform ein Trend in Richtung einer stärkeren Beeinträchtigung der Farbdiskrimination im Blau/Gelb-Bereich im Vergleich zur Rot/Grün-Achse, was den in der Literatur beschriebenen Ergebnissen zur Farbwahrnehmung bei Probanden mit dopaminergen Störungsbildern entspricht (Masson et. al., 1993; Haug et. al., 1995; Desai, et. al., 1997; Djamgoz et. al., 1997; Pieri, et. al., 2000). 


\section{Gruppenebene}

Auf Gruppenebene erbrachte eine Überprüfung der Fehlerdifferenzen auf den Achsen Blau/Gelb und Rot/Grün keine Unterschiede bei Probanden der Kontrollgruppe. Dies entspricht den in der Literatur beschriebenen Ergebnissen (Banaschewski et. al., 2007). Sowohl Probanden der Gruppe ADHS als auch der Gruppe ADHS+CTS zeigten eine Verschiedenheit der Differenzen, was, bzgl. ADHS ebenfalls der Literatur entspricht (Banaschewski et. al., 2007). Für die komorbide Störung liegen bisher keine vergleichbaren Untersuchungen vor.

\section{Zusammenfassung}

Insgesamt kann demnach festgehalten werden, dass die Gruppenzugehörigkeit mit der Anzahl der Gesamtfehler im Farbdiskriminationstest interagiert, wobei dies bei Kindern mit CTS unabhängig von der jeweiligen Farbachse zuzutreffen scheint, bei Probanden mit ADHS jedoch zusätzlich innerhalb der Gruppe eine tendenziell stärkere Beeinträchtigung auf der Blau/Gelb-Achse vorliegt, als auf der Rot/Grün-Achse.

6.1.3 Diskussion der Befunde bzgl. dopaminerger Transmissionstörungen bei CTS und ADHS und der Farbdiskrimination

Dass bei Kindern mit CTS keine Störung der Farbdiskrimination insbesondere die Blau-Gelb-Achse betreffend gefunden wurde, wie sie bei anderen Erkrankungen, die Störungen der Basalganglien betreffen bzw. mit Veränderungen in der dopaminergen Transmission einhergehen, gezeigt werden konnte (Büttner et. al., 1994; Haug et. al., 1995; Müller et. al., 1997), kann durch verschiedene Faktoren bedingt sein.

Zum Einen ist anzunehmen, dass, wie schon im Zusammenhang mit Melun et. al.'s (2001) Stichprobe diskutiert, eine primär auf der Blau/Gelb-Achse gelegene Verschlechterung der Farbdiskriminationsleistung im Zusammenhang mit Alterungsprozessen, Geschlechterverteilung sowie fehlender Kontrolle komorbider Störungen zu sehen sein könnte. 
Des Weiteren wurde bisher eine insbesondere die Blau/Gelb-Achse betreffende Farbdiskriminationsstörung bei Probanden mit Veränderungen im dopaminergen System, wie sie bei Morbus Parkinson, Kokainentzug und ADHS zu finden sind (Haug et. al, 1995; Roy et. al.,1996; Desai et. al., 1997, Shepherd, 2005; Banaschewski et. al., 2006) mit der Theorie erklärt, dass das Blau/Gelb-System aufgrund der geringen Dichte und anatomischen Verteilung der S-Zapfen vulnerabler für systemische Veränderungen sei. Folglich sollte eine Veränderung der Dopaminkonzentration zuerst zu Funktionsveränderungen in diesem Farbsystem führen bzw. in einer schlechteren Diskriminationsleistung für Stimuli dieser Farbachse sichtbar werden (Djamgoz et. al., 1997; Hart, 1987, Masson et. al., 1993; Witkovsky, 2004). Schlussfolglich würde dies bedeuten, dass das Blau/Gelb-System bereits auf geringe dopaminerge Veränderungen reagiere, das Rot/Grün-System möglicherweise jedoch erst bei größeren Veränderungen betroffen wäre und erstgenanntes somit gewissermaßen eine Art „Frühwarnsystem“ für systemische Veränderungen darstellen könnte (siehe Abbildung 21).

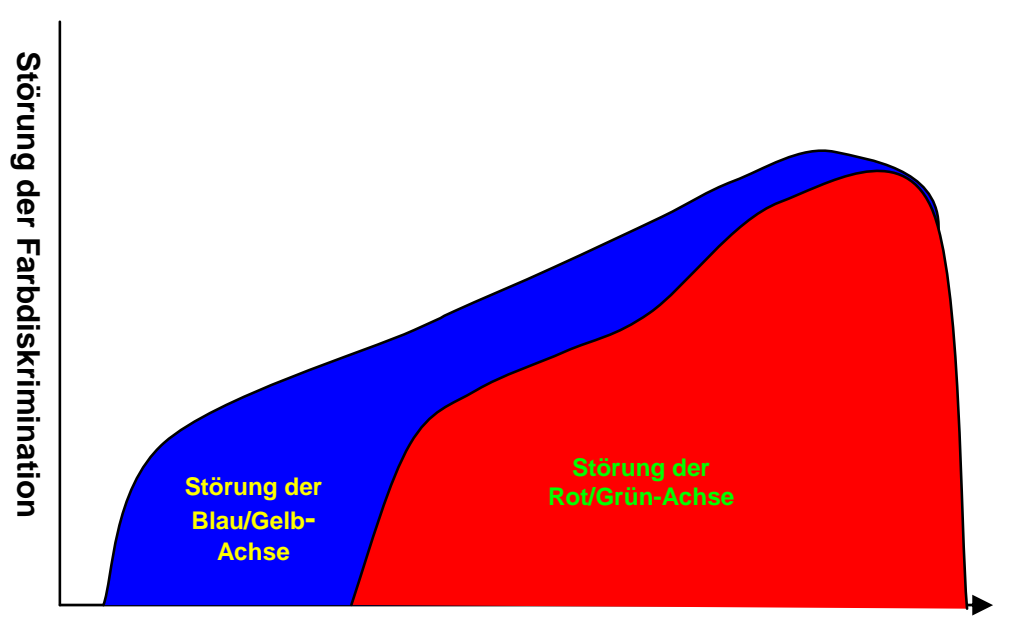

Stärke der dopaminergen Transmissionsstörung

Abbildung 21: Hypothetischer Einfluss der dopaminergen Transmission auf die Farbdiskrimination in Abhängigkeit von der Stärke der Störung im dopaminergen System

Demnach scheint es ebenfalls einleuchtend, dass jene gedachte erforderliche Größe der dopaminergen Modulationsveränderung, die mit einer ausschließlichen bzw. stärkeren Beeinträchtigung im Blau/Gelb-System einhergehen würde, bei Probanden der vorliegenden Arbeit überschritten sein könnte. Zur Überprüfung dieser Überlegungen wäre eine Analyse der Farbdiskrimination in Ab- 
hängigkeit von der Symptomschwere bei ADHS und CTS sinnvoll. Anzunehmen wäre dabei, dass mit zunehmender Symptomschwere eine stärkere Veränderung der dopaminergen Transmission einhergehen würde und dahingehend das Ausmaß der Farbdiskriminationsstörung beeinflusst sein könnte (Müller, Kuhn, Büttner \& Przuntek, 1997). bzw. bei geringerer Symptomausprägung eine möglicherweise ausschließliche Farbdiskriminationsstörung im Blau/Gelb-System sichtbar werden würde. Hinweise auf das Zutreffen dieser Überlegungen lassen sich aus dem Ergebnis ableiten, dass Probanden mit CTS und komorbidem ADHS bedeutsam mehr Fehler in allen Farnsworth-Munsell 100-hueParametern machten, als die isolierten Gruppen. Darüber hinaus zeigte die komorbide Gruppe eine bedeutsame Differenz der Farbachsenfehlerwerte mit einer stärkeren Beeinträchtigung hinsichtlich der Blau/Gelb-Achse. Jedoch zeigte sich diese auch bei Probanden mit isoliertem ADHS.

Eine weitere Erklärung für die in unserer Studie gefundenen Ergebnisse könnte demnach ebenso bzw. darüber hinaus in der unterschiedlichen Veränderung dopaminerger Transmission bei den verschiedenen Störungsbildern zu finden sein, welche möglicherweise mit unterschiedliche Veränderungen in der Farbdiskriminationsleistung einhergehen. Bisher wurde angenommen, dass die $\mathrm{Pa}-$ thophysiologie der ADHS auf einer hypodopaminergen Störung beruht (Taylor, Döpfner, Sergeant, Asherson, Banaschewski, Buitlaar, Coghill, Dankaerts, Rothenberger, Sonuga-Barke, Steinhausen \& Zuddas, 2004; Banaschewski, Hollis, Oosterlaan, Roeyers, Rubia, Willcutt \& Taylor, 2005; Sadile et. al. 2005; Sagvolden et. al., 2005). Bei CTS hingegen wird angenommen, dass die Symptomatik auf ein „Zuviel“ an dopaminerger Aktivierung im Striatum zurückzuführen ist, wodurch das Funktionsdefizit im Bereich des kortiko-striato-thalamokortikalen Regulationssystems die subkortikale Eigenhemmung und Bewegungskontrolle stört (Ziemann et. al., 1997; Rothenberger, Banaschewski \& Siniatchkin, 2002; Minzer et. al., 2004; Yoon et. al., 2007). Überträgt man diese Befunde auf Ergebnisse zur Farbdiskrimination wäre einerseits anzunehmen, dass eine generelle Veränderung der dopaminergen Konzentration (egal ob hypo- oder hyperdopaminerg) mit einer generellen Farbdiskriminationsstörung einhergeht. Darüber hinausgehend wäre jedoch ebenfalls möglich, dass eine spezifische Farbdiskriminationsstörung auf der Blau/Gelb-Achse mit einer hy- 
podopaminerge Funktionsstörung einher geht (Shuwairi et. al., 2002) (siehe Abbildung 22).

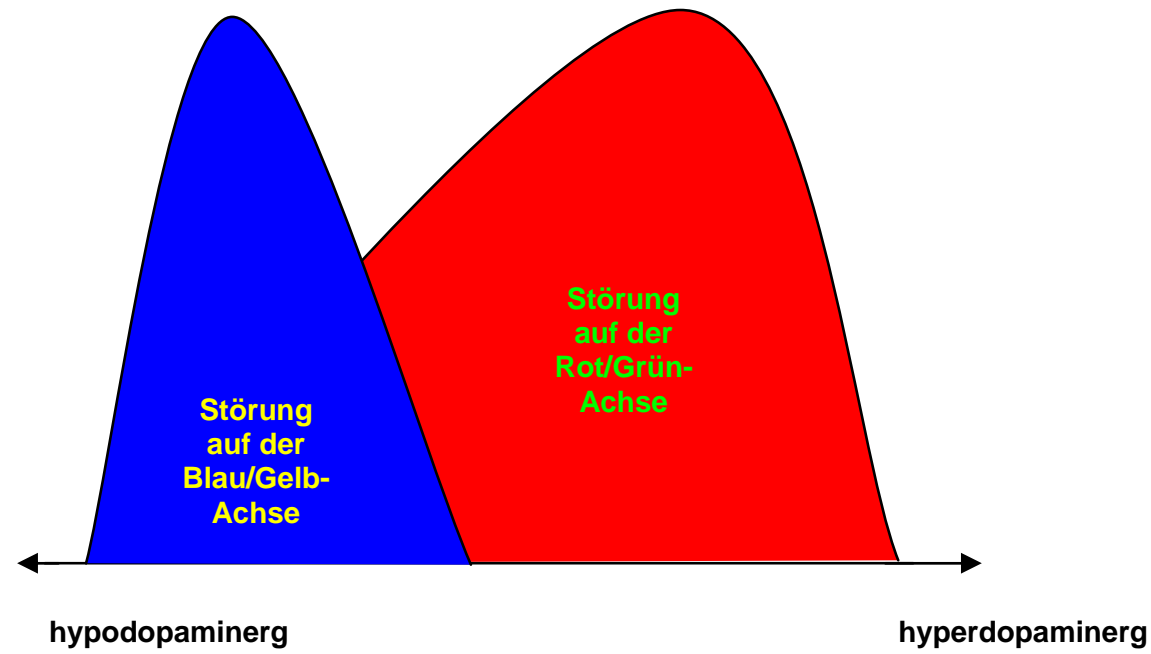

Abbildung 22: Hypothetischer Einfluss von hyper- und hypodopaminerger Transmissionsstörung auf die Farbdiskrimination

Gestützt wird dieser Annahme durch Untersuchungen an Patienten mit Morbus Parkinson. Die durch die Störung bedingte Degeneration nigrostriataler dopaminerger Neurone (hypodopaminerge Störung) (Djamgoz et. al., 1997) geht mit einer insbesondere das Blau/Gelb-System betreffenden Beeinträchtigung der Farbdiskrimination einher (Haug et. al., 1995). Des Weiteren ist bekannt, dass bei Patienten mit Morbus Parkinson eine reduzierte Dopaminkonzentration in den Amakrinenzellen der Retina festzustellen ist (Harnois et. al., 1990; BodisWollner \& Tagliati, 1993).

Untersuchungen zum Kokainabusus weisen in ähnliche Richtung. Kokainentzug führt zu einem zentralen hypodopaminergen Status bei Ratten (Ackermann \& White, 1992; Karum, Egan \& Wyatt, 1992) und geht bei Menschen mit einer signifikant reduzierten Antwort auf blaue Lichtblitze einher, was durch eine Dysregulation der S-Zapfen bedingt sein könnte (Roy et. al., 1996a; Roy, Smelson \& Roy, 1997) und sich in einer, speziell die Blau/Gelb-Achse betreffenden, Farbdiskriminationsschwäche bei erwachsenen kokainentzugigen Patienten manifestiert (Desai et. al., 1997).

Insbesondere Untersuchungen zur Farbwahrnehmung bei Patienten mit Schizophrenie (Shuwairi et. al., 2002) bekräftigen die Annahme eines selektiven Einflusses hypodopaminerger Transmission auf die Diskriminationsfähigkeit für 
Farben auf der Blau/Gelb-Achse. Shuwairi und Mitarbeiter (2002) fanden bei medizierten schizophrenen Patienten ausschließlich eine generelle Störung der Farbwahrnehmung auf beiden Farbachsen, die durch die Gabe von Dopaminblockern nicht beeinflusst werden konnte und argumentierten, dass der bei Schizophrenien vorliegende hyperdopaminerge Status eine ausschließlich die Blau/Gelb-Achse betreffende Farbdiskriminationsstörung verhindert. Interessanterweise vermag selbst eine dopaminregulierende Medikation keinen bedeutsamen Einfluss auf die Farbdiskriminaton zu leisten.

Diese Ergebnisse und Überlegungen lassen es als möglich erscheinen, dass eine allgemeine Veränderung der dopaminergen Konzentration eine Veränderung der Farbwahrnehmung insgesamt zur Folge hat, jedoch ein hypodopaminerger Status speziell mit einer Farbwahrnehmungsstörung auf der Blau-GelbAchse einhergeht. Diese Annahme wird durch Ergebnisse dieser Studie entsprechend des tendenziell höheren Fehlerwerts auf der Blau/Gelb-Achse bei Probanden mit ADHS gestützt sowie den Befunden, dass Probanden mit ADHS und CTS eine insgesamt höhere Fehleranzahl aufweisen, als die isolierte Störungsgruppe sowie eine bedeutsame Diskrepanz zwischen den Fehlerwerten der Blau/Gelb- sowie Rot/Grün-Achse zeigten.

In Anbetracht der Ergebnisse erscheint eine Betrachtung der Störungsebene der Farbdiskrimination bei dopaminergen Transmissionsstörungen interessant. Die Spezifität einer Farbdiskriminationsstörung auf der Blau/Gelb-Achse, also bei Farben an deren Wahrnehmung die S-Zapfen beteiligt sind sowie die damit verbundenen Erklärungstheorien legt die Annahme nahe, dass die Störung ein Verarbeitungslevel betrifft, bevor die Signale der Farbsysteme vereint werden. Somit ließe eine generelle Störung der Farbwahrnehmung eine eher zentrale Störung der Farbverarbeitung oder eine Störung auf beiden Ebenen (zentral und retinal) vermuten (Shepherd, 2005, 2006). Darüber hinaus scheint es möglich, dass eine bestimmte Störungsschwere sich zuerst auf Ebene der retinal Farbverarbeitung niederschlägt, eine größere Veränderung der dopaminergen Transmission jedoch zusätzlich die höheren Informationsverarbeitungsprozesse im visuellen Kortex betrifft. Andererseits wäre ebenfalls denkbar, dass eine ausschließlich hyperdopaminerge Transmissionsstörung vor allem die höheren visuellen Informationsverarbeitungsprozesse beeinflusst, eine hypodopaminerge eher die retinal gelegenen. Zusammenhänge zu Untersuchungen an medi- 
zierten Probanden mit Dopaminblockern scheinen in diesem Rahmen interessant (Shuwairi et. al., 2002).

Die Forschung mit Patienten mit cerebraler Dyschromatopsie weisen in die Richtung, dass Farbdiskriminationsstörungen, auch die Blau/Gelb-Achse betreffend, auf einem zentralen Level gestört sein könnten, der Farnsworth-Munsell 100-hue-Test sich jedoch nicht gut eignet, um Farbdiskriminationsstörungen hinausgehend über retinale Beeinträchtigungen zu erheben (Koyama, Kezuka, Hibino, Tomimitsu \& Kawamura, 2006).

Insgesamt zeigen die Ergebnisse dieser Studie, dass die dopaminergen Transmissionsstörung bei ADHS und CTS nicht nur den kortiko-striato-thalamokortikalen Regelkreis zuzuordnen ist, sonderen offenbar weitere Strukturen und Verarbeitungsprozesse in der Retina betroffen sind. 


\subsection{Beantwortung der Hypothesen zum Stroop-Test}

\subsubsection{Der klassische Papier-Stroop}

Erwartungsgemäß zeigte sich für den Faktor CTS kein Zusammenhang zu längeren Bearbeitungszeiten in den Bedingungen „Farbe benennen“ und „Inkongruenz“. Dies steht im Einklang mit den Ergebnissen zu exekutiven Funktionen bei CTS (Pennington et. al., 1996; Channon et. al., 2003). Die Farbdiskriminationsleistung scheint demnach die Bearbeitung des klassischen Farb-Stroops bei CTS nicht zu beeinträchtigen, was den Ergebnissen anderer Studien entspricht, in denen ebenfalls keine Unterschiede zwischen Kontrollprobanden und Probanden mit CTS in allen Stroop-Parametern gefunden werden konnten (Brand et. al., 2002, Channon et. al., 2003; Lavoie et. al 2007; Marsh et. al. 2007, Roessner et. al, 2007a). Die Interferenzneigung bei CTS erwies sich ebenfalls hypothesenkonform und entsprechend der in der Literatur beschriebenen Ergebnisse in dieser Studie als nicht beeinträchtigt. Darüber hinaus zeigten unsere Probanden mit CTS eine schnellere Bearbeitung in der Bedingung „Wort lesen“, was durch den niedrigeren IQ bei Probanden mit ADHS erklärt werden könnte.

Der Faktor ADHS zeigte hingegen erwartungskonform einen tendenziell bedeutsamen Einfluss auf alle Kennwerte des klassischen Farb-Stroops zu haben. Dieser machte sich dahingehend bemerkbar, dass jene Probanden im Mittel langsamer waren als Probanden ohne ADHS beim Vorlesen von Farbwörtern, bei der Benennung der Farbe von Farbstrichen sowie bei der Benennung der Druckfarbe eines inkongruenten Farbwortes. Bei Patienten mit ADHS stellten wir hypothesen- sowie literaturkonform eine erhöhte Interferenzneigung fest (Nigg et. al., 2002; Banaschewski, 2006; Lansbergen et. al., 2007).

Die Interferenzneigung sowie der Benennungsgeschwindigkeit in der Bedingung „Inkongruenz“ wurde durch einen Interaktionseffekt der Faktoren CTS und ADHS beeinflusst. Eine Post-hoc-Analyse zeigte, dass hypothesenkonform, wie in aktuellen Untersuchungsergebnissen zu dieser Frage beschreiben, ausschließlich Probanden mit isoliertem ADHS schlechtere Leistungen in den Bedingungen „Inkongruenz“ sowie Interferenzwert zeigen (Brand et. al., 2002, Channon et. al., 2003; Lavoie et. al 2007; Marsh et. al. 2007, Roessner et. al, 
2007a). Vermutet werden kann, dass das komorbide Auftreten von CTS und ADHS mit einer Verbesserung der Benennungsgeschwindigkeit der Druckfarbe von inkongruenten Farbwörtern führt sowie einen positiven Effekt auf die Interferenzneigung ausübt. Gleiche Aussagen lassen sich im Bezug auf die beiden Bedingungen "Wort lesen" und „Farbe benennen" treffen. Auch hier scheint der Faktor CTS protektiv zu wirken und eine Verbesserung der Leistungen im Stroop-Test hervorzurufen, was möglicherweise durch die erhöhte frontostriatale Aktivität bei CTS bedingt sein könnte (Serrien, Orth, Evans, Lees \& Brown, 2004; Marsh et. al., 2007). Diese Überaktivierung der kortikalen Frontalregion, welche sowohl in Tests zur exekutiven Funktionen, wie auch bei der Unterdrückung von Tics zu beobachten ist, scheint die bei ADHS bestehenden frontalen Defizite zu kompensieren (Pliska, Liotti \& Woldroff, 2000; Marsh et. al., 2007).

Die ausschließliche Beeinträchtigung der Probanden mit reinem ADHS erweitert die aktuell kontrovers diskutierten Ergebnisse bezüglich der bestehenden Defizite im Stroop-Test (Boonstra, Oosterlaan, Sergeant \& Buitleaar, 2005; van Mourik, et. al., 2005; Lansbergen et. al., 2007; Roessner, et. al., 2007b; Schwartz \& Verhaeghen, 2008). Möglicherweise verhindert die Komplexität des Stroop-Tests und die damit einhergehend hohe Anzahl einflussnehmender Faktoren auf die Ergebnisse, die Beschreibung eines klaren störungsspezifischen Ergebnisprofils.

\subsubsection{Der Computer-Stroop}

Die Analyse der Ergebnisse des Computer-Stroops verfolgte zwei Zielsetzungen. Zum Einen sollte ein Vergleich zwischen einem farbabhängigen sowie einem farbunabhängigen Test zur Interferenzkontrolle erfolgen, um den Einfluss der Farbdiskriminationsfähigkeit auf den Stroop-Test besser beurteilen zu können und zu prüfen, ob es Beeinträchtigungen bei der Bearbeitung des Computer-Stroops gibt, die nicht durch den generellen Aufbau des Stroops erklärbar sind. Zum Anderen sollte eine differenzierte Analyse der Interferenzkontrolle bei CTS, ADHS und CTS+ADHS ermöglicht werden. Hierfür wurden sowohl Reaktionszeiten sowie die Anzahl richtig bearbeiteter Items in den einzelnen Bedingungen erhoben. Da die Konfundierung der Ergebnisse durch den Ver- 
suchsaufbau mit Fehlerquellen wie Links/Rechts-Effekten nicht auszuschließen ist und somit neben den farbspezifische Einflüssen weitere miteinander konfundierende Merkmale Einfluss auf die Reaktionszeiten genommen haben könnten, wurde von einer farbspezifischen Auswertung auf Tastenebene Abstand genommen.

Insgesamt waren keine bedingungsabhängigen Reaktionszeitunterschiede bei richtig bearbeiteten Items festzustellen. Probanden mit CTS reagierten jedoch bei der Bearbeitung des Computer-Farb-Stroops und des Zahlen-Stroops unterschiedlich schnell. Bei Bestehen einer CTS zeigte sich hypothesenkonform eine schnellere Reaktion im Zahlen-Stroop als im Computer-Farb-Stroop. Darüber hinaus reagierten Probanden mit CTS, unabhängig von weiteren Faktoren, langsamer als Probanden ohne CTS in den Computerversionen des Stroops. Dies könnte erklärt werde durch die kompensatorische Überaktivität des Frontalhirns, die es Patienten mit CTS ermöglicht, Tics zu unterdrücken, sowie in Tests zu exekutiven Funktionen entsprechend einer Kontrollgruppe abzuschneiden (Pliska et. al., 2000; Marsh et. al., 2007). Dieser kompensatorische Effekt scheint jedoch zu Lasten der Reaktionszeit zu gehen, dabei aber zu einer Verbesserung der Ergebnisse im Sinne einer höheren Anzahl richtig bearbeiteter Stimuli beizutragen. Ein schlechteres Abschneiden der Probanden mit CTS, gemessen an der Anzahl richtiger Antworten, zeigte sich nämlich hypothesenkonform in der hier untersuchten Stichprobe nicht. Dieser scheinbar protektive Effekt einer komorbiden CTS auf Leistungen im Stroop Test wird darüber hinaus bei Betrachtung der Variabilität der Reaktionszeiten bei korrekter Antwortgabe sichtbar. Sowohl Kontrollprobanden als auch die Patienten mit komorbider Störung zeigten keine bedeutsame Reaktionszeitvariabilität, so dass auch hier ein gemeinsames Auftreten eher mit einer Stabilisierung der Reaktionszeiten einher zu gehen scheint.

Darüber hinaus zeigte sich im Computer-Farb-Stroop allgemein eine höhere Reaktionszeitvariabilität bei korrekt bearbeiteten Items im Computer-FarbStroop als im Zahlen-Stroop, welche durch die Kongruenz der Items moduliert wurde. Augenscheinlich geht die Bearbeitung des Computer-Farb-Stroops mit größeren Schwierigkeiten einhergeht als die Bearbeitung des Zahlen-Stroops. Diese vermehrte Schwierigkeit könnte im Zusammenhnag mit dem Stimulusma- 
terial und den damit verbunden Problemen bei der Verarbeitung von Farben zu finden sein.

Bei Probanden mit ADHS (ADHS allein sowie mit CTS) zeigte sich entgegen der Hypothese kein bedeutsamer Einfluss auf die Reaktionszeiten. Die Variabilität der Reaktionszeiten unterschied sich jedoch bedeutsam von der Reaktionszeitvariabilität der Probanden ohne ADHS. Darüber hinaus machten diese unabhängig von anderen Faktoren mehr Fehler bei der Bearbeitung des Computer-Stroops. Daher kann von einer weitgehenden Übereinstimmung der hier gefundenen Ergebnisse mit denen der Literatur, betreffend variablerer Reaktionszeiten sowie höhere Fehlerraten im Vergleich zu Kontrollprobanden bei Probanden mit ADHS gesprochen werden (z. B. Pennington et. al., 1996; Kuntsi, et. al., 2001; Sergeant, Geurts et. al., 2002).

Hypothesenkonform konnte bei allen Gruppen eine Interferenzneigung festgestellte werden, die sich in langsameren Reaktionszeiten oder mehr Fehlern in der inkongruenten Bedingung als in der kongruenten Bedingung manifestierte (Albrecht et. al., 2007). Darüber hinaus kam es zu einem nicht erwartungskonformen Ergebnis: Bei Probanden der Gruppe CTS (ohne komorbide Diagnose) sowie ADHS (ebenfalls ohne komorbide Diagnose) wurde sowohl im ZahlenStroop als auch im Computer-Farb-Stroop ein Stroop-Effekt festgestellt, welcher bei Kontrollprobanden und Probanden der komorbiden Gruppe lediglich beim Zahlen-Stroop auftrat.

Probanden mit ADHS allein, sowie Probanden mit CTS allein unterschieden sich dabei hinsichtlich des Stroop-Effekts im Farb-Stroops nicht voneinander, wohl aber von den Kontrollprobanden und der komorbiden Gruppe. Im ZahlenStroop zeigte sich diese stärkere Beeinträchtigung der isolierten Störungsgruppen nicht. Bezüglich ADHS steht dies im Einklang mit Ergebnissen von Lansbergen et. al. (2007).

Abschließend scheint hinsichtlich der Zielsetzungen dieser Arbeit im Zusammenhang mit dem Computer-Stroop folgendes festzuhalten zu sein: Die Bearbeitung des Stroop-Tests in Verbindung mit farbigem Stimulusmatial scheint für die Probanden schwieriger als die Bearbeitung eines farbunabhängigen StroopTests. Der Interferenzeffekt ist mit dem Stroop-Test gut zu erheben, sollte aber in Abhängigkeit vom Stimulusmaterial betrachtet werden. 
6.2.3 Beantwortung der Hypothesen zum Zusammenhang zwischen der Farbdiskriminationsfähigkeit und den Ergebnissen im Stroop

Ein bedeutsamer Zusammenhang zwischen der Farbwahrnehmung und Leistungen im klassischen Stroop konnte weder für das Vorhandensein von CTS noch für Kinder mit der Diagnose ADHS nachgewiesen werden. Die entsprechende Hypothese muss somit verworfen werden.

Eine Betrachtung des Einflusses der Farbdiskrimination auf Leistungen im Computer-Stroop zeigte hypothesenkonform einen signifikant positiven $\mathrm{Zu}$ sammenhang zwischen der Farbwahrnehmungsleistung sowie der Benennungsgeschwindigkeit in den Bedingungen „Farbe benennen“ und „Inkongruenz". Je weniger Fehler die Probanden insgesamt machten umso schneller reagierten sie in den genannten Bedingungen. Dies traf gleichermaßen für den Fehlerwert auf der Blau/Gelb-Achse und der Rot/Grün-Achse zu. Warum sich dieser Zusammenhang nicht ebenfalls beim klassischen Farb-Stroop zeigte, kann nur vermutet werden. Eine plausible Erklärung könnte darin zu finden sein, dass die Bestimmung der Bearbeitungszeit im klassischen Farb-Stroop durch den Versuchsleiter vorgenommen wurde und somit der Einfluss externer Variablen nicht ausgeschlossen werden kann. Die Reaktionszeiterhebung über die Computerdarbietung erscheint weniger störanfällig und stellt demnach das objektivere Messinstrument dar.

Der Stroop-Test könnte somit möglicherweise nicht ausschließlich die reine Interferenzleistung von Probanden abbilden, sondern ebenfalls einen, durch das Stimulusmaterial bedingten, farbwahrnehmungsabhängigen Leitungswert (Lang et. al., 2005; Albrecht et. al., 2007). 


\subsection{Beantwortung der Hypothese zu Modellvorstellung bei ADHS+CTS}

Die überzufällige Häufigkeit eines gemeinsamen Auftretens von ADHS und CTS hat zu einer Fülle von Hypothesen über die Beschaffenheit der Komorbidität beider Störungen geführt (Yordanova, Dumais-Huber \& Rothenberger, 1996; Yordanova, Dumais-Huber, Rothenberger \& Woerner, 1997; Roessner, Becker, Banaschewski \& Rothenberger, 2007c). Ob ADHS+CTS eine eigene Störungsentität darstellt, beide Störungsbilder sich additiv ergänzen und somit unabhängig voneinander erscheinen oder beide Modelle auf unterschiedlichen Ebenen zutreffen, ist bisher kontrovers diskutiert worden. Elektrophysiologische Untersuchungen bezüglich grundlegender Funktionen scheinen eher additive Modellvorstellungen zu unterstreichen (Moll et. al., 2001; Kirov et. al., 2007a; Kirov et. al., 2007b; Roessner et. al, 2007c), während Untersuchungen zu höheren kognitiven Prozessen eher das interaktive Modell stützen (Yordanova et. al., 1996; Yordanova et. al., 1997; Yordanova et. al., 2006). Diese Frage scheint insbesondere bei Betrachtung der Farbdiskrimination interessant, wird doch davon ausgegangen, dass eine hyperdopaminerge Transmissionstörung eine zentrale pathophysiologische Rolle der CTS spielt (Minzer et. al, 2004; Yoon et. al., 2007), bei ADHS aber eine hypodopaminerge Transmissionsstörung vorliegt (Sadile et. al., 2005).

Unterstützungen additiver Modellvorstellungen ergeben sich hypothesenkonform bei Betrachtung der Leistungen im Farnsworth-Munsell 100-hue-Test. Die in dieser Studie gefundenen Haupteffekten CTS und ADHS bei Abwesenheit von Interaktionseffekten betreffend aller Parameter (Gesamtfehlerwert, Fehlerwert Blau/Gelb-Achse, Fehlerwert Rot/Grün-Achse) stimmt überein mit Ergebnissen zu Psychopathologie (Rössner et. al., 2007 c), Schlaf (Kirov et. al., 2007 a, b), Neuropsychologyogie (Rössner et. al., 2007 b) und motorischer Inhibition (Moll et. al. 2001). Die Ergebnisse auf Gruppenebene unterstützten ebenfalls das additive Modell. Probanden mit isolierter Diagnose unterscheiden sich signifikant von der Kontrollgruppe in ihren Fehlerwerten, nicht aber untereinander. Probanden mit komorbider Diagnose machten bedeutsam mehr Fehler als Probanden mit isolierter Diagnose. 
Diese erhöhte Farbdiskriminationsschwäche bei Probanden mit ADHS+CTS im Vergleich zu Probanden mit den isolierten Störungsbildern CTS bzw. ADHS weist darüber hinaus in Richtung der diskutierte Annahme, dass eine stärkere Veränderung der dopaminergen Transmission, wie sie möglicherweise durch das Auftreten zweier Störungen vorliegt, mit einer stärkeren Beeinträchtigung in der Farbdiskrimination einhergehen könnte.

Des Weiteren würden die Annahme zweier, auf Ebene der Farbdiskrimination voneinander unabhängigen Störungen die oben formulierten Annahmen bezüglich hyper- sowie hypodopaminerger Transmission unterstützen.

Die Ergebnisse im klassischen Papier-Stroop stehen nicht im Einklang mit additiven Modellvorstellungen. Post-hoc-Analysen zeigten eine ausschließliche Beeinträchtigung der Probanden mit isoliertem ADHS, so dass anzunehmen ist, eine komorbide CTS führe zu einer Verbesserung der Leistungen in allen Stroop-Parametern (Brand et. al., 2002; Channon et. al., 2003; Lavoie et. al., 2007; Roessner et. al., 2007b).

Insbesondere interessant erscheint bei Betrachtung der Ergebnisse zum Stroop-Test sowie zur Farbdiskrimination der Umstand, dass eine komorbide Störung im Farbdiskriminationstest mit einer bedeutsamen Verschlechterung der Leistungen einher geht, im Stroop-Test jedoch zu einer Verbesserung der Leistungen führt. Der in dieser Studie gefundene positive Zusammenhang zwischen der Farbdiskriminationsleistung sowie den Stroop-Parametern „Farbe benennen" und "Inkongruenz" lässt die Bedeutung der kompensatorischen Mechanismen bei komorbidem Störungsvorkommen durch die erhöhte frontostriatale Aktivität in neuem Licht erscheinen (Marsh et. al. 2007).

Das psychopathologischen Profil, erhoben über die CBCL, unterstützt eher additive Modellvorstellungen zur Komorbidität von ADHS und CTS. Probanden mit ADHS waren tendenziell auf allen Skalen stärker beeinträchtigt als Probanden ohne ADHS. Interaktionseffekte zeigten sich dabei auf keiner der Skalen. Bei der CTS ergaben sich stärkere Beeinträchtigungen bezüglich der Skalenwerte "Schizoid/Zwanghaft" und „Angst/Depressivität", sowie ein Trend zu bedeutenderen „Aufmerksamkeitsproblemen“, Interaktionseffekten bleiben aus. Die in der Literatur beschriebene Ergebnisse zur Psychopathologie bei CTS und ADHS weisen in dieselbe Richtung (z. B. Rössner et. al., 2007 c). 
Die Ergebnisse der Verhaltensbeurteilung mit Hilfe der SDQ-Bögen sprechen hingegen gegen das additive Modell. Hier zeigten sich Interaktionseffekte auf den Skalen "Verhaltensprobleme“, „Hyperaktivität" und "Gesamtproblemwert", sowie ein Trend auf der Skala „Prosoziales Verhalten“.

Eine Analyse der Ergebnisse des Aufmerksamkeitstests FAIR ergab keine Interaktionen und unterstützt ebenfalls das additive Modell.

Die Ergebnisse scheinen demnach insgesamt auf das Vorliegen zweier verschiedener Modelle auf unterschiedlichen Störungsebene hinzuweisen. 


\subsection{Beantwortung der Fragen}

Die Untersuchung lässt, Bezug nehmend auf die oben formulierten Fragen, folgende Grundaussagen zu:

1. Kinder mit CTS und/oder ADHS sind in ihrer Farbwahrnehmungsleistung grundsätzlich beeinträchtigt. Eine größere Beeinträchtigung auf der Blau/Gelb-Achse lies sich für Probanden mit CTS (CTS allein und CTS+ADHS) nicht finden. Hinsichtlich des Faktors ADHS zeigte sich jedoch ein Trend in diese Richtung. Die komorbide Gruppe ist insgesamt in der Farbdiskriminationsleistung stärker beeinträchtigt als die isolierten Störungsgruppen.

2. Grundsätzlich geben die Untersuchungsergebnisse Hinweise auf eine Beeinflussung der Leistungen im Stroop-Test durch die Farbdiskriminationsfähigkeit. Dies zeigt sich in den signifikanten Korrelationen zwischen den einzelnen Parametern des Farnsworth-Munsell 100-hue-Tests und dem Computer-Stroop. Des Weiteren zeigen sich anhand der Variabilität in den Reaktionszeiten größere Schwierigkeiten bei der Bearbeitung des Computer-Farb-Stroops als bei der Bearbeitung des Zahlen-Stroops.

3. Ergebnisse zur Farbwahrnehmung, zum psychopathologisches Profil erhoben mit der $\mathrm{CBCL}$ und zur Aufmerksamkeitsleistung unterstützen additive Modellannahmen bei komorbidem ADHS und CTS. Ein Widerspruch auf psychopathologischer Ebene liefern Interaktionseffekte im SDQ. Die Ergebnisse im Stroop-Test stützen hingegen interaktive Störungsmodellvorstellungen. Insgesamt scheint demnach durch die vorliegende Untersuchung die Annahme unterstützt, dass interaktive sowie additive Modellvorstellungen zum komorbiden Auftreten bei ADHS und CTS auf unterschiedlichen Funktionsebenen zutreffen könnten. 


\subsection{Implikation der Ergebnisse für weitere Forschung}

Untersuchungen zum Zusammenhang zwischen Farbdiskriminationsleistungen auf der Blau/Gelb-Achse sowie Rot/Grün-Achse bei ADHS und CTS und der Schwere der Störung erscheinen unter den oben diskutierten Annahmen relevant. Darüber hinaus erscheint eine Analyse von CTS bzw. ADHS in Kombination mit anderen komorbiden Diagnosen interessant. Anhand eines solchen Designs könnten Einflüsse von hypo- bzw. hyperdopaminergen Transmissionsstörungen und spezifischen Farbdiskriminationsschwächen näher betrachtet werden.

Um den Einfluss medikamentöser Effekte auf die Leistungen im Farbdiskriminationstest gänzlich ausschließen zu können, wäre eine Überprüfung der Ergebnisse an einer Patientengruppe, die bisher keine medikamentöse Behandlung erfahren hat, nötig. 


\section{Zusammenfassung}

Ätiologisch sowie pathophysiologisch sind die Grundlagen der CTS sowie der ADHS noch kontrovers in der Diskussion. Die robustesten Befunde weisen bei beiden Störungsbildern auf einen pathophysiologischen Defekt im Bereich der Basalganglien, insbesondere des dopaminerg modulierten sensomotorischen kortiko-striato-thalamo-kortikalen Regelkreises hin. Bei der Verarbeitung von Farben sind ebenfalls dopaminerge Strukturen involviert. Diese Farbverarbeitung erscheint bei Störungen im dopaminergen System, insbesondere auf der Blau/Gelb-Achse, beeinträchtigt, was die Annahme einer gestörten Farbdiskrimination bei ADHS, CTS und deren Komorbidität nahe legte.

Die vorgelegte Studie mit Kinder mit ADHS, CTS, ADHS+CTS sowie Kontrollprobanden zeigt für Kinder mit der Diagnose CTS und/oder ADHS eine hoch bedeutsame Beeinträchtigung in der Diskrimination von Farben, jedoch nicht, wie vermutete ausschließlich bzw. besonders die Blau/Gelb-Achse betreffend. Des Weiteren wurde die Interferenzkontrolle sowie der Zusammenhang zwischen Farbwahrnehmung und Leistungen in einem auf farbigem Stimulusmaterial beruhenden Test (Stroop) untersucht. Die Ergebnisse zur Interferenzkontrolle stimmen dahingehend mit denen der Literatur überein, dass ausschließlich Probanden mit isoliertem ADHS schlechtere Leistungen in diesem Bereich aufweisen. Darüber hinaus fanden sich Hinweise auf einen Zusammenhang zwischen der Farbdiskriminationsleistung und Leistungen im Stroop-Test, die sich zum Einen in einer bedeutsamen Korrelation der Parameter und zum Anderen in größeren Schwierigkeiten in der Bearbeitung des Farb-Stroops als im ZahlenStroop zeigten.

Die Ergebnisse zur Farbwahrnehmung unterstützen die additiven Modellvorstellung zur Komorbidität von ADHS und CTS, Ergebnisse im Stroop liefern Hinweise auf das Zutreffen eines interaktiven Störungsmodells, so dass diese Untersuchung insgesamt eher Hinweise auf zwei unterschiedliche Modelle auf unterschiedlichen Ebenen lieferte. 


\section{Literaturverzeichnis}

Accili, D., Fishburn, C. S., Drago, J., Steiner, H., Lachowicz, J. E., Park, B.-H., Gauda, E. B., Lee, E. J., Cool, M. H., Sibley, D. R., Gerfen, C. R., Westphal, H. \& Fuchs, S. (1996). A target mutation of the $D_{3}$ dopamine receptor gene is associated with hyperactivity in mice. Proceedings of the National Academy of Sciences, 93, 1945-1949.

Achenbach, T. M. (1991a). Manual for the Child Behavior Checklist/4-18 and 1991 Profile. Burlington, VT: University of Vermont, Department of Psychiatry.

Achenbach, T. M. (1991b). Manual for the Teacher's Report Form \& 1991 Profile. Burlington, VT: University of Vermont, Department of Psychiatry.

Achenbach, T. M. (1991c). Manual for the Youth Self-Report \& 1991 Profile. Burlington, VT: University of Vermont, Department of Psychiatry.

Achenbach, T. M., Becker, A., Döpfner, M., Heiervang, E., Roessner, V., Steinhausen, H. C. \& Rothenberger, A. (2008). Multicultural assessment of child and adolescent psychopathology with ASEBA and SDQ instruments: research findings, applications, and future directions. Journal of Child Psychology and Psychiatry, 49, 251-275.

Ackermann, J. \& White, F. (1992). Decreased activity of rat A10 dopamine neurons following withdrawl from repeated cocaine. European Journal of Pharmacology, 218, 171-173.

Adams, J. R., Troiano, A. R. \& Calne, D. B. (2004). Functional imaging in Tourette`s syndrome. Journal of Neural Transmission, 111, 1495-1506.

Albrecht, B., Rothenberger, A. Sergeant, J., Tannock, R., Uebel, H. \& Banaschewski, T. (2007). Interference control in attentiondeficit/hyperactivity disorder: differential Stroop effects for colour-naming versus counting. Journal of Neural Transmission, 115, 241-247. 
Allain, H. Tessier, C., Bentue-Ferrer, D., Tarral, A., Le Braton, S., Gandon, M. \& Bouhours, P. (2003). Effects of risperidone on psychometric and cognitive functions in healthy elderly volunteers. Psychopharmacology, 164, 419-429.

Andersen, S. L. \& Teicher, M. H. (2000). Sex differences in dopamine receptors and their relevance to ADHD. Neuroscience and Biobehavioral Reviews, $24,137-141$.

Apter, A., Pauls, D. L., Bleich, A., Zohar, A. H., Kron, S., Ratzoni, G., Dycian, A., Kotler, M., Weizman, A., Gadot, N. \& Cohen, D. J. (1993). An epidemiological study of Gilles de la Tourette`s syndrome in Israel. Archives of General Psychiatry, 50, 734-738.

Azrin, N. H. \& Nunn, R. G. (1973). Habit reversal: a method of eliminating nervous habits and tics. Behaviour Research and Therapy, 11, 619-628.

Azrin, N. H. \& Peterson, A. L. (1990). Treatment of Tourette syndrome by habit reversal. Behavior Therapy, 21, 305-318.

Bäumler, G. (1985). Farbe-Wort-Interferenztest (FWIT) nach J. R. Stroop. Handanweisung. Hogrefe Verlag. Göttingen.

Bamber, D., Tamplin, A., Park, R. J., Kyte, Z. A. \& Goodyer, I. M. (2002). Development of a short leyton obsessional inventory for children and adolescents. Journal of the American Academy of Child and Adolescent Psychiatry, 41, 1246-1252.

Banaschewski, T. \& Rothenberger, A. (1998). Diagnostische Leitlinien und verhaltenstherapeutische Verfahren bei Tic-Störungen. Kindheit und Entwicklung, 7, 99-111.

Banaschewski, T. \& Rothenberger, A. (2003). Verhaltenstherapie bei TicStörungen. In F. Petermann (Hrsg.) (2003). Kinderverhaltenstherapie. (2. Aufl.). Hohengehren: Schneider Verlag.

Banaschewski, T., Roessner, V., Uebel, H. \& Rothenberger, A. (2004). Neurobiologie der Aufmerksamkeitsdefizit-/Hyperaktivitätsstörung (ADHS). Kindheit und Entwicklung, 13, 137-147. 
Banaschewski, T., Hollis, C., Oosterlaan, J., Roeyers, H., Rubia, K., Willcutt, E. \& Taylor, E. (2005). Towards an understanding of unique and shared pathways in the psychopathophysiology of AD/HD. Developmental Science, 8, 132-140.

Banaschewski, T., Ruppert, S., Tannock, R., Albrecht, B., Becker, A., Uebel, H., Sergeant, J. A. \& Rothenberger, A. (2006). Colour Perception in ADHD. Journal of Child Psychology and Psychiatry, 47, 568-572.

Banascheweski, T., Neale, B. M., Rothenberger, A. \& Roessner, V. (2007). Comorbidity of tic disorders and ADHD - conceptual and methodological consideration. European Child and Adolescent Psychiatry, 16, 5-14.

Bandelow, B. Heise, C. A., Banaschewski, T. \& Rothenberger, A. (2006). Handbuch Psychopharmaka für das Kindes- und Jugendalter. Hogrefe: Göttingen.

Barkley, R. A. (1997a). Attention-deficit hyperactivity disorder, self-regulation, and time: toword a more comprehensive theory. Journal of Developmental and Behavioral Pediatrics, 18, 271-279.

Barkley, R. A. (1997b). Behavioral inhibition, sustained attention, and executive functions: constructing a unifying theory of ADHD. Psychological Bulletin, 121, 65-94.

Barkley, R. A. (1998). Attention-deficit hyperactivity disorder: A handbook of diagnosis and treatment (2nd edition). New York: Guilford press.

Baumgaertel, A., Wolraich, M. \& Dietrich, M. (1995). Comparision of diagnostic criteria for attention deficit disorders in a German elemantary school sample. Journal of the American Academy of Child and Adolescent Psychiatry, 34, 629-638.

Becker, A., Hagenberg, N., Roessner, V., Woerner, W. \& Rothenberger, A. (2004). Evaluation of the self-reported SDQ in a clinical setting: do selfreports tell us more than ratings by adult informants? European Child and Adolescent Psychiatry, 13, 17-24. 
Becker, A., Woerner, W., Hasselhorn, M., Banaschewski, T. \& Rothenberger, A. (2004). Validation of the parent and teacher SDQ in a clinical sample. European Child and Adolescent Psychiatry, 13, 1-6.

Bedard, A.-C., Ickowicz, A. \& Tannock, R. (2002). Methylphenidate improves stroop naming speed, but not response interference, in children with Attention Deficit Hyperactivity Disorder. Journal of Child and Adolescent Psychopharmacology, 12, 301-309.

Biederman, J., Faraone, S. V., Keenan, K., Benjamin, J., Krifcher, B., Moore, C., Sprich-Buckminster, S., Ugaglia, K., Jellinek, M. S., Steingard, R., Spencer, T., Norman, D., Kolodny, R., Kruas, I., Perrin, J., Keller, M. B. \& Tsuang, M. T. (1992). Further evidence for family-genetic risk factors in attention deficit hyperactivity disorder. Patterns of comorbidity in probands and relatives of psychiatrically and pediatrically referred samples. Archives of General Psychiatry, 49, 728-738.

Birbaumer, N. \& Schmidt, R. F. (1999). Biologische Psychologie (4. Aufl.). Springer-Verlag.

Birleson, P. (1981). The validity of depressive disorder in childhood and the development of a self-rating scale: a research report. Journal of Child Psychology and Psychiatry, 22, 73-88.

Bodis-Wollner, I. \& Tagliati, M. (1993). The visual system in parkinson`s disease. Advances in Neurology, 60, 390-394.

Boonstra, A. M., Oosterlaan, J., Sergeant, J. A. \& Buitleaar, J. K. (2005). Executive functioning in adult ADHD: a meta-analytic review. Psychological Medicine, 35, 1097-1108.

Brand, N., Geenen, R., Oudenhoven, M., Lindenborn, B., van der Ree, A., Cohen-Kettenis, P. \& Buitelaar, J. K. (2002). Brief Report: Cognitive functioning in children with Tourette's Syndrome with and without comorbide ADHD. Journal of Pediatric Psychology, 27, 203-208. 
Braun, A. R., Stoetter, B., Randolph, C. R., Hasiao, J. K., Vladar, K., Gernert, J., Carson, R. E., Herscovitch, P. \& Chase, T. N. (1994). The functional neuroanatomy of Tourette's syndrome: an FDG-PET study. I. Regional changes in cerebral glucose metabolism differentiating patients and controls. Neuropsychopharmacology, 9, 277-291.

Brodeur, D. \& Andrade, B. (2002). Attentional control and children with ADHD. Canadian Psychology, 43, 113.

Brühl, B., Döpfner, M. \& Lehmkuhl, G. (2000). Der Fremdbeurteilungsbogen für hyperkinetische Störungen (FBB-HKS) - Prävalenz hyperkinetischer Störungen im Elternurteil und psychometrische Kriterien. Kindheit und Entwicklung, 9, 116-126.

Büttner, T., Schulz, S., Kuhn, W., Blumenschein, A. \& Przuntek, H. (1994). Impaired colour discrimination in Huntington's disease. European Journal of Neurology, 1, 153-157.

Büttner, T., Kuhn, W., Müller, T., Patzold, T., Heidbrink, K. \& Przuntek, H. (1995). Distorted color discrimination in 'de novo'parkinsonian patients. Neurology, 45, 386-387.

Burd, L., Kerbeshian, L., Wikenheiser, M. \& Fisher, W. (1986). Prevalence of Gilles de la Tourette's syndrome in North Dakota in school-age children. Journal of the American Academy of Child and Adolescent Psychiatry, 25, 552-553.

Bush, G., Frazier, J. A., Rauch, S. L., Seidman, L. J., Whalen, P. J., Jenike, M. A., Rosen, B. R. \& Biederman, J. (1999). Anterior cingulate cortex dysfunktion in attention-deficit/hyperactivity disorder revealed by $\mathrm{fMRI}$ and the Counting Stroop. Biological Psychiatry, 45, 1542-1552.

Calkins, D. J., Tsukamoto, Y. \& Sterling, P. (1998). Microcircuitry and mosaic of a blue-yellow ganglion cell in the primate retina. Journal of Neuroscience, 18, 3373-3385.

Calkins, D. J. (2001). Seeing with S-cones. Progress in retinal and eye research, 20, 255-287. 
Cardona, F., Romano, A., Bollea, L. \& Chiarotti, F. (2004). Psychopathological problems in children affected by tic disorders. Study on a large Italian population. European Child and Adolescent Psychiatry, 13, 166-171.

Carter, C., Krener, P., Chaderjian, M., Northcutt, C. \& Wolfe, V. (1995). Abnormal processing of irrelevant information in attention deficit hyperactivity disorder. Psychiatry Research, 56, 59-70.

Castellanos, F. X., Giedd, J. N., Marsh, W. L., Hamburger, S. D., Vaituzis, A. C., Dickstein, D. P., Sarfatti, S. E., Vauss, Y. C., Snell, J. W., Lange, N., Kaysen, D., Krain, A. L., Ritchie, G. F., Rajapakse, J. C. \& Rapoport, J. L. (1996). Quantative brain magnetic resonance imaging in attention-deficit hyperactivity disorder. Archives of General Psychiatry, 53, 607-616.

Castellanos, F. X., Giedd, J. N., Elia, J., Marsh, W. L., Ritchie, G. F., Hamburger, S. D. \& Rapoport, J. L. (1997). Controlled stimulant treatment of ADHD and comorbid Tourette's syndrome: effects of stimulants and dose. Journal of the American Academy of Child and Adolescent Psychiatry, 5, 589-596.

Castellanos, F. X., Lee, P. P., Sharp, W., Jeffries, N. O., Greenstein, D. K., Clasen, L. S., Blumenthal, J. D., James, R. S., Ebens, C. L., Walter, J. M., Zijdenbos, A., Evans, A. C., Giedd, J. N. \& Rapoport, J. L. (2002). Developmental trajectories of brain volume abnormalities in children and adolscents with attention-deficit/hyperactivity disorder. Journal of the American Medical Association, 288, 1740-1748.

Casey, B. J., Durston, S. \& Fossella, J. A. (2001). Evidence for a mechanistic moedel of cognitive control. Clinical Neuroscience Research, 1, 267-282.

Channon, S., Pratt, P. \& Robertson, M. M. (2003). Executive function, memory, and learning in Tourette`s syndrome. Neuropsychologyogy, 17, 247-254.

Chiang-Shan Ray Li, M. D., Hsueh-Ling Chang, M. D., Yuan-Pei Hsu, B. S., Huei-Shyong Wang, M. D. \& Nai-Chi Ko, B. S. (2006). Motor response inhibition in children with Tourette's syndrome. Journal of Neuropsychiatry and Clinical Neurosciences, 18, 417-419. 
Cohen, J. D., Leckman, J. F., Shaywitz, B. A. (1985). The Tourette Syndrome and other tics. In D. Shaffer (ed). The Clinical Guide to Child Psychiatry. The Free Press, London, New York.

Cohen, J. D., Dunbar, K. \& McClelland, J. L. (1990). On the control of automaticprocesses: aparallel distributed processing account of the Stroop effect. Psychological Review, 97, 332-361.

Cohen, A. I., Todd, R. D., Harmon, S. \& O`Malley, K. L. (1992). Photoreceptors of mouse retinas possess D4 receptors coupled to adenylate cyclise. Proceedings of the National Academy of Sciences of the United States of America, 89, 12093-12097.

Cohen, J. D. \& Leckman, J. F. (1994). Developmental psychopathology and neurobiology of Tourette's syndrome. Journal of the American Academy of Child and Adolescent Psychiatry, 33, 2-15.

Comings, B. D., Comings, D. E., Devor, E. J. \& Cloninger, C. G. (1984). Detection of major gene for Gilles de la Tourette Syndrome. American Journal of Human Genetics, 36, 586-600.

Comings, B. D. \& Comings, D. E. (1987). A controlled study of Tourette Syndrome. I. Attention-deficit disorder, learning disorders, and school problems. American Journal of Human Genetics, 41, 701-868.

Comings, D. E., Comings, B. G., Muhleman, D., Dietz, G., Shahbahrami, B., Tast, D., Knell, E., Kocsis, P., Baumgarten, R., Kovacs, B. W., Levy, D. L., Smith, M., Borison, R. L., Evans, D., Klein, D. N., MacMurray, J., Tosk, J. M., Sverd, J., Gysin, R. \& Flanagan, S. D. (1991). The dopamine $D_{2}$ receptor locus as a modifying neuropsychiatric disorders. Journal of the American Medical Association, 266, 1793-1800.

Comings, B. D. \& Comings, D. E. (1993). Comorbide behavioral disorders. In R. Kurlan (ed.), Handbook of Tourette's syndrome and Related Tic and Behavioral Disorders (S. 111-147). New York, Basel, Hong Kong: Marcel Dekker. 
Como, P. G. (2005). Neuropsychologyogical function in Tourette syndrome. In R. Kurlan (ed.), Handbook of Tourette's syndrome and Related Tic and Behavioral Disorders New York, Basel, Hong Kong: Marcel Dekker.

Cook, E. H., Stein, M. A., Krasowski, M. D., Cox, N. J., Olkon, D. M., Kieffer, J. E., \& Leventhal, B. L. (1995). Association at Attention-Deficit Disorder and the dopamine transporter gene. American Journal of Human Genetics, 56, 993-998.

Crognale, M. A. (2002). Development, maturation, and aging of chromatic visual pathways: VEP results. Journal of Vision, 2, 438-450.

Dacey, D. M. (1993) Morphology of a small field bistratified ganglion cell type in the macaque and human retina: Is it the blue-On cell? Visual Neuroscience, 10, 1081-1098.

Dacey, D. M. \& Lee, B. B. (1994). The blue-On opponent pathway in primate retina originates from a distinct bistratified ganglion cell type. Nature, 367, 731-735.

Daw, N. W., Brunken, W. J. \& Parkinson, D. (1989). The functions of synaptic transmission in the retina. Annual Review of Neuroscience, 12, 205-225.

Deeb, S. S. (2004). Molecular genetics of colour vision deficiences. Clinical and Experimental Optometry, 87, 224-229.

Deeb, S. S. (2005). The molecular basis of variation in human color vision. Clinical Genetics, 67, 369-377.

DeJong, W., Lindhorst, A. \& Versteeg, H. G. (1995). The nigrostriatal dopamine system and development of hypertension in the spontaneous hypertensive rat. Archives des Maladies du Coeur et des Vaisseaux, 88, 11931196.

Desai, P., Roy, M., Roy, A., Brown, S. \& Smelson, D. (1997). Impaired color vision in cocaine-withdrawn patients. Archives of General Psychiatry, 54, 696-699. 
Dilling, H., Mombour, M. \& Schmidt, M. H. (Hrsg.). (1993). Internationale Klassifikation psychischer Störungen - ICD-10, Kapitel V (F). Klinischdiagnostische Leitlinien (2. Aufl.). Bern: Huber.

Djamgoz, M. \& Wagner, H. (1992). Location und function of dopamine in the adult vertebrate Retina. Neurochemistry International, 20, 139-191.

Djamgoz, M. B. A., Hankins, M. W., Hirano, J. \& Archer, S. N. (1997). Neurobiology of retinal dopamine in relation to degenerative states of the tissue. Vision Research, 37, 3509-3529.

Döpfner, M. (1996). Behandlung eines Jugendlichen mit Tourette-Syndrome durch Reaktionsumkehr (habit reversal) und Verstärkerrückgabe (response-cost). Kindheit und Entwicklung, 5, 189-196.

Döpfner, M. (2000). Hyperkinetische Störungen. In P. Petermann, (Hrsg.), Lehrbuch der Klinischen Kinderpsychologie und -Psychotherapie (S. 151186) (4. Aufl.). Göttingen: Hogrefe.

Döpfner, M., Fröhlich, J. \& Lehmkuhl, G. (Hrsg.). (2000). Hyperkinetische Störungen. Leitfaden Kinder- und Jugendpsychotherapie. Göttingen: Hogrefe.

Döpfner, M. \& Lehmkuhl, G. (2003). Diagnostik-System für psychische Störungen im Kindes- und Jugendalter nach ICD-10 und DSM-IV (DISYPS-KJ) (2. Aufl.). Bern: Verlag Hans Huber.

Dougherty, D. D., Bonab, A. A., Spencer, T. J., Rauch, S. L., Madras, B. K. \& Fischman, A. J. (1999). Dopamine transporter density in patients with attention deficit hyperactivity disorder. Lancet, 354, 2132-2133.

Eapen, V., Pauls, D. L. \& Robertson, M. M. (1993). Evidence for autosomal dominant transmission in Tourette's syndrome - United Kingdom Cohort Study. British Journal of Psychiatry, 162, 593-596.

Eggers, C., Rothenberger, A. \& Berghaus, U. (1988). Clinical and neurobiological findings in children suffering from tic disease following treatment with tiapride. European Archives of Psychiatry and Neurological Science, 237, 223-229. 
Eidelberg, D., Moeller, J. R., Antonini, A., Kazumata, A., Dhawan, V., Budman, C. \& Feigin, A. (1997). The metabolic anatomy of Tourette`s syndrome. Neurology, 48, 927-934.

Enoch, J. M., Lakshminarayana, V., Itzhaki, A., Khamar, B. M., Landau, K., Lowe, T., Surendran, T. \& Comerford, J. (1991). Anomalous kinetic visual fields found in familiy members of patients with a confirmes diagnosis of Gilles de la Tourette Syndrome. Optometry and Vision Science, 68, 807812.

Erenberg, G., Cruse, R. P. \& Rothner, A. D. (1985). Gilles de la Tourette Syndrome: effects of stimulant drugs. Neurology, 35, 1346-1348.

Faraone, S. \& Biederman, J. (1994a). Genetics of attention deficit hyperactivity disorder. Child and Adolescent Psychiatric Clinics of North America, 3, 285-302.

Faraone, S. \& Biederman, J. (1994b). Is attention deficit hyperactivity disorder familial? Harvard Review of Psychiatry, 1, 271-287.

Faraone, S. V., Biederman, J., Chen, W. J., Milberger, S., Warburton, R. \& Tsuang, M. T. (1995). Genetic heterogenity in attention-deficit hyperactivity disorder (ADHD): gender, psychiatric comorbidity, and maternal ADHD. Journal of Abnormal Psychology, 104, 334-345.

Faraone, S. V. \& Biederman, J. (1998). Neurobiology of Attention-Deficit Hyperactivity Disorder. Biological Psychiatry, 44, 951-958.

Faraone, S. V., Biederman, J., Weiffenbach, B., Keith, T., Chu, M. P., Weaver, A., Spencer, T. J., Wilens, T. E., Frazier, J., Cleves, M. \& Sakai J. (1999). Dopamine D4 gene 7-repeat allele and Attention Deficit Hyperactivity Disorder. American Journal of Psychiatry, 156, 768-770.

Faraone, S. V., Doyle, A. E., Mick, E. \& Biederman, J. (2001). Meta-analysis of the assoiation between the 7-repeat allele of the dopamine $D_{4}$ receptor gene and Attention Deficit Hyperactivity Disorder. American Journal of Psychiatry, 158, 1052-1057. 
Farnsworth, D. (1943). The Farnsworth-Munsell 100-hue and dichotomous tests of color vision. Journal of the optical society of America, 33, 568-578.

Farnsworth, D. (Revised 1957). The Farnsworth-Munsell 100-hue test for the examination of color discrimination. Maryland: Munsell Color Company Inc, 1957.

Flowers, J. H., Warner, J. L. \& Polansky, M. L. (1979). Response and encoding factors in ignoring irrelevant information. Memory and Cognition, 7, 8694.

Freeman, R. D., Fast, D. K., Burd, L., Kerbeshian, J., Robertson, M. \& Sandor, P. (2000). An international perspective on Tourette syndrome: selected findings from 3500 individuals in 22 countries. Developmental Medicine and Child Neurology, 42, 436-447.

Freeman, R. and the Tourette Syndrome International Database Consortium (2007). Tic disorders and ADHD - answers from a world wide clinical data set of Tourette Syndrome. European Child and Adolescent Psychiatry, 16, 15-23.

Gegenfurtner, K. R. (2003). Cortical mechanisms of colour vision. Nature Reviews Neuroscience, 4, 563-572.

Gegenfurtner, K. R. \& Kiper, D. C. (2003). Colour vision. Annual Review of Neuroscience, 26, 181-206.

Geller, A. M. \& Hudnell, H. K. (1997). Critical issues in the use and analysis of the lanthony desturate color vision test. Neurotoxicologyogy and Teratology, 19, 455-465.

Gerjets, P., Graw, T., Heise, E., Westermann, R. \& Rothenberger, A. (2002). Handlungskontrolldefizite und störungsspezifische Zielintentionen bei der Hyperkinetischen Störung II: empirische Befunde. Zeitschrift für Klinische Psychologie und Psychotherapie, 31, 99-109. 
Giedd, J. N., Castellanos, X., Casey B. J., Kozuch, P., King, A. C., Hamburger, S. D. \& Rapoport, J. L. (1994). Quantitative morphology of the corpus callosum in Attention Deficit Hyperactivity Disorder. American Journal of Psychiatry, 151, 665-669.

Gill, M., Daly, G., Heron, S., Hawi, Z. \& Fitzgerald, M. (1997). Confirmation of association between Attention Deficit Hyperactivity Disorder and a dopamine transporter polymorphism. Molecular Psychiatry, 2, 311-313.

Goodman, R. (1997). The Strengths and Difficulties Questionnaire: A research note. Journal of Child Psychology and Psychiatry, 38, 581-586.

Goodman, R., Scott, S. \& Rothenberger, A. (1997). Kinderpsychiatrie kompakt. Steinkopf: Darmstadt.

Harnois, C. \& Paolo, T. D. (1990). Decreased dopamine in the retina of patients with Parkinson's disease. Investigative Ophthalmology and Visual Science, 31, 2473-2475.

Harris, E. L., Schuerholz, L. J., Singer, H. S., Reader, M. J., Brown, J. E., Cox, C., Mohr, J., Chase, G. A. \& Denckla, M. B. (1995). Executive funktion in children with Tourette syndrome and/or attention deficit hyperactivity disorder. Journal of the International Neuropsychologyogical Society, 1, 511-516.

Hart, W. M. (1987). Acquired dyschromatopsias. Surveys in Ophthalmology, 32, 10-32.

Haug, B. A., Kolle, R. U., Trenkwalder, C., Oertel, W. H. \& Paulus, W. (1995). Predominant affection of the blue cone pathway in Parkinson's disease. Brain, 118, 771-778.

Hoekstra, P. J., Anderson, G. M., Limburg, P. C., Kallenberg, C. G. M. \& Minderaa, R. B. (2004). Neurobiology and neuroimmunology of Tourette`s syndrome: an update. Cellular and Molecular Life Sciences, 61, 886-898.

Hofer, H., Carroll, J., Neitz, J., Neitz, M. \& Williams, D. R. (2005). Organisation of the human trichromatic cone mosaic. Journal of Neuroscience, 25, 9669-9679. 
Hood, D. C., Benimoff, N. I. \& Greenstein, V. C. (1984). The response range of the blue-cone pathways: a source of vulnerability to disease. Investigative Ophthalmology and Visual Science, 25, 864-867.

Horn, W. (1983). Leistungsprüfsystem. Handanweisung (2. Aufl.). Göttingen: Hogrefe.

Huber, A. \& Wildberger, H. (1991). Erkrankungen des Sehnervs. In J. Fronciase und F. Hollwich, Augenheilkunde in Klinik und Praxis: in 4 Bänden. Band 4. Stuttgart, New York: Thieme Verlag

Hyde, T. M., Aaronson, B. A., Randolph, C., Rickler, K. C. \& Weinberger, D. R. (1992). Relationship of birth weight to the phenotypic expression of Gilles de la Tourette's syndrome in monozygotic twins. Neurology, 42, 652-658.

Hyde, T. M., Stacey, M. E., Coppopla, R., Handel, S. F., Rickler, K. C. \& Weinberger, D. R. (1995). Cerebral morphometric abnormalities in Tourette syndrome: a quantitative MRI study of monozygotic twins. Neurology, 45, 1176-1182.

Iregren, A., Andersson, M. \& Nylon, P. (2002). Color vision and occopational chemical exposures: 1. An overview of tests and effects. Neurotoxicology, 23, 719-723.

Ishihara, S. The Series of Plates Disigned as a Test for Color-Blindness. 24 Plates. Kanehara Shuppan C., LTD. Tokyo; Japan.

Jensen, A. R. (1965). Scoring the Stroop test. Acta psychological (Amst), 24, 398-408.

Kadesjö, B. \& Gillberg, C. (2000). Tourette`s disorder: epidemiology and comorbidity in primary scholl children. Journal of the American Academy of Child and Adolescent Psychiatry, 39, 548-555.

Kadesjö, B. \& Gillberg, C. (2001). The comorbidity of ADHD in the general population of Swedish school-aged children. Journal of Child Psychology and Psychiatry, 42, 487-492. 
Karum, I., Egan, M. \& Wyatt, R. (1992). Selective reduction in dopamin turnover in the rat frontal cortex and hypothalamus during withdrawl from repeated cocaine exposure. European Journal of Pharmacology, 254, 127-132.

Khalifa, N. \& von Knorring, A. L. (2003). Prevalence of tic disorders and Tourette syndrome in a Swedish school population. Developmental Medicine and Child Neurology, 45, 315-319.

Khalifa, N. \& von Knorring, A. L. (2005). Tourette syndrome and other tic disorders in a total population of children: clinical assessment and background. Acta Paediatrica, 94, 1608-1614.

Khalifa, N. \& von Knorring, A. L. (2006). Psychopathology in a Swedish population of school children with tic disorders. Journal of the American Academy of Child and Adolescent Psychiatry, 45, 1346-1353.

Kinnear, P. R. \& Sahraie, A. (2002). New Farnsworth-Munsell 100 hue test norms of normal observers for each year of age 5-22 and for age decades 30-70. British Journal of Ophthalmology, 86, 1408-1411.

Kirov, R., Banaschewski, T., Uebel, H., Kinkelbur, J. \& Rothenberger, A. (2007a). REM-sleep alterations in children with co-existence of tic disorders and attention-deficit/hyperactivity disorder: impact of hypermotor symptoms. European Child and Adolescent Psychiatry, 16, 45-50.

Kirov, R., Kinkelbur, J., Banaschewski, T. \& Rothenberger, A. (2007b). Sleep patterns in children with attention-deficit/hyperactivity disorder, tic disorder and comorbidity. Journal of Child Psychology and Psychiatry, 48, 561-570.

Klasen, H., Woerner, W., Wolke, D., Meyer, R., Overmeyer, S., Kaschnitz, W., Rothenberger, A. \& Goodman, R. (2000) Comparing the German versions of the Strengths and Difficulties Questionnaire (SDQ-Deu) and the Child Behavior Checklist. European Child and Adolescent Psychiatry, 9, 271-276. 
Knoblauch, K., Saunders, F., Kusuda, M., Hynes, R., Podgor, M., Higgins, K. E. \& Monastero, F. M. (1987). Aged and illuminance effect in the Farnsworth-Munsell 100 hue test. Applied Optics, 26, 1441-1448.

Koschack, J., Kunert, H. J., Derichs, G., Weniger, G. \& Irle, E. (2003). Impaired and enhanced attentional function in children with attention deficit/hyperactivity disorder. Psychological Medicine, 33, 481-489.

Koyama, S., Kezuka, M., Hibino, H., Tomimitsu, H. \& Kawamura, M. (2006). Evaluation of cerebral dyschromatopsia using color afterimage. Neuroreport, 17, 109-113.

Krastel, H. \& Moreland, J. D. (1991). Color vision deficiencies in ophthalmic diseases. In J. R. Cronly-Dillon \& D. H. Foster (ed.). Vision and visual dysfunction: vol. 7; Inherited and aquired colour deficiencies (S. 115-172). Boca Raton, FL: CRC Press.

Krause, K. H., Dresel, S. H., Krause, J., Kung, H. F. \& Tatsch, K. (2000). Increased striatal dopamin transporter in adult patients with attention deficit hyperactivity disorder, effects of methylphenidate as measured by single photon emission computed tomography. Neurscience Letters, 285, 107110.

Krauskopf, J. \& Gegenfurther, K. R. (1992). Color discrimination and adaptation. Vision Research, 32, 2165-2175.

Krebeshian, J. \& Burt, L. (1992). Epidemiology and comorbidity. The North Dakota prevalence studies of Tourette syndrome and other developmental disorders. Advances in Neurology, 58, 67-74.

Kuntsi, J., Oosterlaan, J. \& Stevenson, J. (2001). Psychological mechanisms in hyperactivity: I. Response inhibition deficit, working memory impairment, delay aversion, or something else? Journal of Child Psychology and Psychiatry, 42, 199-210.

Kurlan, R., Como, P. G., Miller, B., Palumbo, D., Deeley, C., Andresen, E. M., Eapen, S. \& McDermott, M. P. (2002). The behavioral spectrum of tic disorders. A community-based study. Neurology, 59, 414-420. 
Kurylo, D. D., Corkin, S., Dolan, R. P., Risso, J. F. $3^{\text {rd }}$, Parker, S. W. \& Growdon, J. H. (1994) Broad-band visual capacities are not selectively impaired in Alzheimer's disease. Neurobiology of Aging, 15, 305-311.

Laeng, B., Lag, T. \& Brennen, T. (2005). Reduced Stroop interference for opponent colors may be due to input factors: evidence from individual differences and a neural network simulation. Journal of Experimental Psychology: Human Perception and Performance, 31, 438-452

Lansbergen, M. M., Kenemans, J. L. \& van Engeland, H. (2007). Stroop interference and attention-deficit/hyperactivity disorder: a review and metaanalysis. Neuropsychology, 21, 251-262.

Lavoie, M. E., Thibault, G., Stip., E. \& O'Conner K. P. (2007). Memory and executive functions in adults with Gilles de la Tourette syndrome and chronic tic disorder. Cognitive Neuropsychiatry, 12, 165-181.

Leckman, J. F., Petersen, B. S., Anderson, E. M., Arnsten, D. L., Pauls, D. L. \& Cohen, D. J. (1997). Pathogenesis of Tourette's sndrome. Journal of Child Psychology and Psychiatry, 38, 119-142.

Leckman, J. F. \& Cohen, D. J. (eds.) (1999). Tourette`s Syndrom - Tics, Obsessions, Compulsions : Developmental Psychopathology and Clinical Care. New York: John Wiley \& Sons.

MacLeod, C. M. (1991). Half a century of research on the Stroop effect: an integrative review. Psychological Bulletin, 109, 163-203.

Mariani, A. P. (1984). Bipolar cells in monkey retina selective for the cones likely to be blue-sensitive. Nature, 308, 184-186.

Marsh, R., Zhu, H., Wang, Z., Skudlarski, P. \& Peterson, B. S. (2007). A develpmental fMRI study of self-regulatory control in Tourette's syndrome. American Journal of Psychiatry, 164, 955-966.

Mason, A., Banerjee, S., Eapen, V., Zeitlin, H. \& Robertson, M. M. (1998). The prevalence of Tourette syndrome in a mainstream school population. Developmental Medicine and Child Neurology, 40, 292-296. 
Masson, G., Mestre, D. \& Blin, O. (1993). Dopaminergic modulation of visual sensitivity in man. Fundamental and Clinical Pharmacology, 7, 449-463.

Melun, J.-P., Morin, L. M., Muise, J. G. \& DesRosiers, M. (2001). Color vision deficiences in Gilles de la Tourette syndrome. Journal of the Neurological Sciences, 186, 107-110.

Milberger, S., Biederman, J., Faraone, S. V., Guite, J. \& Tsuang, M. T. (1997). Pregnancy, delivery and infancy complications and attention deficit hyperactivity disorder: issues of gene environment interaction. Biological Psychiatry, 41, 65-75.

Minzer, K., Lee, O., Hong, J. J. \& Singer, H. S. (2004). Increased prefrontal D2 protein in Tourette syndrome: a post-mortem analysis of frontal cortex and striatum. Journal of the Neurological Sciences, 219, 55-61.

Moll, G. H. \& Rothenberger, A. (1999). Nachbarschaft von Tic und Zwang. Nervenarzt, 70,1-10.

Moll, G. H., Heinrich, H., Trott, G.-E., Wirth, S., Bock, N. \& Rothenberger, A. (2001). Children with comorbid attention-deficit-hyperactivity disorder and tic-disorder: Evidence for additive inhibition deficits within the motor system. Annals of Neurology, 49, 393-396.

Moosbrugger, H. \& Oehlschlägel, J. (1996). FAIR, FrankfurterAufmerksamkeits-Inventar (1. Aufl.). Verlag: Hans Huber.

Müller, T., Kuhn, W., Büttner, T. \& Przuntek, H. (1997). Distorted colour discrimination in Parkinson's disease is related to severity of the disease. Acta Neurologica Scandinavica, 96, 293-296.

Müller, T., Woitalla, D., Peters, S., Kohla, K. \& Przuntek, H. (2002). Progress of visual dysfunction in Parkinson`s disease. Acta Neurologica Scandinavica, 105, 256-260.

Müller-Vahl, K. R., Berding, G., Kolbe, H., Meyer, G. J., Hundeshagen, H., Dengler, R., Knapp, W. H. \& Emrich, H. M. (2000). Dopamine $D_{2}$ receptor imaging in Gilles de la Tourette syndrome. Acta Neurologica Scandinavica, 101, 165-171. 
Mullen, K. \& Kingdom, F. A. A. (2002). Differential distributions of red-green and blue-yellow cone opponency across the visual field. Visual Neuroscience, 19, 109-118.

Mullen, K., Dumoulin, S. O., McMahon, K. L., de Zubicaray, G. I. \& Hess, R. F. (2007). Selectivity of human retinotopic visual cortex to S-cone-opponent, L/M-cone-opponent and achromatic stimulation. European Journal of Neuroscience, 25, 491-502.

Muresan, Z. \& Besharse, J. C. (1993). D2-like dopamine receptors in amphibian retina: localization with fluorescent ligands. Journal of Comparative $\mathrm{Neu}$ rology, 331, 149-160.

Newton, I. (1730). Opticks (4. Aufl.). London: William Innys. Reprint New York: Dover, 1995.

Nguyen-Legros, J., Simon, A., Caille, I. \& Bloch, B. (1997). Immunocytochemical localization of dopamin D1 receptors in the retina of mammals. Visual Neuroscience, 14, 545-551.

Nigg, J., Blaskey, L., Huang-Pollock, C. L. \& Rappley, M. D. (2002). Neuropsychologyogical executive functions and DSM-IV ADHD subtypes. Journal of the American Academy of Child and Adolescent Psychiatry, 41, 59-66.

Ozonoff, S., Strayer, D. L., McMahon, W. M. \& Filloux, F. (1998). Inhibitory deficits in Tourette syndrome: A function of comorbidity and symptome severity. Journal of Child Psychology and Psychiatry, 39, 1109-1118.

Pache, M., Smeets, C. H. W., Gasio, P. F., Savaskan, E., Flammer, J., WirzJustice, A. \& Kaiser, H. J. (2003). Colour vision deficiencies in Alzheimer's disease. Age and Ageing, 32, 422-426.

Pauls, D. L., Pakstis, A. J., Kurlan, R., Kidd, K. K., Leckman, J. F., Cohen, D. J., Kidd, J. R., Como, P. \& Sparkes, R. (1990). Segregation and linkage analyses of Tourette's syndrome and related disorders. Journal of the American Academy of Child and Adolescent Psychiatry, 29, 195-203. 
Pauls, D. L., Leckman, J. F. \& Cohen, D. J. (1993). Familial relationship between Gilles de la Tourette syndrome, attention deficit hyperactivity disorder, learning disabilities, speech disorder, and stuttering. Journal of the American Academy of Child and Adolescent Psychiatry, 32, 1044-1050.

Paulus, W., Schwarz, G., Werner, A., Lange, H., Bayer, A., Hofschuster, M., Müller, N. \& Zrenner, E. (1993). Impairment of retinal increment tresholds in Huntington`s Disease. Annals of Neurology, 34, 574-578.

Pennington, B. F. \& Ozonoff, S. (1996). Executive function and developmental psychopathology. Journal of Child Psychology and Psychiatry, 37, 51-87.

Peterson, B. S., Riddle, M. A., Cohen, D. J., Katz, L. D., Smith, J. C., Hardin, M. T. \& Leckman, J. F. (1997). Reduced basal ganglia volumes in Tourette's syndrome using threedimensional reconstruction techniques from magnetic resonance images. Neurology, 43, 941-949.

Peterson, B. S., Staib, L., Scahill, L., Zhang, H., Anderson, C., Leckman, J. F., Cohen, D. J., Gore, J. C., Albert, J. \& Webster, R. (2001). Regional brain and ventricular volumes in Tourette syndrome. Archives of General Psychiatry, 58, 427-440.

Peterson, B. S., Thomas, P., Kane, M. J., Scahill, L., Zhang, H., Bronen, R., King, R. A., Leckman, J. F. \& Staib, L. (2003). Basal ganglia volumes in patients with Gilles de la Tourette syndrome. Archives of General Psychiatry, 60, 415-424.

Pieri, V., Diederich, N. J., Raman, R. \& Goetz, C. G. (2000). Decreased color discrimination and contrast sensitivity in Parkinson`s disease. Journal of the Neurological Sciences, 172, 7-11.

Pliska, S. R., Liotti, M. \& Woldroff, M. G. (2000). Inhibitory control in children with attention-deficit/hyperactivity disorder: event-related potentials identify the processing component and timing of an impaired right-frontal response-inhibition mechanism. Biological Psychiatry, 48, 238-246.

Pokorny, J., Smith, V. C. \& Lutze, M. (1987). Aging of the human lens. Applied Optics, 26, 1437-1440. 
Price, R. A., Kidd, K. K., Cohen, D. J. \& Leckman, J. F. (1985): A twin study of Tourette syndrome. Archives of General Psychiatry, 42, 815-820.

Reis, R. A. M., Ventura, A. L. M., Kubrusly, R. C. C., de Mello, M. C. F. \& de Mello, F. G. (2007). Dopaminergic signaling in the developing retina. Brain Researchearch Reviews, 54, 181-188.

Riederer, F., Stamenkovic, M., Schindler, S. D. \& Kasper, S. (2002). Das Tourette-Syndrom. Eine Übersicht. Nervenarzt, 73, 805-819.

Rizzo, R., Gulisano, M., Pavone, P., Fogliari, F. \& Robertson, M. M. (2006). Increased antistreptococcal antibody titers and anti-basal ganglia antibodies in patients with Tourette syndrome: controlled cross-sectional study. Journal of Child Neurology, 21, 747-53.

Robertson, M. M. \& Stern, J. S. (2000). Gilles de la Tourette syndrome: symptomatic treatment based on evidence. European Child and Adolescent Psychiatry, 9, 60-75.

Robertson, M. M. (2006). Attention deficit hyperactivity disorder, tics and Tourette's syndrome: the realtionship and treatment implications. A commentary. European Child and Adolescent Psychiatry, 15, 1-11.

Roessner, V., Banaschewski, T. \& Rothenberger, A. (2006). Neuropsychologyogie bei ADHS und Tic-Störungen - eine Follow-up-Untersuchung. Praxis der Kinderpsychologie und Kinderpsychiatrie, 55, 314-327.

Roessner, V., Becker, A., Banaschewski, T., Freeman, R. D. \& Rothenberger, A. (2007a). Developmental psychology of children and adolescent with Tourette syndrome - impact of ADHD. European Child and Adolescent Psychiatry, 16, 24-35.

Roessner, V., Becker, A., Banaschewski, T. \& Rothenberger, A. (2007b). Executive functions in children with chronic tic disorder with/without ADHD new insights. European Child and Adolescent Psychiatry, 16, 36-44. 
Roessner, V., Becker, A., Banaschewski, T. \& Rothenberger, A. (2007c). Psychopathological profile in children with chronic tic disorder and coexisting ADHD: additive effects. Journal of Abnormal Child Psychology, 35, 79-85.

Roman, T., Schmitz, M., Polanczky, G., Eizirik, M., Rohde, L. A. \& Hutz, M. H. (2001). Attention-deficit hyperactivity disorder: a study of association with both the dopamine transporter gene and the dopamin D4 receptor gene. American Journal of Medical Genetics, 105, 471-478.

Rosenthal, R. (1991). Meta-analysis: a review. Psychosomatic Medicine, 53, 247-271.

Rothenberger, A. (1990). Behandlung von Tic-Störungen bei Kindern. Verhaltenstherapeutische Aspekte. Praxis der klinischen Verhaltensmedizin und Rehabilitation, 9, 16-21.

Rothenberger, A. (1991). Wenn Kinder Tics entwickeln. Stuttgart: Fischer

Rothenberger, A. (1993). Fragen und Antworten zum Tourette-Syndrom. Eine Information der Tourette-Gesellschaft Deutschland.

Rothenberger, A. (1994). Neurobiology and drug treatment of Tourette's syndrome and other tic disorders. European Neuropsychopharmacology, 4, 245-247.

Rothenberger, A., Wörner, W., Dumais-Huber, C., Moll, G. H., Röhrkohl, N. \& Yordanova, Y. (1994). Welche Bedeutung haben Merkmale des Hyperkinetischen Syndroms bei Kindern mit Tic-Störungen? In H. Todt \& D. Heinicke (Hrsg.), Aktuelle Neuropädiatrie (S. 52-71). Wehr: Ciba-Geigy Verlag.

Rothenberger, A. (1996). Tourette-Syndrom und assoziierte neuropsychiatrische Auffälligkeiten. Zeitschrift für Klinische Psychologie und Psychotherapie, 25, 259-279. 
Rothenberger, A. \& Banaschweski, T. (2001). Diagnose und Behandlung von Tourette Syndrom und anderen Tic-Störungen. Arbeitsgemeinschaft Medizinischer Fachgesellschaften (AWMF). Leitlinien für Diagnostik und Therapie der deutschen Gesellschaft für Kinder- und Jugendpsychiatrie, psychotherapie (DGKJPP). Internet.

Rothenberger, A., Kostanecka, T., Kinkelbur, J., Cohrs, S. Wörner, W. \& Hajak, G. (2001). Sleep and Tourette Syndrome. Advances in Neurology, 85, $245-259$.

Rothenberger, A., Banaschewski, T. \& Siniatchkin, M. (2002). Tic-Störungen. In B. M. Herpertz-Dahlmann, F. Resch, M. Schulte-Markwort, A. Warnke (Hrsg.) Entwicklungspsychiatrie (S. 548-569). Schattauer-Verlag, Stuttgart.

Rothenberger, A. \& Wörner, W. (2004). Strengths and Difficulties Questionnaire (SDQ) - Evalutions and applications. European Child and Adolescent Psychiatry, 13, 1-2.

Rothenberger, A., Roessner, V., Banaschewski, T. \& Leckman, J. F. (2007). Co-existence of tic disorders and attention deficit/hyperactivity disorder recent advances in understanding and treatment. European Child and Adolescent Psychiatry, 16, 1-4.

Roy, M., Roy, A., Williams, J., Weinberger, L. \& Smelsen, D. (1996a). Reduced blue cone electroretinogram in cocaine-withdrawn patients. Archives of General Psychiatry, 54, 153-156.

Roy, M., Smelson, D. \& Roy, A. (1996b). Abnormal electroretinogram in cocain dependent patients: relationships to craving. British Journal of Psychiatry, 168, 507-511.

Roy, M., Smelson, D. \& Roy, A. (1997). Longitudinal study of blue cone retinal function in cocaine withdrawn patients. Biological Psychiatry, 41, 252253.

Ruppert, S. (2005). Beeinträchtigung der Farbdiskrimination bei Kindern mit Aufmerksamkeitsdefizit-/Hyperaktivitsstörung (ADHS). Dissertation. 
Russell, V., de Villiers, A., Sagvolden, T., Lamm, M. \& Taljaard, J. (1995). Altered dopaminergic function in the prefrontal cortex, nucleus accumbens and caudate-putamen of an animal model of attention-deficit hyperactivity disorder. Brain Research, 676, 343-351.

Sadile, A. G. \& Viggiano, D. (2005). Is the hypodopaminergic hypothesis plausibile as a neural basis of ADHD? Behavioral and Brain Sciences, 28, 440441.

Sagvolden, T., Johansen, E. B., Aase, H. \& Russell, V. (2005). A dynamic developmental theory of attention-deficit/hyperactivity disorder (ADHD) predominantly hyperactive/impulsive and combined subtypes. Behavioral and Brain Sciences, 28, 397-419.

Salomon, S. G. \& Lennie, P. (2007). The machinery of colour vision. Nature Reviews Neuroscience, 8, 276-86.

Sartucci, F. \& Porciatti, V. (2006) Visual-evoked potentials to onset of chromatic red-green and blue-yellow gratings in Parkinson`s disease never treated with L-dopa. Journal of Clinical Neurophysiology, 23, 431-435.

Saß, H., Wittchen, H.-U. \& Zaudig, M. (Hrsg.) (1996). Diagnostisches und statistisches Manual Psychischer Störungen DSM-IV. Göttingen: Hogrefe.

Scheres, A., Oosterlaan, J., Geurt, H., Morein-Zamir, S., Meiran, N., Schut, H., Vlasveld, L. \& Sergeant, J. A. (2004). Executive functioning in boys with ADHD: primarily an inhibition deficit? Archives of Clinical Neuropsychology, 19, 569-594.

Schmidt, R., Lang, F. \& Thews, G. (2004). Physiologie des Menschen. (29. Aufl.). Springer Verlag.

Scholz, A. \& Rothenberger, A. (2001). Mein Kind hat Tics und Zwänge. Verlag: Vandenhoeck und Ruprecht.

Schott, B. H., Niehaus, L., Wittmann, B. C., Schütze, H., Seidenbecher, C. I., Heinze, H. J. \& Düzel, E. (2007). Ageing and early-stage Parkinson's disease affect separable neural mechanisms of mesolimbic reward processing. Brain, 130, 2412-2424. 
Schwartz, K. \& Verhaeghen, P. (2008). ADHD and Stroop interference from age 9 to age 41 years: a meta-analysis of develpomental effects. Psychological Medicine, 29, 1-10.

Seidman, L. J., Biederman, J., Faraone, S. V., Milberger, S., Norman, D., Seiverd, K., Benedict, K., Guite, J., Mick, E. \& Kiely, K. (1995). Effects of family history and comorbidity on the Neuropsychologyogical performance of children with ADHD: Preliminary findings. Journal of the American Academy of Child and Adolescent Psychiatry, 34, 1015-1024.

Semrud-Clikeman, M., Guy, K., Griffin, J. D. \& Hynd, G. W. (2000). Rapid naming deficits in children and adolescents with reading disabilities and attention deficit hyperactivity disorder. Brain and Language, 74, 70-83.

Sergeant, J. A., Geurts, H. \& Oosterlaan, J. (2002). How specific is a deficit of executive functioning in Attention-Deficit/Hyperactivity Disorder? Behavioral Brain Research, 130, 3-28.

Sergeant, J. A., Geurts, H., Huijbregts, S., Scheres, A. \& Oosterlaan, J. (2003). The top and the bottom of ADHD: a Neuropsychologyogical perspective. Neuroscience and Biobehavioral Reviews, 27, 583-592.

Serrien, D. J., Orth, M., Evans, A. H., Lees, A. J. \& Brown, P. (2004). Motor inhibition in patients with Gilles de la Tourette syndrome: functional activation patterns as revealed by EEG coherence. Brain, 128, 116-125.

Seuchter, S. A., Hebebrand, J., Klug, B., Knapp, M., Lehmkuhl, G., Poustka, F, Schmidt, M., Remschmidt, H. \& Baur, M. P. (2000). Complexe segregation analysis of families ascertained throught Gilles de la Tourette syndrome. Genetic Epidemiology, 18, 33-47.

Shapiro, A. K., Shapiro, E. S., Young, J. G., Feinberg, T. E. (1988). Gilles de la Tourette Syndrome. Raven Press, New York.

Shapiro, A. K, Shapiro, E. S, Fulop, G., Hubbard, M., Mandeli, J., Nordile, J. \& Phillips, R. A. (1989). Controlled studys of haloperidol, pimozide and placebo for the treatment of Gilles de la Tourette's syndrome. Archives of General Psychiatry, 46, 722-730. 
Sharanjeet-Kaur, S., Mursyid, A., Kamaruddin, A. \& Ariffin, A. (2004). Effects of petroleum derivatives and solvents on color perception. Clinical and Experimental Optometry, 87, 339-343.

Shepherd, A. J. (2005). Colour vision in migraine: selective deficits for S-cone discrimination. Cephalalgia, 25, 412-423.

Shepherd, A. J. (2006). Color vision but not visual attention is altered in migraine. Headache, 46, 611-621.

Shuwairi, S. M., Cronin-Golomb, A., McCarley, R. W. \& O'Donnell, B. F. (2002). Color discrimination in schizophrenia. Schizophrenia Research, 55, 197204.

Singer, H. S. \& Walkup, T. W. (1991). Tourette syndrome and other tic disorders. Diagnosis, pathophysiology and treatment. Medicine, 70, 15-32.

Singer, H. S. (1997). Neurobiology of Tourette syndrome. Neurologic Clinics, 15, 357-379.

Singer, H. S., Hahn, I.-H. \& Moran, T. H. (1991). Abnormal dopamine uptake sites in postmortem striatum from patients with Tourette`s syndrome. Annals of Neurology, 30, 558-562.

Singer, H. S. \& Minzer, K. (2003). Neurobiology of Tourette`s syndrome: concepts of neuroanatominc localization and neurochemical abnormalities. Brain and Development, 25, 70-84.

Smith, V. C., Pokorney, J. \& Pass, A. S. (1985). Color-axis determination on the Farnsworth-Munsell 100-hue test. American Journal of Ophthalmology, $100,176-82$.

Smith, K. M., Daly, M., Fischer, M., Yiannoutsos, C. T., Bauer, L., Barkley, R. \& Navia, B. A. (2003). Association of the dopamine beta hydroxylase gene with attention deficit hyperactivity disorder: Genetic analysis of the Milwaukee longitudinal study. American Journal of Medical Genetics B Neuropsychiatr Genet, 119, 77-85. 
Smith, C. P., Sharma, S. \& Steinle, J. J. (2007). Age-related changes in sympathetic neurotransmission in rat retina and choroid. Experimental Eye Research, 84, 75-81.

Snider, L. A, Seligman, L. D., Ketchen, B. R, Levitt, S. J., Bates, L. R., Garvey, M. A. \& Swedo, S.E. (2002). Tics and problem behaviors in schoolchildren: Prevalence, characterisation, and assoziations. Pediatrics, 110, 331-336.

Spalletta, G., Pasini, A., Pau, F., Guido, E., Menghini, L. \& Caltagirone, C. (2001). Prefrontal blood flow disregulation in drug naive ADHD children without structural abnormalities. Journal of Neural Transmission, 108, 1203-1216.

Spencer, T., Biederman, J., Harding, M., O’Donnell, D., Wilens, T., Faraone, S. Coffey, B. \& Geller, D. (1998) Disentangling the overlap between Tourette's disorder and ADHD. Journal of Child Psychology and Psychiatry, 39, 1037-1044.

Steinhausen, H. C., Novik, T. S., Baldursson, G., Curatolo, P., Lorenzo, M. J., Rodrigues Pereira, R., Ralston, S. J. \& Rothenberger, A. (2006). Coexisting psychiatric problems in ADHD in the ADORE cohort. European Child and Adolescent Psychiatry, 15, 25-29.

Stern, E., Silbersweig, D. A., Chee, K. Y., Holmes, A., Robertson, M. M., Trimble, M., Frith, C. D., Frackowiak, R. S. \& Dolan, R. J. (2000). A functional neuroanatomy of tics in Tourette syndrome. Archives of General Psychiatry, 57, 741-748.

Stewart, S. E., Illmann, C., Geller, D. A., Leckman, J. F., King, R. \& Pauls, D. L. (2006). A controlled familiy study of attention-deficit/hyperaktivity disorder and Tourette's disorder. Journal of the American Academy of Child and Adolescent Psychiatry, 45, 1354-1362.

Stroop, J. R. (1935): Studies of interference in serial verbal reactions. Journal of Experimental Psychology, 18, 643-662. 
Suzuki, T.-A., Yi, Q., Sakuragawa, S., Tamura, H. \& Okajima, K. (2005). Comparing the visibility of low-contrast color Landold Cs-effect of aging human lens. Color Research and Application, 30, 5-12.

Suzuki, T.-A., Yi, Q., Sakuragawa, S., Tamura, H. \& Okajima, K. (2006). Agerealted changes of reaction time and p300 for low-contrast color stimuli: effects of yellowing of the aging human lens. Journal of Physiological Anthropology, 25, 179-187.

Swanson, J. M., Seargent, J. A., Taylor, E., Sonuga-Barke, E. J. S., Jensen, P. J. \& Cantwell, D. P. (1998). Attention-deficit hyperactivity disorder and hyperkinetric disorder. Lancet, 351, 429-433.

Swanson, J. M., Flodman, P., Kennedy, J., Spence, M. A., Moyzis, R., Schuck, S., Murias, M., Moriarity, J., Barr, C., Smith, M. \& Posner, M. (2000). Dopamine genes and ADHD. Neurosciences and Behavioral Reviews, 24, 21-25.

Swedo, S. E., Leonard, H. L., Garvey, M., Mittelma, B., Allen, A. J., Perlmutter, S., Lougee, L., Dow, S., Zamkoff, J. \& Dubbert, B. D. (1998). Pediatric autoimmune neuropsychiatric disordes associated with streptococcal infections: Clinical description of the first 50 cases. American Journal of Psychiatry, 155, 264-271.

Tannock, R., Martinussen, R. \& Frijters, J. (2000). Naming speed performance and stimulant effects indicate effortful, semantic processing deficits in Attention/Deficit-Hyperactivity Disorder. Journal of Abnormal Child Psychology, 28, 237-252.

Tannock, R., Banaschewski, T. \& Gold, D. (2006). Color naming deficits and attention-deficit/hyperactivity disorder: A retinal dopaminergic hypothesis. Behavioral and Brain Functions, 2, 1-8.

Taylor, E., Sergeant, J., Döpfner, M., Gunning, B., Overmeyer, S., Mobius, H. J. \& Eisert, H. G. (1998). Clinical guidelines for hyperkinetic disorder. European Society for Child and Adolescent Psychiatry. European Child and Adolescent Psychiatry, 7, 184-200. 
Taylor, E., Döpfner, M., Sergeant, J., Asherson, P., Banaschewski, T., Buitlaar, J., Coghill, D., Dankaerts, M., Rothenberger, A., Sonuga-Barke, E., Steinhausen, H. C. \& Zuddas, A. (2004). European clinical guidelines for hyperkinetic disorder - first upgrade. European Child and Adolescent Psychiatry, 13, 7-30.

Teive, H. A. G., Germiniani, F. M. B., Coletta, M. V. D. \& Werneck, L. C. (2001). Tics and tourette syndrome. Clinical evaluation of 44 cases. Arquivos de Neuro-Psichiatria, 59, 725-728.

The Tourette Syndrome Association International Consortium for Genetics (1999). A complete genom screen in sib pairs affected by Gilles de la Tourette syndrome. American Journal of Human Genetics, 65, 14281436.

Till, C., Westall, C. A., Rovet, J. K. \& Koran, G. (2001). Effects of maternal occupation exposure to organic solvents on offspring visual functioning: $A$ prospective controlled study. Tetratology, 64, 134-141.

Quist, J. F., Barr, C. L., Schachar, R., Roberts, W., Malone, M., Tannock, R., Basile, V. S., Beitchman, J. \& Kennedy, J. L. (2003). The serotonin 5 HT1 B receptor gene and attention defecit hyperactivity disorder. Molecular Psychiatry, 8, 98-102.

van Boxtel, M. P., ten Tusscher, M. P., Metsemakers, J. F., Willems, B. \& Jolles, J. (2001). Visual determinants of reduced performance on the Stroop color-word test in normal aging individuals. Journal of Clinical and Experimental Neuropsychology, 23, 620-627.

van Mourik, R., Oosterlaan, J. \& Sergeant, J. A. (2005). The Stroop revisited: a meta-analysis of interference control in AD/HD. Journal of Child Psychology and Psychiatry, 46, 150-165.

Veruki, M. L. \& Wässle, H. (1996). Immunohistochemical localization of dopamine D1 rezeptors in rat retina. European Journal of Neuroscience, 8 , 2286-2297. 
Vloet, T. D., Neufang, S., Herpertz-DahImann, B. \& Konrad, K. (2006). Bildgebungsbefunde bei Kindern und Jugendlichen mit ADHS, Tic-Störungen und Zwangserkrankungen. Zeitschrift für Kinder- und Jugendpsychiatrie und Psychotherapie, 34, 343-355.

Walker, Q. D., Rooney, M. B., Wightman, R. M. \& Kuhn, C. M. (2000). Dopamine release and uptake are greater in female than in male rat striatum as measured by fast cyclic voltammetry. Neuroscience, 95, 1061-1075.

Weale, R. A. (1988). Age and transmittance of the human crystalline lens. Journal of Physiology, 395, 577-587.

Weiß, R. H. (1998). Grundintelligenztest Skala 2; CFT 20. Handanweisung (4. Aufl.) Göttingen: Hogrefe.

Weiß, R. H. \& Osterland, J. (1997). Grundintelligenztest Skala 1; CFT 1. Handanweisung für die Durchführung, Auswertung und Interpretation (5. Aufl.). Göttingen: Hogrefe

Wieczerkowski, W., Nickel, H., Janowski, A., Fittkau, B. \& Rauer, W. (1981). Angstfragebogen für Schüler (AFS) (6. Aufl.). Göttingen: Westermann.

Wijk, H. \& Sivik, L. (1995). Some aspects of colour perception among patients with Alzheimer disease. Scandinavian Journal of Caring Sciences, 9, 3-9

Wijk, H., Berg, S., Sivik, L. \& Steen, B. (1999). Colour discrimination, colour naming and colour preference among individuals with Alzheimer Disease. International Journal of Geriatric Psychiatry, 14, 1000-1005.

Willcutt, E. G., Pennington, B. F., Boada, R., Ogline, J. S., Tunick, R. A., Chabildas, N. A. \& Olson, R. K. (2001). A comparison of the cognitive deficits in reading disability and attention-deficit/hyperactivity disorder. Journal of Abnormal Psychology, 110, 157-172.

Witkovsky, P. (2004). Dopamin and retinal function. Ducumenta Ophthalmologica, $108,17-40$ 
Woerner, W., Becker, A., Friedrich, C., Klasen, H., Goodman, R. \& Rothenberger, A. (2002). Normierung und Evaluation der deutschen Elternversion des Strengths and Difficulties Questionnaire (SDQ): Ergebnisse einer repräsentativen Felderhebung. Zeitschrift für Kinder- und Jugendpsychiatrie und Psychotherapie, 30, 105-112.

Wright, I., Waterman, M., Prescott, H. \& Murdoch-Eaton, D. (2003). A new Stroop-like measure of inhibitory function development: typical developmental trends. Journal of Child Psychology and Psychiatry, 44, 561-575.

Yoon, D. Y., Gause, C. D., Leckman, J. F. \& Singer, H. S. (2007). Frontal dopaminergic abnormality in Tourette syndrome: apostmortem analysis. Journal of the Neurological Sciences, 255, 50-56.

Yordanova, J., Dumais-Huber, C. \& Rothenberger, A. (1996). Coexistence of tics and hyperactivity in children: no additive effect at the psychophysiological level. International Journal of Psychophysiology, 21, 121-133.

Yordanova, J., Dumais-Huber, C., Rothenberger, A. \& Woerner, W. (1997). Frontocortical activity in children with comorbidity of tic disorder and attention-deficit hyperactivity disorder. Biological Psychiatry, 41, 585-594.

Yordanova, J., Heinrich, H., Kolev, V. \& Rothenberger, A. (2006). Increased event-related theta activity as a psychophysiological marker of comorbidity in children with tics and attention-deficit/hyperactivity disorders. Neuroimage, 32, 940-955.

Ziemann, U., Paulus, W. \& Rothenberger, A. (1997). Decreased motor inhibition in Tourette's disorder: Evidence from transcranial magnetic stimulation. American Journal of Psychiatry, 154, 1277-1284. 


\section{Anhang}

Abkürzungen

Tabellenverzeichnis

Abbildungsverzeichnis

Erklärung

Lebenslauf 


\section{Abkürzungsverzeichnis}

ADHS

AFS

CBCL/4-18

CFT

CGL

CTS

DSM-IV

DISYPS-KJ

Aufmerksamkeits-Defizit/Hyperaktivitäts-Störung

Angstfragebogen für Schüler

Child Behavior Checklist

Culture Fair Test

Corpus geniculatum laterale

chronische Tic-Störung

Diagnostisches und statistisches Manual Psychischer Störungen

Diagnostiksystem zur Erfassung psychischer Störungen bei Kindern und Jugendlichen

FAIR

Frankfurter Aufmerksamkeits-Inventar

fMRI

funktionelle Magnetresonanztomographie

FMT

Farnsworth-Munsell 100-hue-Test

GABA

Gamma-Amino-Buttersäure

ICD-10

Internationale Klassifikation psychischer Störungen

IQ

Intelligenzquotient

$\mathrm{nm}$

Nanometer

M

Mittelwert

$\mathrm{N}$

Anzahl

$\mathrm{KI}$

Konfidenzintervall

KON

Kontrollen

LPS

Leistungsprüfsystem

PET

Positronenemissionstomograpie

SD

SDQ

Strengths and Difficulties Questionnaire

SPECT

Singlephotonenemissionstomographie 
TGD-Fragebogen Fragebogen zum Tourette-Syndrom

TMS transkranieller Magnetstimulation

TRF Teachers Report Form

TS Tourette-Syndrom

TSSS Tourette-Syndrome-Schweregrad-Skala

YSR Youth Self Report

YTSS Yale-Tourette-Syndrome-Symptome-Liste 
Tabellenverzeichnis

Tabelle 1: $\quad 2$ × 2 ANOVA für die Faktoren CTS und ADHS, deskriptive Statistiken

Tabelle 2: $\quad 2$ x 2 ANOVA mit den Faktoren CTS und ADHS, Psychopathologie CBCL (T-Werte)

Tabelle 3: $\quad 2 \times 2$ ANOVA mit den Faktoren CTS und ADHS, Psychopathologie SDQ-EItern

Tabelle 4: Farbdiskriminationsleistung im Farnsworth-Munsell 100-Hue-Test

Tabelle 5: Konfidenzintervallanalyse der Farbdiskriminationsleistung im FMT auf Gruppenebene

Tabelle 6: 2 × 2 ANOVA mit den Faktoren CTS und ADHS, klassischer Papier-Stroop

Tabelle 7: Aufklärung der Interaktion CTS*ADHS im klassischen PapierStroop, Bedingung Inkongruenz; Konfidenzintervallanalyse

Tabelle 8: Aufklärung des Interaktionstrends im Interferenzwert CTS*ADHS im klassischen Papier-Stroop; Konfidenzintervallanalyse

Tabelle 9: Post-hoc Gruppenvergleich in der Bedingung "Wort lesen“ des klassischen Papier-Stroops

Tabelle 10: Post-hoc Gruppenvergleich in der Bedingung "Farbe benennen" des klassischen Papier-Stroops.

Tabelle 11: Partial-Korrelation zwischen der Leistung im Farnsworth-Munsell 100-hue-Test und dem klassischen Papier-Stroop, kontrolliert für Alter der Probanden

Tabelle 12: Aufklärung der Interaktion CTS*ADHS*Bedingung; Konfidenzintervallanalyse

Tabelle 13: Aufklärung der Interaktion Kongruenz ${ }^{*} C T S^{*} A D H S$; Konfidenzintervallanalyse, Differenz der Reaktionszeiten

Tabelle 14: Korrelation zwischen der Leistung im Farnsworth-Munsell 100hue-Test und dem Computer-Farb-Stroop

Tabelle 15: Computer-Stroop 


\section{Abbildungsverzeichnis}

Abbildung 1: $\quad$ Das Auge (aus www.wikipedia.de)

Abbildung 2: Empfindlichkeit der Zapfen beim Menschen (aus http://de.wikipedia.org

Abbildung 3: Aufbau und Informationsverarbeitung in der Retina (aus: http://de.wikipedia.org)

Abbidlung 4: $\quad$ Verschaltungsmodell der Zapfen

Abbildung 5: $\quad$ Stimulusmaterial des Farbe-Wort-Interferenztests

Abbildung 6: $\quad$ Modell der Verhaltensinhibition nach Barkley (1997a,b)

Abbildung 7: Schematische Darstellung des kortiko-striato-thalamokortikalen Kreislaufs

Abbildung 8: $\quad$ Ablauf der Untersuchung

Abbildung 9: $\quad$ klassischer Farb-Stroop und Computer-Farb-Stroop

Abbildung 10: Tastatur des Computer-Stroops

Abbildung 11: Zahlen-Stroop

Abbildung 12: Stichprobenzusammensetzung

Abbildung 13: $\quad$ Psychopathologisches Profil CBCL

Abbildung 14: $\quad$ Farnsworth-Musell 100-hue-Test, deskriptive Darstellung der Fehlerwerte

Abbildung 15: Konfidenzintervalle der Fehlerwerte im Farnsworth-Munsell 100-hue-Test

Abbildung 16: Konfidenzintervallanalyse klassischer Papier-Stroop

Abbildung 17: $\quad$ Mittlere Reaktionszeiten (ms) korrekter Antworten im Computer-Stroop

Abbildung 18: Differenz der Reaktionszeiten im Computer-Stroop in Abhängigkeit bzgl. des Vorliegens einer Tic-Störung bzw. keiner Tic-Störung

Abbildung 19: Farb-Stroop vs. Zahlen-Stroop, Reaktionszeiten und Anzahl korrekt bearbeiteter Items 
Abbildung 20: Differenzen in der Anzahl korrekter Antworten bei neutralen und inkongruenten Items über die Bedingungen ComputerFarb-Stroop und Zahlen-Stroop

Abbildung 21: Hypothetischer Einfluss der dopaminergen Transmission auf die Farbdiskrimination in Abhängigkeit von der Stärker der Störung im dopaminergen System

Abbildung 22: Hypothetischer Einfluss von hyper- und hypodopaminerger Transmissionsstörung auf die Farbdiskrimination 


\section{Erklärung}

Ich, Anke Fillmer-Otte, versichere, dass ich die vorliegende Arbeit selbständig verfasst und keine anderen als die angegebenen Quellen und Hilfsmittel verwendet habe.

Göttingen, März 2009 
Lebenslauf

Persönliche Daten

Name:

Anke Fillmer-Otte

Geburtsdatum:

17.02.1979

Geburtsort:

Göttingen

Familienstand:

ledig

Staatsangehörigkeit: deutsch

\section{Schulausbildung}

1985-1989

Mittelberg-Grundschule in Hetjershausen/Göttingen

1989-1991

Orientierungsstufe Leinebergschule Göttingen

$1991-1998$

Felix-Klein-Gymnasium Göttingen, Abitur

Hochschulausbildung

1998-2001

Psychologiestudium an der Georg-August-Universität Göttingen, Diplomvorprüfung

2001-2004 Psychologiestudium an der Georg-August-Universität Göttingen, Abschluss mit Diplom

\section{Fachspezifische Fortbildungen und berufliche Tätigkeiten}

2003-2004

ungeprüft studentische Hilfskraft in der Klinik und Poliklinik für Kinder- und Jugendpsychiatrie der Universität Göttingen

2004-2006 geprüft studentische Hilfskraft in der Klinik und Poliklinik für Kinder- und Jugendpsychiatrie der Universität Göttingen

2003-2005

Durchführung forensischer Begutachtungen an der Psychiatrischen Klinik der Universität Göttingen Urlaubsvertretung in der Sozialpsychiatrischen Gemeinschaftspraxis Messer-Besmens/Decker 
01/2005-07/2005 Mitarbeiterin des Neuropsychologischen Zentrums Kassel, befristete Therapieprojekt in Zusammenarbeit mit der TUChemnitz

2005-2009 Doktorandin in der Kinder- und Jugendpsychiatrie der Universität Göttingen

2006-2007

Psychotherapeutin im Praktikum in der Klinik und Poliklinik für Kinder- und Jugendpsychiatrie der Universität Göttingen

Seit 2006 Auszubildende zur Kinder- und Jugendlichen Psychotherapeutin, Verhaltenstherapie, an der AWKV in Kassel

2006-2008 Durchführung familienrechtlicher Begutachtungen an der Kinder- und Jugendpsychiatrie der Universität Göttingen

2007 Zwischenprüfung an der AWKV, Erlangung der Abrechnungsgenehmigung im Ermächtigungsverfahren

Seit 2007 Angestellte (Vollzeit) als Diplom-Psychologin in Sozialpsychiatrischer Gemeinschaftspraxis, Aufgabenbereich: Diagnostik und Therapie

Seit 2008

Mitarbeiterin im SPZ Göttingen im Rahmen der klinischen Ausbildung zur Kinder- und Jugendlichen Psychotherapeutin, Durchführung ambulanter Therapie

\section{Publikationen und Posterbeiträge}

Poster:

TeaP in Chemnitz

Büttner, N., Backes, S., Fillmer-Otte, A., Frühauf, V., Prasse, A., Wojcik, T. \& Brandler, S. (2002). Ist das Persönliche Tempo ein eigenständiges Persönlichkeitsmerkmal?

\section{Publikationen:}

Roessner, V., Banaschewski, T., Fillmer-Otte, A., Becker, A., Albrecht, B., Uebel, H., Sergeant, J., Tannock, R. \& Rothenberger, A. (2007). Color perception 
deficits in co-existing attention-deficit/hyperactivity disorder and chronic tic disorders. Journal of Neural Transmission, 115, 235-239. 